ESTABLISHING THE VALIDITY AND RELIABILITY OF THE SURVEY OF

HIGHER EDUCATION INSTRUCTIONAL PRACTICES IN THE MILLENNIAL AGE

\begin{tabular}{c} 
A Dissertation \\
presented to \\
the Faculty of the Graduate School \\
University of Missouri-Columbia \\
\hline In Partial Fulfillment \\
of the Requirements for the Degree \\
Doctor of Education \\
By \\
CYNTHA WELLS \\
Dr. Carole Edmonds, Dissertation Co-Supervisor \\
Dr. Timothy Wall, Dissertation Co-Supervisor \\
DECEMBER 2013
\end{tabular}


(C) Copyright by Cynthia (Cindy) Wells - 2013

All Rights Reserved 
The undersigned, appointed by the dean of the Graduate School, have examined the dissertation entitled

ESTABLISHING THE VALIDITY AND RELIABILITY OF THE SURVEY OF HIGHER EDUCATION INSTRUCTIONAL PRACTICES IN THE MILLENNIAL AGE

\author{
presented by Cynthia I. Wells \\ a candidate for the degree of Doctor of Education, \\ and hereby certify that, in their opinion, it is worthy of acceptance.
}

Dr. Carole Edmonds

Dr. Joyce Piveral

Dr. William Hedge

Dr. Rochelle Hiatt

Dr. Max Fridell 


\section{Dedication}

With love to my dad, Byron R. Ott, who never stopped believing in me.

I did it, just like you said I could! 


\section{ACKNOWLEDGMENTS}

As I reflect on this dissertation journey, I realize how truly lucky and blessed I am. I have a trove of friends and family whom have provided support, inspiration and encouragement along the way. Without them, this voyage would not have been possible. The path has had many twists and turns, but I am definitely better for the passage.

First of all, huge "thank-yous" to Dr. Carole Edmonds and Dr. Tim Wall. Your essential knowledge, sage advice, valuable assistance, unwavering support, hours of reading and gentle prodding when needed, as well as your friendships, mean more than I will ever be able to adequately express. I absolutely could not have reached the end of this journey without you. To my committee, Dr. Max Fridell, Dr. Bill Hedge, Dr. Shelly Hiatt and Dr. Joyce Piveral, thank you for your support and constructive feedback. I would not have been able to complete this endeavor without your valuable assistance.

I would also be remiss if I did not extend thanks to Dr. Phil Messner, who is now enjoying retirement. Your questions and feedback throughout this education journey have caused me to consider the world around me in a different light. Thank you for changing my thought processes. Also, thank you for patience as I struggled to understand, asked for answers and received more questions. My thinking will never be the same.

Thank you to my cohort group. Class and group discussions enlightened me and caused me to consider concepts in ways I did not know possible. Special thanks to Dr. Peggy Harwood. Summers in Columbia would not have been the same without you. I cannot express how much your support, brainstorming, proofreading, feedback, deep conversations and most of all, friendship have meant to me. We began this journey together, my friend, and look what we have accomplished! 
To my family; thank you for your love, support and patience. I know you all have sacrificed along the way, which I do appreciate. To my husband, Michael, thank you for the support and the steadfast love that you have always shown. You have been there for over 36 years and I don't know what I would do without you by my side. Without your help and unwavering belief in me, this would have been a much more difficult path. To my sons, Dustin, Doren and Daman; thank you for your support and patience. Always remember that you can do anything you put your mind to; don't ever give up. I hope Mom has made you proud. I love you all more that you will ever know. Thanks to my mother, Mary Jean Gray, for compelling me to learn the value of hard work and for my love of adventure; both have served me well.

As I reflect, I remember the day Dr. Max Ruhl and I were visiting after a meeting we both attended. I can picture Dr. Ruhl's easy smile, as he asked the magic question, "Have you ever considered a doctorate? You know Northwest has a cohort program through MU." Not convinced, I related the conversation to my dad and told him I did not think I was going to apply. Dad looked at me and said "Girl, you need to go for it." followed by an enthusiastic "You can do it!" Thus, it was decided and the goal was set. Dad passed as I was beginning the program, but made me promise I would go on. Dad, this one's for you. I know you have been with me the entire way. I hope your little girl has made you proud.

I also want to thank one of the wisest people I will ever know, my grandmother, Shirley Lorene Ott. Grandma instilled in me a passion for learning and the ability to face a challenge with a smile. Grandma always laughed and said I got my "smarts" from her. While I have no doubt that is true, I hope I can eventually gain her wisdom. 


\section{TABLE OF CONTENTS}

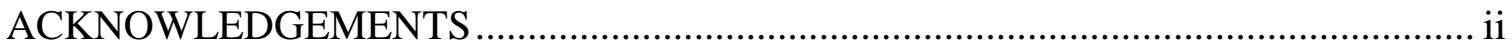

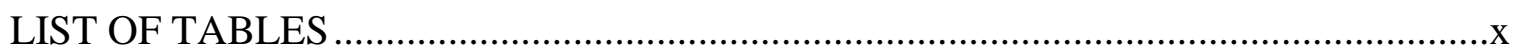

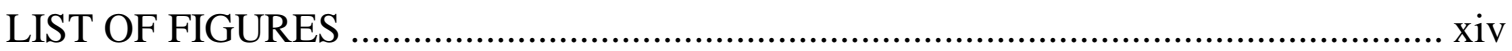

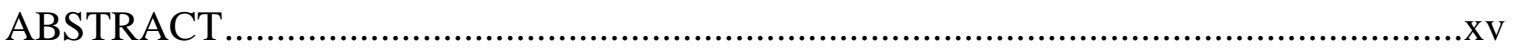

\section{CHAPTER}

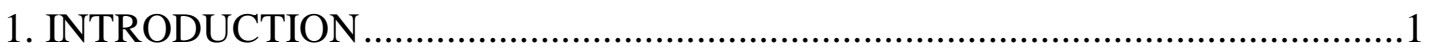

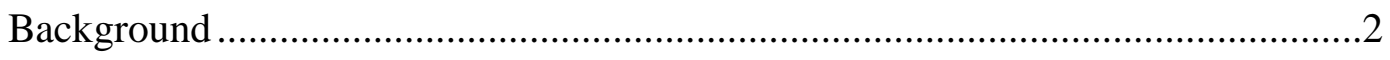

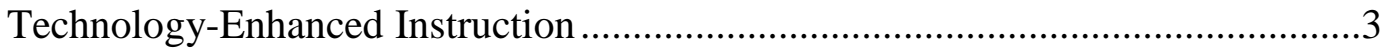

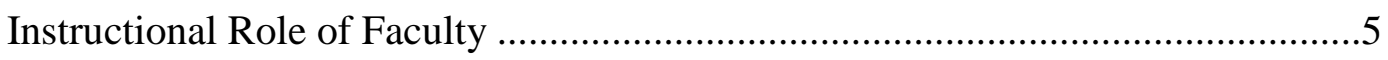

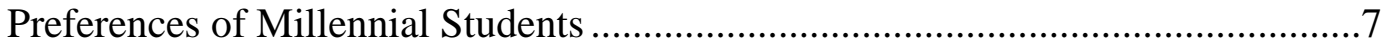

Theoretical Framework for the Study ....................................................

Background/History of Disruptive Innovation ........................................10

Influence on Education...............................................................................

Reason or Need for Use in Education .....................................................11

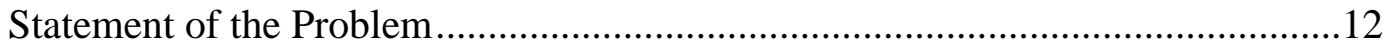

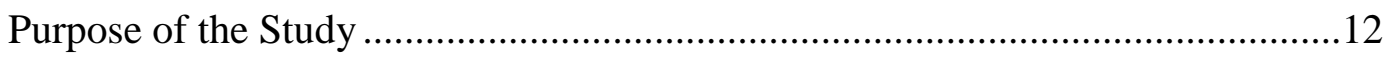

Research Questions and Null Hypotheses ....................................................14

Research Question 1 ................................................................... 14

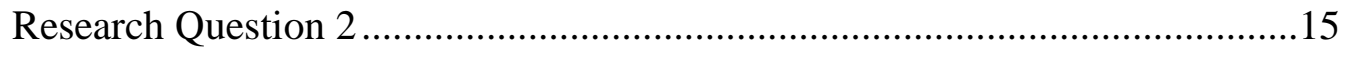

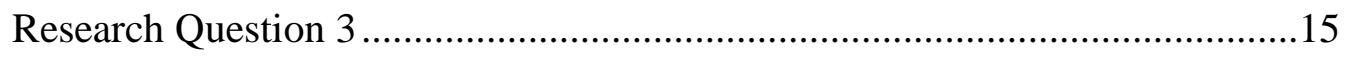

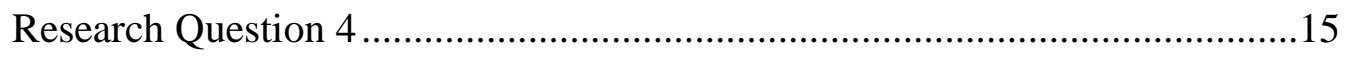

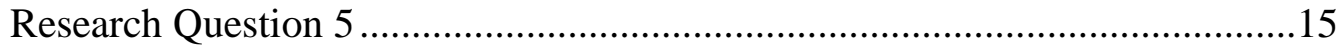




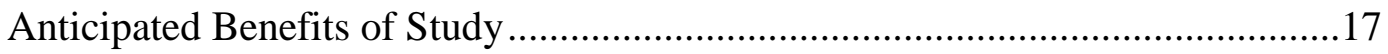

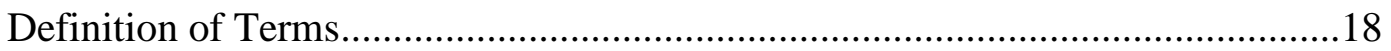

Limitations, Delimitations and Anticipated Benefits........................................19

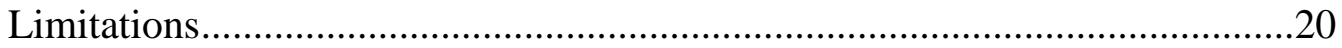

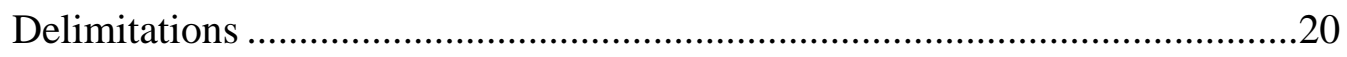

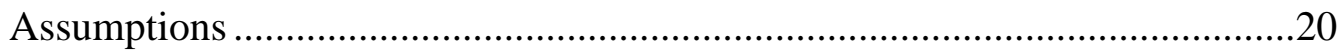

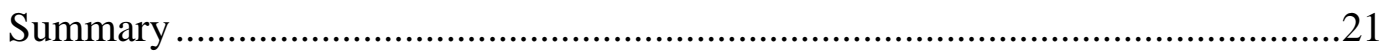

2. REVIEW OF RELATED LITERATURE .....................................................24

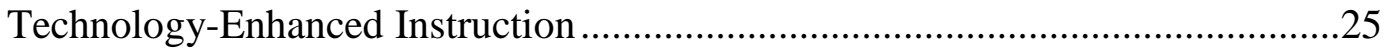

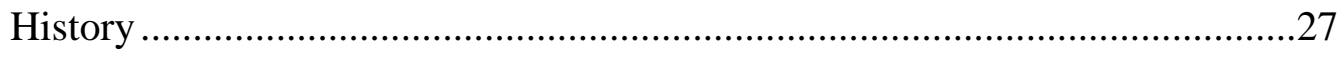

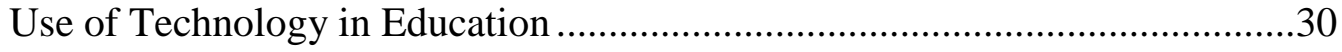

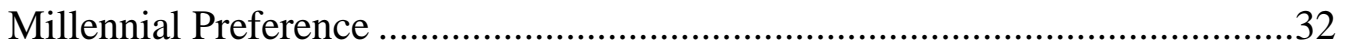

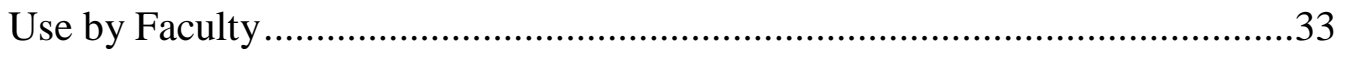

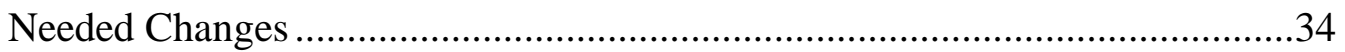

Disruptive Innovation and Technology-Enhanced Instruction .......................36

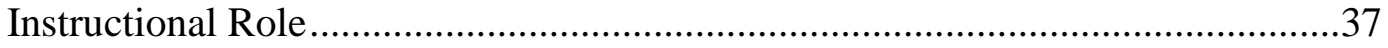

Historical and Current Instructional Role of HE Faculty ...............................37

Millennial Preferred Learning Styles ........................................................40

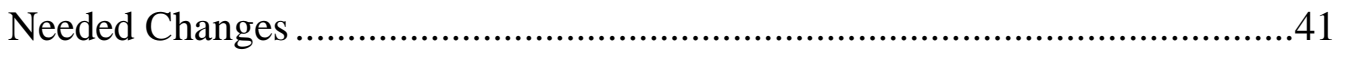

Disruptive Innovation and Instructor Role ...........................................44

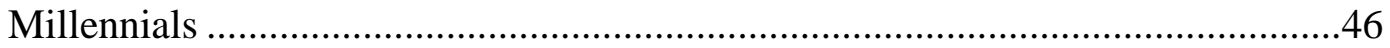

Characteristics - Analysis of Current Research .......................................47

Examination of Learning Styles of Current HE Students .............................48 
Changes - Differences From Previous Generations of Students

Disruptive Innovation and Millennials .....................................................51

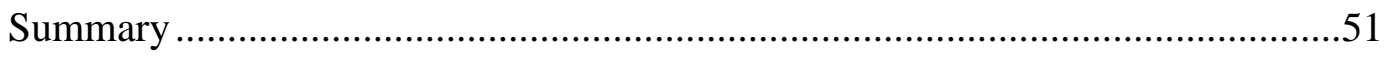

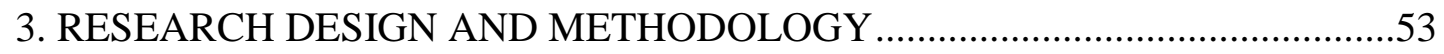

Statement of the Problem............................................................................53

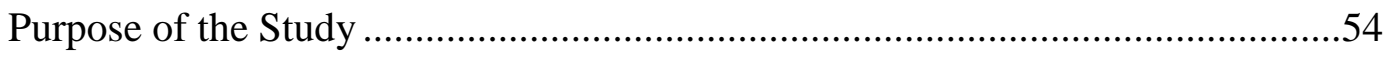

Research Questions and Null Hypotheses ...................................................54

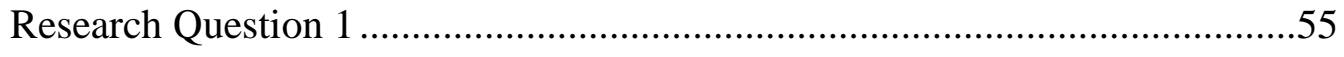

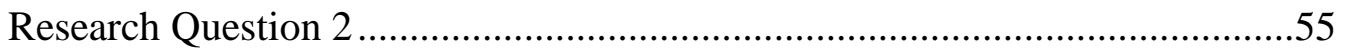

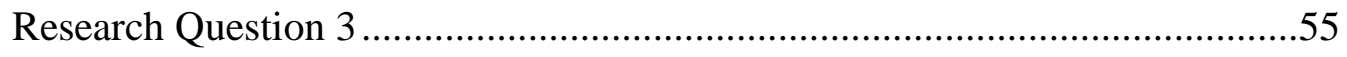

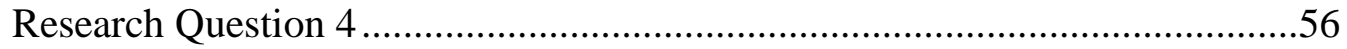

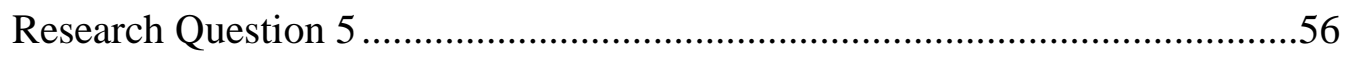

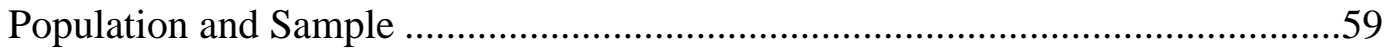

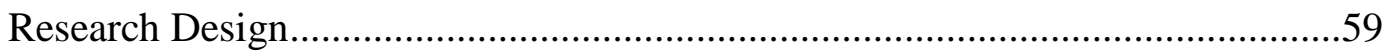

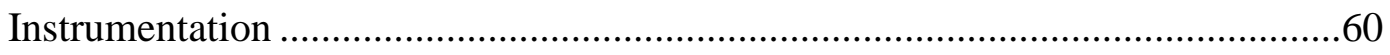

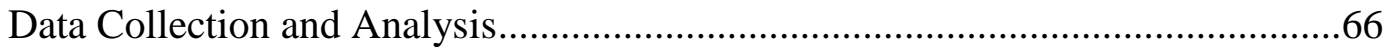

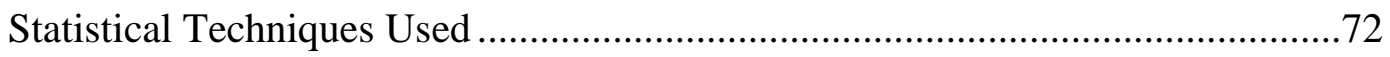

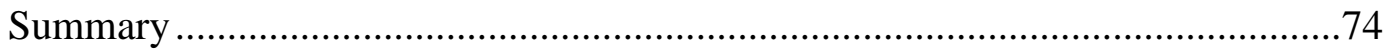

4. PRESENTATION AND ANALYSES OF DATA …........................................ 75

Review of Survey and Research Design ......................................................76

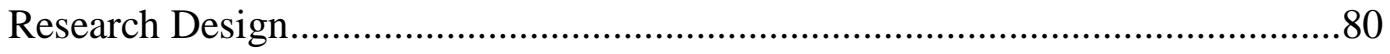

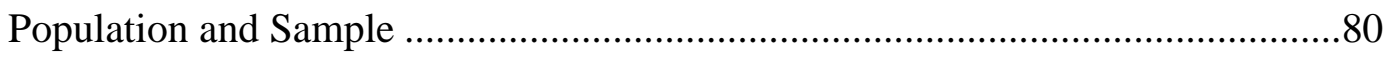

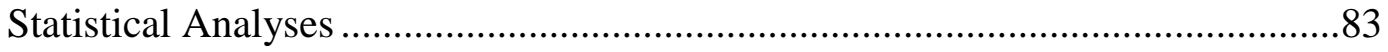


Research Question 1 - Validity and Reliability Measures

Research Question 2 - Utilization of Technology-Enhanced Instruction .88

Research Question 3 - Perceptions of Missouri HE Faculty Concerning

Instructional Role

Research Question 4 - Perceptions of Missouri HE Faculty Concerning

Millennials Students' Preferred Learning Characteristics. .104

Research Question 5 - Overall Summary Statistics by Demographic 111

Summary .163

5. OVERVIEW, FINDINGS AND RECOMMENDATIONS .164

Overview .165

Statement of the Problem 166

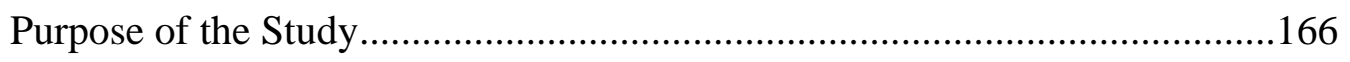

Research Questions and Null Hypotheses..............................................168

Research Question 1 .......................................................................... 168

Research Question 2 ................................................................... 168

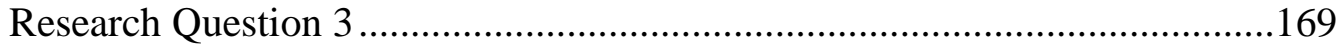

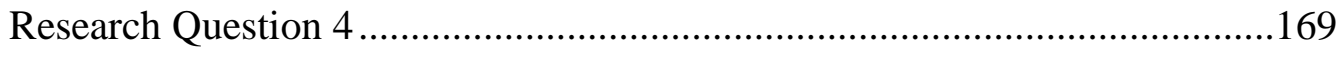

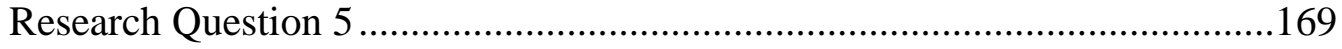

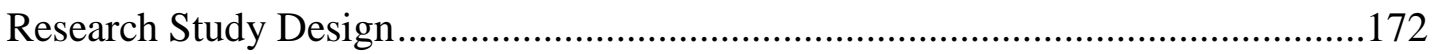

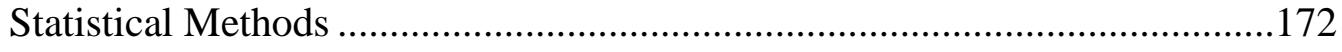

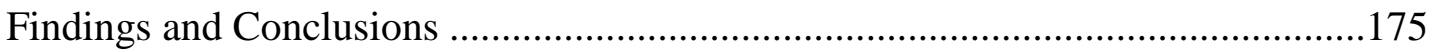

Research Question 1 - Validity and Reliability Measures ............................175

Research Question 2 - Utilization of Technology-Enhanced Instruction ........177 
Research Question 3 - Perceptions of Missouri HE Faculty Concerning

Instructional Role

Research Question 4 - Perceptions of Missouri HE Faculty Concerning

Millennials Students' Preferred Learning Characteristics.............................180

Research Question 5 - Overall Summary Statistics by Demographic ............181

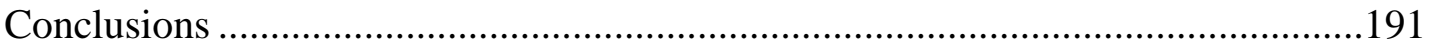

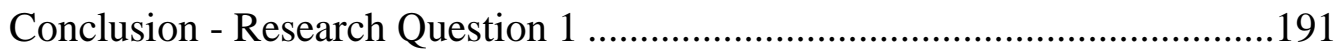

Conclusion - Research Question 2 .....................................................192

Conclusion - Research Question 3 ..........................................................193

Conclusion - Research Question 4 .....................................................194

Conclusion - Research Question 5 .........................................................194

Discussion and Recommendations for Future Research ....................................195

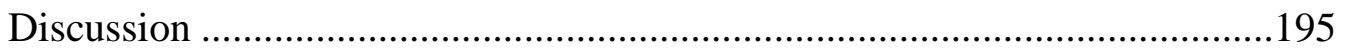

Recommendations for Future Research ................................................198

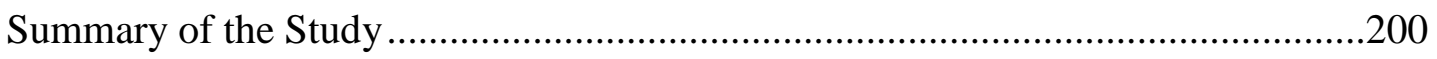

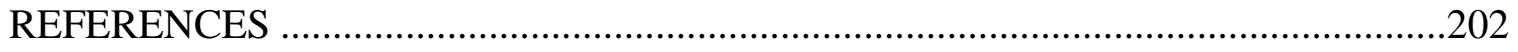

\section{APPENDIX}

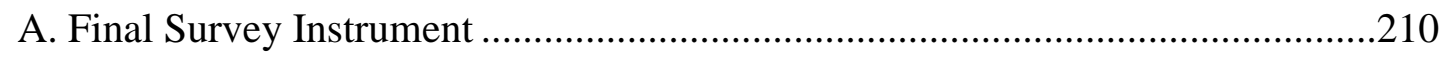

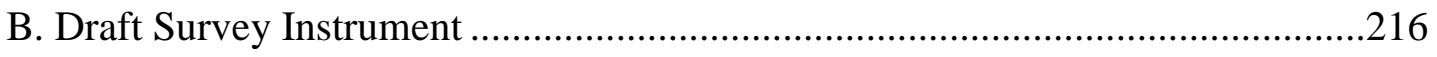

C. Expert Panel Initial Email..............................................................................2. 219

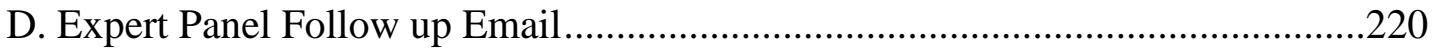

E. Letter of Informed Consent/Recipient Invitation........................................221

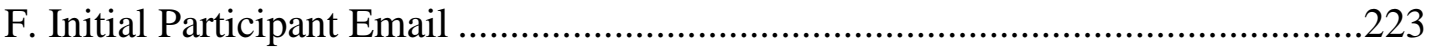


G. Follow up Participant Email.

H. List of Missouri Higher Education Institutions from MDHE .226

I. Tables Appendix

VITA

.244 


\section{LIST OF TABLES}

Table

1. Summary Listing of Research Questions and Applied Statistical Techniques .59

2. Questions asked of Expert Panel Concerning Draft Survey .62

3. Identification of Independent and Dependent Variables in the SHEIP

4. Summary of Data Sources, Types and Measures Applied to Research Questions ......74

5. Identification of Independent and Dependent Variables in the SHEIP .77

6. Questions for Expert Panel - Survey of Higher Education Instructional Practices (SHEIP) Pilot

7. Frequency and Percentages of Responses (RQ2) - Technology-Enhanced Instruction (Items 7 - 14). .88

8. Measures of Central Tendency and Dispersion - Technology-Enhanced Instruction Methods (RQ2) .90

9. Frequency of Responses (Usage vs. Non-Usage) - Technology-Enhanced Instruction (RQ2) .93

10. Frequency of Responses - Perceptions of Instructional Role (RQ3) .97

11. Frequency of Responses - Contemporary vs. Traditional Instructor Role (RQ3)......98

12. Measures of Central Tendency and Dispersion-Perception of Instructor Role(RQ3)100

13. Frequency of Responses (Agree vs. Disagree) - Perceptions of Instructional Role (RQ3) .101

14. Frequency of Responses - Perceptions of Millennial Students' Learning Preferences (RQ4) .105 
15. Measures of Central Tendency and Dispersion - Perceptions of Millennial Students' Learning Preferences (RQ4) 108

16. Frequency of Responses (Agree vs. Disagree) - Perceptions of Millennial Students' Preferred Learning Styles (RQ4) 109

17. Frequency and Percentages of Responses-Independent Variables (Demographics) .114

18. Frequency of Responses (Agree vs. Disagree) - Technology-Enhanced Instructional Practices (RQ5.1) - Disaggregated by Type of Institution 116

19. Chi-square Analysis Results for Type of Institution and Items 7-14 (RQ5.1)

20. Frequency of Responses (Agree vs. Disagree) - Perception of Instructional Role (RQ5.1) - Disaggregated by Type of Institution.....

21. Chi-square Analysis Results for Type of Institution and Items 15-24 (RQ5.1) ........120

22. Frequency of Responses (Agree vs. Disagree) - Perception of Millennial Students' Preferred Learning Styles (RQ5.1) - Disaggregated by Type of Institution 121

23. Chi-square Analysis Results for Type of Institution and Items 25 - 40 - (RQ5.1)....122

24. Frequency of Responses (Agree vs. Disagree)-Utilization of Technology-Enhanced Instructional Practices (RQ5.2) - Disaggregated by Carnegie Size Classification ...230

25. Chi-square Analysis Results for Size of Institution and Items 7 - 14 - (RQ5.2) .......125

26. Frequency of Responses (Agree vs. Disagree) - Perception of Instructor Role (RQ5.2) - Disaggregated by Carnegie Size Classification .232

27. Chi-square Analysis Results for Size of Institution and Items 15 - 24 - (RQ5.2) .....127

28. Frequency of Responses (Agree vs. Disagree) - Perception of Millennial Students' Preferred Learning Styles (RQ5.2)-Disaggregated by Carnegie Size Classification 234 29. Chi-square analysis results for size of institution and Items 25 - 40 - (RQ5.2)........130 
30. Frequency of Responses (Agree vs. Disagree) - Utilization of Technology-Enhanced Instruction (RQ5.3) - Disaggregated by Department...................................................236

31. Chi-square Analysis Results for Department and Items 7 - 14 - (RQ5.3) .................133

32. Frequency of Responses (Agree vs. Disagree) - Perception of Instructional Role (RQ5.3) - Disaggregated by Department …………………….................................238

33. Chi-square Analysis Results for Department and Items 15 - 24 - (RQ5.3) ...............136

34. Frequency of Responses (Agree vs. Disagree) - Millennial Students' Preferred Learning Styles (RQ5.3) - Disaggregated by Department..........................................240

35. Chi-square Analysis Results for Department and Items 25 - 40 - (RQ5.3) ...............138

36. Frequency of Responses (Agree vs. Disagree) - Utilization of Technology-Enhanced Instructional Practices (RQ5.4) - Disaggregated by Rank .242

37. Chi-square Analysis Results for Rank and Items 7 - 14 - (RQ5.4)

38. Frequency of Responses (Agree vs. Disagree) - Perceptions of Instructional Role (RQ5.4) - Disaggregated by Rank .243

39. Chi-square Analysis Results for Rank and Items 15 - 24 - (RQ5.4)

40. Frequency of Responses (Agree vs. Disagree) - Perceptions of Millennial Students' Preferred Learning Styles (RQ5.4) - Disaggregated by Rank .244

41. Chi-square Analysis Results for Rank and Items 25 - 40 - (RQ5.4) 145

42. Frequency of Responses (Agree vs. Disagree) Disaggregated by Gender - Utilization of Technology-Enhanced Instructional Practices (RQ5.5) 147

43. Chi-square Analysis Results for Gender and Items 7 - 14 - (RQ5.5) .148

44. Frequency of Responses (Agree vs. Disagree) Disaggregated by Gender Instructional Role (RQ5.5) 150 
45. Chi-square Analysis Results for Gender and Items 15 - 24 - (RQ5.5)

46. Frequency of Responses (Agree vs. Disagree) Disaggregated by Gender - Millennial Students' Preferred Learning Styles (RQ5.5) 152

47. Chi-square Analysis Results for Gender and Items 25 - 40 - (RQ5.5) .154

48. Frequency of Responses (Agree vs. Disagree) - Utilization of Technology-Enhanced Instructional Methods (RQ5.6) - Disaggregated by Age Range 156

49. Chi-square Analysis Results for Age Range and Items 7 - 14 - (RQ5.6) 157

50. Frequency of Responses (Agree vs. Disagree) - Perceptions of Instructional Role (RQ5.6) - Disaggregated by Age Range .158

51. Chi-square Analysis Results for Age Range and Items 15 - 24 - (RQ5.6)

52. Frequency of Responses (Agree vs. Disagree) - Perceptions of Millennial Learning Styles (RQ5.6) - Disaggregated by Age Range 161

53. Chi-square Analysis Results for Age Range and Items 25 - 40 - (RQ5.6) .162

54. Summation of Research Questions and Applied Statistical Techniques 171

55. Summary of Data Sources, Types and Analysis Applied by Research Question .174 


\section{LIST OF FIGURES}

Figure

1. Technology-enhanced instructional practices, instructional role and students' preferred learning styles relationships ........................................................... 19

2. Factors influencing change in use of instructional technology ..............................27

3. Random selection and email retrieval process of HE institutions ............................60

4. Timeline for completion of survey, data collection, analyzation and findings...........66

5. Explanation of survey creation, data collection and analysis .................................66

6. Number of responses by choice - technology - enhanced instruction (RQ2) - survey

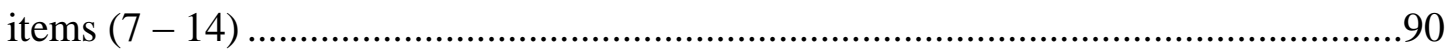

7. Agree vs. disagree percentages; responses from survey items 7-14 (RQ2)...............94

8. Number of responses by choice - instructor role (RQ3) - survey items 15-24.........99

9. Percentage of responses (agree vs. disagree)-instructional role-items 15-24 (RQ3).102

10. Agreement versus disagreement percentages - traditional instructor role versus contemporary instructor role

11. Number of responses by choice - millennial students' learning preferences (RQ4) survey items $24-40$

12. Percentage of responses (agree versus disagree) (RQ4) - millennial students' preferred learning styles - items 25 - 40 


\title{
ESTABLISHING THE VALIDITY AND RELIABILITY OF THE INVENTORY OF HIGHER EDUCATION INSTRUCTIONAL PRACTICES IN THE MILLENNIAL AGE
}

\author{
Cynthia I. Wells
}

Dr. Carole Edmonds and Dr. Tim Wall, Dissertation Supervisors

\begin{abstract}
The primary purpose of this study was to design a valid and reliable survey instrument gauging three concepts; (a) utilization of technology-enhanced instructional practices, (b) perceptions of Missouri higher education faculty concerning self-reported instructor role and (c) perceptions of millennial students' preferred learning styles. The secondary purpose of this study was to identify differences and similarities among various subsets of the data, examined by investigated concepts, as well as disaggregated by each demographic for individual survey items.

The six independent variables included type of institution, size of institution (based on Carnegie Size Classification), department, rank, gender and age range. The study also included 34 dependent variables divided into three sections. First were 8 items (items 7-14), designed to discern the HE faculty's self-reported utilization of technologyenhanced instruction in their classroom. Next were 10 items (items 15-24), focusing on faculty perceptions of their instructional role in the classroom. Following were 16 items (items 25-40) asking for self-reported faculty perceptions concerning the learning preferences of higher education students.

The population for this study included 2,978 faculty at a randomly selected group of 15 two-year and four-year, public and private Missouri higher education institutions based on a listing of Missouri higher education institutions provided by the Missouri Department of Higher Education (MDHE). The survey was completed by 249 of these
\end{abstract}


faculty members. Cronbach's alpha and a pilot survey were conducted to determine validity and reliability. Univariate analyses, including cross tabulations and graphs showing frequency counts and percentages and measures of central tendency and dispersion, consisting of mean, median, mode, standard deviation and variance, were employed to determine utilization of technology-enhanced instruction by Missouri HE faculty as well as perceptions concerning instructional roles and millennial students' learning characteristics as identified by research. Finally, Chi-square analysis and cross tabulations showing frequency numbers and percentages of each survey item were generated for each of the six demographic items.

The findings confirmed that the Survey of Higher Education Instructional Practices (SHEIP) was a valid and reliable instrument for collecting information concerning utilization of technology-enhanced instruction as well as perceptions of instructor role and students' preferred learning styles. It was also shown a majority of Missouri higher education faculty are employing technology-enhanced instruction. Findings also indicated percentages of faculty using traditional and contemporary instructor roles were nearly equal. A small percentage more faculty did report using more contemporary instructor roles, but this is a point that could be explored in further research. Furthermore, outcomes indicated that a majority of faculty did agree with the manners which current research indicated millennial students prefer to learn. The theory of disruptive innovation indicated manners in which higher education can implement the change needed to "disrupt" the current system in academia. Research indicates change is needed if higher education is going to prosper in the rapidly changing academic world. 


\section{CHAPTER ONE \\ INTRODUCTION TO THE STUDY}

Learning styles of contemporary, traditional students should be closely examined in the world of higher education. According to researchers, a "new and unique population of learners" is converging on higher education "distinctly different in their characteristics and learning expectations" (Skiba \& Barton, 2006, p. 2-3) and a student population unlike those from previous years is being served (Frand, 2000; Garcia, 2007; Oblinger, 2003). Traditional students currently enrolling at universities are known by several names: Millennials, the N-Generation, the Net Generation, Digital Natives, Gen Ys or Generation Ys being some of the most prevalent (Dziuban, Moskal, \& Hartman, 2004; Howe \& Strauss, 2007; Jonas-Dwyer \& Pospisil, 2004; Lancaster \& Stillman, 2010; Newton, 2000; Prensky, 2001a; Tapscott, 1998). For the purposes of this study, these students will be identified as Millennials.

Today's higher education institutions are experiencing a different type of student population than foregoing eras. Traditional students are known as "gadget fanatics, social networkers, Internet enthusiasts, optimists, multitaskers, and inductive learners" (Garcia, 2007, p. 12). Their viewpoints and aptitudes concerning technology differ from those rarely using it (Frand, 2000; Newton, 2000; Oblinger, 2003; Prensky, 2001a, 2008, 2012). Moreover, research indicates that this generation has been "connected" to technology almost since birth, and this perpetual connection has led to issues that must be addressed by universities (Bok, 2006; Carlson, 2005; Healy, 1998, 1999; Israel, 2006; Knapper, 2007; Nicoletti \& Merriman, 2007; Oblinger \& Oblinger, 2005, Prensky, 2005; Skiba \& Barton, 2005). 
For Millennials, using technology is as "fundamental as reading was for their parents and grandparents" (Prensky, 2012, p. 1). The extensive degree to which the current generation has been affected by technology is of critical importance to academia and presents challenges to higher education institutions (Gorman, Nelson, \& Glassman, 2004; Tapscott, 1998, 2009). These issues have led higher education faculty and administrators to re-examine philosophical and pedagogical views of students and professors with regard to effective delivery systems (Bok, 2006; Carlson, 2005; McGlynn, 2005; Nevgi, Virtanen, \& Niemi, 2006; Nicoletti \& Merriman, 2007; Schneider, 2001). "Facilities, faculty, and curriculum may not be prepared to address the demand of students' differing learning preferences and expectations (Christensen, et al., 2008; Christensen \& Eyring, 2011).

This chapter provided a brief overview of technology-enhanced instruction, higher education faculty's instructional role and the learning preferences of current traditional students known as Millennials. The disruptive innovation theory highlights these issues and was utilized as the theoretical framework for this study. The problem statement was given, a purpose for the study formulated and research questions guiding the study outlined. Terms used throughout this study, as well as assumptions, limitations, and delimitations were delineated. Lastly, anticipated benefits of this study are proposed and a summary provided.

\section{Background}

Nationwide, higher education faculty are discerning current students do not respond to the same degree when employing traditional teaching methods (Carlson, 2005; Howe \& Strauss, 2007; Tapscott, 1998, 2009). Research indicates Millennials think and 
learn in a different manner and traditional methods of instruction taking place on most campuses may no longer meet their learning needs (Carlson, 2005; Howe \& Strauss, 2007; Sweeney, 2007; Tapscott, 1998, 2009). With a shifting traditional student body, it is imperative that academia understands the learning needs of current students and recognizes challenges to be faced and needed changes (Bok, 2006; Carlson, 2005; Knapper, 2007; Nicoletti \& Merriman, 2007; Oblinger \& Oblinger, 2005, Prensky, 2005; Skiba \& Barton, 2005). Higher education administrators and faculty need to understand the need for currency in a technologically-driven world and needed changes in instructor role to meet the demands of students with different preferred learning styles. Some authors argue technology is not needed for deep learning to take place (Healy, 1998), but this study will examine the multitude that the current generation of learners on higher education campuses prefer technology to be integrated in their learning (Christensen, et al., 2008; Oblinger \& Oblinger, 2005; Prensky, 2001a, Tapscott, 2008)

This study investigated technology-enhanced instruction in higher education as documented by research. Perceptions of higher education faculty concerning their instructional roles and the preferred learning styles of millennial students in their classrooms were also explored. While researching these concepts, no tools were located to help identify utilization of technology-enhanced instruction, identify perceived instructor roles and faculty perceptions of students' preferred learning styles. This study will determine if a valid and reliable tool to establish the use of technology-enhanced instruction in Missouri higher education as well as self-perceived instructor roles and perceptions concerning preferred learning styles of students in Missouri higher education classrooms can be developed. 


\section{Technology-enhanced Instruction}

Millennial students feel disengaged in traditional classrooms as higher education institutions have not fully integrated many of the ways students in current higher education classrooms access information and communicate using technology (Levin \& Arafeh, 2002; Prensky, 2005; Tapscott, 1998, 2009). Researcher Seymour Pappert identifies part of the issue, “The reason most kids don't like school is not that the work is too hard, but that it is utterly boring" (as cited in Prensky, 2001a, p. 03.1). "Millennials . . . feel hemmed in by an educational system that continually looks to history, that does not take students seriously and that squelches creativity, a key characteristic of Millennials" (Carlson, 2005, p. 3). Using technology-enhanced instructional practices "spawns engagement" and "allows students to follow spontaneous ideas and interests" (Jukes, et al., 2011, p. 17) thus fitting into identified Millennial preferred learning modes (Oblinger \& Oblinger, 2005; Prensky, 2001a, 2005; Tapscott, 1998, 2009).

Millennial students desire to create their own learning, including using preferred communication channels and interacting in their preferred manners, which frequently includes using technology. Woempner (2007) states:

Digital natives are increasingly disengaged by the styles of digital immigrants, like their teachers, who insist on lecture, text and segmented single tasks. These Millennials parallel-process and multi-task; they prefer their graphics before their text; they prefer random access and perform best when they are "plugged-in". They thrive on instant gratification. And they do not often find these conditions at school. (p. 4) 
While schools have resisted integrating technology into everyday instructional practices, Millennials have embraced and implemented technology, both in their personal and academic lives, and bring this expectation to higher education classrooms. Millennials "want to be users-not just viewers or listeners" (Tapscot, 1998, p. 3). To assure these altered student demands are met, higher education faculty must be encouraged to change to "meet students where they are" (Blackboard, 2007). "Kids are bombarded by media," says Blake. "They're completely high tech, and don't know a different way. When you hand them a book, they're going to say, 'Is this all there is?"' (cited in McHugh, 2005, p. 33) "The typical student reaction is, 'I'm bored to tears,'" states Moersch. "There's a total disconnect between my life and what's going on in the classroom" (as cited in McHugh, 2005, p. 34). Changing that reaction and disconnect could have an immediate and widespread effect on education (Christensen, et al., 2008; McHugh, 2005). "Millennials increasingly see little relevance of traditional instructional delivery of content to their own experiences and reality" (Woempner, 2007, p. 4). If learners' needs are not met or learners are disengaged, deep learning may not take place (Prensky, 2001a, 2001b, 2005; Tapscott, 1998, 2009).

\section{Instructional Role of Faculty}

Prensky (2001c) states “today's students are no longer the people our educational system was designed to teach" (p. 1). Traditionally, faculty have seen their role as the font of all information and have acted as the "sage on the stage" (Jukes, et al., 2010; King, 1993; Howe \& Strauss, 2007; Oblinger \& Oblinger, 2005; Prensky, 2001c, 2005; Skiba \& Barton, 2006; Tapscott, 1998, 2009). Education systems have conventionally been linear or sequential in nature, but real learning "often follows a nonlinear path" and 
some researchers believe the "educator's role in nonlinear learning is to be a facilitator or guide" (Jukes, et al., 2010, p. 17). Moreover, the "world is changing" and faculty must reevaluate their instructional role to "prepare students for their lives in the future" (Jukes, et al., 2010, p. 15). "Faculty from previous generations were text based; focused on logical sequencing of knowledge; emphasized memorization, repetition, and recall; believed one size fits all" (Skiba \& Barton, 2006, p. 5). A disconnect exists between Millennials' learning styles and instructional practices traditionally supported in higher education (Jukes, et al., 2010; Prensky, 2001a, 2001c; Tapscott, 1998, 2009).

Implications for higher education "stem from the dichotomy between the millennial mindset and that of most higher education faculty" (Oblinger \& Oblinger, 2008, p. 2.10) influenced by the Millennials' preferences for "digital literacy, experiential learning, interactivity, and immediacy" (Skiba \& Barton, 2006, p. 6). To achieve congruence between these two, change must take place. Millennial students expect learning to be pertinent to their lives and "demand a new learning paradigm" (Skiba \& Barton, 2006, p. 4). Skiba and Barton (2006) postulate "Faculty from previous generations were text based; focused on logical sequencing of knowledge; emphasized memorization, repetition, and recall; believed one size fits all" (p. 4). Research indicates Millennials prefer a "learner-centered model... with a shift from the traditional teaching paradigm to a constructivist learning paradigm" and a focus on "understanding, constructing knowledge using discovery methods and active engagement" (Skiba \& Barton, 2006, p. 4).

A question now facing institutions of higher learning is, "Are higher education faculty employing instructional roles that meet the learning needs of the millennial 
students, specifically integrating technology-enhanced instruction?" "Faculty must understand these learners, their expectations, and their learning needs" (Skiba \& Barton, 2006, p. 9). "Teachers must make a fundamental shift in their paradigm for teaching and learning ...the current education system has been set up to prepare students perfectly for a world that no longer exists" (Jukes, et al., 2010, p. 21). Higher education must adapt and face this challenge to provide millennial students with the education they desire (Christensen, et al., 2011; Oblinger \& Oblinger, 2005; Tapscott, 2009).

\section{Preferences of Millennial Students}

An analysis of research gleaned information concerning millennial students and delineated specific Millennial preferred learning styles. One piece of information gained from current research is millennial students prefer technology-enhanced learning (Oblinger \& Oblinger, 2005; Prensky, 2001a, 2005; Tapscott, 1998, 2009). Research indicates these students are dissimilar from any generation of students before them and these disparities are present not only in traits and characteristics, but also in learning styles (Howe \& Strauss, 2000; Jonas-Dwyer \& Pospisil, 2004; McGlynn, 2005; Nicoletti \& Merriman, 2007; Skiba \& Barton, 2006).

The generation of students now on university campuses is unlike any generations that have roamed campuses before them (Howe \& Strauss, 2000; McGlynn, 2005; Prensky, 2005; Tapscott, 1998). An information-age or digital native mindset, distinctly different from the mindset of those of us who have transitioned from the industrial age or digital immigrant, is common among students growing up in the "globally connected, information- intense digitally based culture" (Frand, 2000, p. 16, Prensky, 2001a, Tapscott, 1998, 2009). Studies show that Millennials “don’t read as much as previous 
generations did. They prefer video, audio, and interactive media" (Carlson, 2005, p. 3).

This difference in mindset may lead to a mismatch of learning styles and traditional instructional practices in higher education classrooms.

Millennials have different temperaments, expectations and operate in a completely different, technology-enhanced world than any students coming before them (Howe \& Strauss, 2000; Jonas-Dwyer \& Pospisil, 2004; McGlynn, 2008; Nicoletti \& Merriman, 2007; Prensky, 2001a; Tapscott, 1998; Skiba \& Barton, 2006). Higher education institutions, historically slow to change, are confronting the reality of serving students "who are technologically advanced, are likely to be in the workforce and who do not follow traditional educational paths" (Blackboard, 2007). According to Fine (2008): Millennials are fascinating for how they work (collaboratively); what they believe (that they can make the world a better place); and how they are living (immersed in causes). Their signature characteristic is their digital fluency. They are uniquely comfortable using a wide variety of social-media tools like cell phones, e-mail, Facebook and instant messages. (p. 6)

The aspirations for schools are not coming to fruition as previously hoped in today's society (Christensen, et al., 2008). Research shows that education has always been slow to implement change (Kent \& McNergney, 1999; Greenberg, 2010; Milliron, 2000). In an effort to start addressing the educational needs of the millennial student population, postsecondary institutions must transition from the "old generation of learning" to the "new generation of learning" (Milliron, 2008). Historically education has employed traditional instructional practices, most of which have not included technology as anything more than a presentation mode (Fine, 2008; Howe \& Strauss, 2007; 
McGlynn, 2008; Prensky, 2001a). However, students currently coming to higher education institutions are like none which have come to higher education campuses before (Fine, 2008; Frand, 2000; Howe \& Strauss, 2007; McGlynn, 2008; Prensky, 2001a; Tapscott, 1998). As generations and students change, so must educators in order to form their students into what is needed for the most current changing culture (Howe \& Strauss, 2007). The higher education institution is now considered a more commercial enterprise where students of varying intellectual abilities and ages expect to be admitted and treated as individual customers (Christensen, et al., 2007; Howe \& Strauss, 2000, 2007; Sacks, 1999).

While research supported these statements, an instrument to gauge higher education faculty use of technology-enhanced instruction and perceptions of current instructional practices and millennial students learning styles was not identified. By identifying faculty actions concerning technology-enhanced instruction and faculty perceptions of their instructional role and millennial student learning styles, higher education institutions will be able to better identify student learning preferences being met and changes to be implemented to better meet the learning preferences of current students. In an effort to start addressing educational needs of the millennial student population, higher education institutions must transition from the "old generation of learning" to the "new generation of learning" (Christensen, et al., 2008; Christensen \& Eyring, 2011; Milliron, 2000). Higher education institutions exist in a rapidly changing society. This environment coupled with the new generation of students on campuses, make this transition crucial. "Higher education is in more demand and plays a more significant role in society today than it has in any other period in history" (Blackboard, 
2007). However, "a lack of understanding and appreciation for generational

characteristics and values can bring about conflict and impasse" (Woempner, 2007, p. 5).

Theoretical Framework for the Study

This study used the lens of disruptive innovation theory to examine the information. Disruptive innovation, while developed as a business model, has many points applicable to academia and gives helpful perspectives for some of the issues facing higher education today. In "Disrupting Class: How Disruptive Innovation Will Change the Way the World Learns" and "The Innovative University", the theory of disruptive innovation and the relationship of technology and education are espoused. Further postulated were manners in which this theory could help higher education face many of the challenges due to the changing environment and shifting composition of the contemporary student body.

\section{Background/History of Disruptive Innovation}

Disruptive innovation theory, as applied to business models, was first introduced by Clayton Christensen in 1997 in a book “The Innovator's Dilemma”. In 2008, Christensen, along with co-authors Michael Horn and Curtis Johnson, conducted additional research and applied disruptive innovation theory to the academic world in another book "Disrupting Class: How Disruptive Innovation Will Change the Way the World Learns". Following was additional research and authoring of another book, "The Innovative University" in 2010, which further examined disruptive innovation in the academic realm.

Christensen's theory identifies two principal types of innovations that take place, sustaining and disruptive. Sustaining innovations tend to take place using structures 
already in place while disruptive innovation changes traditional structure and "morphs" that structure into something completely different (Christensen, et al., 2008). Disruptive innovation in essence disrupts the status quo and replaces traditional structures with something new and altered (Christensen, et al., 2008). According to Christensen, Horn and Johnson (2008), all "disruptions share a pattern; disruptions first compete against non-consumption in a new plane of competition. In that plane, technology improves and the underlying cost declines" (p. 96).

\section{Influence on Education}

The lens of "the theory of disruptive innovation" was suggested to view some of the "challenges currently facing higher education" (Christensen, 2012, p. xxii). Using the lens of disruptive innovation, this study examined "conflict between schools standardizing the way they teach in the face of students needing customization for the way they learn" (Christensen, et al., 2008, p. 29). As seen through this lens, Christensen and Eyring (2011) state "universities are at a critical crossroad" (p. xxii). According to Christensen and Eyring (2011), higher education has yet to address the issue of transforming to "serve the changing educational needs of a knowledge economy" in an "evolving marketplace characterized by new needs and paradigms" (p. 3), namely demands of the Millennials.

\section{Reason or Need for Use in Education}

The unique teaching design of higher education has basically been unchanged since the late nineteenth century, but innovations in modern society, namely technology, are "disrupting the status quo" (Christensen \& Eyring, 2011, p. xxiii). According to Christensen, Horn and Johnson (2008), society has asked academia to change and improve using new measures, but academia is to make these improvements within 
existing structures and with improvements being measured using old standards or methodology. Disruptive innovations cannot be effective if implemented within traditional structures; the structure itself must change (Christensen \& Eyring, 2011; Richardson, 2010). To stay competitive and meet needs of the current society, as well as current students, education needs suitable tools and strategies. According to Christensen and Eyring (2011), to “avoid disruption, institutions of higher education must develop strategies that transcend imitation" (p. xxvi). Disruptive innovation theory provides the framework for this needed change as well as meeting requests being forced on academia (Christensen, et al., 2008; Christensen \& Eyring, 2011; Richardson, 2010).

\section{Statement of the Problem}

Current research indicated millennial students prefer technology-enhanced instructional practices (Howe \& Strauss, 2000; Jonas-Dwyer \& Pospisil, 2004; McGlynn, 2008; Nicoletti \& Merriman, 2007; Prensky, 2001a; Tapscott, 1998; Skiba \& Barton, 2006). However, little research determining utilization of technology-enhanced instruction by Missouri higher education faculty or faculty perceptions concerning their instructional role in college classrooms and millennial students' preferred learning styles was discovered. Additionally, the researcher's investigation yielded no known inventory or survey instrument assessing the three concepts examined in this study: (a) utilization of technology-enhanced instructional practices, (b) perceptions of Missouri higher education faculty concerning self-reported instructor role and (c) perceptions of millennial students' preferred learning styles. 


\section{Purpose of the Study}

The primary purpose of this study was to design a valid and reliable survey instrument gauging three concepts; (a) utilization of technology-enhanced instructional practices, (b) perceptions of Missouri higher education faculty concerning self-reported instructor role and (c) perceptions of millennial students' preferred learning styles. The secondary purpose of this study was to identify differences and similarities among various subsets of the data, examined by investigated concepts, as well as disaggregated by each demographic for individual survey items.

While current research indicated millennial students' learning preferences have evolved and the desire for technology-enhanced instructional practices have increased, little research was discovered determining utilization of technology-enhanced instructional practices by Missouri higher education faculty or faculty perceptions concerning their instructional role and students' preferred learning styles. There was no current survey or instrument identified to determine the faculty utilization of technologyenhanced instructional practices or faculty perceptions regarding instructional roles and preferred learning methods of current students, the Millennials.

Higher education institutions nationwide are experiencing a disengagement of millennial students in the classroom (Levin \& Arafeh, 2002; Prensky, 2005, 2012; Tapscott, 1998, 2009; Woempner, 2007). Instructional practices previously deemed effective now seem to be unproductive (Prensky, 2001a, 2001b, 2005; Tapscott, 1998, 2009). Traditionally used higher education teaching methodologies seem to be ineffective for the millennial student (McGlynn, 2008; Nicoletti \& Merriman, 2007). Nicoletti and Merriman (2007) asserted, "Millennial students are different with different learning styles 
requiring different teaching methods" (p. 28). As stated by McGlynn (2008), "these students learn ... and interact differently than former students" (p. 13). While research showed instructional practices currently employed by higher education faculty may not be meeting the learning preferences of millennial students, little had been done to bring about change. Little information was discovered concerning higher education faculty perceptions of millennial students and knowledge of their preferred learning styles, specifically the utilization of technology-enhanced instructional practices.

This study explored research highlighting the millennial generation and methodologies best supporting their preferred learning styles. Student learning preference changes were identified and the reasons for needed changes recapitulated. Perceptions of Missouri higher education faculty related to their instructional roles and millennial students' preferred learning styles were examined. Missouri higher education faculty utilization of technology-enhanced instructional practices to help meet learning demands or needs of millennial students was also researched.

\section{Research Questions and Null Hypotheses}

Guiding Question: Are Missouri Higher Education (HE) faculty utilizing technologyenhanced instructional practices, identified by current research to be a preferred learning style of millennial students?

\section{Research Questions}

Five research questions were developed to guide this study. The questions, subquestions and null hypotheses follow. 


\section{Research Question 1}

Is the Survey of Current Instructional Practices and Perceptions reliable and valid?

Sub research question 1.1. Is the survey instrument valid?

Sub research question 1.2. Is the survey instrument reliable?

$\mathrm{H}_{\mathrm{o}} 1$ : The Survey of Current Instructional Practices and Perceptions is neither reliable nor valid.

\section{Research Question 2}

To what degree do Missouri HE faculty significantly utilize technology-enhanced instructional practices (Items 7-14)?

$\mathrm{H}_{\mathrm{o}} 2$ : Missouri HE faculty do not significantly utilize technology-enhanced instructional practices.

\section{Research Question 3}

To what degree do Missouri HE faculty perceptions of their instructional role in the classroom significantly match those identified in current research as preferred by millennial students (Items 15-24)?

$\mathrm{H}_{\mathrm{o}} 3$ : Missouri HE faculty perceptions of their instructional role in the classroom do not significantly match those identified in current research as preferred by millennial students.

\section{Research Question 4}

To what degree do Missouri HE faculty perceptions of millennial students' learning characteristics significantly match learning characteristics identified in current research (Items 25-40)? 
Ho4: Missouri HE faculty perceptions of millennial students' learning characteristics do not significantly match learning characteristics identified in current research.

\section{Research Question 5}

What are the overall summary statistics broken down by demographic (Items 1$6)$ ?

Sub research question 5.1. What are the significant differences of responses among the different types of Missouri HE institutions (Item 1) - (2-year, 4-year public and 4-year private) as determined by frequency counts and percentages and Chi square analysis applying a .05 significance level?

Sub research question 5.2. What are the significant differences of responses among the various size institutions based on Carnegie Size Classifications (Item 2) - (Very small 2-year (<500 FTE student enrollment), small 2-year (500-1,999 FTE student enrollment), medium 2-year (2,000-4,999 FTE student enrollment), large 2-year (5,000-9,999 FTE student enrollment), very large 2-year (10,000 or more FTE student enrollment), very small 4-year (< 1,000 FTE student enrollment), small 4-year (1,000-2,999 FTE student enrollment), Medium 4-year (3,000-9,999 FTE student enrollment), and Large-4 year $(10,000$ or more FTE student enrollment) as determined by frequency counts and percentages and Chi square analysis applying a .05 significance level?

Sub research question 5.3. What are the significant differences of responses among Departments (Item 3) as determined by frequency counts and percentages and Chi square analysis at a .05 significance level? 
Sub research question 5.4. What are the significant differences in responses among Rank (Item 4) - (Adjunct, Instructor, Assistant Professor, Associate Professor, and Full Professor) as determined by frequency counts and percentages and Chi square analysis applying a .05 significance level?

Sub research question 5.5. What are the significant differences in responses between Gender (Item 5) - (Male and Female) as determined by frequency counts and percentages and Chi square analysis applying a .05 significance level?

Sub research question 5.6. What are the significant differences in responses among Age Range (Item 6) - (Under 30, 31-50, and Over 50) as determined by frequency counts and percentages and Chi square analysis applying a .05 significance level?

$\mathrm{H}_{0}$ 5: There are no significant differences among respondents according to demographics when applying a .05 significance level.

\section{Anticipated Benefits of Study}

According to the Digest of Education Statistics 2011, college enrollment was 21.0 million in fall 2010, higher than in any previous year (Snyder \& Dillow, 2012, p. 279). Expectations are for college enrollment to continue setting new records from 2011 through 2020 (Snyder \& Dillow, 2012). Between 2010 and 2020, expectations are for enrollments to increase by another 15 percent (Snyder \& Dillow, 2012, p. 280). The traditional college-age population rose 34 percent between 2000 and 2010 (Snyder \& Dillow, 2012, p. 280). This rise in traditional or millennial student enrollment will have a major impact on higher education institutions, as these non-traditional learners, the Millennials, become a major challenge to traditional higher education culture. These students with their differing characteristics and learning styles as well as their 
predilection for technology may well cause a mismatch with existing faculty instructional practices.

Knowledge gained from this study will inform higher education institutions concerning techniques to discover and improve areas of current weaknesses when analyzing utilization of technology-enhanced instructional practices and perceptions of instructor role. This study will further serve to pinpoint issues or lack of knowledge concerning faculty perceptions regarding preferred learning methods of traditional students or Millennials, now being served in higher education classrooms. These results could enable higher education administrators to gain new knowledge allowing better focus of resources to areas of identified needs. Results will also benefit higher education faculty's knowledge and understanding of technology-enhanced instructional practices and desired changes in instructional role. Results will further provide an informed perspective to analyze and better understand how millennial students prefer to learn and relationships among technology-enhanced instructional practices, instructional role and students' preferred learning styles. This is illustrated in Figure 1. This validated survey could also be a valuable tool used by other researchers replicating this study for future investigations at other higher education institutions. 


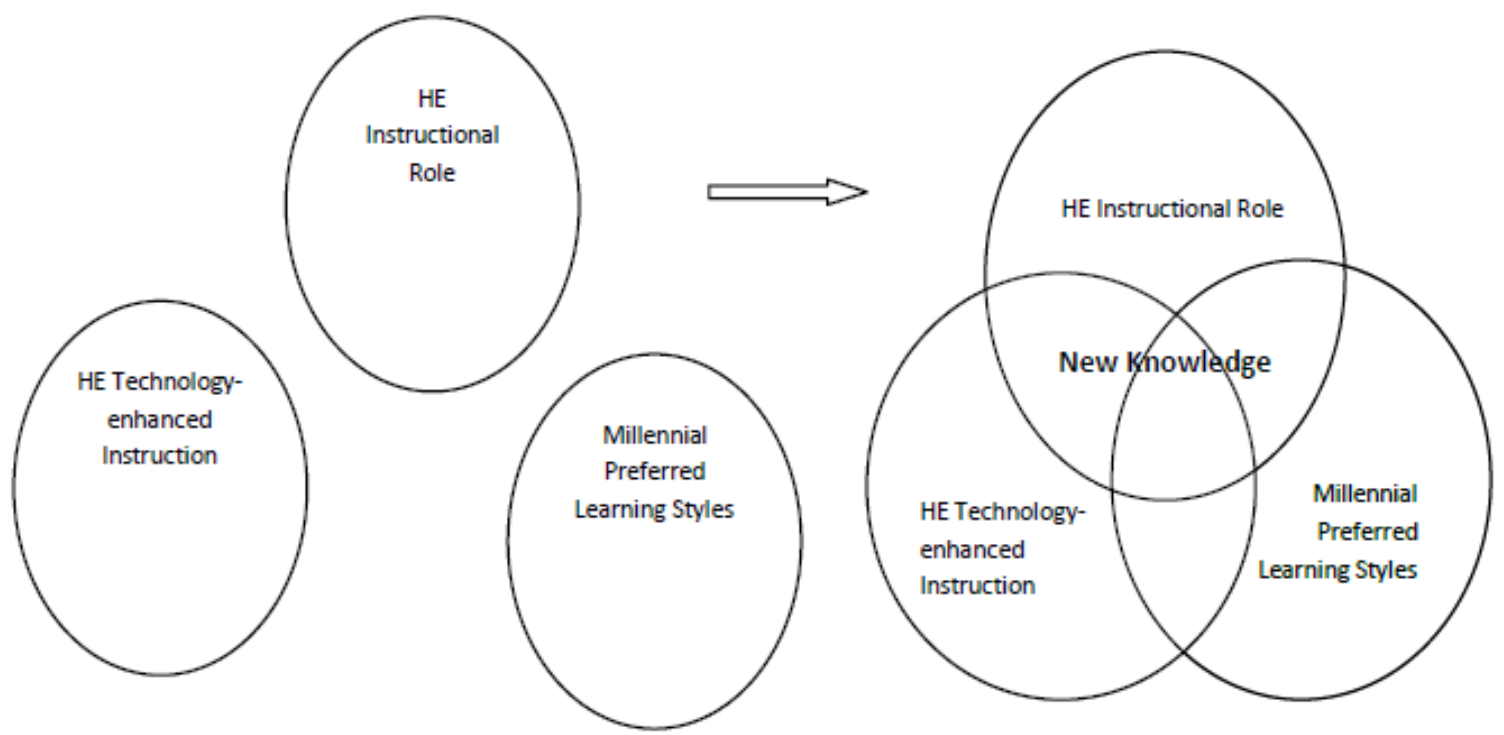

Figure 1. Technology-enhanced instructional practices, instructional role and students' preferred learning styles relationships

\section{Definition of Terms}

Some key terms will used throughout remaining chapters of this study. These terms will be used in reference to the following explanations.

Carnegie size classification. A framework for recognizing and describing institutions' size and residential character developed by the Carnegie Commission.

Digital immigrant. An individual who was born before the existence of digital technology and adopted it to some extent later in life.

Digital native. An individual who was born during or after the general introduction of digital technologies and through interacting with digital technology from an early age.

Generation Y or Gen Ys. Another term used to reference Millennials or those born between 1982 and 2002 . 
Higher education institution. Schools that provide education after completion of secondary school; includes institutions such as colleges and universities.

Instructional practices. Methods used by faculty or instructors to teach course content.

Learning preferences. The manner in which students prefer to learn or gain knowledge.

Millennials or millennial students. Individuals born between the years of 1982 and 2002 (Straus \& Howe, 2000).

Net Generation or N-Geners. Interchangeable term for Millennials

Technology-enhanced instruction. Instructional practices which integrate technology in some manner.

\section{Limitations, Delimitations and Anticipated Benefits}

The following will be considered limitations, delimitations and anticipated benefits of this study:

\section{Limitations}

The limitations of this study are as follows: (a) this study employed a pilot survey instrument. While statistics validating the survey were used, the instrument has not been tested during broad, varied usage. (b) The survey included limited instructional practices and could not attempt to cover every instructional practice, thus some congruent strategies may not be identified. (c) Results are limited to those from surveys completed by only participants in this study and may not characterize the entire population due to the fact that data were self-reported and the representative sample was self-selected. (d) The survey was delivered via the Internet, thus limiting results to the degree which 
participants have easy access to the World Wide Web. (e) Results were limited by the degree to which all respondents understood and honestly responded to questions in the survey.

\section{Delimitations}

The following are considered delimitations in this study: (a) This study was conducted in a limited geographical area, involving only Missouri higher education institutions. More definitive results might have been achieved by use of a larger geographic area. (b) This study used an instrument limiting reported perceptions of student learning to those contained in the survey and chosen for this study.

Assumptions

The following assumptions are made throughout this study: (a) Participants were practicing faculty in an institution of higher education in Missouri. (b) Participants understood all survey questions presented. (c) Participants responded to all survey questions reflectively and honestly. (d) All participants voluntarily chose to participate in this study. (e) Millennial students do not all possess the same characteristics or learning styles. (f) Individuals from previous generations whom heavily use technology may have characteristics similar to Millennials.

Summary

Students on higher education campuses today have different learning preferences than students before them (Fine, 2008; Howe \& Strauss, 2000; Jonas-Dwyer \& Pospisil, 2004; McGlynn, 2005; Nicoletti \& Merriman, 2007; Prensky, 2001a, 2005; Skiba \& Barton, 2006; Tapscott, 1998, 2009). Existing research indicates one preferred learning method is the use of technology in knowledge creation (Frand, 2000; Newton, 2000; 
Oblinger, 2003; Oblinger \& Oblinger, 2005; Prensky, 2001a, 2008, 2012). The traditional higher education environment has not embraced this change in methodology, but current pressures, from society and particularly from current students, are forcing higher education to reconsider and adopt different instructional practices (Christensen, et al., 2008; Christensen \& Eyring, 2011).

Chapter 1 introduced this study outlining issues and concerns, including discontent of current students. Also summarized were student considerations of poor academic service and education perceived as not meeting their needs. Next highlighted was the issue of instructional practices currently employed by higher education faculty not seeming to match learning styles of current or millennial students. Next initiated was an examination of learning styles of incoming students and differences between the millennial generation of students and previous generations. Following, an overview of historical versus current instructional practices of Missouri higher education faculty was given.

The theoretical framework for this study, disruptive innovation, was next introduced. Following was an examination of the history and background of this theory. Disruptive innovation's influence on education and reasons or needs for use in education were summarized. Conceptual underpinnings or ties to disruptive innovation, as related to technology-enhanced instruction, instructor role and millennial students' preferred learning styles, were demarcated. Next, the problem was stated, followed by the purpose for this proposed study. Following were research questions guiding the study. Next detailed were key terms as related to this study. Lastly delineated were limitations, delimitations, assumptions and anticipated benefits of the study. 
Chapter 2 provided a literature review related to technology-enhanced instructional practices. Examinations of the history of technology and the its in education took place. Preferences by millennial students and uses by higher education faculty were delineated. Next explored were instructor roles. Instructor role importance and traditional and current educational practices were highlighted and connections to preferred millennial students' learning styles were shown. Next explicated were millennial students learning preferences. Historical context was then given and the conceptual underpinning of disruptive innovation was related for each of the concepts. Chapter 3 provided the methodology used in the study. A description of utilized research design, sample population, and the developed and piloted survey instrument were included in this chapter. Sampling techniques, examined independent and dependent variables as well as data collection and analysis procedures were also integrated in Chapter 3. 


\section{CHAPTER TWO}

\section{REVIEW OF RELATED LITERATURE}

The onslaught of traditional students so different from previous generations of students is proving challenging for higher education. According to Howe and Strauss (2007), Millennials are the "new generational wave breaking across campuses in America" and are dramatically changing the "basic nature" of every college function, including instructional practices, and will "transform" traditional higher education (p. 34). Additionally, Howe and Strauss (2007) state current higher education institutions are facing four choices:

[Institutions] can ignore this breaking Millennial wave, by treating today's collegians as [they] did the last generation. [Institutions] can resist it, by pursuing decades-old agendas. [Institutions] can ride it by adapting as fast as they can to new needs as they arise. Or [institutions] can lead this new youth wave, by embracing Millennials as they arrive in full force. (p. 5)

The focus of this study was to determine ways in which higher education can analyze information to help identify and meet challenges that emanate with the new generation of millennial students.

Chapter 1 introduced the study, outlining areas of focus or themes. Each area was demarcated and a brief overview was given. Five research questions, as well as the problem statement, purpose of the study and anticipated benefits were specified. Chapter 2 uses related literature to further expound on identified themes. First, technologyenhanced instructional practices in the world of education were examined, including historical background. Next investigated was utilization of technology-enhanced 
instruction in modern universities, including traditional use, preferences by millennial students for learning and current use by higher education faculty. Suggested changes in existing technology-enhanced instructional practices were elucidated. Relationships of these practices to the theory of disruptive innovation were explored.

Instructional practices were next examined. Examination from a historical or traditional as well as current perspective was given. Next delineated were Millennial learning preferences as associated to instructional practices. Also summarized were the underpinnings of disruptive innovation as related to instructional practices. Subsequently, the students known as Millennials were explored. First, an overview of Millennials, based on an analysis of current research was given, including characteristics, particularly learning preferences. Changes from previous generations of college students were expounded and again ties to the theory of disruptive innovation were shown.

\section{Technology-Enhanced Instruction}

Technology use in education has long been a topic of discussion, but the rapidly changing world and technology currently being introduced and used makes this discussion increasingly important in higher education as "new educational technologies promise to change forever the way students learn and teachers teach" (Kent \& McNergney, 1999, p. 1). Kent and McNergney (1999) assert "technology will continue to play an increasingly prominent role in education in the years to come" (p. vii). Trending technology innovations in education have been disappointing in the past, (Kent \& McNergney, 1999; Prensky, 2001a) but societal trends and Millennials are forcing education to consider technology an important instructional tool (Green, 2010; Kent \& McNergney, 1999; Prensky, 2001a, 2001b, 2010; Tapscott, 1998. 2009). One 
consideration supporting the need for technology-enhanced instruction in higher education is the "acceleration in the sheer pace of knowledge production, and ... the proliferation of knowledge(s), or the sharp and indeed escalating increase in the volume and quantity of knowledge that the rapidly changing, technology-enhanced society is producing" (Green, 2010, p. 46).

Another important consideration is "the future(s) of knowledge," and the way it "is being transformed by the forces for change" (Green, 2010, p. 46) or technology in modern society. Traditional learning and content "are still foundational" (Prensky, 2013, p. 2). However, academia should recognize "that technology is equally foundational in our times" (Prensky, 2013, p. 2). "Just as [educators] wouldn’t do a day, a unit or a lesson in any school or grade without incorporating some reading and writing, [educators] should never do anything in school without incorporating technology" (Prensky, 2013, p. 1). Additionally academia “must be aware of how today's digital environment introduces subtle and significant shifts in learning" (Oblinger, 2010, p. 4) as well as "the impact on knowledge of new technologies and digital practices, and . . . their impact on knowing and learning" (Green, 2010, p. 46). This concept of changing educational technology and factors influencing this change is further delineated in Figure 2. 


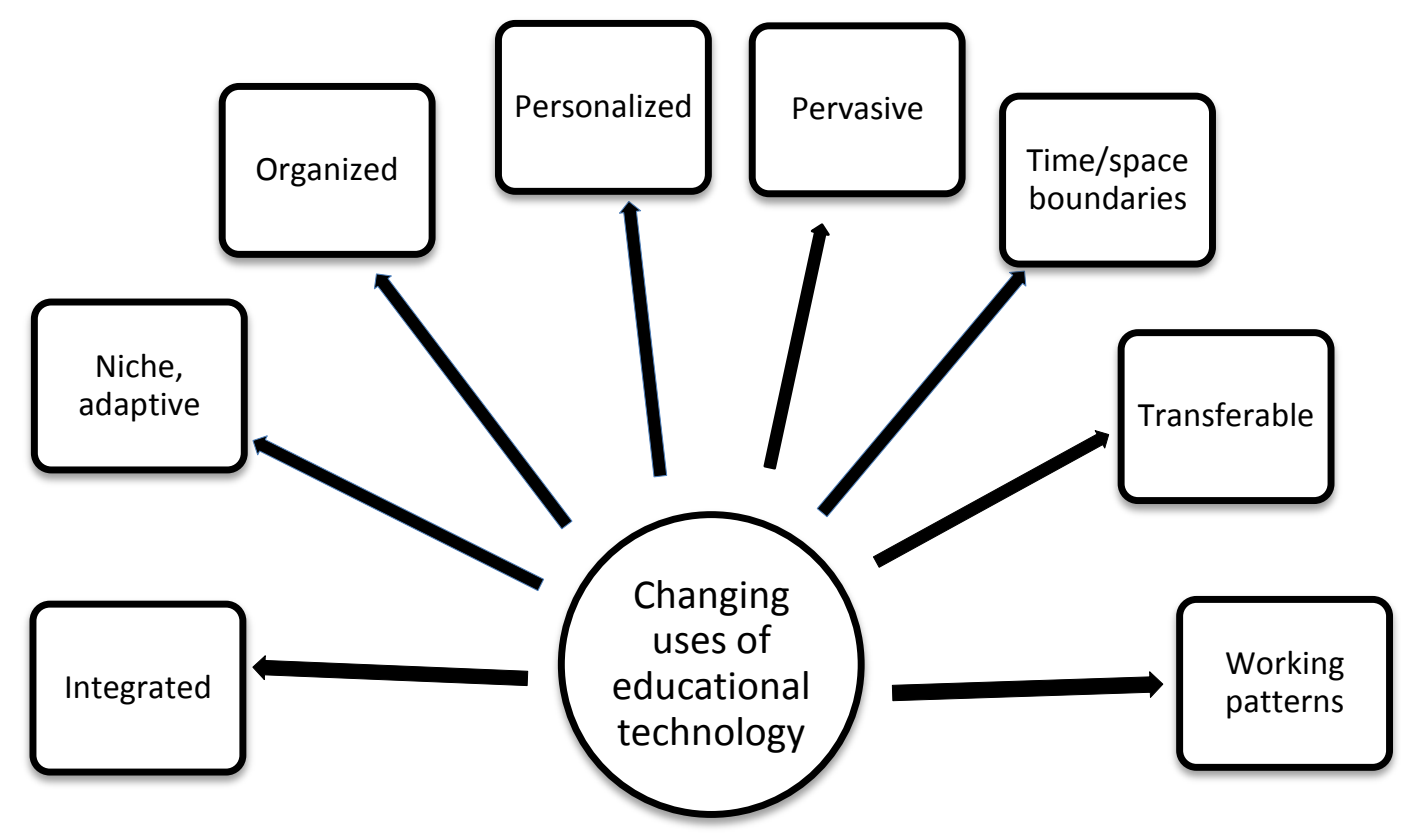

Figure 2. Factors influencing change in use of instructional technology

Adapted from Conole, de Latt, Dillion \& Darby (2008), Computers in Education, 50, p. 511-524.

History

"In the view of Robert McClintock, Frank Moretti and Luyen Chou, the evolution of ... teaching and learning goes hand-in hand with the evolution of technology" (Prensky, 2001a, p. 03.7). Originally, education "was a process of imitation and coaching" (Prensky, 2001a, p. 03.7). Pictures and symbols were the next "technical addition to this process. .." followed by "the next great technological innovation in learning ... the development of spoken language. With spoken language," (Prensky, 2001a, p. 03.7) instructors could ask questions and students could answer. "This . . . socalled dialectical or 'Socratic Method' of questioning is still in use" (Prensky, 2001a, p. 03.7)

Closely following the innovation of spoken language came the "introduction of literacy: writing and reading. . Ideas and learning could now be codified in other ways" (Prensky, 2001a, p 03.8) besides just imitation, pictures and symbols or orally. "Learners 
could read the thoughts of others on their own" (Prensky, 2001a, p 03.8) in printed form. "However this form of written knowledge and learning was . . rare" as "this type of learning required knowledge of reading and writing," (Prensky, 2001a, p 03.8) something the masses did not yet possess.

Following literacy was an invention considered by many as the "next-to-last great technological change" (Prensky, 2001a, p. 03.8), the printing press. "Now 'educational' materials could be distributed to the masses ... allowing access to learning to many new people" (Prensky, 2001a, p. 03.8) as well as the need to further the teaching of reading and writing. Prensky (2001a) cites Neil Postman who believes our modern education system and the desire to "bring everyone to a basic level of literacy" (p. 03.8) began essentially at the introduction of the printing press. Although Postman believes school was developed primarily to teach people to read books "over time much of 'teaching' has been reduced to pre-prepared lecturing, and learning has turned into merely 'reading or listening"” (Prensky, 2001a, p. 03.8). "The industrial revolution led to further standardization of the school system ... leading to the tradition of 'tell-test' education" (Prensky, 2001a, p. 03.8).

Traditional instructional practices fulfilled educational needs through the late 19th and early to mid-20th century, and were affected little by "new technologies coming along such as the telephone, radio and television" (Prensky, 2001a, p.03.9). "Radio promised to open classrooms to the world. It would allow students access to the finest teachers, the best authorities in every field, and the world's leaders. Radio was to become the 'textbook of the air'" (Darrow, 1932 as cited in Kent \& McNergney, 1999, p. 26). Some argue these technologies were really less transformational "than language, literacy 
or the printing press", but Luyen Chou suggests these technologies had little influence on education because the system made a "concerted effort to keep them out" (Prensky, 2001a, p. 03.8). As quoted by Chou, "I wonder if there had been a telephone on every student's desk for educational purposes, how much it would have changed things" (Prensky, 2001a, p. 03.8).

Kent and McNergney (1999) state that some experts attribute the lack of training and the fact that no one, including educators, had a "good conception of what teachers should be doing with these machines in their classrooms" (p. 27). In actuality, "the content and instructional implementation of these media reflected little understanding of the daily reality of the classroom teacher" (Kent \& McNergney, 1999, p. 28). Another factor was the passive nature of all three of these technologies. Classroom implementation involved simply watching and/or listening by the students. As stated by Kent and McNergney (1999):

With each technology, an expert other than the classroom teacher created the instructional objectives and lesson delivery. These media lacked any interactivity and depended on the skill of the teacher to integrate the content with existing curriculum. In each case, the success of the medium was determined by how the teacher valued and used it in the classroom. (p. 28)

Next pioneered was what is considered the greatest technological revolution of the $20^{\text {th }}$ century and beyond; the computer (Prensky, 2001a). This innovation brought about increased interactivity and other associated technologies to use as tools in education. According to Prensky (2001a), Brian Ferrin, Walt Disney Head of Research and Development, calls multimedia computing "the most important technical innovation 
since the invention of language. It makes the printing press look small” (p. 03.9).

Previously introduced educational technology tools never produced significant effects on classroom instruction (Kent \& McNergney, 1999; Prensky, 2010; Tapscott, 2009).

According to some researchers, this was due to the fact these technologies did not have the capabilities of providing the array of choices needed to fit most classroom situations (Kent \& McNergney, 1999; Prensky, 2010; Tapscott, 2009) while newly introduced "computer technologies had the flexibility to be used in a variety of ways for a variety of purposes" (Kent \& McNergney, 1999, p. 57). "Seemingly gradual, but extremely quick" (Prensky, 2001a, p. 03.9) if compared to previous historical educational transformations, this new technology led to some extremely important changes. Written language became less dominant and the linear style organization prevalent in traditional instructional practice became supplemented with "random-access (hypertext) organization" (Prensky, 2001a, p 03.9). Traditional or "passive media, such as books and TV, were supplemented with active ones, such as interactive games and the Internet" (Prensky, 2001a, p. 03.9).

\section{Use of Technology in Education}

Kent and McNergney (1999) observe, "Support for the instructional use of computers continues to increase" (p. 1) and "the use of technology in classrooms is growing every day" (p. 2). Despite the fact scholars may not fully understand the trend of using technology to allow students to take control of their own learning and some educators may "want to sidestep technology . . . it will play an increasingly prominent role in classroom instruction in the coming decades" (Kent \& McNergney, 1999, p. 4). Support for "technology persists, or, more accurately, rages" (Kent \& McNergney, 1999, p. 5). Kent and McNergney (1999) further assert society is "unequivocal in its desire to see more technology in our schools. 
Americans overwhelmingly understand that technology can play a vital role in education ... and preparing students for the jobs of the future" (p. 7).

Faculty are key elements to success in using technologies in the educational

environment, including current available computer technologies (Kent \& McNergney, 1999). Lack of adoption and use of specific instructional technology tools may be correlated to the tools' failure to address the perceptions and instructional needs of educators (Kent \& McNergney, 1999; Prensky, 2001a; Tapscott, 1998, 2008). Throughout educational history, many technology tools have either failed to prove valuable in the educational environment or have been replaced by newer technologies (Kent \& McNergney, 1999). Some have claimed educators were "unwilling to change their instructional practices adequately to take advantage of the promises offered" (Kent \& McNergney, 1999, p.7). Cuban (1986) as as cited in Kent and McNergney (1999) argues:

Teachers have always been willing to change practice, and have done so with other low technologies, so long as they have perceived that the new technologies would help them address the problems they have identified. The problem is that reformers did not match the innovations to teachers' views of daily classroom realities. (p. 2324)

For successful deployment of technology in the educational environment, tools must be able to be launched and used within an instructional framework, decided upon by the educator (Kent \& McNergney, 1999). Technology-enhanced instructional tools must be adaptable to instructional needs of teachers and to daily realities of classroom life (Kent \& McNergney, 1999). According to Kent and McNergney (1999), "accessibility is another key to the successful integration of technology into classroom teaching" (p. 29). Educators have to be able to able to preview materials and be able to use these tools when planning for instruction and the technology must be adaptable to the flexible instructional schedules of 
schools (Kent \& McNergney, 1999). Kent and McNergney (1999) emphasize two specific factors differentiating computer tools from the earlier technologies:

First, the content developed in other segments of the economy is now accessible to classrooms through the Internet, and teachers can integrate this content into lessons they create. Second, computer technology pervades nearly every business and professional sector of our economy. Increasingly, employees must master computer technologies to perform their jobs. The ubiquity of computers in our economy and culture puts increasing pressure on schools to produce students who are familiar with their use. (p.31)

Research suggests using technologies in combination with other instructional tools can enhance existing instructional models and fashion new techniques for teaching and learning (Kent \& McNergney, 1999; Prensky, 2012; Tapscott, 1998). Current technology can allow educators and students to connect in new ways and if implemented properly can reveal previously "unimagined models of educational practice" (Kent \& McNergney, 1999, p. 48). These tools can make content and traditional instructional practices available in completely new ways.

\section{Millennial Preference}

Tapscott (1998) asserts Millennials are unique due to "not just their large numbers, but that they are growing up during the dawn of a completely new interactive medium of communication" (p. 15) and a "new medium of human communication is emerging, one that may prove to surpass all previous revolutions. This is . . a paradigm shift" (p. 24). Carlson (2005) states "Millennials consume and learn from a wide variety

of media, often simultaneously" (p. 4) and collaboration or group work is "both in person 
and virtual" (p. 3). "They like everything being electronic -- it's speaking their language" (McHugh, 2005, p. 34).

When discussing introduction of modern technology into education, Prensky (2001a) states 'Speed in general increased — to what I call 'twitch speed,' — leaving far less time and opportunity for reflection" (p. 3.9). These seemingly few changes changed the landscape of student expectations of education inexplicably (Prensky, 2001a, 2013, Tapscott, 1998). "When children grow up around technologies, make those technologies part of their lives, and cooperate with one another in their use, new models are bound to emerge" (Kent \& McNergney, 1999, p. 48). The traditional classroom becomes "antiquated and perhaps even obsolete" (Kent \& McNergney, 1999, p. 52). Millennial students view higher education "as a means to an end" and do not support the traditional scholastic beliefs "regarding knowledge for its own sake" (Greenberg, 2004, p. 14).

\section{Use by Faculty}

Since its inception in education, computer technology has improved greatly. (Kent \& McNergney, 1999; Prensky, 2001a, 2001b, 2013; Tapscott, 1998, 2009) However, educator qualms regarding quality and content of technology-related instructional materials continue to be issues (Kent \& McNergney, 1999). Many of these issues could be averted if "decisions regarding the appropriate place of computer technology" in instructional practice were made by individual educators, as they are the ones whom could determine how technology tools can best "fit into the daily routine of classroom life" (Kent \& McNergney, 1999, p. 34). Instructional technology tools are merely basic resources educators can use to develop specific course content (Kent \& McNergney, 1999; Prensky, 2001a, 2001c; Tapscott, 1998, 2009). According to Kent and McNergney (1999) while current technology provides effective instructional tools, educators must 
still decide "when, where and how they are used" as well as "create objectives and plan instruction" (p. 27). Furthermore, computers in classrooms allow educators to "maintain control of the instructional process" (Kent \& McNergney, 1999, p. 33).

While no "right way" to use technology in instructional practice has been identified, the flexibility of this medium allows proven instructional models to be enhanced and expanded to include technology tools (Green, 2010; Kent \& McNergney, 1999; Prensky, 2001a, 2001b, 2012; Tapscott, 1998, 2009). Rapid introductions of new technologies provide increasing numbers of ways for educators to react to changing learning preferences and demands of millennial students. Educators can select or even create instructional models by focusing on desired outcomes and effects of instruction (Kent \& McNergney, 1999). While it is recognized educators possess expertise to determine which instructional practices work best, regardless of technological proficiency, educators are most likely to prosper in this technological age if instructional technology tools support "professional knowledge of teaching, of learning, and of content to be mastered" (Kent \& McNergney, 1999, p. 39). The role of technology in education is "primarily influenced by two factors: (a) whether teachers find value in instructional possibilities offered by new technologies, and (b) whether patterns of implementation of new technologies avoids mistakes made with past technologies" (Kent \& McNergney, 1999, p. 23).

\section{Needed Changes}

Prensky (2001a) asserts "if an observer from 200 years ago were to come to the US in the year 2000, they would be amazed and uncomfortable with changes everywhere except in a school" (p. 03.1) as there has been little change in classroom environment. Current students "live in the world into which they are born, and do the things" of their generation 
(Prensky, 2001a, p. 03.2). Due to technological advances, the "outside forces around them as they grew up," and just "living their entire life in the twentieth century, learners' habits, preferences, and needs have radically changed" (Prensky, 2001a, p. 03.2). Despite school's hundreds of years of tradition, it is now time for education to finally change as "it no longer holds the interest of its students, even under duress" (Prensky, 2001a, p. 03.3). Prensky (2001a) maintains "while there are still . . many students who succeed at learning . . they do it in spite of, not because of, their schools and training" (p. 03.3).

Faculty are expected to use technology to communicate with students and instruct online courses. Many faculty bemoan the fact that time once assured professors for scholarship and research is encroached upon by hours spent digitally communicating with students on non-academic matters, developing online courses, and managing them (Carlson, 2005; Plous, 2000; Wilson \& Harris, 2002). "Faculty members feel pressured to shorten lectures, increase group discussion time, and ignore the 'multitasking' student ...in the back of the room" (Carlson, 2005, p. 2). Most instructional practices in higher education classrooms "center around what to teach — what is known, . . . the 'curriculum', rather than how to learn it" (Prensky, 2001a, p. 3.3).

Research indicates education should move towards a student-centric learning model. According to Christensen, Horn and Johnson (2008), one method which may be employed to help attain that goal is computer-based learning, a step toward "student-centric technology" (p. 38). In the academic world, computer-based learning is appearing as a disruptive innovation (Christensen, et al., 2008). "Computers have been in schools for decades, but schools have looked much the same and more importantly, teaching and learning have looked much the same" (Christensen, et al., 2008, p. 72). Perhaps the most important piece of integration or using technology to actually enhance instruction has been, and for the most 
part, is still missing (Fine, 2008; Oblinger \& Oblinger, 2005; Prensky, 2001a, 2012; Tapscott, 1998, 2009).

The use of technology in traditional manners will not "allow schools to migrate to a student-centric classroom" (Christensen, et al., 2008, p. 73) preferred by millennial students. Most schools have computers, but students report little use (Christensen, et al., 2008; National Education Commission, 1994; Tapscott, 1998, 2009). As long as schools use technology "as a tool and a topic, not as a primary instructional mechanism that helps students learn in ways customized to their type of intelligence" (Christensen, et al., 2008, p. 81), change needed to reach Millennials will not take place (Oblinger, 2010; Prensky, 2012; Tapscott, 2008). Technology-enhanced instructional practices must be put into place allowing "students to learn in the way their brains are wired to learn" (Christensen, et al., 2008, p. 73). Disruptive Innovation and Technology-Enhanced Instruction

Finn and Rebarber (1992) state "for the first time in . . . history, the business of schooling is being redefined in relation to its customers" (p. 7), the Millennials. According to Laseter (2012) "almost every major modern business grounds itself solidly in research shaped by practical questions concerning how that business' products function and can be used effectively in context," but education does not (p. 3). Laseter (2012) further suggests that due to all of the current "disruptive changes, higher education needs a new, more innovative... model" (p. 1). Technology can provide this model (Christensen, et al., 2008; Fine, 2008; Kent \& McNergney, 1998; Laseter, 2012; Prensky, 2001a, 2012; Tapscott, 1998, 2008).

"Motivation is the catalyzing ingredient for every successful innovation" (Christensen, et al., 2008, p. 7). In traditional instructional practices, student motivation has not always been considered. However, today's students may require a re-examination 
of these practices. Millennial students prefer feeling connected to content they want to view as pertinent or meaningful to their lives. Students learn in different manners and research indicates Millennials prefer to have learning customized to fit their individual needs. Nevertheless, learning has typically been delivered in only one manner, the traditional model (Prensky, 2001a, 2001b, 2001c, 2012; Tapscott, 1998, 2009). To increase learning and student motivation, as well as meet Millennials' preference for customized learning, change in this traditional model must take place. Computers have been used in "limited ways to simply maintain rather than transform prevailing instructional practices" (Christensen, et al., 2008, p. 82). Despite introduction of computers and other technologies, traditional instructional practices in education have changed very little and continue to lag behind expectations of our students (Christensen, et al., 2008; Prensky, 2001a, 2012; Tapscott, 1998). According to disruptive innovation theory, in order to be effective change agents, changes cannot be "crammed" or implemented into existing models and will only be successful when "allowed to compete against non-consumption" (Christensen, et al., 2008, p. 86).

\section{Instructional Role}

Traditional instruction has been based on an 'instructor's view of the subject and the instructor's perception of the student” (McDermott, 1993, p. 295). Prensky (2001a) postulates one reason traditional instruction seems to be "failing to do the job it used to is that the world of the learner has changed so dramatically" (p. 3.9). Traditionally, education is slow to change (Green, 2010, Kent \& McNergney, 1999; Prensky, 2012; Tapscott, 1998, 2009), but now there is the challenge of "kids who have totally outpaced their parents and elders in the new ways of the world" (Prensky, 2001a, p. 3.10). 
Millennial students have broad experience and knowledge before they arrive in a university classroom (Prensky, 2012; Tapscott, 1998, 2009). Traditional methods of lecture or "tell-test" no longer serve the learning demands of these students. As Prensky (2001a) states, "we have to stop telling, because almost nobody's listening" (p. 03.10). The arrival of the Millennials presents significant changes in student bodies of higher education institutions. Digital technology has been an important part of these students' lives since birth, giving them a natural affinity towards digital technology and an expectation for a "connected world" (Prensky, 2008, p.48). Prensky (2008) alludes to part of the change needed:

Older professors advocate that because students have not attained "college level" proficiency, they should be shunted to remedial courses, and at the same time deride the students' technology as "the new spitball." Many of these same professors have achieved little or no mastery in the students' digital world, and would perhaps be shocked to know their students view them as functional illiterates. (p. 48)

Prensky (2001c) also states, "linear thought processes that dominate educational systems now can actually retard learning for brains developed through game and Web surfing processes on the computer" (p. 3).

\section{Historical and Current Instructional Role of HE Faculty}

Historically ingrained notions of schools as sheltered monopolies, or delivery systems are breaking down under infiltrations of a market philosophy into education (Boyd, 1990; Boyd \& Hartman 1988). At the same time, better understanding of the education production function has begun to be translated into what William Spady (1988) 
terms "dramatically different way[s] of thinking about the design, and delivery, of instructional programs" (p. 10). In classrooms, "traditional emphasis on content coverage and rote learning of basic skills is being challenged" (Finn \& Rebarber, 1992, p.8).

Standardized, teacher-directed models of instruction which dominated traditional classrooms (Prensky, 2001a, 2001b, 2001c, 2005, 2013; Tapscott, 1998, 2009) "gives way to a greater variety of approaches when teaching for understanding is stressed" (Finn \& Rebarber, 1992, p. 13). As stated by McDermott (1993), traditional instruction has been based solely on instructors' views and perceptions, but “meaningful learning will not take place unless students are intellectually active" (p. 297). Making meaning of learning or "ability to interpret and use knowledge in situations different from those in which it was initially acquired, requires that students be intellectually active" (McDermott, 1993, p. 298). Millennials focus on "understanding, constructing knowledge using discovery methods and active engagement" (Skiba \& Barton, 2006, p. 17). Unless instructional practices are designed to "meet the needs and abilities of students, efforts to update teaching ... will produce little of either intellectual or motivational value" (McDermott, 1993, p. 298).

Many challenges for higher education "stem for the dichotomy between the millennial mindset and that of most higher education" (Oblinger \& Oblinger, 2005, p. 2.10) influenced by Millennials' preferences for “digital literacy, experiential learning, interactivity, and immediacy" (Skiba \& Barton, 2006, p. 6). Research indicates that at "all levels of instruction the difference between what is taught and what is learned is often greater than most instructors realize" (McDermott, 1993, p. 295). What faculty see as impatience may be considered by Millennials “as immediacy - responses are supposed to 
be fast" (Oblinger \& Oblinger, 2005, p. 1.2) which students have came to expect (Prensky, 2001a, 2012, Tapscott, 2009).

\section{Millennial Preferred Learning Styles}

Millennial students "communicate regularly via e-mail, instant messaging, and cell phones ... and gather [digital] information with ease and without [face-to-face] contact" (Greenberg, 2004, p. 15). As technology has been an integral part of their lives since birth, this type of communication is all they have ever known (Greenberg, 2004; Prensky, 2001a, 2001b, 2001c, 2008, 2012; Tapscott, 1998, 2009). This proclivity for instantaneous communication has implications for academia. Millennials bring this expectation to the classroom and expect faculty to be available instantly or " $24 / 7$ ", an expectation clearly outside traditional classroom tenets (Greenberg, 2004; Prensky, 2001a, 2008, 2012; Tapscott, 1998, 2009).

Online courses offer consumer-minded Millennials a service, a market-driven curriculum that is part of American culture (Christensen, et al., 2008). These courses meet needs of well-connected consumers of information and provide digital convenience with which Millennials are comfortable (Christensen, 2012; Tapscott, 2009). They provide a means of digitally communicating with professors and fellow students as often as they like while they are multi-tasking with other media (Prensky, 2001a, 2008).

The Ipsos MORI Survey of Secondary School Pupils (2007) included a section specifically for the Campaign for Learning and provided some interesting insights concerning Millennial learning activities and preferences. The study showed that when students were asked to choose three activities they most often did in the classroom, 52\% replied copying from a book or the board, 33\% said they routinely listened to a teacher 
talking for a long time and $25 \%$ responded they took notes. When students responded concerning their preferred ways to learning 55\% replied learning in groups, $39 \%$ responded doing practical things, 35\% answered learning with friends and $31 \%$ preferred to learn by using computers. These responses from students further highlight the discrepancy between Millennials' preferred learning styles and learning activities actually practiced in the classroom. This study serves to further emphasize the fact that millennial students prefer non-traditional learning methods such as group learning and technologyenhanced instruction. Students involved in this study are now the age to be college students, thus indicating this same preference for non-traditional learning methods. Needed Changes

"Instruction ... has traditionally been based on the instructor's view of the subject and the instructor's perception of the student” (McDermott, 1993, p. 295). In order for "meaningful learning to take place" students must be "intellectually active" (McDermott, 1993, p. 297). Meaningful learning must include critical thinking or "the ability to interpret and use knowledge in situations different from those in which it was initially acquired" and must require learners to be involved (McDermott, 1993, p. 298). To assure meaningful learning takes place, instruction needs to be designed to meet the needs and abilities of students (McDermott, 1993). Efforts to simply "update teaching ... will produce little of either intellectual or motivational value" (McDermott, 1993, p. 298) and will not produce the disruptive innovation that needs to take place in education (Christensen, et al., 2008; Christensen \& Eyring, 2011). Implications for higher education "stem for the dichotomy between the millennial mindset and that of most higher education institutions" (Oblinger \& Oblinger, 2005, p. 2.10) further influenced by 
Millennials' preferences for “digital literacy, experiential learning, interactivity and immediacy" (Skiba \& Barton, 2006, p. 6).

Spady (1988) states "The most fundamental revision is a shift from teacherdominated to learner-centered pedagogy. The emphasis is the student, not the delivery system; teachers will no longer be in the coverage business but in the learning success business" (p. 7). Educators will act as facilitators, modelers, and coaches who invest students with more power and responsibility for their own educational benefit (Greenberg, 2010; Kent \& McNergney, 1998; Prensky, 2001c, 2010; Tapscott, 1998). Standardized teacher-directed models of instruction which have dominated traditional classrooms give way to approaches where teaching for understanding is stressed and students are active in acquiring their own knowledge (Greenberg, 2010; Kent \& McNergney, 1998; Prensky, 2010; Tapscott, 1998). "What matters is not the act of distribution, but the act of consumption ... The power is now in the hands of those who control the limited resource of attention" (Oblinger, 2010, p.4).

Needed strategies may involve using new digital technologies including social media, digital storytelling and other available instructional tools to involve and support more students as they interact and become included in creating their own learning. (Greenberg, 2010; Kent \& McNergney, 1998; Prensky, 2010; Tapscott, 1998).The result, as Malcolm Brown (as cited in Oblinger, 2010) notes, is engaged learners who "work willingly, instead of by coercion, and approach their assignments as something that matters to them personally" (p. 4). Although lecture or "tell-test" have been the traditional instructional practice in higher education and in "almost all the new "elearning' experiences being offered ... and touted as 'the new way to learn,' "tell-test 
education is highly ineffective with today's [students]-it just bores them to tears" (Prensky, 2001a, p. 03.5).

Education "must create a community that is committed to learning" (Oblinger, 2010, p. 6). Educators once vied for students attention principally "against daydreams, passed notes, class clowns, and cross-aisle flirting" (McHugh, 2004, p. 34). Now, they further face a "formidable array of gadgets and digitized content" make use of by millennial students (McHugh, 2004, p. 34). Astute academic institutions and perceptive educators are hastening to ascertain instructional techniques utilizing these devices and altered dissemination methods to "reach and excite young minds" (McHugh, 2004, p. 34). Modern systems in academia with multimedia technology resources, which are available on demand, require "different collaborative ... properties, in which ... individual(s) ... are the focal point and ... organizational units are rendered secondary" (Greenberg, 2004, p. 16).

Research indicates millennial learners want something different, but it seems most educators come "from a previous generation and set of experiences and generally don't understand the new generation's needs or learning methods" (Prensky, 2001a, p. 03.18), According to Prensky (2001a):

Teaching is a lot like the rest of business - there is no formula for doing it right. Given the changes in the world, we will probably need the help of our students to do it. Today's generation ... is the first to know more than their elders about a key technology ... computers. How did today's kids learn so much ... . Certainly not "tell-test" in a classroom, but in their own newly-acquired learning style. [Education is] in desperate need of new ideas and methodologies that will engage 
these new generations and help them learn. We can no longer "tell" them anything, because they're not listening. We can't drill, because it does often kill. .

. Like all big systems, training and education are slow to change. (p. 3-19)

Oblinger (2010) states "the greatest challenge of information technology and education is to commit to implementing strategies we know work to improve learningby scaling effective programs to reach millions of learners who need education" (p. 6).

For academia to achieve this goal requires shifts in traditional focus to include entrenched instructional change, rethinking of beliefs, and change in classroom authority to include students (Oblinger, 2010; Prensky, 2005). While "tools, policies, and technologies to create the next generation of learning" (Oblinger, 2010, p. 6) are in place, more must be done to initiate widespread change in education (Christensen, et al., 2008).

Disruptive Innovation and Instructor Role

Schools are similar to many big bureaucracies in the modern business world and as such may be very ingrained in traditional methods of operating (Christensen, et al., 2008; Prensky, 2001a). The rapid evolution of the world in which education now operates is requiring educational institutions initiate innovations, but innovations require change (Green, 2010; Kent \& McNergney, 1999; Oblinger \& Oblinger, 2005; Prensky, 2001a, 2001b. 2001c; Tapscott, 1998, 2009) and "change creates disruption" (Prensky, 2001a, p. 03.20). Furthermore, "for the first time in our history, the business of schooling is being redefined in relation to its customers" (Finn and Rebarber, 1992, p. 7), adding to this disruption.

"Until the relatively recent emergence of the Internet and online learning, the higher education industry enjoyed an anomalously long run of disruption-free growth" 
(Laseter, 2012, p. 2). As well as the introduction of online learning, universities need to "navigate through these forces, [and] follow the example of . . . business counterparts" (Laseter, 2012, p. 2) and fundamentally rethink what they do. Similar to most businesses over the past decade, higher education should focus on "disruptive implications of Internet-enabled innovation" (Laseter, 2012, p. 2). Online learning would seem to be an apparent manner in which to apply these implications. However, not even the 'online' universities "seem to have developed any breakthrough technology for delivering education; they have simply avoided the capital investment in facilities while extending their reach to a larger target market" (Laseter, 2012, p.2). That's a traditonal "virtual model," not disruptive innovation (Christensen, et al., 2008; Laseter, 2012). “Although profitable for some investors and executives, these institutions seem to have exploited a niche but have not truly innovated" (Laseter, 2012, p.2). Universities need to also examine current practices as "there are also sources of innovation within universities themselves" (Laseter, 2012, p.2).

Innovative companies, including Carnegie Learning and Coursera, are redesigning curriculum "based on learners preferred learning styles and customized to the learners specific needs and knowledge" (Laseter, 2012, p. 4). Other companies are designing programs focusing on "ability not pedigree" (Laseter, 2012, p. 5) which calls into question the need for degrees. Gaming used in education is yet another example of a disruptive innovation that could be used (Laseter, 2012; Prensky, 2001a). Laseter (2012) states:

These examples of disruptive applications of technology represent threat or an opportunity, depending on how institutions of higher education react. The creation 
of new understanding and capabilities, for society as a whole (and perhaps for faculty egos), resides at the center of the mission of leading universities. To meet growing demands an admissions director captured the essence of the philosophy: 'We train you for nothing... but we educate you for anything.' . . . in a fastchanging world, the ability to build on foundational knowledge and adapt can be a highly prized asset. (p. 4)

\section{Millennials}

The majority of traditional students attending the new American university are Millennials born in the 1980's and 1990's. Millennials grew up in the postmodern condition of immersion of media and technology into American culture (Howe \& Strauss, 2000; Skiba \& Barton, 2006). They keyboarded, used cellular technology, and operated computers before they could write — they are the Net Generation (Healy, 1998, 1999; Howe \& Strauss, 2000; Skiba \& Barton, 2006; Tapscott, 1998). Coomes and DeBard (2004) identify the demographics of the current generations on campuses today as the Silents (birth years 1925 to 1942), the Boomers (birth years 1943 to 1960), Generation X (Birth years 1961 to 1981), and the Millennials (birth years 1982 to 2002). Each of these generations influences the way universities do business - especially Millennials with their savvy technological know-how and "me" centered attitudes (Levine \& Cureton, 1998; Tapscott, 1998).

Millennials are unique due to "not just their large numbers, but that they are growing up during the dawn of a completely new interactive medium of communication" (Tapscott, 1998, p. 15). According to Blackmore, (as as cited in McHugh, 2005): 
Today's brains are shaped by various information streams -- sometimes referred to as memes -- constantly popping and sparking and competing for attention. This new generation of digital learners -- call them the MEdia Generation -- take in the world via the filter of computing devices: the cellular phones, handheld gaming devices, PDAs, and laptops they take everywhere, plus the computers, TVs, and game consoles at home. Educators must figure out how to compete with this frenetic memestorm coming at them from marketers and other students. (p. 33) A common complaint in American universities today relates to consumer-minded attitudes of students (Carlson, 2005; Howe \& Strauss, 2007; Tapscott, 1998). Millennials feel a sense of birthright entitlement and professors feel a sense of earned entitlement (Carlson, 2005; Howe \& Strauss, 2007; Tapscott, 1998). Millennials believe professors should be immediately accessible to answer e-mails and online assignments quickly; professors believe time is valuable and best spent in research, debate, and reflection (Carlson, 2005; Howe \& Strauss, 2007; Tapscott, 1998). Millennials expect professors to serve their needs like their "helicopter" parents; but professors expect students to be individually responsible adults (Carlson, 2005; Howe \& Strauss, 2007; Tapscott, 1998). Characteristics - Analysis of Current Research

Howe and Strauss (2007) introduce university professionals to Millennials characteristics. Millennials are identified as having seven core traits: (a) they feel entitled and special, and expect universities to accommodate their social and learning needs; (b) they are incredibly sheltered with "helicopter" parents hovering around universities, ensuring their safety and success; (c) they are confident, especially women, and will meet and beat any standard universities set for them; (d) they are team-oriented which stems 
from being constantly digitally connected; (e) they are more traditional in their lifestyle and attitudes than their parents; (f) they feel pressure like no previous generation to succeed academically and to maintain safety and balance in life at the same time; and finally, (g) they are extremely achievement focused with over three-quarters of high school students aiming for a four year college degree (Howe \& Strauss, 2007, p. 59-60).

Millennials oppose hierarchical structures. They work collaboratively and find their fluency in social media naturally leads to sharing information and connections, resulting in the desire for "a side-by-side style of leadership" (Fine, 2008, p.32). Other characteristics include the desire for immediacy and connectivity and proclivity for multitasking leading to mixing work and play (Carlson, 2005; McGlynn, 2008; Skiba \& Barton, 2006). "They love hard work because working, learning, and playing are the same thing to them" (Carlson, 2005, p. 10). Millennials consume and learn from a wide variety of media, often simultaneously (Carlson, 2005, p. 4). Carlson (2005) further maintains:

Time is short; if Millennials are caught working on a paper during a lecture, it's because they have to maximize what they can get done in a given time. If they are seen constantly chatting on phones and computers, it's because the importance of networking... has been ground into them. If they balk at learning subjects that seem unnecessary, it's because there are so many other things to do. (p. 6)

\section{Examination of Learning Styles of Current HE Students}

Millennial students are different, with different learning styles, requiring different teaching methods (Nicoletti \& Merriman, 2007; Prensky, 2001a, 2012; Tapscott, 1998). “Today's students communicate and think differently than did students of previous 
generations" (Nicoletti \& Merriman, 2007, p. 30). They have technology allowing them to be connected and mobile so multi-tasking with different media and each other can be accomplished quickly, which fosters social relationships (Skiba \& Barton, 2006; Tapscott, 1998). They were born into a "consumer driven, mass media culture that bombards them with images and ideas about what they need and who they should emulate" (Nicoletti \& Merriman, 2007, p. 30). “Today's students communicate and think differently than did students of previous generations" (Nicoletti \& Merriman, 2007, p. 30). According to Howe and Strauss (2007), "Millennials are unlike any other youths in living memory" (p. 13) and "they will transform the university world" (p. 4).

Implications for higher education "stem from the dichotomy between the millennial mindset and that of most higher education" (Oblinger \& Oblinger, 2005, p. 2.10). Implications are further influenced by Millennials' preferences for "digital literacy, experiential learning, interactivity, and immediacy" (Skiba \& Barton, 2006, p. 6). Millennials are not interested in listening to lectures and learn better when they are actively involved in the learning process (Knapper, 2007; Koehn, 1995; Levine \& Cureton, 1998; Martin, 2007; Pope, 2007; Prensky, 2001a, 2012; Schneider, 2001; Strauss, 2003; Tapscott, 1998). “They want to learn, but they want to learn only what they have to learn, and they want to learn it in a style that is best for them" (Carlson, 2005, p. 3). Skiba \& Barton (2006) state, Millennials need a "learner-centered model . . with a shift from the traditional teaching paradigm to a constructivist-learning paradigm" (p. 4).

Millennials are well connected socially and prefer group work and active learning related to real-life (Bok, 2006; Fink, 2003; Howe \& Strauss, 2000, 2007; Koehn, 1995; 
Kuh et al., 2005). “There's something about changing over to an electronic medium, something about that screen. It's psychological. It's a generational thing" (Prensky, 2001a, p. 3.12).

\section{Changes - Differences from Previous Generations of Students}

A "new and unique population of learners" is converging on higher education "distinctly different in their characteristics and learning expectations" (Skiba \& Barton, 2006, p. 5-6). Millennial students are different, have different learning preferences and require different teaching methods. (Nicoletti and Merriman, 2007) “Today’s students communicate and think differently than did students of previous generations . . and ... demand a new learning paradigm" (Nicoletti \& Merriman, 2007, p. 30). "Faculty from previous generations were text based; focused on logical sequencing of knowledge; emphasized memorization, repetition, and recall; and believed one size fits all" (Skiba \& Barton, 2006, p. 17). Millennials require a more "learner-centered model... with a shift from the traditional teaching paradigm to a constructivist learning paradigm" including a focus on "understanding, and constructing knowledge using discovery methods and active engagement" (Skiba \& Barton, 2006, p. 17).

Millennials have different learning preferences than other generations as they have been connected to technology since birth. They multi-task, have short attention spans, seldom read books, lack writing skills, and are used to having their attention divided (Howe \& Strauss, 2007; Oblinger \& Oblinger, 2005; Prensky, 2001a, 2001b; Tapscott, 1998, 2009). Millennials expect information-immediacy, mobility, and at the same time expect course content to be delivered in a social manner that is applicable to real-life (Nicoletti \& Merriman, 2007; Oblinger \& Oblinger, 2005; Skiba \& Barton, 
2006). "Millennials consume and learn from a wide variety of media, often simultaneously" (Carlson, 2005, p. 4).

Oblinger and Oblinger (2005) state, Millennials “don't think in terms of technology; they think in terms of the activity technology enables" (p. 2.10). Millennials respond well to web-based content retrieval and communication, but need structured activities in the classroom to effectively assimilate the knowledge and build meaningful relationships (Nevgi, Virtanen, \& Niemi, 2006, Nicolette \& Merriman, 2007; Tapscott, 1998).

\section{Disruptive Innovation and Millennials}

Millennials are accustomed to their demands and/or expectations being met (Howe \& Strauss, 2007; Prensky, 2001a, 2001c, 2012; Tapscott, 1998, 2009). "In the emerging disruptive environment, all universities should start with an explicit articulation of the customer value proposition and design a path forward that leverages technology to deliver it" (Laseter, 2010, p. 5). "Modern universities emerged in the fourth and fifth centuries A.D. as monastic schools in Europe, focusing on disseminating knowledge rather than creating it. The disruptions of the Internet may return education to those roots" (Laseter, 2010, p.5) "Institutions of higher education have the ability to solve the

crisis they currently face. .. . Will [institutions] leverage the disruptive technology of the Internet by applying the principles of business strategy... or will [others be] offering a better value proposition?" (Laseter, 2010, p. 5)

\section{Summary}

Chapter 2 detailed concepts introduced in Chapter 1, based on a review of current literature. First examined were technology-enhanced instructional practices. Following, 
historical perspectives were highlighted. Next, uses in education, including traditional use, uses preferred by Millennials and utilization by faulty, as well as changes wanted were emphasized. Disruptive innovation theory, as related to technology-enhanced instructional practices, was detailed using reviews of current literature. Following was the delineation of the instructor role in education. Historical or traditional perspectives were next discussed.

Instructional role was then examined from both historical and current standpoints. Millennial preferred learning styles as related to instructor role were next investigated. In addition, the theory of disruptive innovation, as connected to instructor role, was considered. Next, an examination of Millennials was completed by analyzing contemporary literature. This examination included an overview of the millennial generation. Specific Millennial characteristics were delineated, using a meta-analysis of existing research. An in-depth examination of Millennial preferred learning styles and differences when compared to past generations of students was next completed. Lastly examined was the theory of disruptive innovation as related to Millennials.

Chapter 3 detailed methodology used in this study. The explanation of methodology included purpose of the study, sample population, research questions, research design, data collection process, explanation of survey processes, as well as data analysis techniques employed in this study. Lastly provided was a summary of Chapter 3 . 


\section{CHAPTER THREE}

\section{RESEARCH DESIGN AND METHODOLOGY}

A "powerful change has taken place in the [traditional] student body—-the arrival of the first generation raised with digital technology from birth" (Prensky, 2008, p.1) and academia is facing needed transformations, "to a significant degree energized by what has been described as the digital revolution" (Green, 2010, p. 56). According to Prensky (2001c), "linear processes which have dominated traditional education . . can actually retard learning for brains developed through game and Web surfing processes on the computer" (p. 3). These significant shifts in the academic world make it imperative educators understand student populations on college campuses and needed changes to meet these students' learning needs (Christensen, et al., 2008; Christensen, 2010; Prensky, 2008).

A review of current literature identified millennial characteristics and preferred learning methods, specifically preferences for technology-enhanced instruction in college classrooms (Christensen, et al., 2008; Green, 2010; Prensky, 2001c, 2012; Tapscott, 1998, 2009). Additionally, needed changes in traditional instructor role were also suggested (Carlson, 2005; Garcia, 2007; Jukes, 2010; Oblinger \& Oblinger, 2005; Prensky, 2001a; Tapscott, 1998, 2009). Furthermore, review of current literature indicated higher education faculty may lack a complete understanding of traditional students currently within their classrooms, the Millennials (McGlynn, 2008; Oblinger \& Oblinger, 2005; Prensky, 2001a, 2001b; Tapscott, 1998, 2009). Moreover, there was a lack of information regarding actual faculty use of technology-enhanced instruction as well as perceptions of faculty concerning their instructional role and millennial students' 
preferred learning styles. Further investigation identified no known instrument to analyze all three of these concepts.

This study piloted and authenticated a valid and reliable instrument which could be used to assess self-reported technology-enhanced instructional strategies as well as self-reported perceptions concerning instructional role and millennial students' learning preferences. Additionally identified, through review of current literature, were needed changes in use of technology-enhanced instructional practices and instructional roles to match students' learning preferences. This study further developed the relationship of disruptive innovation theory to these concepts.

Chapter 3 outlined methods used to study utilization of technology-enhanced instruction in higher education. Missouri higher education faculty perceptions of instructional role and millennial students' learning preferences were also examined. First given was an overview, followed by a statement of the problem. Next defined was the purpose of the study. Then presented were five research questions, along with sub questions and null hypotheses. The population and sample, along with research design and instrumentation were next delineated. Information concerning the survey tool and instrumentation for the study was then summarized. Additionally, data collection, analysis as well as statistical techniques used were detailed. Lastly provided was a summary of Chapter 3.

\section{Statement of the Problem}

Current literature reveals millennial students prefer technology-enhanced instructional practices (Fine, 2008; Green, 2010; Oblinger, 2010; Oblinger \& Oblinger, 2005; Prensky, 2001a, 2001c, 2012; Tapscott, 1998, 2009). Furthermore, research 
indicated Millennials learn differently, preferring non-traditional instructional roles (Nicoletti \& Merriman, 2007; Oblinger, 2010; Oblinger \& Oblinger, 2005; Prensky, 2001a, 2012; Tapscott, 1998, 2009). However, little research determining utilization of technology-enhanced instruction by Missouri higher education faculty or faculty perceptions concerning their instructional role in college classrooms and millennial students' preferred learning styles was discovered. Additionally, the researcher's investigation yielded no known inventory or survey instrument assessing the three concepts examined in this study: (a) utilization of technology-enhanced instructional practices, (b) perceptions of Missouri higher education faculty concerning self-reported instructor role, and (c) perceptions of millennial students' preferred learning styles. Purpose of the Study

The primary purpose of this study was to design a valid and reliable survey instrument gauging three concepts; (a) utilization of technology-enhanced instructional practices, (b) perceptions of Missouri higher education faculty concerning self-reported instructor role, and (c) perceptions of millennial students' preferred learning styles. The secondary purpose of this study was to identify differences and similarities among various subsets of the data, examined by investigated concepts, as well as disaggregated by each demographic for individual survey items.

\section{Research Questions and Null Hypotheses}

\section{Research Questions}

Five research questions were developed to guide this study. The questions, subquestions and null hypotheses follow and are summarized in Table 1. Table 1 reviews the purpose of and statistical techniques utilized for each question. 


\section{Research Question 1}

Is the Survey of Current Instructional Practices and Perceptions reliable and valid?

Sub research question 1.1. Is the survey instrument valid?

Sub research question 1.2. Is the survey instrument reliable?

$\mathrm{H}_{\mathrm{o}} 1$ : The Survey of Current Instructional Practices and Perceptions is neither reliable nor valid.

\section{Research Question 2}

To what degree do Missouri HE faculty significantly utilize technology-enhanced instructional practices (Items 7-14)?

$\mathrm{H}_{\mathrm{o}} 2$ : Missouri HE faculty do not significantly utilize technology-enhanced instructional practices.

\section{Research Question 3}

To what degree do Missouri HE faculty perceptions of their instructional role in the classroom significantly match those identified in current research as preferred by millennial students (Items 15-24)?

$\mathrm{H}_{\mathrm{o}}$ 3: Missouri HE faculty perceptions of their instructional role in the classroom do not significantly match those identified in current research as preferred by millennial students.

\section{Research Question 4}

To what degree do Missouri HE faculty perceptions of millennial students' learning characteristics significantly match learning characteristics identified in current research (Items 25-40)? 
Ho4: Missouri HE faculty perceptions of millennial students' learning characteristics do not significantly match learning characteristics identified in current research.

\section{Research Question 5}

What are the overall summary statistics broken down by demographic (Items 1$6)$ ?

Sub research question 5.1. What are the significant differences of responses among the different types of Missouri HE institutions (Item 1) - (2-year, 4-year public and 4-year private) as determined by frequency counts and percentages and Chi square analysis applying a .05 significance level?

Sub research question 5.2. What are the significant differences of responses among the various size institutions based on Carnegie Size Classifications (Item 2) - (Very small 2-year (<500 FTE student enrollment), small 2-year (500-1,999 FTE student enrollment), medium 2-year (2,000-4,999 FTE student enrollment), large 2-year (5,000-9,999 FTE student enrollment), very large 2-year (10,000 or more FTE student enrollment), very small 4-year (< 1,000 FTE student enrollment), small 4-year (1,000-2,999 FTE student enrollment), Medium 4-year (3,000-9,999 FTE student enrollment), and Large-4 year $(10,000$ or more FTE student enrollment) as determined by frequency counts and percentages and Chi square analysis applying a .05 significance level?

Sub research question 5.3. What are the significant differences of responses among Departments (Item 3) as determined by frequency counts and percentages and Chi square analysis at a .05 significance level? 
Sub research question 5.4. What are the significant differences in responses among Rank (Item 4) - (Adjunct, Instructor, Assistant Professor, Associate Professor, and Full Professor) as determined by frequency counts and percentages and Chi square analysis applying a .05 significance level?

Sub research question 5.5. What are the significant differences in responses between Gender (Item 5) - (Male and Female) as determined by frequency counts and percentages and Chi square analysis applying a .05 significance level?

Sub research question 5.6. What are the significant differences in responses among Age Range (Item 6) - (Under 30, 31-50, and Over 50) as determined by frequency counts and percentages and Chi square analysis applying a .05 significance level?

$\mathrm{H}_{0}$ 5: There are no significant differences among respondents according to demographics when applying a .05 significance level. 


\section{Table 1}

\section{Summary Listing of Research Questions and Applied Statistical Techniques}

\author{
Research Question \\ RQ1 - Is the Survey of \\ Higher Education \\ Instructional Practices \\ valid and reliable? \\ RQ2- To what degree are \\ Missouri HE faculty \\ utilizing technology- \\ enhanced instructional \\ practices (Items 7-14)?
}

To determine utilization of technology-enhanced instructional practices by Missouri HE faculty
Methodology

Anticipated Outcome

To determine validity and Expert Panel Pilot Survey reliability of survey items (RQ1.1)

Cronbach's alpha (RQ1.2)

Univariate analysis including:

Cross tabulations and graphs showing frequency counts and percentages

Measures of central tendency and dispersion; mean, median, mode and standard deviation

RQ3- To what degree do Missouri HE faculty perceptions of their instructional role in the classroom match those identified in current research as preferred by millennial students (Items 15-24)?

RQ4- To what degree do Missouri HE faculty perceptions of millennial students' learning characteristics match learning characteristics identified in current research (Items 25-40)?

RQ5- What are the overall summary statistics broken down by demographic (Items 1-6)?
To determine perceptions Univariate analysis including: of Missouri HE faculty concerning classroom instructional roles and the showing frequency counts and "match" to millennial percentages students' learning preferences

Measures of central tendency and dispersion; mean, median, mode and standard deviation

To determine Missouri HE faculty perceptions of millennial students' learning characteristics as identified by research

Univariate analysis including: Cross tabulations and graphs showing frequency counts and percentages

Measures of central tendency and dispersion; mean, median, mode and standard deviation

To compare summary results disaggregated by the various demographic items
The validity and reliability of The Survey of Higher Education Instructional Practices (SHEIP) will be established

The degree of technologyenhanced instruction utilization by MO HE

The perceptions of MO HE faculty concerning their instructional role will be reported and the degree to which these correspond to identified Millennial learning styles will be established.

The perceptions of MO HE faculty concerning millennial students' learning characteristics and the degree to which these match those identified by research will be established.

The number and percent for each scale response will be reported by demographic

Similarities and differences between \& among the various demographic groups will be identified

\section{Chi Square}

Cross tabulations showing frequency numbers and percentages of each survey item disaggregated for each of the six demographic items 


\section{Population and Sample}

The population for this study included 2,978 faculty at a randomly selected group of 2-year and 4-year, public and private Missouri higher education institutions. The selected group was based on a listing of Missouri higher education institutions provided by Missouri Department of Higher Education (MDHE), shown in Appendix H. The random selection included 5 from each of the groups, 2 -year public, 4-year public and 4year private, for a total of 15 higher education institutions. Faculty instructing at these institutions during the spring 2013 semester, as publicized on institutions' websites, were sent an email describing the study and including a clickable link directing them to the online explanation and survey instrument with an access code or password. A summary of this process is shown in Figure 3.

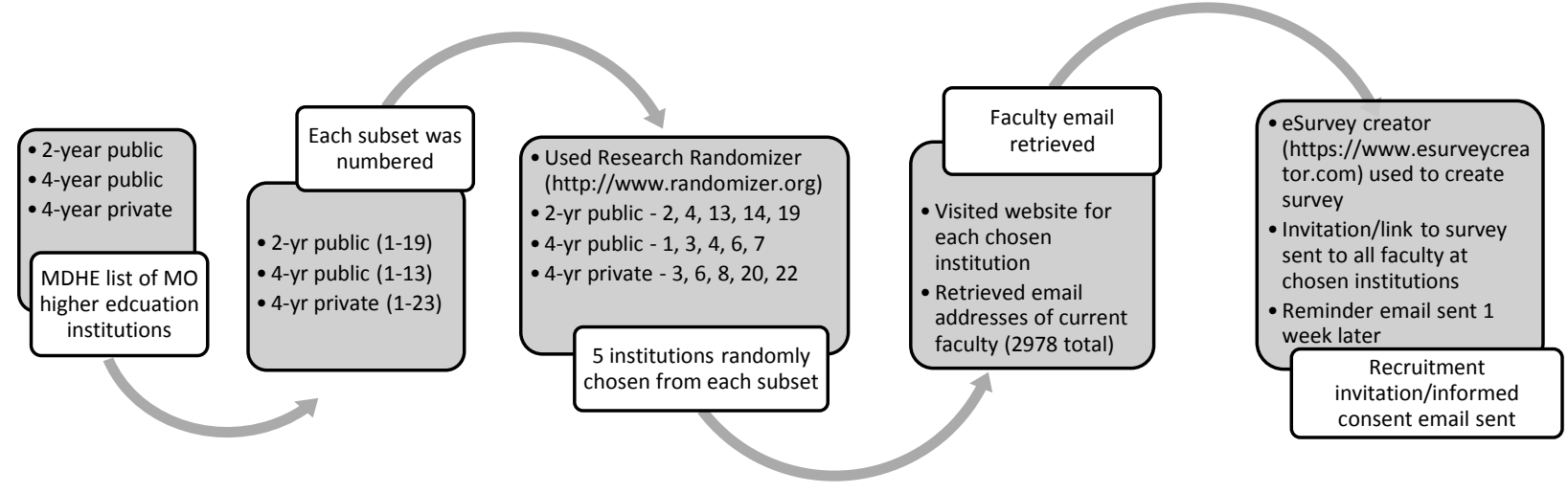

Figure 3. Random selection and email retrieval process of HE institutions

\section{Research Design}

This research study employed a quantitative, non-experimental, descriptive research design. Quantitative research is defined as research involving the collection of data in numerical form and analyzed numerically (Field, 2005; Springer, 2010). 
Furthermore, according to experts, a non-experimental, descriptive design includes utilization of a survey instrument (Springer, 2010).

This study employed stratified random sampling. Springer (2010) and Trochim (2006) define stratified random sampling as the process of dividing the population into subgroups, then randomly choosing a specific number of participants from each subgroup. The population for this study included faculty at Missouri higher education institutions and subgroups (2-year public, 4-year public and 4-year private institutions) were identified, followed by the random selection of 5 institutions from each of these subgroups. This indicated stratified random sampling (Springer, 2010; Trochim, 2006).

Furthermore, this is a cross-sectional study as it takes place at a single point in time (Springer, 2010; Trochim, 2006). Accordingly, this study utilized a quantitative, non-experimental, descriptive research design employing stratified random sampling to investigate five research questions identified in this study (Field, 2005; Springer, 2010; Trochim, 2006).

\section{Instrumentation}

The instrument used in this study was the Survey of Higher Education Instructional Practices (SHEIP), designed by the researcher. This survey was based on the Maine Learning Technology Initiative (MLTI) Teacher Survey Form B - Fall 2003 (Gritter, 2005) as summarized by Hawley (2004) and the Survey of Current Teaching Instructional Practice and Application of Internet Technology for University Faculty: Faculty Form (Li, 2008). Both surveys had been tested and determined to be both reliable and valid (Hawley, 2004, p. 44; Li, 2008, p. 81) 
An expert panel was chosen to pilot the researcher-developed survey, SHEIP, to determine validity. The expert panel chosen included ten experts in the higher education realm. Panel members selected were current HE faculty with at least 10 years academic experience or recently retired professors with over 30 years in the higher education realm. All active panel members selected were assistant professors, associate professors or full professors at the institutions at which they taught. All expert panel participants had also completed dissertations and research publications, indicating they were familiar the process of survey creation, data collection and analysis, as well as dissertation completion. The researcher deemed these factors gave all panel participants adequate expertise needed to pilot the initial survey and give expert and constructive feedback. An email (see Appendix C), including a hyperlink to a draft of the researcherdeveloped instrument used in this study, the Survey of Higher Education Instructional Practices (SHEIP) (see Appendix B), was sent to a researcher-selected panel of 10 expert educators, from various higher education institutions and higher educational subject backgrounds. This email asked the participant to view and complete the survey. Participants were then asked to provide feedback by answering eight questions concerning their experience. Questions asked of the 10 selected panel members are summarized in Table 2. 
Table 2

Questions asked of Expert Panel Concerning Draft Survey

\begin{tabular}{l} 
Question \\
\hline Are the directions for taking the survey clear and concise? \\
Is the language in each item clear and understandable? \\
Are there any items which should be eliminated or added? \\
Which items are unclear or confusing? \\
Is the survey too time consuming or appropriate in length? \\
Are there items which may not be answered? \\
How long did it take for you to complete the survey? \\
Do you have any comments concerning the survey?
\end{tabular}

The researcher-developed instrument, the Survey of Higher Education

Instructional Practices (SHEIP), shown in Appendix A, included 40 individual items. The first six items were demographics. The six independent demographic variables included: type of institution (2-year, 4-year public and 4-year private) (Item 1), size of institution, based on enrollment (Item 2), Department (Item 3), Rank (adjunct, instructor, assistant professor, associate professor and full professor) (Item 4), Gender (male, female) (Item 5), and Age Range (under 30, 31-50 and over 50) (Item 6). These variables were used to examine relationships between dependent variables examining utilization of technologyenhanced instruction, instructional role and perception of millennial students' learning styles and independent demographic variables. Data collected from survey Item 1 (type of institution) and Item 2 (full time enrollment) were combined to determine respondent's institution size, based on the Carnegie Size Classifications.

The next section included eight items (Items 7-14), designed to discern Missouri higher education faculty's self-reported utilization of technology-enhanced instruction in classrooms. Responses were gathered via a 4-point Likert scale, with only two written descriptors, Always to Never, as poles. Survey items in this section included teaching in a 
technology-enhanced classroom (Item 7), faculty use of technology-enhanced instructional tools (Item 8), utilization of video-based instruction (Item 9), and faculty use of technology-based communication with students (Item 10). Other items included encouraging student use of technology-based communication (Item 11), faculty utilization of smart or wireless devices to conduct lessons or disperse course materials (Item 12), use of guest speakers via technology driven methods (Item 13), and requiring students to use web-based tools to complete course assignments (Item 14).

The third section of the SHEIP survey instrument focused on faculty perceptions of their instructional role in HE classrooms and included 10 items (Items 15-24). To obtain information concerning faculty's self-reported perceptions of their instructional role, survey participants were given quotes or statements related to instructional role within the classroom and asked for a response indicating their level of agreement with the given statement. Participants' responses were gathered using a 4-point Likert Scale, including only two written descriptors, Strongly Agree to Strongly Disagree. These statements related to issues such as instructional role as mainly class facilitator (Item 15), the most important part of instruction - curriculum content or what students are able to do (Item 16), activity within the classroom (Item 17), and students learning basic skills in the context of complex content (Item 18). Other items concerning instructor role, such as assignment structure (Item 19), importance of core content within textbooks (Item 20), importance of student thinking concerning content (Item 21), importance of student interest (Item 22), importance of course materials' structure (Item 23) and importance of students learning basic skills before mastering course content (Item 24) were also included. 
The final section of the Survey of Higher Education Instructional Practices examined self-reported faculty perceptions concerning the learning preferences of their students. This section contained 16 items (items 25-40) asking for perceptions concerning the learning preferences of higher education students. These statements asked for respondents' level of agreement using a 4-point Likert Scale, including only two written descriptors, Strongly Agree to Strongly Disagree. These survey items asked for levels of agreement regarding what participants believed students should be able to do, based on respondents' educational perceptions. Items included establishing understanding based on individual experiences (Item 25), integrating learning concepts into self-directed projects (Item 26), further research concerning questions related to new concepts (Item 27), pursing learning concepts to create individual learning (Item 28) and exploring new learning concepts independently (Item 29).

Also investigated were items which examined demonstrating methods to realistically solve problems (Item 30), connecting current practice to individual experiences (Item 31), expecting immediate feedback (Item 32), applying knowledge independently in other contexts (Item 33) and explaining learning concepts using individual perspectives (Item 34). Other survey items examined were working in groups to establish individual knowledge (Item 35), working in groups to share knowledge and reach agreement (Item 36), integrating learning concepts in and out of the classroom (Item 37), understanding individual thinking and how to seek needed help (Item 38), showing mastery of knowledge using self-chosen assessments (Item 39), and relating individual experiences to explaining learning concepts (Item 40). Further details concerning research questions, data and applied methods are shown in Table 4. 


\section{Data Collection and Analysis}

Survey data collection was completed electronically via the eSurvey Creator website located at http://esurveycreator.com. Electronic collection of data were chosen to minimize risk of entry error and provide a means of easily sending reminders and tracking the progress of survey responses. Once complete, responses were electronically downloaded and imported into the Statistical Package for the Social Sciences (SPSS).

Data analyses were then completed and nominal values extracted for each variable.

Further details are given in Figure 4 and Figure 5.

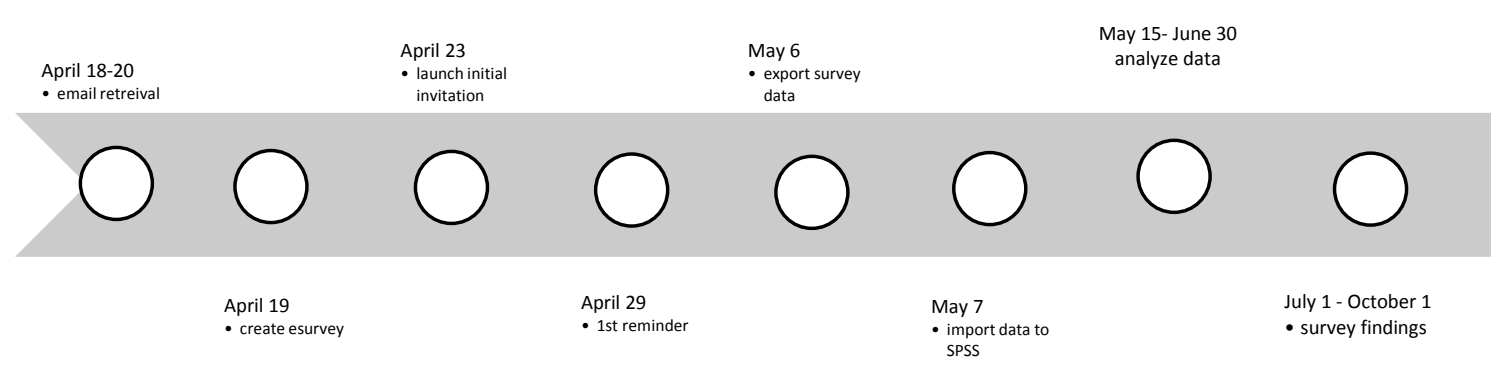

Figure 4. Timeline for completion of survey, data collection, analyzation and findings

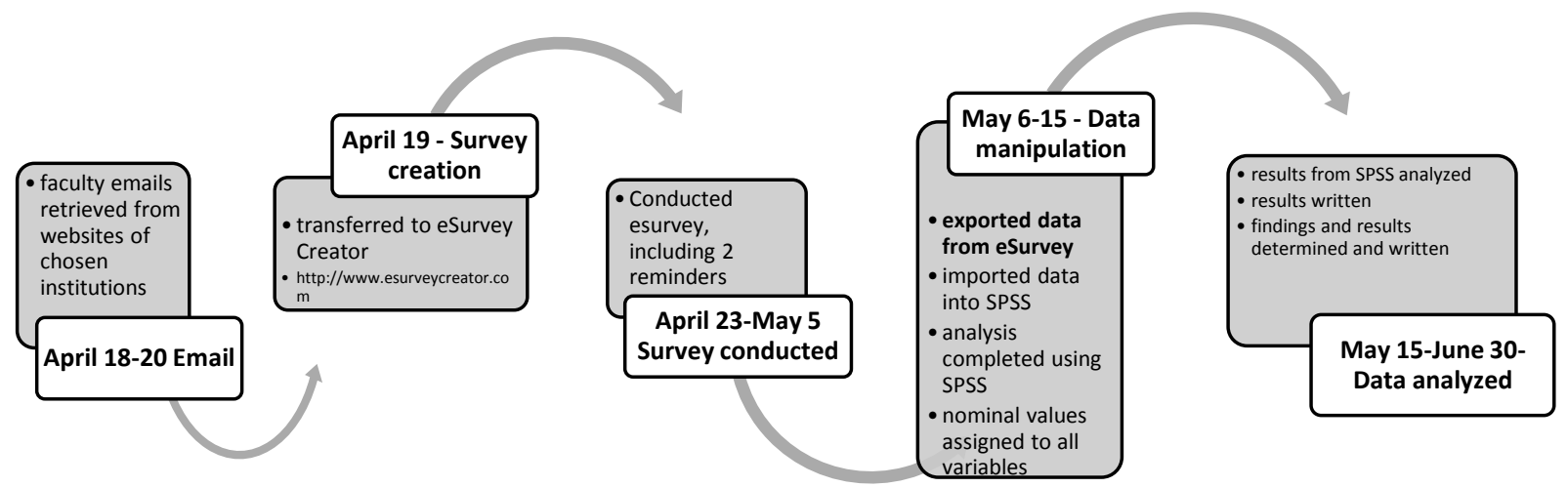

Figure 5. Explanation of survey creation, data collection and analysis 
The survey tool included both independent and dependent values, shown in Table 3. The six independent demographic variables included; Item 1) type of institution (2year, 4-year public and 4-year private), Item 2) size of institution, based on enrollment, Item 3) Department, Item 4) Rank (adjunct, instructor, assistant professor, associate professor and full professor), Item 5) Gender (male, female), and Item 6) Age Range (under 30, 31-50 and over 50). These variables were used to examine relationships between dependent variables examining utilization of technology-enhanced instruction, instructional role and perception of millennial students' learning styles and independent demographic variables displayed in Table 3. Data collected from survey Item 1 (type of institution) and Item 2 (full time enrollment) were combined to determine respondent's institution size, based on the Carnegie Size Classifications.

The remaining 34 independent variables were divided into three sections (Section 2 through Section 4. Section 2 included eight items (Items 7-14), designed to discern Missouri higher education faculty's self-reported utilization of technology-enhanced instruction in classrooms. The items included teaching in a technology-enhanced classroom (Item 7), faculty use of technology-enhanced instructional tools (Item 8), utilization of video-based instruction (Item 9), and faculty use of technology-based communication with students (Item 10). Other items included encouraging student use of technology-based communication (Item 11), faculty utilization of smart or wireless devices to conduct lessons or disperse course materials (Item 12), use of guest speakers via technology driven methods (Item 13), and requiring students to use web-based tools to complete course assignments (Item 14). 
The third section of the SHEIP survey instrument focused on faculty perceptions of instructional role in higher education classrooms and included 10 items (Items 15-24. These statements related to issues such as instructional role as mainly class facilitator (Item 15), the most important part of instruction - curriculum content or what students are able to do (Item 16), activity within the classroom (Item 17), and students learning basic skills in the context of complex content (Item 18). Other items concerning instructor role, such as assignment structure (Item 19), importance of core content within textbooks (Item 20), importance of student thinking concerning content (Item 21), importance of student interest (Item 22), importance of course materials' structure (Item 23) and importance of students learning basic skills before mastering course content (Item 24) were also included.

The final and fourth section of the Survey of Higher Education Instructional Practices (SHEIP) examined self-reported faculty perceptions concerning learning preferences of their students. This section contained 16 items (items 25-40) asking for perceptions concerning learning preferences of higher education students. Survey items in this section included establishing understanding based on individual experiences (Item 25), integrating learning concepts into self-directed projects (Item 26), further research concerning questions related to new concepts (Item 27), pursing learning concepts to create individual learning (Item 28) and exploring new learning concepts independently (Item 29). Also investigated were items which examined demonstrating methods to realistically solve problems (Item 30), connecting current practice to individual experiences (Item 31), expecting immediate feedback (Item 32), applying knowledge independently in other contexts (Item 33) and explaining learning concepts using 
individual perspectives (Item 34). Other variables examined were working in groups to establish individual knowledge (Item 35), working in groups to share knowledge and reach agreement (Item 36), integrating learning concepts in and out of the classroom (Item 37), understanding individual thinking and how to seek needed help (Item 38), showing mastery of knowledge using self-chosen assessments (Item 39), and relating individual experiences to explaining learning concepts (Item 40). These variables are further delineated in Table 3. 
Table 3

Identification of Independent and Dependent Variables in the SHEIP

\begin{tabular}{|c|c|c|}
\hline Variable & Type & Scale \\
\hline I1 - Type of institution (2-yr or $4 \mathrm{yr}$ public, $4 \mathrm{yr}$ private) & Independent & Nominal \\
\hline e (based on enrollment and ty & Independent & Nominal \\
\hline I3 - Department & Independent & Nominal \\
\hline $\mathrm{I} 4-\mathrm{Facu}$ & Independent & Nominal \\
\hline $\mathrm{I} 5-\mathrm{Ge}$ & Independent & Nominal \\
\hline I6 - Age & Independent & Nominal \\
\hline I7 - Tecl & Dependent & Likert (1-4) \\
\hline I8 - Use & Dependent & Likert (1-4) \\
\hline I9 - Use & Dependent & Likert (1-4) \\
\hline to communi & Dependent & Likert (1-4) \\
\hline eans & Depe & Likert (1-4) \\
\hline $\mathrm{I} 12$ & Depe & Likert \\
\hline I13 -Us & & Likert \\
\hline I14 - & & Likert (1-4) \\
\hline $\mathrm{I} 15-\mathrm{Rc}$ & & Likert (1-4) \\
\hline I16 -Mc & De & Likert ( \\
\hline $\mathrm{I} 17-\mathrm{Al}$ & Dep & Likert ( \\
\hline & & Like \\
\hline & & Like \\
\hline & & Like \\
\hline I21 - & & \\
\hline $\mathrm{I} 22-\mathrm{Cr}$ & & Likert ( \\
\hline I23 -Mat & & Likert \\
\hline I24 - & & \\
\hline & & \\
\hline I26 & $\mathrm{De}$ & Lik \\
\hline I27 - & & Likert (1-4) \\
\hline learning & & Like \\
\hline $\mathrm{I} 29-\mathrm{St}$ & & Likert (1-4) \\
\hline $\mathrm{I} 30-\mathrm{S}$ & & \\
\hline & & Lik \\
\hline & & Like \\
\hline & & Likert (1-4) \\
\hline I34 - & & Likert (1-4) \\
\hline I35 - & Dep & Likert (1-4) \\
\hline I36 - & $\mathrm{De}$ & $\mathrm{Lil}$ \\
\hline & & \\
\hline & & Likert (1-4) \\
\hline I39-Stu & Depe & Likert (1-4) \\
\hline I40 -Students relate experiences when explaining learning concepts & Dependent & Likert (1-4) \\
\hline
\end{tabular}


To assure data obtained from this study were indicative of the population being studied, it was essential a representative sample was obtained to be able to generalize the results to a bigger population. In this study, a representative sample was chosen from Missouri higher education faculty practicing during the spring 2013 semester. Creative Research Systems (2012), located at http://www.surveysystem.com/sscalc.htm, provides a sample size calculator. This sample size calculator uses a provided formula for sample size (ss) calculated as ss $=\mathrm{z}$ value (e.g. 1.96 for $95 \%$ confidence level) $\mathrm{x}$ (p) (percentage such as .5 used for sample size needed) x (1-p) divided by c2 (confidence interval, expressed as a decimal, e.g. .04) (Creative Research Systems, 2012).

Use of a sample size calculator provided calculations confirming needed sample size (Creative Research Systems, 2012). According to data provided by the Missouri Department of Higher Education (MDHE), the population of higher education faculty at all 2-year and 4-year public and 4-year private higher education institutions in Missouri equates to 16,343 . With a population of 16,343 Missouri higher education faculty, if a $95 \%$ confidence level with a confidence interval of 10 is desired, the Creative Research Systems Sample Size Calculator shows a sample size of 95 is needed. With the same population of 16,343 , a $99 \%$ confidence level with a confidence interval of 10 would require a sample size of 165 . For this study, a $99 \%$ confidence level with a confidence interval of 10 is desired; therefore, a sample of size of 165 respondents was deemed acceptable. The greater number of responses or size of the sample responding could more likely confirm the level of reliability and validity of the instrument (Field, 2005).

All responses were reported in an analysis of group data rather than individual responses to assure there was no bias associated with being able to identify individual 
participants' responses. Results from independent, demographic variables including the type of institution, size of institution, department, rank, gender, and age range were converted to nominal data, exported in the form of a csv file and imported into the SPSS statistical software application.

\section{Statistical Techniques Used}

Statistical techniques used in this study include survey pilot by an expert panel and Cronbach's alpha. Univariate analysis techniques, including cross tabulations showing frequency counts and frequency percentages, as well as measures of central tendencies including mean, median, mode and standard deviation were further utilized. Chi square analysis and cross tabulations showing frequency numbers and percentages are also applied for each demographic.

\section{A pilot of the Survey of Higher Education Instructional Practices (SHEIP)} completed by an expert panel was employed to determine the validity of survey items. Cronbach's alpha was utilized to determine reliability of survey items included in the SHEIP. Dependent variables within the last three sections of the SHEIP examing technology-enhanced instruction utilization, perceptions of instructional role and perceptions of students' preferred learning styles were investigated. Univariate analysis including cross tabulations, frequency counts and percentages and measures of central tendency including mean, median, mode and standard deviation, were employed. To investigate variables disaggregated by demographics, statistical techniques of Chi-square and cross tabulations illustrating frequency numbers and percentages were implemented. Table 4 further delineates the data sources, type of responses, data types and statistical analysis applied for each research question. 
Table 4

Summary of Data Sources, Types and Measures Applied by Research Question

\begin{tabular}{|c|c|c|c|c|c|}
\hline $\begin{array}{l}\text { Research } \\
\text { Question \# }\end{array}$ & $\begin{array}{l}\text { Data } \\
\text { Source }\end{array}$ & $\begin{array}{l}\text { Number } \\
\text { of Items }\end{array}$ & $\begin{array}{l}\text { Response } \\
\text { Type }\end{array}$ & Data Type & $\begin{array}{l}\text { Analysis } \\
\text { Applied }\end{array}$ \\
\hline 1.1 & $\begin{array}{l}\text { Survey } \\
\text { Responses }\end{array}$ & 40 & Likert Scale & Nominal & $\begin{array}{l}\text { Expert Panel Pilot } \\
\text { Survey }\end{array}$ \\
\hline 1.2 & $\begin{array}{l}\text { Survey } \\
\text { Responses }\end{array}$ & 40 & Likert Scale & Nominal & Cronbach's alpha \\
\hline 2 & $\begin{array}{l}\text { Survey } \\
\text { Responses }\end{array}$ & 8 & Likert Scale & Nominal & Univariate Analysis \\
\hline 3 & $\begin{array}{l}\text { Survey } \\
\text { Responses }\end{array}$ & 10 & Likert Scale & Nominal & Univariate Analysis \\
\hline 4 & $\begin{array}{l}\text { Survey } \\
\text { Responses }\end{array}$ & 16 & Likert Scale & Nominal & Univariate Analysis \\
\hline 5.1 & $\begin{array}{l}\text { Survey } \\
\text { Responses }\end{array}$ & 35 & Likert Scale & Nominal & $\begin{array}{l}\text { Chi Square \& Cross } \\
\text { Tabulations }\end{array}$ \\
\hline 5.2 & $\begin{array}{l}\text { Survey } \\
\text { Responses }\end{array}$ & 35 & Likert Scale & Nominal & $\begin{array}{l}\text { Chi Square \& Cross } \\
\text { Tabulations }\end{array}$ \\
\hline 5.3 & $\begin{array}{l}\text { Survey } \\
\text { Responses }\end{array}$ & 35 & Likert Scale & Nominal & $\begin{array}{l}\text { Chi Square \& Cross } \\
\text { Tabulations }\end{array}$ \\
\hline 5.4 & $\begin{array}{l}\text { Survey } \\
\text { Responses }\end{array}$ & 35 & Likert Scale & Nominal & $\begin{array}{l}\text { Chi Square \& Cross } \\
\text { Tabulations }\end{array}$ \\
\hline 5.5 & $\begin{array}{l}\text { Survey } \\
\text { Responses }\end{array}$ & 35 & Likert Scale & Nominal & $\begin{array}{l}\text { Chi Square \& Cross } \\
\text { Tabulations }\end{array}$ \\
\hline 5.6 & $\begin{array}{l}\text { Survey } \\
\text { Responses }\end{array}$ & 35 & Likert Scale & Nominal & $\begin{array}{l}\text { Chi Square \& Cross } \\
\text { Tabulations }\end{array}$ \\
\hline
\end{tabular}




\section{Summary}

Chapter 3 described methodologies used in this study. Methods used to study the utilization of technology-enhanced instruction in higher education, as well as faculty perceptions of instructional role and millennial students' learning preferences were outlined. First an overview was given, followed by a statement of the problem guiding this study. Next defined was the purpose of this study. The five research questions, along with sub-questions and null hypotheses were then presented. Details were given concerning the population, consisting of faculty at 15 randomly chosen Missouri higher education institutions. The research design, determined to be a quantitative, nonexperimental, cross-sectional case study survey was next described and supported (Field, 2005, Trochim, 2010). Following, information was outlined concerning the researcher designed survey tool, the Survey of Higher Education Instructional Practices (SHEIP). Next elucidated was instrumentation for this study, including details concerning various sections of the SHEIP, a researcher-designed instrument. Independent and dependent variables were investigated. Subsequent were details concerning the data collection and analysis process, as well as statistical techniques used.

Data collected and analyzed were detailed as findings in Chapter 4 in order to support or answer research questions put forth in this study. Chapter 5 further expounded data collected and findings providing conclusions, recommendations and ideas for future research. 


\section{CHAPTER FOUR}

\section{PRESENTATION AND ANALYSES OF DATA}

Research has shown learning styles preferred by millennial students differ from those met by traditional higher education (Carlson, 2005; Howe \& Strauss, 2007;

Tapscott, 1998, 2009). Prensky (2001) conveyed that educational institutions continue to focus on traditional learning. Traditional higher education assumes today's learners are the same as previous generations and teaching and learning methods which have always seemed to work in classrooms, will work for students now (Prensky, 2001; Tapscott, 1998, 2009). However, research indicates Millennials have different expectations and learning preferences, when compared to previous generations (Oblinger, 2003; Tapscott, 1998, 2009; Strauss \& Howe, 2000). This research study utilized Christensen's theory of disruptive innovation which states in order to be effective change agents, changes cannot be implemented into existing models and transformation must be allowed to take place (Christensen, et al., 2008). This theory was used as the lens to examine changes and trends in higher education concerning technology-enhanced instruction. The theory of disruptive innovation was also used to focus the study of perceptions of instructor role and students' preferred learning styles.

Chapter 4 presented information gleaned from the survey used in this study, including analyses of data, as well as the findings of this research. First, reviews of the survey and research design were completed. Next, the population and sample for this research study were detailed. Statistical analyses, including Cronbach's alpha, univariate analyses, including measures of central tendency and dispersion and cross tabulations or contingency tables, indicating frequencies and percentages of responses, as well as Chi- 
square analyses were then detailed for the related research question(s), and survey item. A summary of the chapter was then presented.

Review of Survey and Research Design

This study established validity and reliability of a researcher-developed survey, the Survey of Higher Education Instructional Practices (SHEIP). The researcher-designed instrument, shown in Appendix A, included 40 individual items. The first six items were demographics. The six independent demographic variables included; type of institution (2-year, 4-year public and 4-year private) (Item 1), size of institution, based on enrollment (Item 2), Department (Item 3), Rank (adjunct, instructor, assistant professor, associate professor and full professor) (Item 4), Gender (male, female) (Item 5), and Age Range (under 30, 31-50 and over 50) (Item 6). These variables were used to examine relationships between dependent variables examining utilization of technology-enhanced instruction, instructional role and perception of millennial students' learning styles and independent demographic variables. Data collected from survey Item 1 (type of institution) and Item 2 (full time enrollment) were combined to determine respondent's institution size, based on the Carnegie Size Classifications.

The next section included eight items (Items 7-14), designed to discern Missouri higher education faculty's self-reported utilization of technology-enhanced instruction in classrooms. Responses were gathered via a 4-point Likert scale, with only two written descriptors, Always to Never, as poles. Survey items in this section included teaching in a technology-enhanced classroom (Item 7), faculty use of technology-enhanced instructional tools (Item 8), utilization of video-based instruction (Item 9), and faculty use of technology-based communication with students (Item 10). Other items included 
encouraging student use of technology-based communication (Item 11), faculty utilization of smart or wireless devices to conduct lessons or disperse course materials (Item 12), use of guest speakers via technology driven methods (Item 13), and requiring students to use web-based tools to complete course assignments (Item 14).

The third section of the SHEIP survey instrument focused on faculty perceptions of their instructional role in HE classrooms and included 10 items (Items 15-24). To obtain information concerning faculty's self-reported perceptions of their instructional role, survey participants were given quotes or statements related to instructional role within the classroom and asked for a response indicating their level of agreement with the given statement. Participants' responses were gathered using a 4-point Likert Scale, including only two written descriptors, Strongly Agree to Strongly Disagree. These statements related to issues such as instructional role as mainly class facilitator (Item 15), the most important part of instruction - curriculum content or what students are able to do (Item 16), activity within the classroom (Item 17), and students learning basic skills in the context of complex content (Item 18). Other items concerning instructor role, such as assignment structure (Item 19), importance of core content within textbooks (Item 20), importance of student thinking concerning content (Item 21), importance of student interest (Item 22), importance of course materials' structure (Item 23) and importance of students learning basic skills before mastering course content (Item 24) were also included.

The final section of the Survey of Higher Education Instructional Practices examined self-reported faculty perceptions concerning the learning preferences of their students. This section contained 16 items (items 25-40) asking for perceptions concerning 
the learning preferences of higher education students. These statements asked for respondents' level of agreement using a 4-point Likert Scale, including only two written descriptors, Strongly Agree to Strongly Disagree. These survey items asked for levels of agreement regarding what participants believed students should be able to do, based on respondents' educational perceptions. Items included establishing understanding based on individual experiences (Item 25), integrating learning concepts into self-directed projects (Item 26), further research concerning questions related to new concepts (Item 27), pursing learning concepts to create individual learning (Item 28) and exploring new learning concepts independently (Item 29).

Also investigated were items which examined demonstrating methods to realistically solve problems (Item 30), connecting current practice to individual experiences (Item 31), expecting immediate feedback (Item 32), applying knowledge independently in other contexts (Item 33) and explaining learning concepts using individual perspectives (Item 34). Other survey items examined were working in groups to establish individual knowledge (Item 35), working in groups to share knowledge and reach agreement (Item 36), integrating learning concepts in and out of the classroom (Item 37), understanding individual thinking and how to seek needed help (Item 38), showing mastery of knowledge using self-chosen assessments (Item 39), and relating individual experiences to explaining learning concepts (Item 40). The variables, their type and scale are further delineated in Table 5. 
Table 5

Identification of Independent and Dependent Variables in the SHEIP

\begin{tabular}{|c|c|c|}
\hline Variable & Type & $\mathrm{Sc}$ \\
\hline I1 - Type of institution (2-yr or 4-yr public, 4-yr private) & Independent & Nominal \\
\hline I2 - Institution size (based on enrollment) & Inde & Nominal \\
\hline I3 - Department & Inde & Nominal \\
\hline I4 - Faculty rank & Inde & Nominal \\
\hline - Gender & Inde & Nominal \\
\hline I6 - Age Range & Independent & Nominal \\
\hline I7 - Technology-enabled classroom & Dependent & Likert (1-4) \\
\hline I8 - Use technology-based tools & Dependent & Likert (1-4) \\
\hline I9 - Use video-based instruction & Dependent & Likert (1-4) \\
\hline nicate $w /$ students & Dependent & Likert (1-4) \\
\hline 1- Enco & Dependent & Likert (1-4) \\
\hline 12 -Use & Dep & Likert (1-4) \\
\hline 13 -Use & Del & Likert (1-4) \\
\hline 14 -Studen & & Likert (1-4) \\
\hline 15 -Role of & Dep & Likert (1-4) \\
\hline 6 -Most il & Dep & Likert (1-4) \\
\hline I17 - All s & Dep & Likert (1-4) \\
\hline $18-\mathrm{Stt}$ & & Like \\
\hline $19-\mathrm{Bet}$ & & Like \\
\hline $20-$ Tex & & Likert (1-4) \\
\hline $21-$ Mos & & Likert (1-4) \\
\hline 22 - Criti & De & Likert (1-4) \\
\hline I23 - Materia & Dependent & Likert (1-4) \\
\hline I24 - Stuc & & Lik \\
\hline$F$ & & Lik \\
\hline $26-$ & ent & $(1-4)$ \\
\hline I27 - Stuc & De & Likert (1-4) \\
\hline I28 - Students $\mathrm{p}$ & dent & Likert (1-4) \\
\hline I29 - Students e & Dependent & Likert (1-4) \\
\hline $\mathrm{I} 30$ - & & Like \\
\hline I31 - & $\mathrm{De}$ & Like \\
\hline & ent & Likert (1-4) \\
\hline dependently in other contexts & adent & Likert (1-4) \\
\hline I34 - Students & ndent & Likert (1-4) \\
\hline $\mathrm{I} 35-\mathrm{S}$ & ent & Like \\
\hline reement & & \\
\hline & & Likert (1- \\
\hline ividual thinking \& seek independent help & Dependent & Likert (1-4) \\
\hline & Dependent & Likert (1-4) \\
\hline I40 - Students relate experiences when explaining learning concepts & Dependent & Likert (1-4) \\
\hline
\end{tabular}




\section{Research Design}

This study employed a quantitative, non-experimental, descriptive research design. Quantitative research is defined as research involving the collection of data in numerical form and analyzed numerically (Field, 2005; Springer, 2010). Furthermore, according to experts, a non-experimental, descriptive design includes utilization of a survey instrument (Springer, 2010). Springer (2010) and Trochim (2006) postulate stratified random sampling is the process of dividing the population into subgroups, then randomly choosing a specific number of participants from each subgroup.

As the population for this study included faculty at Missouri higher education institutions, and subgroups were formed from this population (2-year public, 4-year public and 4-year private), followed by the random selection of five institutions from each of these subgroups, this study employed stratified random sampling (Springer, 2010; Trochim, 2006). Furthermore, this is a cross-sectional study, as it takes place at a single point in time (Springer, 2010; Trochim, 2006). Accordingly, this study utilized a quantitative, non-experimental, descriptive research design, employing stratified random sampling to investigate five research questions identified earlier in this dissertation (Field, 2005; Springer, 2010; Trochim, 2006).

\section{Population and Sample}

The population for this study included 2,978 faculty at a randomly selected group of two-year and four-year, public and private Missouri higher education institutions based on a listing of Missouri higher education institutions provided by the Missouri Department of Higher Education (MDHE), shown in Appendix H. The Research Randomizer (http://www.randomizer.org) was used to complete random selection which 
included five from each group, 2-year public, 4-year public and 4-year private, for a total of 15 higher education institutions. Faculty instructing at these institutions during the spring 2013 semester, as publicized on the institutions' websites, were sent an email (see Appendix F) on April 22, 2013 including a statement of informed consent (see Appendix E), describing the study and including a clickable link directing them to the online explanation of the survey as well as the survey instrument and access code or password. A follow-up, or reminder email (see Appendix G) was sent to only those participants who had not completed the survey following the initial email on April 29, 2013 including a reminder message as well as the original information, including the statement of informed consent.

No data were rejected due to lack of informed consent as all respondents acknowledged an informed consent statement through email before being directed to the survey instrument. Responses were received from 278 respondents, a 9.3\% response rate. Of those, 26 did not fully complete the survey. Completion by participants provided 252 surveys, for an $8.5 \%$ return rate with 2978 faculty members. Closer examination of the completed surveys showed eight which were unusable due to incomplete data, giving a total of 244 usable surveys from which to analyze the data and an overall response rate of $8.2 \%$.

Use of a sample size calculator provided calculations confirming needed sample size (Creative Research Systems, 2012). The sample size calculator provided by Creative Research Systems (2012) at http://www.surveysystem.com/sscalc.htm was used for this purpose. This sample size calculator uses a provided formula for sample size (ss) calculated as ss $=\mathrm{z}$ value (e.g. 1.96 for $95 \%$ confidence level) $\mathrm{x}$ (p) (percentage such as 
.5 used for sample size needed) x (1-p) divided by c2 (confidence interval, expressed as a decimal, e.g. .04) (Creative Research Systems, 2012). According to Springer (2010) and Field (2005), a confidence interval is the range of values within which the population mean is expected to fall, to some degree of likelihood or based on a given confidence level which is the statistical measure of the number of times out of 100 that test results can be expected to be within a specified range. This formula is used "to determine how many people you need to respond in order to get results that reflect the target population as precisely as needed" (Creative Research Systems, 2012). Creative Research Systems (2012) further observes, "The mathematics of probability proves the size of the population is irrelevant. A sample of 500 people is equally useful in examining the opinions of a state of $15,000,000$ as it would a city of $100,000 . "$

According to data provided by Missouri Department of Higher Education (MDHE), the population of higher education faculty at 2-year and 4-year public and 4year private higher education institutions in Missouri equals 16,343. With a population of 16,343 faculty, for a $95 \%$ confidence level and confidence interval of 10 , Creative Research Systems Sample Size Calculator indicates a sample size of 95 is needed. With the same population of 16,343 , a $99 \%$ confidence level with a confidence interval of 10 would require a sample size of 165 . For this study, a 99\% confidence level with a confidence interval of 10 is desired; therefore, a sample of size of 165 respondents was deemed acceptable (Creative Research Systems, 2012). The greater number of responses or size of the sample responding could more likely confirm the level of reliability and validity of the instrument (Field, 2005). Based on this information, 244 usable surveys were deemed adequate for desired statistical analyses at a 99\% confidence level. 
All responses were reported in an analysis of group data rather than individual responses. This removed bias based on individual respondents choices, but instead looked only at summaries of all survey data collected. Results from the independent, demographic variables including the Carnegie Classification for the institution using the type and enrollment of institution, as well as the department, rank, gender, and age range of the respondents were converted to nominal data, exported in the form of a .csv file and imported into the SPSS statistical software application.

\section{Statistical Analyses}

Several methods were used to analyze the collected survey data to analyze and interpret of the findings for this study. The results of these analyses were described within five sub-sections. The first section addressed validity and reliability tests of the Survey of Higher Education Instructional Practices (SHEIP), Research Question 1. To test for validity and reliability, pilot surveys and Cronbach's alpha analyses were completed and reported. Section two explored the utilization of technology-enhanced instructional practices. This section responded to Research Question 2. Frequency counts and percentages were reported for this group of survey questions. Measures of central tendencies and dispersion including mean, median, mode, standard deviation and variance were also reported.

The third section reports on perceptions of Missouri higher education faculty concerning their instructional role in the classroom. This section describes the data collected to respond to Research Question 3. Frequency counts and percentages for this group of survey questions were reported as well as the measures of central tendency and dispersion including mean, median, mode, standard deviation and variance. The fourth 
section in Chapter 4 analyzed the data collected concerning Missouri higher education faculty perceptions concerning millennial students' preferred learning styles, responding to Research Question 4. Frequency counts and percentages were reported. Furthermore, the measures of central tendency and dispersion, including the mean, median, mode, standard deviation and variance were again reported.

The fifth section of this analysis reported the overall summary statistics delineated by the study participants' demographics. Cross tabulations showing frequency numbers and percentages for each survey item disaggregated by the six demographic items were presented. Chi-square analysis was also furnished. This section details the data as related to Research Question 5. Lastly, a chapter summary was completed and an introduction to Chapter 5 given.

Research Question 1 - Validity and Reliability Measures

Before credence was given to findings of the study, validity and reliability tests were conducted. Research Question 1 was "Is the Survey of Higher Education Instructional Practices (SHEIP) valid and reliable?" More specifically, Research Question 1.1 asked "Is the survey instrument valid?" and Research Question 1.2 asked "Is the survey instrument reliable?"

The instrument used in this study was the Survey of Higher Education Instructional Practices (SHEIP), designed by the researcher. This survey was based on the Maine Learning Technology Initiative (MLTI) Teacher Survey Form B - Fall 2003 (Gritter, 2005) as summarized by Hawley (2004) and the Survey of Current Teaching Instructional Practice and Application of Internet Technology for University Faculty: 
Faculty Form (Li, 2008). Both surveys had been tested and determined to be both reliable and valid (Hawley, 2004, p. 44; Li, 2008, p. 81)

To determine face and construct validity of the researcher-designed survey and address Research Question 1.1, a pilot of the Survey of Higher Education Instructional Practices (SHEIP) was conducted. Accordingly, an expert panel was chosen. The expert panel chosen included ten experts in the higher education realm. Panel members selected were current HE faculty at the with at least 10 years academic experience or recently retired with over 30 years in the higher education realm. All active panel members selected were assistant professors, associate professors or full professors at the institutions at which they taught. All expert panel participants had also completed dissertations and research publications, indicating they were familiar the process of survey creation, data collection and analysis, as well as dissertation completion. The researcher deemed these factors gave all panel participants adequate expertise needed to pilot the initial survey and give expert and constructive feedback.

An email (see Appendix C), including a link to a draft of the researcher-developed instrument used in this study, the Survey of Higher Education Instructional Practices (see Appendix B), was sent to a researcher-selected panel of 10 expert educators, from various higher education institutions and higher educational subject backgrounds. This email asked participants to complete the survey and provide feedback by answering eight questions concerning their experience in addition to completing the survey.

These questions included items regarding the directions for the survey as well as the language and clearness of each survey item. Questions were also asked concerning survey items which were unclear, confusing, could not be answered or could be 
eliminated. Furthermore, the expert panel was asked to comment concerning the time taken to complete the survey and its appropriateness. The final question asked for further comments and feedback concerning the survey and procedures. Of the selected panel members, five responded to this initial email, which also included a purpose message, a hyperlink and randomly-generated password to the online survey. A reminder email (see Appendix D) was launched one week later, prompting a response from four of the remaining panel members. The remaining panel member replied with a message declining to participate, due to time constraints. Questions asked of the expert panel are further delineated in Table 6.

Table 6

Questions for Expert Panel - Survey of Higher Education Instructional Practices (SHEIP) Pilot

\begin{tabular}{l}
\hline Question \\
Are the directions for taking the survey clear and concise? \\
Is the language in each item clear and understandable? \\
Are there any items which should be eliminated or added? \\
Which items are unclear or confusing? \\
Is the survey too time consuming or appropriate in length? \\
Are there items which may not be answered? \\
How long did it take for you to complete the survey? \\
Do you have any comments concerning the survey?
\end{tabular}

Once the pilot survey was completed and answers to questions submitted to the researcher, feedback from the panel was examined closely to discern what recommendations were made. Based on responses from the nine expert panel members whom provided feedback, the draft survey was edited and made ready for launch to the faculty members from the selected group of Missouri higher education institutions in spring 2013. Changes were made based on the feedback given by the expert panel 
principally involving rewording items on the Survey of Higher Education Instructional Practices (SHEIP), particularly in section 3, on the survey items concerning preferred student learning styles.

Once the pilot survey was completed and data collected, reliability was analyzed. To check for internal reliability, Cronbach's alpha analysis was conducted using SPSS software. According to research, Cronbach's alpha is a method to check on reliability or internal consistency of survey item responses (Field, 2005; Fraenkel \& Wallen, 2006). When all 40 survey items were analyzed, Cronbach's alpha yielded a 0.735 . According to Field (2005), a Cronbach's alpha value above 0.70 is deemed acceptable, thus the yielded value was judged acceptable for this research study. According to Field (2005) "if several factors exist the formula should be applied separately to items relating to different factors" (p.668). Based on this expertise, the researcher chose to conduct a Cronbach's alpha analysis for each subset or section of the Survey of Higher Education Instructional Practices (SHEIP) as there were three distinct sets of factors: (a) technology-enhanced instruction, (b) perceptions of instructor role and (c) perceptions of students' learning preferences.

To determine reliability for individual sections of the SHEIP, Cronbach's alpha analysis was conducted and examined for each section. The Cronbach's alpha analysis was completed for survey items 7-14, which surveyed the utilization of technologyenhanced instruction. The analysis for these items revealed a Cronbach's alpha of 0.714 , again deemed acceptable (Field, 2005). Items 15 -24, which examined perceptions of Missouri higher education faculty's perceptions of their instructional role showed a Cronbach's alpha of 0.457 . As a reliability measure, this was deemed weak (Field, 2005). 
As survey items concerning instructor role were ones which could be divided into two discernible groups, traditional and contemporary instructional roles. Cronbach's alpha was conducted again for only the five questions in each sub-group. Cronbach's alpha for the first group of statements, focused on traditional teaching roles, yielded a 0.553. The statements focused on contemporary teaching roles yielded a Cronbach's alpha of 0.624 . While neither met the 0.70 benchmark for acceptable, the Cronbach's alpha scores were higher when the questions were separated. Field (2005) indicated that dependent on the diversity of the data being measured, Cronbach's alpha values below 0.7 can be realistically considered reliable. Based on the analysis, Items $15-24$ were deemed reliable. Lastly, Cronbach's alpha analysis was employed to examine items 2540, pertaining to faculty's perceptions of millennial students' learning styles. The results showed a Cronbach's alpha of 0.892 . The 0.892 result was well above the 0.70 needed to be deemed acceptable (Field, 2005), indicating these survey items were reliable. Research Question 2 - Utilization of Technology-Enhanced Instruction

Research Question 2 was given as "To what degree do Missouri HE faculty significantly utilize technology-enhanced instructional practices?" This question determined the utilization of technology-enhanced instructional practices by Missouri higher education faculty and involved survey items 7 - 14. Cross tabulations showing frequency counts and percentages of responses as well as the total number of responses for each survey item 7 - 14, are shown in Table 7 (Fraenkel \& Wallen, 2006).

As shown in Table 7, Item 10, using technology to communicate with students, indicated 199 or $81.6 \%$ of responses as 1 or always, Item 7, addressing using a technology-enabled classroom environment, obtained 197 or $80.7 \%$ of responses chosen 
as 1 or always, and Item 8 , indicating the respondent used technology-based tool to support classroom instruction, had 180 or $73.8 \%$ responses of 1 or always. Further examination shows that Item 10 had 35 responses of 2, and only 9 respondents selected Choice 3 (7 respondents) and Choice 4 (2 respondents) indicating only $3.7 \%$ of the respondents did not regularly use technology to communicate with students. These data indicated a majority of the Missouri higher education faculty responding to the SHEIP used these types of technology-enhanced instruction. Visual representation of frequency of responses disaggregated by choice for Items 7-14 is also included in Figure 6.

\section{Table 7}

Frequency and Percentages of Responses (RQ2) -Technology-Enhanced Instruction (Items 7-14)

\begin{tabular}{|c|c|c|c|c|c|c|c|c|c|}
\hline \multirow[b]{2}{*}{ Variable } & \multicolumn{2}{|c|}{ Always - 1} & \multicolumn{2}{|c|}{2} & \multicolumn{2}{|r|}{3} & \multicolumn{2}{|c|}{ Never - 4} & \multirow[b]{2}{*}{$\mathrm{N}$} \\
\hline & $\mathrm{n}$ & $\%$ & $\mathrm{n}$ & $\%$ & $\mathrm{n}$ & $\%$ & $\mathrm{n}$ & $\%$ & \\
\hline I7 - Technology-enabled classroom environment & 197 & 80.7 & 30 & 12.3 & 10 & 4.1 & 7 & 2.9 & 244 \\
\hline I8 - Use technology-based tools to support instruction & 180 & 73.8 & 49 & 20.1 & 13 & 5.3 & 2 & 0.8 & 244 \\
\hline I9 - Use video-based instruction to support activities & 71 & 29.1 & 87 & 35.7 & 64 & 26.2 & 22 & 9.0 & 244 \\
\hline I10 - Use technology means to communicate w/ students & 199 & 81.6 & 35 & 14.3 & 7 & 2.9 & 2 & 0.8 & 243 \\
\hline I11 - Encourage student communication using technology & 67 & 27.5 & 61 & 25.0 & 60 & 24.6 & 55 & 22.5 & 243 \\
\hline I12 - Use smart or wireless devices to conduct lessons/materials & 27 & 11.1 & 32 & 13.1 & 42 & 17.2 & 143 & 58.6 & 244 \\
\hline I13 - Use of guest speakers via technology-driven means & 6 & 2.5 & 17 & 7.0 & 54 & 22.1 & 165 & 67.6 & 242 \\
\hline I14 - Students use web-based tools to complete assignments & 104 & 42.6 & 78 & 32.0 & 36 & 14.8 & 26 & 10.7 & 244 \\
\hline
\end{tabular}

Figure 6 illustrates the responses of 1 or always to survey items 7, 8 and 10. These responses indicated a majority of Missouri higher education faculty surveyed use the technology-enabled instructional practices indicated in items 7, 8 and 10. Responses to Item 11 were all fairly equal with Option 1 (always) receiving 67 responses, Option 2 receiving 61 responses, Option 3 receiving 60 responses and Option 4 (never) receiving 55 responses. This indicated approximately the same number of respondents agree and 
disagree with the technology-enhanced instructional practice described in Item 11, encouraging student communication using some type of technology-based tool.

Figure 6 reveals Item 12 (143 responses) and Item 13 (165 responses) exhibited the maximum number of responses for choice 4 or never concerning use of smart or wireless devices to conduct lessons or disseminate class materials (Item 12) and the use of guest speakers via technology-driven means (Item 13), indicating a majority of Missouri higher education faculty do not utilize these types of technology-enhanced instructional practices in higher education classrooms.

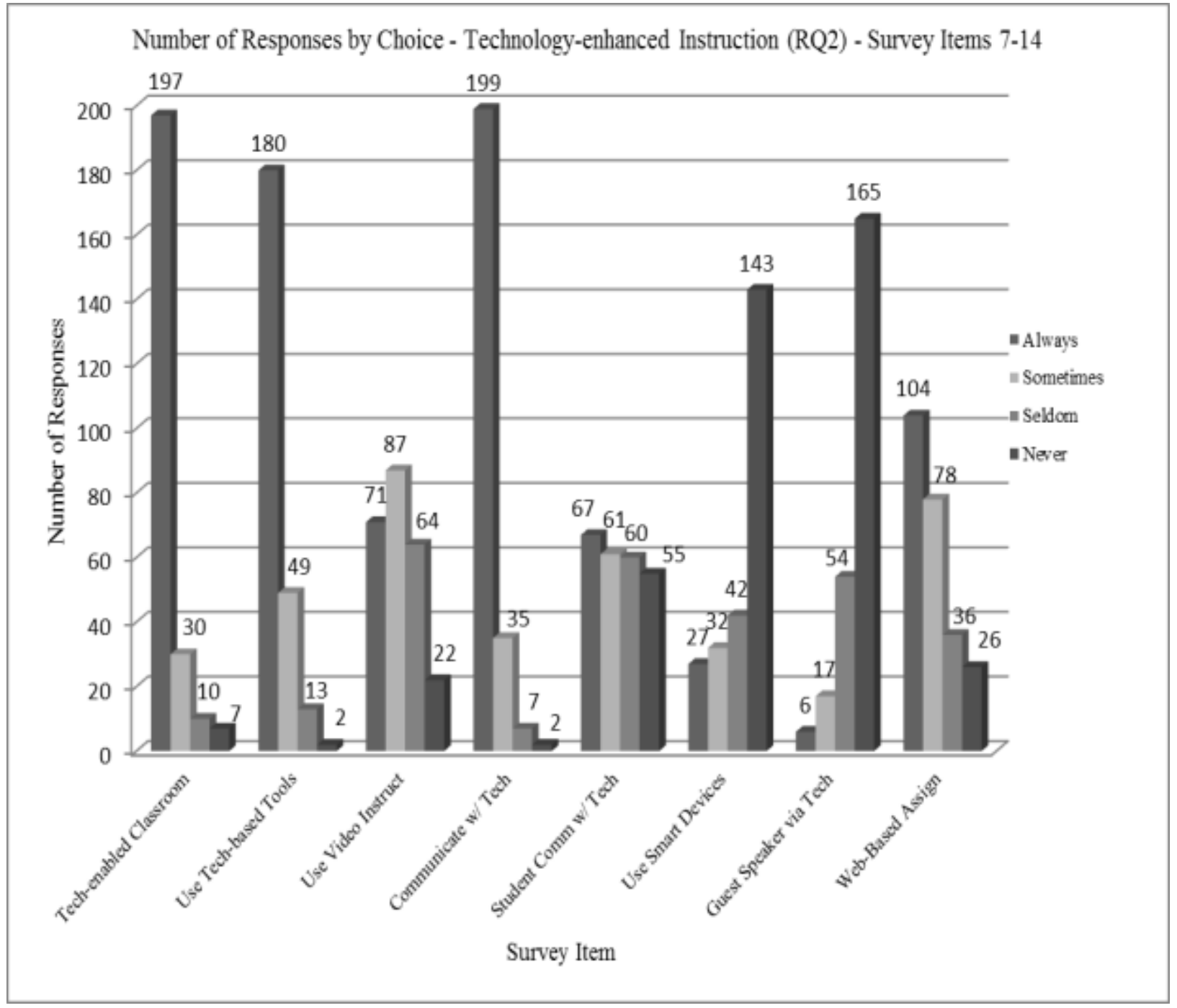

Figure 6. Number of responses by choice - technology-enhanced instruction (RQ2) - items 7-14 
Measures of central tendency and dispersion for this data are shown in Table 8 including mean, median, mode, standard deviation and variance. Table 8 shows survey items 12 and 13 have the highest means, 3.23 and 3.56 respectively, indicating these two items had the most responses of three or four. These two items also had the highest median (4) and mode (4). This indicated that this item has the highest number of responses marked four. Items 11 and 12 had the highest standard deviation among all survey items concerning technology-enhanced instructional practices. Item 11 had a standard deviation of 1.120 and item 12 had a standard deviation of 1.053 , indicating these items had scores on average the most widely dispersed from the mean (Field, 2005; Springer, 2010). These items also showed the highest variance with Item 11 showing a variance of 1.253 , while Item 12 had a variance of 1.110 , indicating these two items have the highest average error between the mean and observations made in the data (Field, 2005, p. 6). Item 14 was similar in standard deviation and variance with a standard deviation of 1.0 and a variance of 1.0. The item with the lowest mean (1.23) as well as the lowest standard deviation (0.532) and lowest variance (0.283), indicating the lowest level of dispersion and lowest average error between the mean and observations made in the data were Item 10, indicating that this is the item that had the highest level of agreement among respondents.

Table 8

Measures of Central Tendency and Dispersion - Technology-Enhanced-instruction (RQ2)

\begin{tabular}{|c|c|c|c|c|}
\hline Variable & Mean & Median & Mode SD. & . Var. \\
\hline I7 - Technology-enabled clas & 1.29 & 1.00 & 1.680 & .462 \\
\hline I8 - Use technology-based tools to support instruction & 1.33 & 1.00 & 1.616 & .379 \\
\hline I9 - Use video-based instruction to support activities & 2.15 & 2.00 & 2.946 & .895 \\
\hline I10 - Use technology means to communicate w/ students & 1.23 & 1.00 & 1.532 & .283 \\
\hline I11 - Encourage student communication using technology & 2.42 & 2.00 & 11.120 & 1.253 \\
\hline
\end{tabular}




\begin{tabular}{llllcc} 
I12 - Use smart or wireless devices to conduct lessons/materials & 3.23 & 4.00 & 4 & 1.053 & 1.110 \\
I13 - Use of guest speakers via technology-driven means & 3.56 & 4.00 & 4 & .733 & .538 \\
I14 - Students use web-based tools to complete assignments & 1.93 & 2.00 & 1 & 1.000 & 1.000 \\
\hline
\end{tabular}

Responses from survey items 7 through 14, pertaining to Research Question 2 as related to technology-enhanced instructional practices, were more closely analyzed to examine the use (Likert scale choices 1 or 2) versus non-use (Likert scale choices 3 or 4 ). Both the number of responses and the percentage of the respondents were evaluated. Results are shown in Table 9.

As shown in Table 9, three survey items revealed over a 90\% percentage usage rate. Survey item 7 showed responses of 1 or 2 by 227 respondents (93\%), 229 respondents chose responses of 1 or 2 for Item 8 (93.9\%), and 234 respondents chose those same responses for survey item 10 (96.3\%). Results indicated a large majority (over 90\%) of Missouri higher education faculty are teaching in a technology-enabled classroom and are also using technology-enhanced instructional practices to teach and communicate. Three other survey items, Item 9, Item 11 and Item 14 showed over a 50\% usage rate with $158(64.8 \%), 128(52.7 \%)$ and $182(74.6 \%)$ of respondents reporting use respectively. Research suggests using technologies in combination with other instructional tools can enhance existing instructional models and fashion new techniques for teaching and learning (Kent \& McNergney, 1999; Prensky, 2012; Tapscott, 1998). Results indicated a majority of Missouri higher education faculty responding to the survey are using these types of technology-enhanced instructional practices in their respective classrooms. A chart depicting responses in percentages is shown in Figure 7. 
Table 9

Frequency of Responses (Usage vs. Non-Usage) - Technology-Enhanced Instruction $(R Q 2)$

\begin{tabular}{llllll}
\hline \multicolumn{1}{c}{ Variable } & \multicolumn{3}{c}{ Use } & \multicolumn{3}{c}{ Non-use } \\
& \multicolumn{1}{c}{$\mathrm{n}$} & \multicolumn{1}{c}{$\%$} & $\mathrm{n}$ & $\%$ & $\mathrm{~N}$ \\
\hline I7 - Technology-enabled classroom environment & 227 & 93.0 & 17 & 7.0 & 244 \\
I8 - Use technology-based tools to support instruction & 229 & 93.9 & 15 & 6.1 & 244 \\
I9 - Use video-based instruction to support activities & 158 & 64.8 & 86 & 35.2 & 244 \\
I10 - Use technology means to communicate w/ students & 234 & 96.3 & 9 & 3.7 & 243 \\
I11 - Encourage student communication using technology & 128 & 52.7 & 11547.3 & 243 \\
I12 - Use smart or wireless devices to conduct lessons/materials & 59 & 24.2 & 18575.8 & 244 \\
I13 - Use of guest speakers via technology-driven means & 23 & 9.5 & 21990.5 & 242 \\
I14 - Students use web-based tools to complete assignments & 182 & 74.6 & 62 & 25.4 & 244 \\
\hline \multicolumn{1}{c}{$* n=244$} & & & & &
\end{tabular}

Figure 7 further illustrates the percentage of responses for those survey items pertaining to technology-enhanced instruction. A high level of usage for Items 7, 8 and 10 is readily apparent. When the chart in Figure 7 is evaluated, it is evident that six of the eight items have above a 50\% usage rating. This indicated a majority of Missouri higher education faculty survey participants are utilizing technology-enhanced instructional practices as discerned by responses to items $7-14$ in the Survey of Higher Education Instructional Practices (SHEIP).

Further examination of Figure 7 showed a high level of non-usage for Item 13 $(90.5 \%)$. This high level of non-usage indicates that few Missouri higher education faculty survey participants make use of guest speakers via technology-driven means such as Internet video, Skype and similar tools. Furthermore, a high level of non-usage for Item 12 (75.8\%) suggested few Missouri higher education faculty survey participants are utilizing smart or wireless devices, such as iPods, androids, iPhones, iPads and tablets, to conduct lessons or disperse course materials. The six remaining survey items indicated 
higher use took place regarding utilization of technology-enhanced instructional tools and methods. Figure 7 indicated usage of technology-enhanced instructional practices by a majority of participants, as six of the eight survey items assessed had a response rate of over 50\%. Usages versus non-usage rates for Item 11 were comparable with $52.7 \%$ respondents indicating use and $47.3 \%$ respondents reporting non-usage. This suggested an approximately equal amount of Missouri higher education faculty use technologyenhanced instructional practice as do not use technology when encouraging student communication using some type of technology-based tool, such as blogs, wikis, or threaded discussions.

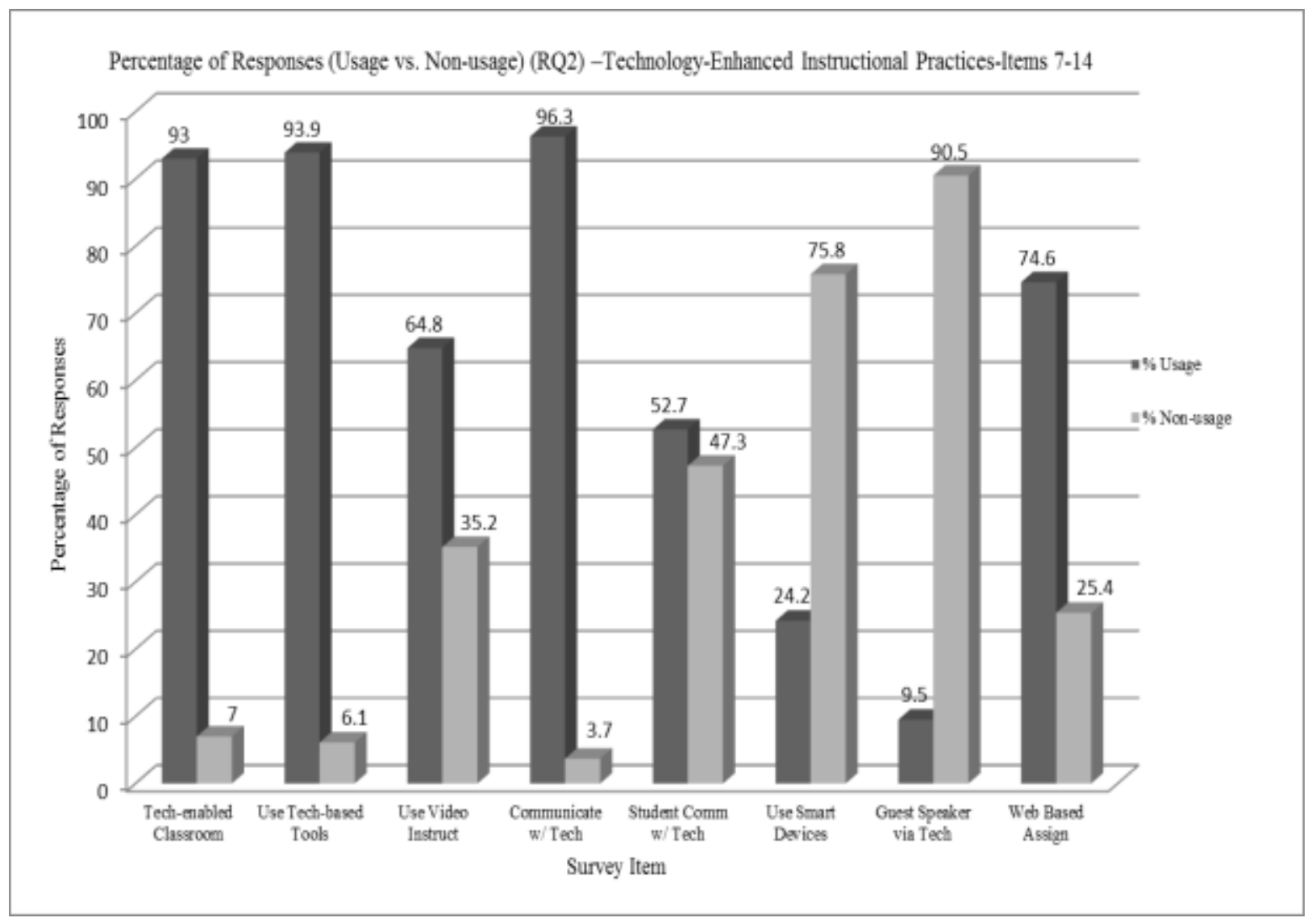

Figure 7. Percentage of responses (usage vs. non-usage) (RQ2) - technology-enhanced instructional practices - items $7-14$ 
Research Question 3 - Perceptions of Missouri HE Faculty Concerning Instructional Role

Research Question 3 states “To what degree do Missouri HE faculty perceptions of their instructional role match those identified in current research as preferred by millennial students?" This question explored perceptions of instructor role by Missouri higher education faculty and involved survey items $15-24$. The ten survey items in this section of the Survey of Higher Education Instructional Methods (SHEIP) were divided into two components. Agreement, or choosing Choice 1 or 2, on survey items 15, 17, 18, 21 and 22 indicate faculty implement a "guide on the side" or perceive themselves as using a more contemporary instructor role (King, 1993; Howe \& Strauss, 2007; Oblinger \& Oblinger, 2005; Prensky, 2005; Skiba \& Barton, 2006; Tapscott, 1998). This is the type of instruction current research shows preferred by Millennials. Responses indicating agreement on survey items 16, 19, 20,23 and 24 are indicative of faculty adopting a "sage on the stage" or more traditional instructor role (King, 1993; Howe \& Strauss, 2007; Oblinger \& Oblinger, 2005; Prensky, 2005; Skiba \& Barton, 2006; Tapscott, 1998).

When data were examined, the largest number respondents chose Strongly Agree (Choice 1) or Agree (Choice 2) on Survey Item 18, indicating a majority or 209 of the respondents have a perception of their role as more contemporary or see themselves as "guides on the side" (King, 1993; Howe \& Strauss, 2007; Oblinger \& Oblinger, 2005; Prensky, 2005; Skiba \& Barton, 2006; Tapscott, 1998). However, the number of respondents agreeing with survey item 16 , indicating faculty adopted a more traditional role or "sage on the stage" (King, 1993; Howe \& Strauss, 2007; Oblinger \& Oblinger, 
2005; Prensky, 2005; Skiba \& Barton, 2006; Tapscott, 1998), was very similar with 204 of the survey participants choosing the strongly agree or agree option (Choice 1 or Choice 2). At first examination of the data, it appears that respondents are fairly equally divided between support of traditional and contemporary instructor roles in the classroom. Frequency counts and percentages of responses are shown in Table 10. 
Table 10

Frequency of Responses - Perceptions of Instructional Role (RQ3)

\begin{tabular}{|c|c|c|c|c|c|c|c|c|c|}
\hline \multirow[b]{2}{*}{ Variable } & \multicolumn{3}{|c|}{$\begin{array}{l}\text { Strongly } \\
\text { Agree-1 }\end{array}$} & \multicolumn{2}{|c|}{2} & 3 & \multicolumn{3}{|c|}{$\begin{array}{c}\text { Never } \\
-4\end{array}$} \\
\hline & $\mathrm{n}$ & $\%$ & $\mathrm{n}$ & $\%$ & $\mathrm{n}$ & $\%$ & $\mathrm{n}$ & $\%$ & $\mathrm{~N}$ \\
\hline II15 - Role of facilitator; students construct knowledge for selves & 88 & 36.1 & 102 & 41.8 & 43 & 17.6 & 10 & 4.1 & 243 \\
\hline II16 - Most important part of instruction is the content/curriculum & 92 & 37.7 & 112 & 45.9 & 35 & 14.3 & 4 & 1.6 & 243 \\
\hline II17 - All sorts of activities going on in the classroom & 67 & 27.5 & 100 & 41.0 & 61 & 25.0 & 14 & 5.7 & 242 \\
\hline II18 - Students learn basic skills in context of mastering content & 89 & 36.5 & 120 & 49.2 & 31 & 12.7 & 2 & .8 & 242 \\
\hline II19 - Better to give the whole class same assignment-small intervals & 33 & 13.5 & 104 & 42.6 & 80 & 32.8 & 23 & 9.4 & 240 \\
\hline II20 - Textbook core content is more important-not student motivation & 27 & 11.1 & 95 & 38.9 & 84 & 34.4 & 35 & 14.3 & 241 \\
\hline II21 - Most important instruction encourages “sense-making"/thinking & 38 & 15.6 & 118 & 48.4 & 70 & 28.7 & 12 & 4.9 & 238 \\
\hline II22 - Critical for students to become interested in doing academic work & 23 & 9.4 & 115 & 47.1 & 84 & 34.4 & 18 & 7.4 & 240 \\
\hline II23 - Material must be covered in a structured way; job to explain & 52 & 21.3 & 127 & 52.0 & 56 & 23.0 & 8 & 3.3 & 243 \\
\hline II24 - Students learn basic skills before mastering complex content & 79 & 32.4 & 113 & 46.3 & 47 & 19.3 & 3 & 1.2 & 242 \\
\hline
\end{tabular}

$* \mathrm{n}=244$

The researcher delved into analysis of the data concerning instructor role, Items $15-24$ and examined the data divided into groups of survey items indicative of a contemporary instructor role compared to survey items divulging a more traditional instructor role. This was accomplished by analyzing Items 15, 17, 18, 21 and 24 as one set of data and examining the frequency of responses and percentages for only these five items. The same procedure was used for analyzing Items 16, 19, 20, 23 and 24 as a second set of data. When the sets of data were more closely examined, it showed more respondents supporting contemporary instructor roles, with 26 (2.39\%) more respondents strongly agreeing (Choice 1 ) or agreeing (Choice 2).

When responses were more specifically delineated by Strongly Agree (Choice 1), a larger percentage of respondents chose Strongly Agree (Choice 1) with 22 or $1.9 \%$ more of the participants supporting contemporary instructor role than espousing Strongly Agree (Choice 1) in support of more traditional instructor roles. The results of the breakdown of the data into those supporting contemporary or "guide on the side" versus 
traditional or "sage on the stage" instructor roles are shown in Table 11 (King, 1993;

Howe \& Strauss, 2007; Oblinger \& Oblinger, 2005; Prensky, 2005; Skiba \& Barton, 2006; Tapscott, 1998).

Table 11

Response Frequency and Percentages - Contemporary Vs. Traditional Instructor Role (RQ3)

\begin{tabular}{|c|c|c|c|c|c|c|c|c|c|}
\hline \multirow[b]{2}{*}{ Variable } & \multicolumn{3}{|c|}{$\begin{array}{l}\text { Strongly } \\
\text { Agree-1 }\end{array}$} & \multicolumn{2}{|l|}{2} & \multicolumn{4}{|c|}{$\begin{array}{l}\text { Never } \\
-4\end{array}$} \\
\hline & $\mathrm{n}$ & $\%$ & $\mathrm{n}$ & $\%$ & $\mathrm{n}$ & $\%$ & $\mathrm{n}$ & $\%$ & $\mathrm{~N}$ \\
\hline \multicolumn{10}{|l|}{ Contemporary Instructor Role } \\
\hline I15 - Role of facilitator; students construct knowledge for selves & 88 & 36.1 & 102 & 41.8 & 43 & 17.6 & 10 & 4.1 & 243 \\
\hline I17 - All sorts of activities going on in the classroom & 67 & 27.5 & 100 & 41.0 & 61 & 25.0 & 14 & 5.7 & 242 \\
\hline I18 - Students learn basic skills in context of mastering content & 89 & 36.5 & 120 & 49.2 & 31 & 12.7 & 2 & 0.8 & 242 \\
\hline I21 - Most important instruction encourages "sense-making"/thinking & 38 & 15.6 & 118 & 48.4 & 70 & 28.7 & 12 & 4.9 & 238 \\
\hline I22 - Critical for students to become interested doing academic work & 23 & 9.4 & 115 & 47.1 & 84 & 34.4 & 18 & 7.4 & 240 \\
\hline Total responses supporting contemporary instructor role & 305 & 25.31 & 555 & 46.06 & 289 & 23.98 & 56 & 4.65 & 1205 \\
\hline \multicolumn{10}{|l|}{$\underline{\text { Traditional Instructor Role }}$} \\
\hline I16 - Most important part of instruction is the content/curriculum & 92 & 37.7 & 112 & 45.9 & 35 & 14.3 & 4 & 1.6 & 243 \\
\hline I19 - Better to give the whole class same assignment-small intervals & 33 & 13.5 & 104 & 42.6 & 80 & 32.8 & 23 & 9.4 & 240 \\
\hline I20 - Textbook core content is more important-not student motivation & 27 & 11.1 & 95 & 38.9 & 84 & 34.4 & 35 & 14.3 & 241 \\
\hline I23 - Material must be covered in a structured way; job to explain & 52 & 21.3 & 127 & 52 & 56 & 23.0 & 8 & 3.3 & 243 \\
\hline I24 - Students learn basic skills before mastering complex content & 79 & 32.4 & 113 & 46.3 & 47 & 19.3 & 3 & 1.2 & 242 \\
\hline Total responses supporting traditional instructor role & 283 & 23.41 & 551 & 45.57 & 302 & 24.98 & 73 & 6.04 & 1209 \\
\hline
\end{tabular}

Figure 8 illustrates the number of responses delineated by choice of the specific survey item, for Items $15-24$, associated to perceptions of Missouri higher education faculty concerning their instructor role. When Figure 8 was more closely examined, Choice 2 or Agree was chosen by the majority of the survey respondents. It was clearly evident Choice 2 was the most common selection for all 10 of the survey items pertaining to instructor role. This indicates a majority of the respondents show at least some level of agreement to all survey items pertaining to instructor role. The lowest response rate for Choice 2 with 95 responses was shown in Item 20 (38.9\%), which also showed similar 
responses for Choice 3 with 84 responses (34.4\%). This indicated an almost equal amount of strongly agree and agree as disagree and strongly disagree indicating faculty are equally divided on their perception of their role in that item. Respondents to this survey also seemed to be fairly similar with their perceptions concerning the use of traditional and contemporary instructor roles.

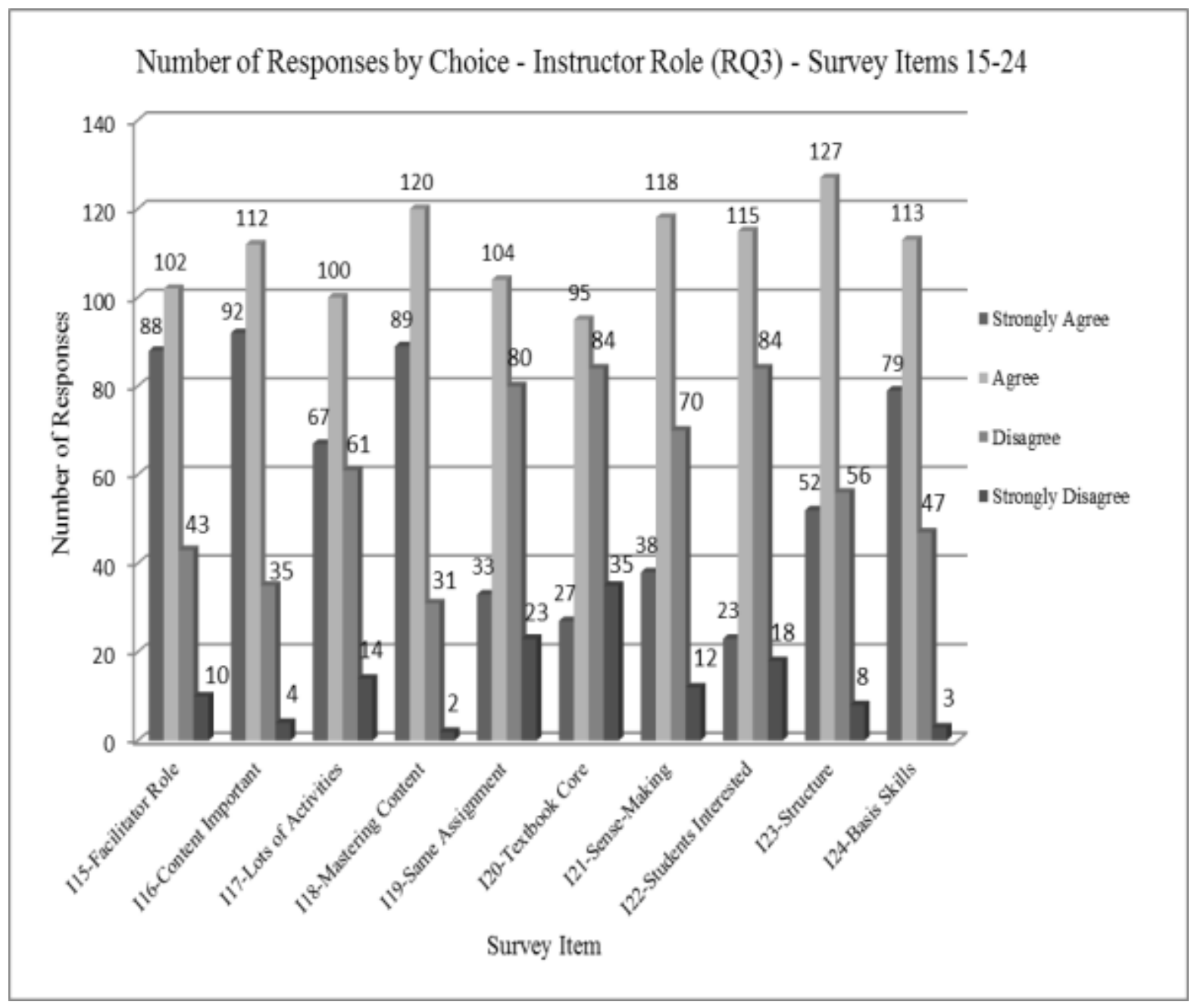

Figure 8. Number of responses by choice - instructor role (RQ3) - survey items 15 - 24

Table 12 examines measures of central tendency and dispersion of responses to Survey Items $15-24$, related to perceptions of Missouri higher education faculty concerning their instructor role. All items showed a median and mode of two indicating 
Choice 2 was the most commonly selected response by survey participants. The highest mean (2.53) appeared for Item 20 which measured participants' views concerning the importance of the core content of textbooks versus student motivation, indicating the most selection of choices 3 and 4 . The highest standard deviation (0.876) and variance (0.767) was also recorded for Item 20. The lowest mean, indicating the highest level of agreement to an item, was 1.78 for Item 18. Furthermore, the lowest standard deviation (0.694) and lowest variance (0.481) was also shown for Item 18.

Table 12

Measures of Central Tendency and Dispersion - Perception of instructor role (RQ3)

\begin{tabular}{lccccc}
\hline \multicolumn{1}{c}{ Variable } & Mean & Median & Mode SD. & Var. \\
\hline I15 - Role of facilitator; students construct knowledge for selves & 1.90 & 2.00 & 2 & .834 & .696 \\
I16 - Most important part of instruction is the content/curriculum & 1.80 & 2.00 & 2 & .742 & .550 \\
I17 - All sorts of activities going on in the classroom & 2.09 & 2.00 & 2 & .869 & .755 \\
I18 - Students learn basic skills in context of mastering content & 1.78 & 2.00 & 2 & .694 & .481 \\
I19 - Better to give the whole class same assignment-small intervals & 2.39 & 2.00 & 2 & .841 & .707 \\
I20 - Textbook core content is more important-not student motivation & 2.53 & 2.00 & 2 & .876 & .767 \\
I21 - Most important instruction encourages "sense-making"/thinking & 2.24 & 2.00 & 2 & .776 & .603 \\
I22 - Critical for students to become interested in doing academic work & 2.40 & 2.00 & 2 & .765 & .585 \\
I23 - Material must be covered in a structured way; job to explain & 2.08 & 2.00 & 2 & .756 & .572 \\
I24 - Students learn basic skills before mastering complex content & 1.89 & 2.00 & 2 & .749 & .561 \\
\hline
\end{tabular}

Responses from survey items 15 through 24, pertaining to Research Question 3 were more closely analyzed to examine the agreement (Likert scale choices one or two) versus disagreement (Likert scale choices three or four). Both the number of responses and the percentage of the respondents were evaluated. When all survey items were analyzed, all items showed a response rate over $50 \%$, indicating that a majority of respondents agreed with the statements relating to instructor role. This also indicated that respondents were equally agreeing with the use of contemporary versus traditional instructor role. The highest level of agreement, indicating the largest number of 
participants chose Choice 1 or Choice 2, appeared for Item 16, the most important part of instruction is the content of the curriculum. That specific item showed agreement (Choice 1 or 2) by 204 respondents for an $84 \%$. The lowest agreement percentage (50.6\%) as well as the most similar percentage of agreement (50.6\%) versus disagreement $(49.4 \%)$ is shown for Item 20 which stated textbook core content is most important, not student motivation. This indicated similar viewpoints among respondents. The results are further delineated in Table 13.

Table 13

Frequency of Responses (Agree vs. Disagree) - Perceptions of Instructional Role (RQ3)

\begin{tabular}{lccccc}
\hline \multicolumn{1}{c}{ Variable } & Agree (1\&2) & \multicolumn{3}{c}{ Disagree (3\&4) } \\
& $\mathrm{n}$ & $\%$ & $\mathrm{n}$ & $\%$ & $\mathrm{~N}$ \\
\hline I15 - Role of facilitator; students construct knowledge for selves & 190 & 78.2 & 53 & 21.8 & 243 \\
I16 - Most important part of instruction is the content/curriculum & 204 & 84.0 & 39 & 16.0 & 243 \\
I17 - All sorts of activities going on in the classroom & 167 & 69.0 & 75 & 31.0 & 242 \\
I18 - Students learn basic skills in context of mastering content & 209 & 86.4 & 33 & 13.6 & 242 \\
I19 - Better to give the whole class same assignment-small intervals & 137 & 57.1 & 103 & 42.9 & 240 \\
I20 - Textbook core content is more important-not student motivation & 122 & 50.6 & 119 & 49.4 & 241 \\
I21 - Most important instruction encourages "sense-making"/thinking & 156 & 65.5 & 82 & 34.5 & 238 \\
I22 - Critical for students to become interested in doing academic work & 138 & 57.5 & 102 & 42.5 & 240 \\
I23 - Material must be covered in a structured way; job to explain & 179 & 73.7 & 64 & 26.3 & 243 \\
I24 - Students learn basic skills before mastering complex content & 192 & 79.3 & 50 & 20.7 & 242 \\
\hline
\end{tabular}

$* \mathrm{n}=244$

The percentage of responses, indicating agreement versus disagreement for survey items 15 - 24 concerning perceptions of instructor role addressed in Research Question 3, is further illustrated in Figure 9. Examination of Figure 9 shows the strong level of agreement, particularly for Items 15, 16, 18, 23 and 24, each showing over 70\% agreement levels. Comparatively equivalent percentages of agreement and disagreement were also apparent for Items 19 (better to give the whole class the same assignment) and 20 (textbook core content is more important - not student motivation). A closer 
examination of the items showed a majority of the items showing the high levels of agreement appeared to be items indicating a "sage on the stage" (King, 1993; Howe \& Strauss, 2007; Skiba \& Barton, 2006; Tapscott, 1998) or more traditional type of instructor role. Items 16, 19, 20, 23 and 24 were all items measuring respondents' perceptions of "sage on the stage" (King, 1993; Howe \& Strauss, 2007; Skiba \& Barton, 2006; Tapscott, 1998) instructional style or the more traditional instructor role. The researcher determined that a closer look at the data, separated by traditional instructor role and contemporary instructor role, would be pertinent. Figure 10 illustrates the results of a more in depth analysis of Items $15-24$.

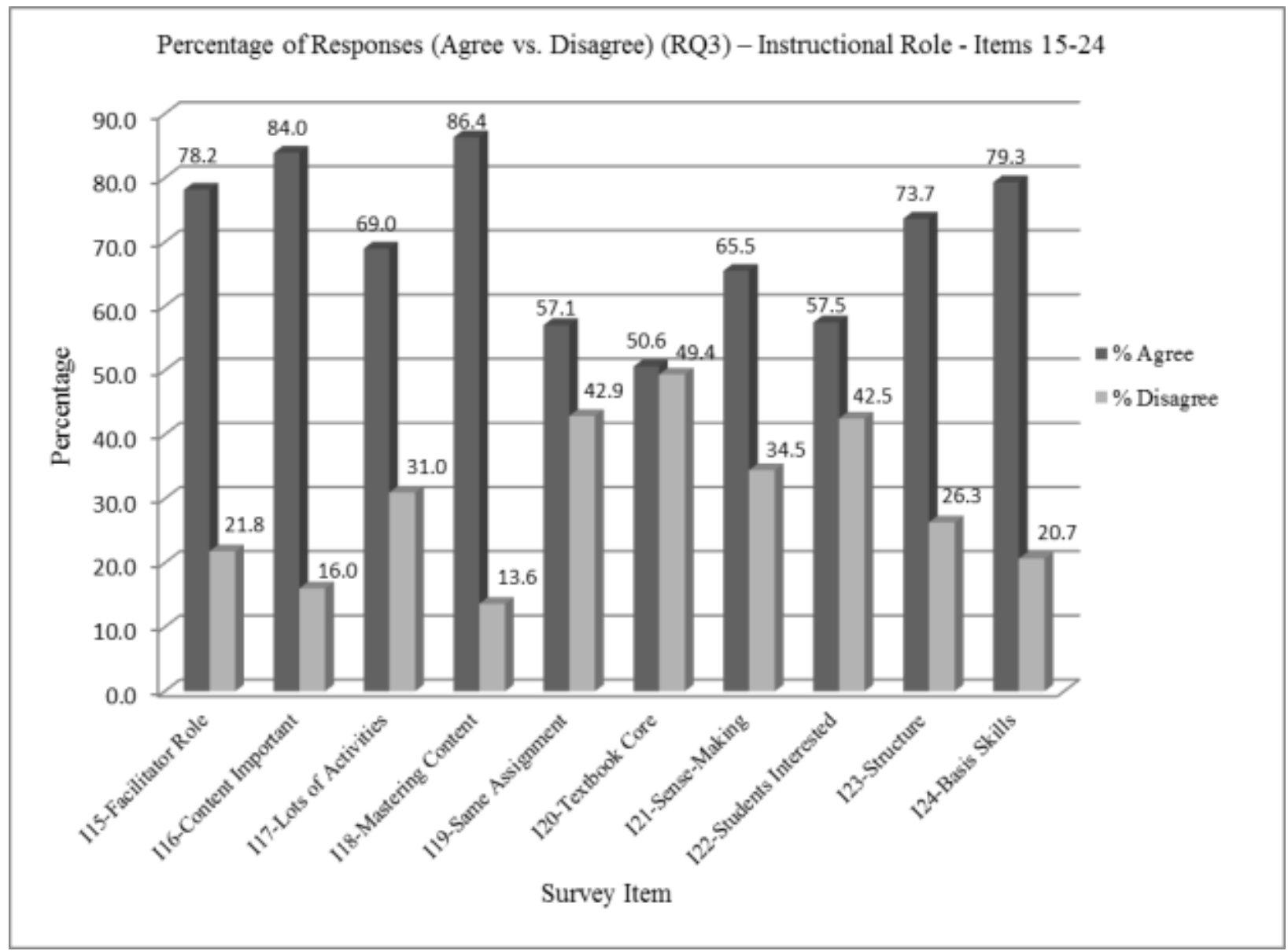

Figure 9. Percentage of responses (agree vs. disagree) - instructional role - items 15-24 (RQ3) 
Examination of Figure 10 indicated high levels of agreement (> 50\%) for all survey items $15-24$, relating to instructor role. The division between items examining perceptions of contemporary instructor role (Items 15, 17, 18, 21 and 22) and more traditional instructor role (Items 16, 19, 20, 23 and 24) showed higher levels of agreement on survey items representative of contemporary instructor role. All items were over 50\% agreement, but two items (Item 19 and Item 20), comparable in agreement versus disagreement percentages, were both items referring to more traditional instructor roles. When overall agreement numbers and percentages for both contemporary and traditional instructor role, the statistics showed 860 total responses or $71.37 \%$ agreeing with the statements pertaining to contemporary instructor role while there were 834 responses or $66.98 \%$ agreeing with the statements pertaining to the more traditional instructor role. Even though similar, results showed a slight majority of Missouri higher education faculty responding to the Survey of Higher Education Instructional Practices (SHEIP) perceived they used more contemporary instructor role, taking a more "guide on the side" (King, 1993; Howe \& Strauss, 2007; Skiba \& Barton, 2006; Tapscott, 1998) role, shown by research to be preferred by current higher education students or Millennials. 


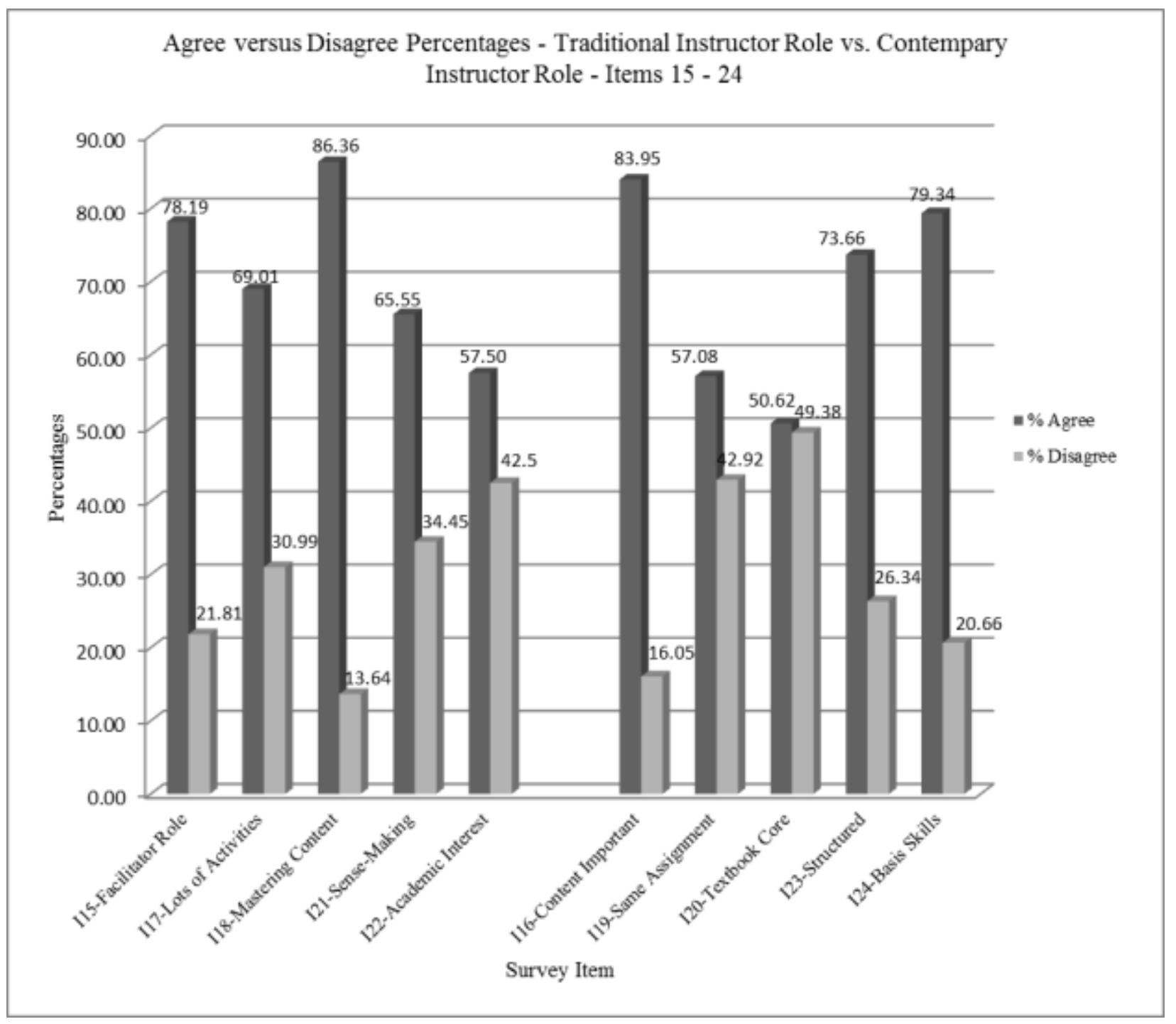

Figure 10. Agree versus disagree percentages - traditional instructor role versus contemporary instructor role - Items 15 - 24

Research Question 4 - Perceptions of Missouri HE Faculty Concerning Millennial Students' Preferred Learning Characteristics

Research Question 4 states “To what degree do Missouri HE faculty perceptions of millennial students' learning characteristics significantly match learning characteristics identified in current research?” Perceptions of Millennials' learning characteristics by Missouri higher education faculty were explored involving survey items 25 through 40 . 
Cross tabulations showing frequency counts and percentages of responses are shown in

Table 14. The highest levels of Strongly Agree (Option 1) were shown for Item 38, indicating respondents believed students "understand individual thinking and how to seek help independently if needed" with 164 responses (67.2\%). Item 32, stating students expect immediate feedback on learning from teachers and peers, received the lowest number of Choice 1 responses (Strongly Agree), disclosing a majority of respondents did not perceive this a Millennial learning preference. When data were analyzed, only $25 \%$ of the respondents $(\mathrm{N}=61)$ chose Option 1 (Strongly Agree). This signifies a majority of Missouri higher education faculty do not agree that millennial students expect immediate feedback, although research indicates this is a Millennial preferred learning styles (Skiba \& Barton, 2006). Data are further delineated in Figure 11 and Table 14.

Table 14

Frequency of Responses - Perceptions of Students' Learning Preferences (RQ4)

\begin{tabular}{|c|c|c|c|c|c|c|c|c|c|}
\hline \multirow[b]{2}{*}{ Variable } & \multicolumn{3}{|c|}{ Strongly Agree-1 } & 2 & \multicolumn{2}{|c|}{3} & \multicolumn{3}{|c|}{ Never - 4} \\
\hline & $\mathrm{n}$ & $\%$ & $\mathrm{n}$ & $\%$ & $\mathrm{n}$ & $\%$ & $\mathrm{n}$ & $\%$ & $\mathrm{~N}$ \\
\hline I25 - Students establish understanding based on individual experiences & 100 & 41.0 & 117 & 48.0 & 23 & 9.4 & 1 & .4 & 244 \\
\hline I26 - Students integrate learning concepts into self-directed projects & 118 & 48.4 & 96 & 39.3 & 23 & 9.4 & 4 & 1.6 & 241 \\
\hline I27 - Students research new concepts/questions further individually & 129 & 52.9 & 81 & 33.2 & 27 & 11.1 & 3 & 1.2 & 240 \\
\hline I28 - Student pursue learning concepts to create individual learning & 108 & 44.3 & 109 & 44.7 & 22 & 9.0 & 0 & .0 & 239 \\
\hline I29 - Students explore a new learning concept independently & 91 & 37.3 & 112 & 45.9 & 31 & 12.7 & 7 & 2.9 & 241 \\
\hline I30 - Students demonstrate methods to realistically solve problems & 134 & 54.9 & 90 & 36.9 & 12 & 4.9 & 4 & 1.6 & 240 \\
\hline I31 - Students connect current practice to individual experiences & 144 & 59.0 & 84 & 34.4 & 10 & 4.1 & 2 & .8 & 240 \\
\hline I32 - Students expect immediate feedback from teachers and peers & 61 & 25.0 & 122 & 50.0 & 51 & 20.9 & 6 & 2.5 & 240 \\
\hline I33 - Students can apply knowledge independently in other contexts & 145 & 59.4 & 81 & 33.2 & 15 & 6.1 & 1 & .4 & 242 \\
\hline I34 - Students explain a learning concept using individual perspectives & 123 & 50.4 & 101 & 41.4 & 18 & 7.4 & 0 & 0.0 & 242 \\
\hline I35 - Students can work in groups to establish individual knowledge & 107 & 43.9 & 94 & 38.5 & 34 & 13.9 & 7 & 2.9 & 242 \\
\hline I36 - Students work in groups to share knowledge; reach agreement & 114 & 46.7 & 93 & 38.1 & 30 & 12.3 & 6 & 2.5 & 243 \\
\hline I37 - Students integrate learning of concepts with other activities & 152 & 62.3 & 70 & 28.7 & 18 & 7.4 & 0 & 0 & 240 \\
\hline I38 - Students understand individual thinking ;seek independent help & 164 & 67.2 & 61 & 25.0 & 14 & 5.7 & 2 & .8 & 241 \\
\hline I39 - Students show mastery of knowledge by various assessments & 63 & 25.8 & 80 & 32.8 & 75 & 30.7 & 22 & 9.0 & 240 \\
\hline I40 - Students relate experiences when explaining learning concepts & 121 & 49.6 & 102 & 41.8 & 16 & 6.6 & 1 & .4 & 240 \\
\hline
\end{tabular}


Figure 11 depicts the number of responses for each choice, one through four. Closer examination shows the highest levels of agreement for Items 38, 37, 33, 31, 30 and 27. This indicated Missouri higher education faculty believe students understand individual thinking (Item 38), integrate learning of concepts with other activities (Item 37), and can apply knowledge independently in other contexts (Item 33). Agreement with Item 31 indicates respondents believe students connect current practice to individual experiences, while Item 30, students demonstrate methods to realistically solve problems and Item 27, students research new concepts/questions further individually, also indicate faculty agree with what is shown by research to be preferred Millennial learning styles (Howe \& Strauss, 2000; Jonas-Dwyer \& Pospisil, 2004; McGlynn, 2005; Nicoletti \& Merriman, 2007; Skiba \& Barton, 2006).

Strong responses (>50\%) of Strongly Agree (Choice 1) or Agree (Choice 2) are shown on all items except Item 39. This indicated that a majority of the respondents agreed with the statements regarding millennial students preferred learning styles. Item 39, indicating students should be able to show mastery of knowledge by self-choosing various means of assessments, such as quizzes, projects, presentations, videos, etc., showed fairly equal levels of agreement or disagreement by respondents, indicating participants were evenly divided on this concept. Depictions of all responses are shown in more detail in Figure 11. 


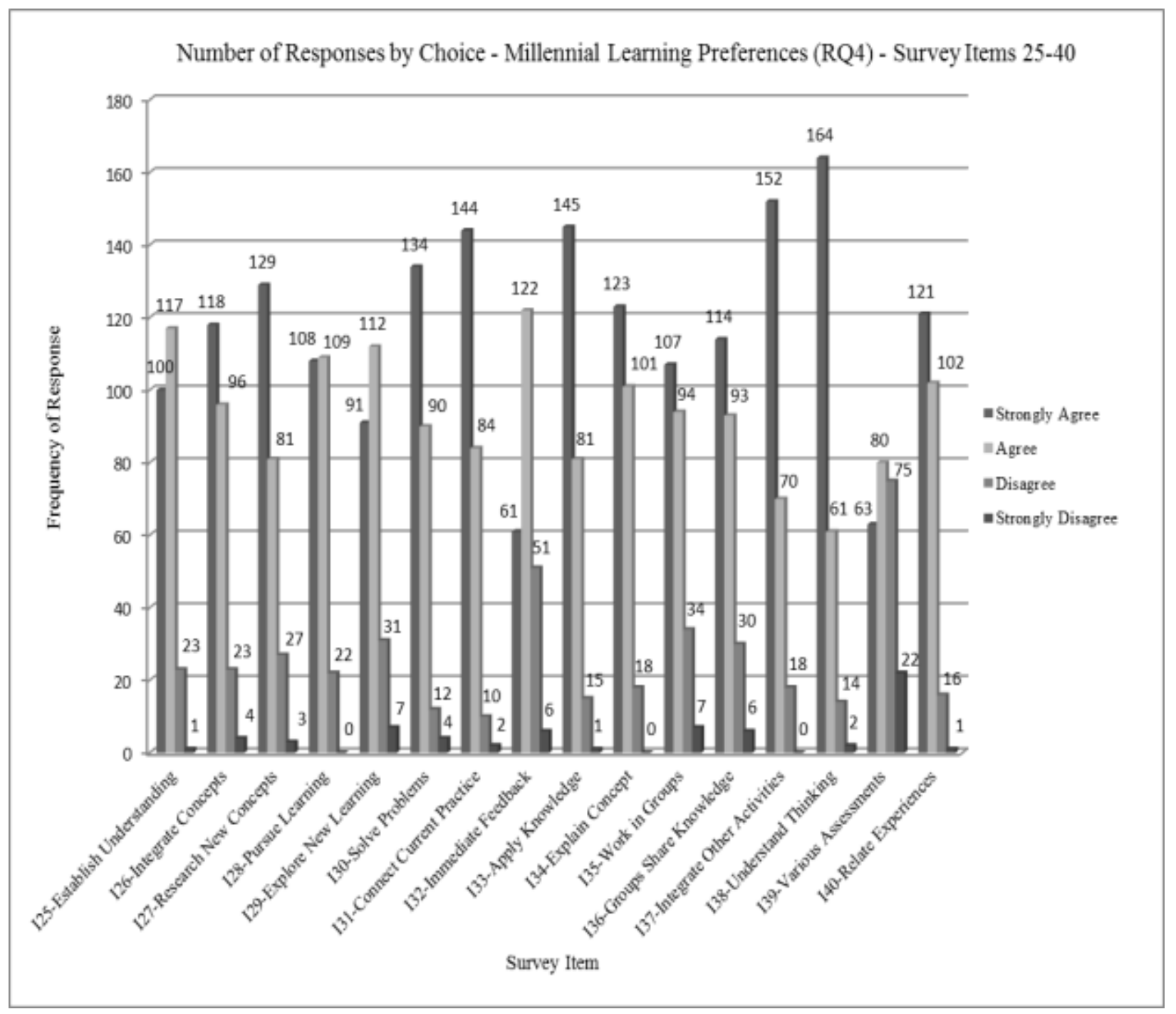

Figure 11. Number of responses by choice - millennial students' learning preferences (RQ4) - items $25-40$

Measures of central tendency and dispersion for responses to items $25-40$, examining Missouri higher education faculty perceptions of millennial students' preferred learning styles, are delineated in Table 15. All of the survey items concerning perceptions of millennials students' learning styles had standard deviations below 1, with the highest standard deviation (0.944) being shown for Item 39, students show mastery of knowledge by self-choosing various assessments. This indicated there was not a wide dispersion in the data for this section of the survey. The variances were also low, with the 
highest variance $(0.891)$ also being shown for item 39. These lower measures of central tendency and dispersion indicated there was close levels of agreement among the respondents for survey items $25-40$.

Table 15

Measures of Central Tendency and Dispersion - Perceptions of Millennial Students' Learning Preferences (RQ4)

\begin{tabular}{lccccc}
\hline \multicolumn{1}{c}{ Variable } & Mean & Median & Mode & SD. & Var. \\
\hline I25 - Students establish understanding based on individual experiences & 1.69 & 2.00 & 2 & .657 & .432 \\
I26 - Students integrate learning concepts into self-directed projects & 1.64 & 2.00 & 1 & .723 & .523 \\
I27 - Students research new concepts/questions further individually & 1.60 & 1.00 & 1 & .736 & .542 \\
I28 - Student pursue learning concepts to create individual learning & 1.64 & 2.00 & 2 & .645 & .416 \\
I29 - Students explore a new learning concept independently & 1.81 & 2.00 & 2 & .767 & .588 \\
I30 - Students demonstrate methods to realistically solve problems & 1.53 & 1.00 & 1 & .672 & .451 \\
I31 - Students connect current practice to individual experiences & 1.46 & 1.00 & 1 & .619 & .383 \\
I32 - Students expect immediate feedback from teachers and peers & 2.01 & 2.00 & 2 & .754 & .569 \\
I33 - Students can apply knowledge independently in other contexts & 1.47 & 1.00 & 1 & .632 & .400 \\
I34 - Students explain a learning concept using individual perspectives & 1.57 & 1.00 & 1 & .629 & .396 \\
I35 - Students can work in groups to establish individual knowledge & 1.76 & 2.00 & 1 & .801 & .642 \\
I36 - Students work in groups to share knowledge; reach agreement & 1.70 & 2.00 & 1 & .778 & .606 \\
I37 - Students integrate learning of concepts with other activities & 1.44 & 1.00 & 1 & .631 & .398 \\
I38 - Students understand individual thinking ;seek independent help & 1.39 & 1.00 & 1 & .638 & .406 \\
I39 - Students show mastery of knowledge by various assessments & 2.23 & 2.00 & 2 & .944 & .891 \\
I40 - Students relate experiences when explaining learning concepts & 1.57 & 1.00 & 1 & .636 & .405 \\
\hline
\end{tabular}

Responses from survey items 25 through 40 pertaining to Research Question 4 were more closely analyzed to examine the agreement (Likert scale choices 1 or 2) versus disagreement (Likert scale choices 3 or 4 ). Both the number of responses and the percentage of the respondents were evaluated. The results are shown in Table 16. The item with the highest level of agreement is Item 31 which examined faculty perceptions concerning students connecting current practices to individual experiences. Responses of Strongly Agree or Agree were given by 228 faculty or $95 \%$ of the respondents. All items 
indicated over a $50 \%$ rate of agreement and all but one item had over a $70 \%$ rate of agreement. Item 39 showed at 59.6\% agreement rate with 143 responses. The data indicated that a majority of Missouri higher education faculty were knowledgeable of or agreed with statements of millennial students' preferred learning styles.

Table 16

Frequency of Responses (Agree vs. Disagree) - Perceptions of Millennial Students' Preferred Learning Styles (RQ4)

\begin{tabular}{lccccc}
\hline \multicolumn{1}{c}{ Variable } & \multicolumn{3}{c}{ Agree } & \multicolumn{3}{c}{ Disagree } \\
& $\mathrm{n}$ & $\%$ & $\mathrm{n}$ & $\%$ & $\mathrm{~N}$ \\
\hline I25 - Students establish understanding based on individual experiences & 217 & 90.0 & 24 & 10.0 & 241 \\
I26 - Students integrate learning concepts into self-directed projects & 214 & 88.8 & 27 & 11.2 & 241 \\
I27 - Students research new concepts/questions further individually & 210 & 87.5 & 30 & 12.5 & 240 \\
I28 - Student pursue learning concepts to create individual learning & 217 & 90.8 & 22 & 9.2 & 239 \\
I29 - Students explore a new learning concept independently & 203 & 84.2 & 38 & 15.8 & 241 \\
I30 - Students demonstrate methods to realistically solve problems & 224 & 93.3 & 16 & 6.7 & 240 \\
I31 - Students connect current practice to individual experiences & 228 & 95.0 & 12 & 5.0 & 240 \\
I32 - Students expect immediate feedback from teachers and peers & 183 & 76.3 & 57 & 23.8 & 240 \\
I33 - Students can apply knowledge independently in other contexts & 226 & 93.4 & 16 & 6.6 & 242 \\
I34 - Students explain a learning concept using individual perspectives & 224 & 92.6 & 18 & 7.4 & 242 \\
I35 - Students can work in groups to establish individual knowledge & 201 & 83.1 & 41 & 16.9 & 242 \\
I36 - Students work in groups to share knowledge; reach agreement & 207 & 85.2 & 36 & 14.8 & 243 \\
I37 - Students integrate learning of concepts with other activities & 222 & 92.5 & 18 & 7.5 & 240 \\
I38 - Students understand individual thinking ;seek independent help & 225 & 93.4 & 16 & 6.6 & 241 \\
I39 - Students show mastery of knowledge by various assessments & 143 & 59.6 & 97 & 40.4 & 240 \\
I40 - Students relate experiences when explaining learning concepts & 223 & 92.9 & 17 & 7.1 & 240 \\
\hline \multicolumn{1}{c}{$*$ n = 244 } & & & & &
\end{tabular}

Figure 12 shows the percentage of responses that agreed versus the number of responses that disagreed concerning survey items 25 - 40 examining Missouri higher education faculty perceptions of millennial students preferred learning styles. The percentages shown by the self-reported responses to these survey items seem to indicate that Missouri higher education faculty are in agreement with the indicators of preferred learning styles of millennial students as shown by current research (Howe \& Strauss, 
2000; Jonas-Dwyer \& Pospisil, 2004; McGlynn, 2005; Nicoletti \& Merriman, 2007;

Skiba \& Barton, 2006). The lowest level of agreement was shown on Item 39 (59.6\%), which addressed millennial students being able to show mastery of course content by self-choosing varied means of assessment. While a majority of the survey respondents agree with this statement, but with a percentage of $59.6 \%$, this item received a sizably lower percentage of agreement than the other survey items, all of which indicated a percentage of agreement over $76 \%$.

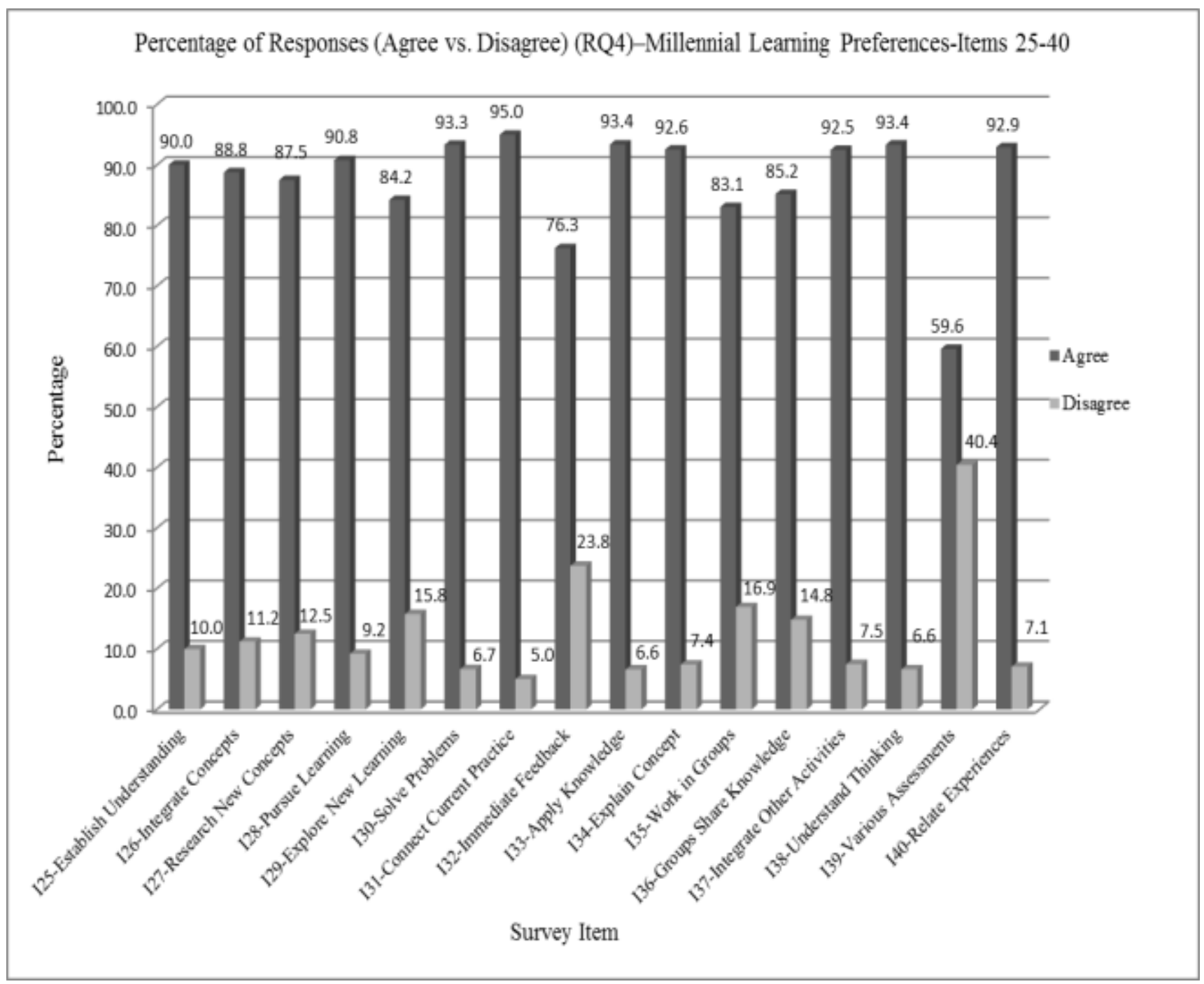

Figure 12. Percentage of responses (agree versus disagree) (RQ4) - millennial students' preferred learning styles - items $25-40$ 


\section{Research Question 5 - Overall Summary Statistics by Demographic}

Research Question 5 states "What are the overall summary statistics broken down by demographic?" This question explored the demographics of the survey participants and involved survey questions one through six. Cross tabulations showing frequency counts and percentages of responses are for each demographic were examined. Cross tabulations listing the number of participants' responses and the percentage for each of the six demographic items are shown in Table 17.

As illustrated in Table 17, when Item 1, type of higher education institution, was examined, the largest numbers of respondents were from 4-year public higher education institutions with 157 respondents or $64.3 \%$ reporting that demographic. The 2-year and 4year private institutions were similar in numbers with 45 or $18.4 \%$ of the respondents asserting they were from 2-year higher education institutions and 42 or $17.2 \%$ survey participants affirming 4-year private as their type of higher education institution.

Carnegie size classification was the next demographic investigated. The researcher chose this classification as Carnegie has been the "leading framework for recognizing and describing institutional diversity in U.S. higher education for the past four decades" (Carnegie, 2013). The Carnegie Commission on Higher Education developed a classification system of colleges and universities in 1970, based on the type of institution (2-year or 4-year) and full-time enrollment (Carnegie, 2013). This framework is "widely used in the study of higher education, both as a way to represent and control for institutional differences, and also in the design of research studies to ensure adequate representation of sampled institutions, students, or faculty" (Carnegie, 2013). 
Carnegie size classification was determined for each institution by pairing the type of institution and the reported full-time enrollment for each respondent. When survey responses were examined by the Carnegie size classification of participants' higher education institution, the data showed that a majority of survey respondents were from medium 4-year institutions (44.44\%). When examining the data from SPSS for this demographic, the smallest group of respondents were from very large 2-year institutions, reporting $1.23 \%$, closely followed by very small 2 -year institutions (1.65\%) and large 2year $(2.06 \%)$. None of the respondents reported the demographic of small 4- year institution as categorized by the Carnegie size classification.

Examination by department showed a fairly equal distribution among the 12 departmental divisions. The department grouping showing the most responses was Computer Science, Math, Physics and Engineering with 32 or 14.04\% of the participants reporting this demographic. Reporting statistics close to that of the Computer Science, Math, Physics and Engineering department grouping was Education with 31 respondents or $13.60 \%$. The Nursing/Health and Science (Biology, Chemistry and Agriculture) department respondents were also similar with 27 responses (11.84\%) and 26 responses $(11.40 \%)$ respectively. The department grouping showing the lowest number of responses was Political Science, History and Geography with eight or $3.51 \%$ of the participant indicating this demographic.

As further revealed in Table 17, the largest number of respondents had the rank of Full Professor ( $\mathrm{N}=64$ or 26.2\%) with Assistant Professor and Associate Professor close behind reporting 52 responses or $21.94 \%$ and 50 responses or $21.10 \%$ respectively. Instructor rank was also fairly similar and had 46 responses or $19.41 \%$. Adjunct was the 
lowest reported rank showing a $10.55 \%$ response rate with a total of 25 responses. This showed a fairly evenly distributed return rate among all of the respondents' ranks.

When survey responses were disaggregated by gender, the data revealed 141 female respondents or $58.26 \%$ of the 242 participants and 101 male respondents or $41.74 \%$ of the 242 participants. Examination of the age range demographic showed 157 or $64.3 \%$ of the respondents reported an age range of $31-50$. The under 30 and over 50 age ranges reported similar statistics with 45 or $18.4 \%$ and 42 or $17.2 \%$ of the respondents showing these demographics respectively. The age range demographic showed the most disproportionate number and percentage of responses from participants. Demographic frequencies and percentages for all respondents are shown in more detail in Table 17. 
Table 17

Frequency and Percentages of Responses - Independent Variables (Demographic)-(RQ5)

\begin{tabular}{|c|c|c|c|}
\hline Independent Variable & Response & $\mathrm{N}$ & $\%$ \\
\hline \multirow[t]{4}{*}{ Type of Institution } & 2-Year & 45 & 18.44 \\
\hline & 4-Year Public & 157 & 64.34 \\
\hline & 4-Year Private & 42 & 17.21 \\
\hline & Total N & 244 & \\
\hline \multirow[t]{9}{*}{ Carnegie Size Classification } & Very Small 2-Year & 4 & 1.65 \\
\hline & Small 2-Year & 13 & 5.35 \\
\hline & Medium 2-Year & 23 & 9.47 \\
\hline & Large 2-Year & 5 & 2.06 \\
\hline & Very Large 2-Year & 3 & 1.23 \\
\hline & Very Small 4-Year & 30 & 12.35 \\
\hline & Medium 4-Year & 108 & 44.44 \\
\hline & Large 4-Year & 57 & 23.46 \\
\hline & Total N & 243 & \\
\hline \multirow[t]{13}{*}{ Department } & Business/Economics & 15 & 6.58 \\
\hline & Com. Studies/Speech & 12 & 5.26 \\
\hline & Cr Just, Soc. Sc/Hum, Behav Sc & 16 & 7.02 \\
\hline & CS, Math, Physics, Engineering & 32 & 14.04 \\
\hline & Education & 31 & 13.60 \\
\hline & English/Foreign Lang/Reading & 20 & 8.77 \\
\hline & Fine Arts (Theater, Mus, Film)/Art & 18 & 7.89 \\
\hline & Nursing/Health & 27 & 11.84 \\
\hline & Political Science/History/Geo & 8 & 3.51 \\
\hline & Psychology/Sociology/Social Work & 10 & 4.39 \\
\hline & Science (Bio, Chem, Agric) & 26 & 11.40 \\
\hline & Other & 13 & 5.70 \\
\hline & Total N & 228 & \\
\hline \multirow[t]{6}{*}{ Rank } & Adjunct & 25 & 10.55 \\
\hline & Instructor & 46 & 19.41 \\
\hline & Assistant Professor & 52 & 21.94 \\
\hline & Associate Professor & 50 & 21.10 \\
\hline & Full Professor & 64 & 27.00 \\
\hline & Total N & 237 & \\
\hline \multirow[t]{3}{*}{ Gender } & Male & 101 & 41.74 \\
\hline & Female & 141 & 58.26 \\
\hline & Total N & 242 & \\
\hline \multirow[t]{4}{*}{ Age Range } & Under 30 & 45 & 18.4 \\
\hline & $31-50$ & 157 & 64.3 \\
\hline & Over 50 & 42 & 17.2 \\
\hline & Total N & 244 & \\
\hline
\end{tabular}


Research Question 5 was further delineated in five sub-questions. Research Question 5.1 stated "What are the significant differences of responses among the different types of Missouri higher education institutions (2-year, 4-year public and 4-year private) as determined by frequency counts and percentages?" Frequency and percentage of responses from survey items 7-14 concerning technology-enhanced instructional practices are shown in Table 18. The data for 2-year institutions showed the highest level of agreement for Item 8 pertaining to utilization of technology-based tools (i.e. Internet, PowerPoint, etc.) to support teaching activities. Item 8 showed $97.78 \%$ or 44 of the 45 responses, indicating that almost all of the respondents from 2-year institutions employed this particular technology-enhanced instruction. Among the 4-year public institutions, Item 10 exhibited the highest agreement with 151 or $96.79 \%$ of the respondents indicating utilization of using technology means to communicate with students. Responses from all three types of institutions showed that a vast majority of Missouri higher education faculty do use technology to support classroom activities.

The 4-year private institutions reported the highest utilization for two items, Item 7, pertaining to teaching in a technology-enabled classroom environment and Item 10, pertaining to using e-mail or other technology means to communicate with students. Both of these items reported 41 respondents utilizing these technology-enhanced instruction tools for a $97.62 \%$ for both items. The lowest item among the showing agreement responses for all types of institutions was Item 13 which pertained to using technologyenhanced methods such as Skype and WebMeeting to utilize guest speakers. This item documented only five responses or $11.11 \%$ from the 2-year institutions, 16 responses or $10.32 \%$ for the 4 -year public institutions and 2 responses or $4.76 \%$ of the 4 -year private 
institutions. Item 12, using smart or wireless devices (iPhone, Android, iPods, tablets, etc.) to conduct lessons or disperse course materials, was the item with lowest agreement ratings reporting 15 responses or $33.33 \%$ for 2 -year institutions, 33 responses or $21.02 \%$ for 4 -year public institutions and 11 responses or $26.19 \%$ for 4 -year private institutions. Responses indicating agreement versus disagreement for Items 7-14, examining technology-enhanced instructional methods, disaggregated by type of institutions (2-year, 4-year public and 4-year private) and the total number of responses for each item are shown in Table 18.

Table 18

Frequency of Responses (Agree vs. Disagree) - Technology-Enhanced Instructional Practices (RQ5.1) - Disaggregated by Type of Institution

\begin{tabular}{|c|c|c|c|c|c|c|c|c|c|c|c|c|}
\hline \multirow[b]{3}{*}{ Variable } & \multicolumn{4}{|c|}{2 - Year } & \multicolumn{3}{|c|}{$4-$ Year Public } & \multicolumn{5}{|c|}{$4-$ Year Private } \\
\hline & \multicolumn{2}{|c|}{ Agree } & \multicolumn{2}{|c|}{ Disagree } & Agree & \multicolumn{2}{|c|}{ Disagree } & \multicolumn{5}{|c|}{ Agree Disagree } \\
\hline & $\mathrm{n}$ & $\%$ & $\mathrm{n}$ & $\%$ & $\%$ & $\mathrm{n}$ & $\%$ & & & & $\%$ & $\mathrm{~N}$ \\
\hline I7 - Technology-enabled classroom environment & 43 & 95.56 & 2 & 4.44 & 14391.08 & 14 & 8.92 & 41 & 97.62 & 1 & 2.38 & 244 \\
\hline $\begin{array}{l}\text { I8 - Use technology-based tools to support } \\
\text { instruction }\end{array}$ & 44 & 97.78 & 1 & 2.22 & 14894.27 & 9 & 5.73 & 37 & 88.10 & 5 & 11.90 & 244 \\
\hline $\begin{array}{l}\text { I9 - Use video-based instruction to support } \\
\text { activities }\end{array}$ & 31 & 68.89 & 14 & 31.11 & 9963.06 & 58 & 36.94 & 28 & 66.67 & 14 & 33.33 & 244 \\
\hline $\begin{array}{l}\text { I10 - Use technology means to communicate w/ } \\
\text { students }\end{array}$ & 42 & 93.33 & 3 & 6.67 & 15196.79 & 5 & 3.21 & 41 & 97.62 & 1 & 2.38 & 243 \\
\hline $\begin{array}{l}\text { I1 } 1 \text { - Encourage student communication using } \\
\text { technology }\end{array}$ & 28 & 62.22 & 17 & 37.78 & 7950.64 & 77 & 49.36 & 21 & 50.00 & 21 & 50.00 & 243 \\
\hline $\begin{array}{l}\text { I12 - Use smart or wireless devices to conduct } \\
\text { lessons/materials }\end{array}$ & 15 & 33.33 & 30 & 66.67 & $33 \quad 21.02$ & 124 & 78.98 & 11 & 26.19 & 31 & 73.81 & 244 \\
\hline $\begin{array}{l}\text { I13 - Use of guest speakers via technology- } \\
\text { driven means }\end{array}$ & 5 & 11.11 & 40 & 88.89 & $16 \quad 10.32$ & 139 & 89.68 & 2 & 4.76 & 40 & 95.24 & 242 \\
\hline $\begin{array}{l}\text { I14 - Students use web-based tools to complete } \\
\text { assignments }\end{array}$ & 38 & 84.44 & 7 & 15.56 & 11271.34 & 45 & 28.66 & 32 & 76.19 & 10 & 23.81 & 244 \\
\hline
\end{tabular}

Chi-Square analysis was also completed, checking for relationship of technologyenhanced instructional practices to the type of higher education institution (2-year, 4-year public and 4-year private). Table 19 delineates the results. When Chi-square distribution tables were examined, (Field, 2005; Fraenkel \& Wallen, 2006) it was shown at a 0.05 
level of significance (p) and 6 degrees of freedom (df) as specified for these items by SPSS, a Chi-square $\left(\mathrm{X}^{2}\right)$ value of 12.59 is needed to show a relationship between the type of institution demographic and the survey item. When the data were analyzed, all significance levels (p) were greater than 0.05 although the Chi-square values were lower than 12.59. This indicated that the null hypothesis for this research question could not be rejected, thus indicating no significant relationship between the individual survey items and the type of higher education could be established.

Table 19

Chi-square Analysis Results for Type of Institution and Items 7-14 - (RQ5.1)

\begin{tabular}{lccc}
\hline \multicolumn{1}{c}{ Item } & $\mathrm{X}^{2}$ & $\mathrm{df}$ & $\mathrm{p}$ \\
\hline I7 - Technology-enabled classroom environment & 3.730 & 6 & .713 \\
I8 - Use technology-based tools to support instruction & 5.676 & 6 & .460 \\
I9 - Use video-based instruction to support activities & 4.842 & 6 & .564 \\
I10 - Use technology means to communicate w/ students & 4.292 & 6 & .637 \\
I11 - Encourage student communication using technology & 5.056 & 6 & .537 \\
I12 - Use smart or wireless devices to conduct lessons/materials & 6.940 & 6 & .326 \\
I13 - Use of guest speakers via technology-driven means & 6.923 & 6 & .328 \\
I14 - Students use web-based tools to complete assignments & 4.327 & 6 & .633 \\
\hline
\end{tabular}

When responses for survey items 15-24, examining faculty perceptions of instructor role, were disaggregated, there appeared to be little difference in responses by type of institution (2-year, 4-year public and 4-year private). The highest level of agreement when examining responses from 2-year institutions included two items, Item 16 and Item 24. The instructor roles referred to in these items were the most important part of instruction is the content of the curriculum or what students need to know and be able to do (Item 16) and students must learn basic skills before they can master complex content (Item 24), both more traditional instructor roles. The responses for both items indicated 39 or $86.67 \%$. 
When data reported for 4-year public institutions were examined, it was shown the item indicating the lowest percentage of agreement was Item 18, stating students can learn basic skills in the context of mastering complex content. Agreement to this statement was shown by 139 respondents resulting in $89.68 \%$ of the total responses for 4 year public institutions. The data for 4-year private institutions also showed the highest agreement rating for Item 18 with 35 respondents or $83.33 \%$ agreeing with the statement. The statement receiving the lowest agreement responses for 2-year institutions was Item 22 , it is critical for students to become interested in doing academic work-interest and efforts are more important than the particular subject matter they are working on. This item showed agreement of 23 of the responses or $51.11 \%$. The 4-year public and 4-year private institutions both showed the lowest agreement rating for Item 20 stating while student motivation is important, it should not drive what students study as the core content in textbooks is most important. This item received a $49.68 \%$ (4-year public) and $39.02 \%$ (4-year private) agreement rating. Frequencies and percentages for all responses for Items $15-24$, disaggregated by type of institution are shown in Table 20 . 
Table 20

Frequency of Responses (Agree vs. Disagree) - Perception of Instructional Role (RQ5.1)

- Disaggregated by Type of Institution

\begin{tabular}{|c|c|c|c|c|c|c|c|c|c|c|c|c|c|}
\hline \multirow[b]{3}{*}{ Variable } & \multicolumn{4}{|c|}{2 - Year } & \multicolumn{4}{|c|}{4 - Year Public } & \multicolumn{5}{|c|}{4 - Year Private } \\
\hline & \multicolumn{2}{|c|}{ Agree } & \multicolumn{2}{|c|}{ Disagree } & \multicolumn{2}{|c|}{ Agree } & \multicolumn{2}{|c|}{ Disagree } & \multicolumn{2}{|c|}{ Agree } & \multicolumn{3}{|c|}{ Disagree } \\
\hline & $\mathrm{n}$ & $\%$ & $\mathrm{n}$ & $\%$ & $\mathrm{n}$ & $\%$ & $\mathrm{n}$ & $\%$ & $\mathrm{n}$ & $\%$ & $\mathrm{n}$ & $\%$ & $\mathrm{~N}$ \\
\hline $\begin{array}{l}\text { I15 - Role of facilitator; students construct knoy } \\
\text { for selves }\end{array}$ & 33 & 73.33 & 12 & 26.67 & 123 & 78.85 & 33 & 21.15 & 34 & 80.95 & 8 & 19.05 & 243 \\
\hline $\begin{array}{l}\text { I16 - Most important part of instruction is the } \\
\text { content/curriculum }\end{array}$ & 39 & 86.67 & 6 & 13.33 & 135 & 86.54 & 21 & 13.46 & 30 & 71.43 & 12 & 28.57 & 243 \\
\hline I17 - All sorts of activities going on in the classroom & 31 & 68.89 & 14 & 31.11 & 111 & 71.15 & 45 & 28.85 & 25 & 60.98 & 16 & 39.02 & 242 \\
\hline $\begin{array}{l}\text { I18 - Students learn basic skills in context of mastering } \\
\text { content }\end{array}$ & 35 & 77.78 & 10 & 22.22 & 139 & 89.68 & 16 & 10.32 & 35 & 83.33 & 7 & 16.67 & 242 \\
\hline $\begin{array}{l}\text { I19 - Better to give the whole class same assignment- } \\
\text { small intervals }\end{array}$ & 29 & 64.44 & 16 & 35.56 & 88 & 57.52 & 65 & 42.48 & 20 & 47.62 & 22 & 52.38 & 240 \\
\hline $\begin{array}{l}\text { I20 - Textbook core content is more important-not } \\
\text { student motivation }\end{array}$ & 29 & 64.44 & 16 & 35.56 & 77 & 49.68 & 78 & 50.32 & 16 & 39.02 & 25 & 60.98 & 241 \\
\hline $\begin{array}{l}\text { I21 - Most important instruction encourages "sense- } \\
\text { making"/thinking }\end{array}$ & 31 & 68.89 & 14 & 31.11 & 102 & 66.67 & 51 & 33.33 & 23 & 57.50 & 17 & 42.50 & 238 \\
\hline $\begin{array}{l}\text { I22 - Critical for students to become interested in } \\
\text { doing academic work }\end{array}$ & 23 & 51.11 & 22 & 48.89 & 88 & 57.14 & 66 & 42.86 & 27 & 65.85 & 14 & 34.15 & 240 \\
\hline $\begin{array}{l}\text { I } 23 \text { - Material must be covered in a structured way; job } \\
\text { to explain }\end{array}$ & 35 & 77.78 & 10 & 22.22 & 116 & 74.36 & 40 & 25.64 & 28 & 66.67 & 14 & 33.33 & 243 \\
\hline $\begin{array}{l}\text { I24 - Students learn basic skills before mastering } \\
\text { complex content }\end{array}$ & 39 & 86.67 & 6 & 13.33 & 127 & 81.41 & 29 & 18.59 & 26 & 63.41 & 15 & 36.59 & 242 \\
\hline
\end{tabular}

Chi-Square analysis was next completed, checking for relationship of perceptions of instructional role to type of higher education institution (2-year, 4-year public and 4year private). When Chi-square distribution tables were examined, (Field, 2005; Fraenkel $\&$ Wallen, 2006) it was shown at a 0.05 level of significance (p), using 6 degrees of freedom (df) as specified by SPSS, a Chi-square $\left(\mathrm{X}^{2}\right)$ value of 12.59 is needed to show relationships between the type of institution demographic and individual survey item. When the data were analyzed, nine of the ten items has significance levels (p), greater than 0.05 although Chi-square values were lower than 12.59 . Item 16 did have a significance level below 0.05 , showing 0.02 , but when the Chi-square value was more closely examined it was greater than 12.59 (15.025). Therefore, it was determined a relationship was not shown among these items and type of institution demographic. Thus, 
the null hypothesis for this research question could not be rejected. Results details are shown in Table 21.

Table 21

Chi-square Analysis Results for Type of Institution and Items 15 - 24 - (RQ5.1)

\begin{tabular}{lrrr}
\hline \multicolumn{1}{c}{ Item } & \multicolumn{1}{c}{$\mathrm{X}^{2}$} & $\mathrm{df}$ & $\mathrm{p}$ \\
\hline I15 - Role of facilitator; students construct knowledge for selves & 2.673 & 6 & .849 \\
I16 - Most important part of instruction is the content/curriculum & 15.025 & 6 & .020 \\
I17 - All sorts of activities going on in the classroom & 2.524 & 6 & .866 \\
I18 - Students learn basic skills in context of mastering content & 5.809 & 6 & .445 \\
I19 - Better to give the whole class same assignment-small intervals & 4.610 & 6 & .595 \\
I20 - Textbook core content is more important-not student motivation & 8.703 & 6 & .191 \\
I21 - Most important instruction encourages "sense-making"/thinking & 8.638 & 6 & .195 \\
I22 - Critical for students to become interested in doing academic work & 2.604 & 6 & .857 \\
I23 - Material must be covered in a structured way; job to explain & 4.395 & 6 & .623 \\
I24 - Students learn basic skills before mastering complex content & 11.320 & 6 & .079 \\
\hline
\end{tabular}

Data pertaining to perceptions of preferred student learning styles (Items 25-40) were examined and delineated in Table 22. When data were analyzed, there was a high level of agreement among respondents from 2-year institutions. Of the 16 items, 15 showed an agreement rating above $80 \%$. The only item with an agreement rating less than $80 \%$ was Item 39 , students show mastery of knowledge by self-choosing various means of assessment (quizzes, projects, presentations, videos, etc.). A 62.22\% agreement was shown, still indicating that a strong majority of respondents agreed with this statement. Similar circumstances were discovered when data for 4-year public and private institutions were examined. These two types of institutions showed a lower rating for Item 39, reporting a 59.09\% (4-year public) and 58.54\% (4-year private) agreement rating. Data for 4-year public institutions also showed agreement percentages above $80 \%$ for 14 of the 16 items. Item 39, which was already discussed, and Item 32, students 
expect immediate feedback on learning from instructor and peers, showed a $75.32 \%$

$(\mathrm{N}=116)$ agreement rating. Data for 4-year private institutions showed lower agreement

ratings for Item 39 and Item 32, both discussed previously, revealing 28 responses for a

$68.29 \%$ agreement rating.

Table 22

Frequency of Responses (Agree vs. Disagree) - Perception of Millennial Students'

Preferred Learning Styles (RQ5.1) - Disaggregated by Type of Institution

\begin{tabular}{|c|c|c|c|c|c|c|c|c|c|c|c|c|c|}
\hline \multirow[b]{3}{*}{ Variable } & \multicolumn{4}{|c|}{$2-$ Year } & \multicolumn{5}{|c|}{$4-$ Year Public } & \multicolumn{4}{|c|}{$4-$ Year Private } \\
\hline & \multicolumn{2}{|c|}{ Agree } & \multicolumn{2}{|c|}{ Disagree } & \multicolumn{3}{|c|}{ Agree } & \multicolumn{2}{|c|}{ Disagree } & \multicolumn{2}{|c|}{ Agree } & \multicolumn{2}{|c|}{ Disagree } \\
\hline & $\mathrm{n}$ & $\%$ & $\mathrm{n}$ & $\%$ & $\mathrm{n}$ & $\%$ & $\mathrm{n}$ & $\%$ & $\mathrm{n}$ & $\%$ & $\mathrm{n}$ & $\%$ & $\mathrm{~N}$ \\
\hline $\begin{array}{l}\text { I25 - Students establish understanding based on } \\
\text { individual experiences }\end{array}$ & 41 & 91.11 & 4 & 8.89 & 138 & 89.03 & 17 & 10.97 & 38 & 92.68 & 3 & 7.32 & 241 \\
\hline $\begin{array}{l}\text { I26 - Students integrate learning concepts into self- } \\
\text { directed projects }\end{array}$ & 40 & 88.89 & 5 & 11.11 & 137 & 88.39 & 18 & 11.61 & 37 & 90.24 & 4 & 9.76 & 241 \\
\hline $\begin{array}{l}\text { I } 27 \text { - Students research new concepts/questions } \\
\text { further individually }\end{array}$ & 40 & 88.89 & 5 & 11.11 & 133 & 86.36 & 21 & 13.64 & 37 & 90.24 & 4 & 9.76 & 240 \\
\hline $\begin{array}{l}\text { I28 - Student pursue learning concepts to create } \\
\text { individual learning }\end{array}$ & 39 & 86.67 & 6 & 13.33 & 140 & 91.50 & 13 & 8.50 & 38 & 92.68 & 3 & 7.32 & 239 \\
\hline $\begin{array}{l}\text { I } 29 \text { - Students explore a new learning concept } \\
\text { independently }\end{array}$ & 38 & 84.44 & 7 & 15.56 & 131 & 84.52 & 24 & 15.48 & 34 & 82.93 & 7 & 17.07 & 241 \\
\hline $\begin{array}{l}\text { I30 - Students demonstrate methods to realistically } \\
\text { solve problems }\end{array}$ & 41 & 93.18 & 3 & 6.82 & 145 & 93.55 & 10 & 6.45 & 38 & 92.68 & 3 & 7.32 & 240 \\
\hline $\begin{array}{l}\text { I31 - Students connect current practice to individual } \\
\text { experiences }\end{array}$ & 42 & 93.33 & 3 & 6.67 & 148 & 95.48 & 7 & 4.52 & 38 & 95.00 & 2 & 5.00 & 240 \\
\hline $\begin{array}{l}\text { I32 - Students expect immediate feedback from } \\
\text { teachers and peers }\end{array}$ & 39 & 86.67 & 6 & 13.33 & 116 & 75.32 & 38 & 24.68 & 28 & 68.29 & 13 & 31.71 & 240 \\
\hline $\begin{array}{l}\text { I33 - Students can apply knowledge independently } \\
\text { in other contexts }\end{array}$ & 44 & 97.78 & 1 & 2.22 & 143 & 91.67 & 13 & 8.33 & 39 & 95.12 & 2 & 4.88 & 242 \\
\hline $\begin{array}{l}\text { I34 - Students explain a learning concept using } \\
\text { individual perspectives }\end{array}$ & 43 & 95.56 & 2 & 4.44 & 143 & 92.26 & 12 & 7.74 & 38 & 90.48 & 4 & 9.52 & 242 \\
\hline $\begin{array}{l}\text { I35 - Students can work in groups to establish } \\
\text { individual knowledge }\end{array}$ & 41 & 91.11 & 4 & 8.89 & 129 & 82.69 & 27 & 17.31 & 31 & 75.61 & 10 & 24.39 & 242 \\
\hline $\begin{array}{l}\text { I36 - Students work in groups to share knowledge; } \\
\text { reach agreement }\end{array}$ & 42 & 93.33 & 3 & 6.67 & 132 & 84.62 & 24 & 15.38 & 33 & 78.57 & 9 & 21.43 & 3243 \\
\hline $\begin{array}{l}\text { I37 - Students integrate learning of concepts with } \\
\text { other activities }\end{array}$ & 43 & 97.73 & 1 & 2.27 & 141 & 90.97 & 14 & 9.03 & 38 & 92.68 & 3 & 7.32 & 240 \\
\hline $\begin{array}{l}\text { I38 - Students understand individual thinking ;seek } \\
\text { independent help }\end{array}$ & 43 & 95.56 & 2 & 4.44 & 143 & 92.26 & 12 & 7.74 & 39 & 95.12 & 2 & 4.88 & 241 \\
\hline $\begin{array}{l}\text { I39 - Students show mastery of knowledge by } \\
\text { various assessments }\end{array}$ & 28 & 62.22 & 17 & 37.78 & 91 & 59.09 & 63 & 40.91 & 24 & 58.54 & 17 & 41.46 & 5240 \\
\hline $\begin{array}{l}\text { I } 40 \text { - Students relate experiences when explaining } \\
\text { learning concepts }\end{array}$ & 43 & 95.56 & 2 & 4.44 & 145 & 93.55 & 10 & 6.45 & 35 & 87.50 & 5 & 12.50 & 240 \\
\hline
\end{tabular}

$*_{n}=244$

Chi-Square analysis was also completed, checking for relationship of perceptions

of instructional role to type of higher education institution (2-year, 4-year public and 4- 
year private). Chi-square distribution tables (Field, 2005; Fraenkel \& Wallen, 2006)

indicate at a 0.05 level of significance (p) using 6 degrees of freedom (df) as specified for 13 of these items by SPSS, a Chi-square $\left(X^{2}\right)$ value of 12.59 is needed to show a relationship between the type of institution demographic and the survey item. Three items have 4 degrees of freedom. Chi-square distribution tables indicate at 4 degrees of freedom, when applying a 0.05 significance level, the value should be below 9.49. The data showed all but one of the survey items reported significance levels (p), greater than 0.05. Item 32, students expect immediate feedback from instructors and peers, showed a p-value of 0.015, but the Chi-square value was 15.712, greater than 9.49. Therefore, it was determined a relationship was not shown among these items and the type of institution demographic and the null hypothesis could not be rejected. Table 23 details the results.

Table 23

Chi-square Analysis Results for Type of Institution and Items 25 - 40 - (RQ5.1)

\begin{tabular}{lccc}
\hline Item & $\mathrm{X}^{2}$ & $\mathrm{df}$ & $\mathrm{p}$ \\
\hline I25 - Students establish understanding based on individual experiences & 8.090 & 6 & .232 \\
I26 - Students integrate learning concepts into self-directed projects & 5.467 & 6 & .486 \\
I27 - Students research new concepts/questions further individually & 1.895 & 6 & .929 \\
I28 - Student pursue learning concepts to create individual learning & 1.909 & 4 & .752 \\
I29 - Students explore a new learning concept independently & 3.892 & 6 & .691 \\
I30 - Students demonstrate methods to realistically solve problems & 4.497 & 6 & .610 \\
I31 - Students connect current practice to individual experiences & 4.620 & 6 & .593 \\
I32 - Students expect immediate feedback from teachers and peers & 15.712 & 6 & .015 \\
I33 - Students can apply knowledge independently in other contexts & 2.703 & 6 & .845 \\
I34 - Students explain a learning concept using individual perspectives & 3.408 & 4 & .492 \\
I35 - Students can work in groups to establish individual knowledge & 6.129 & 6 & .409 \\
I36 - Students work in groups to share knowledge; reach agreement & 7.436 & 6 & .282 \\
I37 - Students integrate learning of concepts with other activities & 3.421 & 4 & .490 \\
I38 - Students understand individual thinking ;seek independent help & 1.877 & 6 & .931 \\
I39 - Students show mastery of knowledge by various assessments & 1.953 & 6 & .924 \\
I40 - Students relate experiences when explaining learning concepts & 5.376 & 6 & .497 \\
\hline
\end{tabular}


Research question 5.2 stated "What are the significant differences of responses among the various size institutions based on Carnegie Size Classifications (Item 2) (Very small 2-year (<500 FTE student enrollment), small 2-year (500-1,999 FTE student enrollment), medium 2-year (2,000-4,999 FTE student enrollment), large 2-year (5,0009,999 FTE student enrollment), very large 2-year (10,000 or more FTE student enrollment), very small 4-year ( $<1,000$ FTE student enrollment), small 4-year $(1,000-$ 2,999 FTE student enrollment), medium 4-year (3,000-9,999 FTE student enrollment), and Large 4-year (10,000 or more FTE student enrollment) as determined by frequency counts and percentages and Chi square analysis?" The analysis of data for this question was completed and results reported.

When data were extracted from SPSS, it was shown no survey respondents were from very large 2-year institutions, thus data reported did not include information pertaining to this category of the Carnegie Size Classification. Further analysis of data pertaining to technology-enhanced instruction, Items $7-14$, indicated all respondents, disaggregated by Carnegie size classifications, showed strong agreement with Item 7 , Item 8 and Item 10 with response percentages above 70\%, indicating a large majority of the institutions employed these technology-enhanced instructional practices. Item 14, students using web-based tools to complete assignments, showed agreement by a majority of the respondents with only small 2-year institutions and large 4-year institutions showing an agreement rating below $70 \%$ with a $69.23 \%$ and $68.42 \%$ agreement rating respectively, indicating a large majority of the institutions did employ these technology-enhanced instructional practices. 
Item 9, using video-based instruction to support classroom activities, showed agreement ratings above $70 \%$ by only two of the categories of institutions, very small 2year institutions (100\%) and very small 4-year institutions (100\%). The remaining six categories of institutions had an agreement rating of below 70\%. Item 11, encouraging student communication using some type of technology-based tool (blog, wiki, and threaded discussion) showed agreement ratings of over $70 \%$ by only one category of the institutions, very small 2-year which reported a $75 \%$ agreement rating. Item 12 , using smart or wireless devices to conduct lessons and disseminate course materials, also showed an agreement rating above $70 \%$ by only one category of the institutions, very small 4-year which indicated a $100 \%$ agreement rating.

Analysis of data, disaggregated by Carnegie Size Classification, indicated all eight reported categories of institutions reported agreement percentages of below $70 \%$ for Item 13, reporting utilization of guest speakers via technology driven means such as Skype or WebMeeting. The highest agreement rating for this item was 33.3\%, reported by very small 4 -year institutions, followed by a $25 \%$ agreement rating for very small 2 year institutions. Data for Items 7-14, pertaining to the utilization of technologyenhanced instructional practices, disaggregated by Carnegie Size Classification, are further delineated in Table 24 located in Appendix I.

Chi-Square analysis was also completed, checking for relationship of technologyenhanced instructional practices to size of institution, based on Carnegie Size Classification. Table 25 delineates the results. When Chi-square distribution tables were examined, (Field, 2005; Fraenkel \& Wallen, 2006) it was shown at a 0.05 level of significance (p) and 21 degrees of freedom (df) as specified for these items by SPSS, a 
Chi-square $\left(\mathrm{X}^{2}\right)$ value of 32.67 is needed to show a relationship between the type of institution demographic and the survey item. When the data were analyzed, no relationship was shown as all significance levels (p), were greater than 0.05 even though the Chi-square values were well below 32.67. This indicates there is no relationship between these variables and the null hypothesis should be accepted.

Table 25

Chi-square Analysis Results for Size of Institution and Items 7 - 14 - (RQ5.2)

\begin{tabular}{lccc}
\hline \multicolumn{1}{c}{ Item } & $\mathrm{X} 2$ & $\mathrm{df}$ & $\mathrm{p}$ \\
\hline I7 - Technology-enabled classroom environment & 10.716 & 21 & .968 \\
I8 - Use technology-based tools to support instruction & 18.158 & 21 & .639 \\
I9 - Use video-based instruction to support activities & 16.731 & 21 & .727 \\
I10 - Use technology means to communicate w/ students & 18.190 & 21 & .637 \\
I11 - Encourage student communication using technology & 12.614 & 21 & .922 \\
I12 - Use smart or wireless devices to conduct lessons/materials & 26.435 & 21 & .190 \\
I13 - Use of guest speakers via technology-driven means & 22.208 & 21 & .388 \\
I14 - Students use web-based tools to complete assignments & 22.214 & 21 & .387 \\
\hline
\end{tabular}

Table 26 demarcates data for Items 15 to 24 , pertaining to survey respondents' perceptions of instructor role, disaggregated by Carnegie Size Classification. When examining the data, Item 16, the most important part of instruction is the content of curriculum, received agreement above $70 \%$ for all eight categories for the institutions. Item 18, students learn basic skills in the context of mastering content, reported agreement percentages above $70 \%$ for seven categories with only small 2-year institutions reporting an agreement percentage below $70 \%$ (61.54\%). Item 24, students learn basic skills before mastering more complex content, showed agreement above 70\% by six of the size categories with very small 4 -year institutions showing a $33.33 \%$ and small 4-year institutions showing a $65.52 \%$ agree response. This indicated that a majority 
of the Missouri higher education faculty's responses showed agreement for Items 16, Item 18 and Item 24.

Further examination of the data also showed agreement below $70 \%$ for Item 23 by five of the eight Carnegie Size Classification categories. Categories indicating an agreement rating below $70 \%$ were very small 4-year $(66.7 \%)$, small 4-year $(66.67 \%)$ and large 4-year (68.42\%) institutions. Items 17 and 22 presented percentages over $70 \%$ for four of the Carnegie Size Classifications, indicating strong agreement. However, very small 2-year institutions showed a 50\% agreement rating, small 2-year institutions 69.23\% agreement, and medium 2-year institutions $69.57 \%$ agreement while small 4-year institutions reported $56.67 \%$ agreement. Item 22 revealed agreement ratings below $70 \%$ by very small 2-year institutions (50\%), small 2-year institutions (46.15\%), medium 2year institutions (52.17\%) and large 2-year institutions (60\%), indicating a majority of the respondents did not agree with Item 22 when data were disaggregated by Carnegie Size Classification.

Data for Items 20 and 21 showed percentages over $70 \%$ by two of the Carnegie Size Classifications, very small 2-year and large 2-year. Item 20 showed 100\% agreement for very small 2-year institutions and $80 \%$ for large 2-year institutions. Analysis of Item 21 showed $75 \%$ agreement for very small 2-year institutions and $80 \%$ for large 2-year institutions. Item 19, it is better to give the whole class the same assignment in small intervals, revealed agreement below $70 \%$ for all eight Carnegie Size Classifications. Data for Items 15 - 24, disaggregated by Carnegie Size Classification categories are further delineated in Table 26 located in Appendix I. 
Chi-Square analysis was also completed, checking for relationship of perceptions of instructional role to the size of institution based on the Carnegie Size Classifications. When Chi-square distribution tables were examined, (Field, 2005; Fraenkel \& Wallen, 2006) it was shown at a 0.05 level of significance (p) using 21 degrees of freedom (df) as specified for these items by SPSS, a Chi-square $\left(\mathrm{X}^{2}\right)$ value of 12.59 is needed to show a relationship between the size of institution demographic and the survey item. When the data were analyzed, nine of the ten items has significance levels (p), greater than 0.05 but the Chi-square values were lower than 12.59. Item 16 did have a significance level below 0.05 , showing 0.02 , but when the Chi-square value was more closely examined it was greater than 12.59 (15.025).Therefore, it was determined a relationship was not shown among these items and the type of institution demographic. Results are shown in Table 27.

Table 27

Chi-square Analysis Results for Size of Institution and Items 15 - 24 - (RQ5.2)

\begin{tabular}{lrrr}
\hline \multicolumn{1}{c}{ Item } & \multicolumn{1}{c}{$\mathrm{X}^{2}$} & $\mathrm{df}$ & $\mathrm{p}$ \\
\hline I15 - Role of facilitator; students construct knowledge for selves & 19.587 & 21 & .548 \\
I16 - Most important part of instruction is the content/curriculum & 30.484 & 21 & .083 \\
I17 - All sorts of activities going on in the classroom & 27.962 & 21 & .141 \\
I18 - Students learn basic skills in context of mastering content & 52.257 & 21 & .000 \\
I19 - Better to give the whole class same assignment-small intervals & 14.813 & 21 & .832 \\
I20 - Textbook core content is more important-not student motivation & 30.730 & 21 & .078 \\
I21 - Most important instruction encourages "sense-making"/thinking & 17.342 & 21 & .690 \\
I22 - Critical for students to become interested in doing academic work & 9.652 & 21 & .983 \\
I23 - Material must be covered in a structured way; job to explain & 15.667 & 21 & .788 \\
I24 - Students learn basic skills before mastering complex content & 22.310 & 21 & .382 \\
\hline
\end{tabular}

Table 28 (see Appendix I) delineated the data for responses for Items 25 - 40 indicating perceptions of preferred student learning styles, disaggregated by Carnegie 
Size Classifications. Closer analysis of the data showed high levels of agreement among respondents to this section of survey items. Eight of the ten survey items showed an agreement percentage of over $70 \%$ by all eight of the Carnegie Size Classification categories of institutions. Item 29, asking for responses concerning the perceptions of Missouri higher education faculty regarding the statement that students should be able to explore a new learning concept independently, had an agreement percentage of $50 \%$ for the very small 2-year institutions. Responses of the other seven Carnegie Size Classifications also showed agreement by a large majority of the participants.

The only other item having an agreement percentage of less than $70 \%$ was Item 39. This item examined the perceptions of Missouri higher education faculty concerning students showing mastery of knowledge by using various assessments. When studying the data disaggregated by Carnegie Size Classification for this item, an agreement percentage rating of $75 \%$ was shown for very small 2 -year institutions. The other seven categories showed agreement percentages below 70\%. Small 2-year institutions' data exhibited a $69.23 \%$ agreement, medium 2-year institutions revealed $60.87 \%$, while large 2-year institutions showed a $40 \%$.

Further examination of the data showed a $66.7 \%$ agreement rating for very small 4-year institutions and a $51.72 \%$ for small 4-year institutions. Medium 4-year institutions reported a $60.38 \%$ while large 4-year institutions indicated a 58.93\% agreement rating. Overall, the data indicated a large majority of Missouri higher education faculty agreed with the data which indicated they perceived student learning styles as indicated by current research. The results of the univariate analysis for the data from Items $25-40$ are shown in Table 28 located in Appendix I. 
Chi-Square analysis was next completed, checking for relationship of perceptions of preferred learning styles to the size of institution. Chi-square distribution tables (Field, 2005; Fraenkel \& Wallen, 2006) indicate at a 0.05 level of significance (p) using 21 degrees of freedom (df) as specified for 13 of these items by SPSS, a Chi-square $\left(\mathrm{X}^{2}\right)$ value of 33.92 is needed to show a relationship between the department demographic and the survey item. Three of these items reported 14 degrees of freedom. Chi-square distribution tables indicate at 14 degrees of freedom, applying a 0.05 significance level, values should be below 23.68 .

Data showed all survey items being analyzed yielded significance levels (p), greater than 0.05 , indicating no relationship. Based on this data, it was determined a relationship was not shown among these items and the size of institution demographic and the null hypothesis could not be rejected. The results of the Chi-square analysis are detailed in Table 29. 
Table 29

Chi-square analysis results for size of institution and Items 25 - 40 - (RQ5.2)

\begin{tabular}{lccc}
\hline \multicolumn{1}{c}{ Item } & $\mathrm{X}^{2}$ & $\mathrm{df}$ & $\mathrm{p}$ \\
\hline I25 - Students establish understanding based on individual experiences & 23.285 & 21 & .329 \\
I26 - Students integrate learning concepts into self-directed projects & 27.644 & 21 & .151 \\
I27 - Students research new concepts/questions further individually & 12.073 & 21 & .938 \\
I28 - Student pursue learning concepts to create individual learning & 10.037 & 14 & .760 \\
I29 - Students explore a new learning concept independently & 25.719 & 21 & .217 \\
I30 - Students demonstrate methods to realistically solve problems & 14.791 & 21 & .833 \\
I31 - Students connect current practice to individual experiences & 13.735 & 21 & .881 \\
I32 - Students expect immediate feedback from teachers and peers & 29.082 & 21 & .112 \\
I33 - Students can apply knowledge independently in other contexts & 17.011 & 21 & .710 \\
I34 - Students explain a learning concept using individual perspectives & 11.989 & 14 & .607 \\
I35 - Students can work in groups to establish individual knowledge & 19.084 & 21 & .580 \\
I36 - Students work in groups to share knowledge; reach agreement & 24.233 & 21 & .282 \\
I37 - Students integrate learning of concepts with other activities & 17.171 & 14 & .247 \\
I38 - Students understand individual thinking ;seek independent help & 12.782 & 21 & .916 \\
I39 - Students show mastery of knowledge by various assessments & 19.809 & 21 & .533 \\
I40 - Students relate experiences when explaining learning concepts & 12.541 & 21 & .924 \\
\hline
\end{tabular}

Research question 5.3 stated "What are the significant differences of responses among Departments (Item 3) as determined by frequency counts and percentages and Chi-square analysis?" The analysis for Research Question 5.3 is shown in Tables 29, 31 and 33. The Chi-square results are illustrated in Tables 30, 32 and 34. To respond to Research Question 5.3, data concerning utilization of technology-enhanced instructional practices was disaggregated and examined by department. Items 7, 8 and 10 revealed a strong agreement by all departments, indicating all respondents, disaggregated by department, utilized technology-enhanced instruction. More specifically, technologyenable classroom environments were being used (Item 7), technology-based tools were being utilized to support instruction (Item 8 ) and technology means were being used to 
communicate with students (Item 10). All 12 department groupings reported above a 70\% agreement, with the lowest percentage reported being a $77.78 \%$.

Further examination of the data showed five departments yielded agreement percentages below $70 \%$ for Item 9 which examined the use of video-based instruction to support classroom activities. Item 14 , use by students of web-based tools to complete classroom assignments, showed four department groupings exhibited percentages below $70 \%$. However, a majority of these respondents did utilize the technology-enhanced instructional tool referred to in these items, as only one department grouping for each item reported agreement percentages below 50\%. Those departments were Business/Economics (26.67\%) for Item 9 and the Other grouping (46.15\%) for Item 14.

Data reported for Item 11, encouraging student communication using technology, revealed nine departments with agreement ratings below $70 \%$. Seven of those departments reported percentages below 50\%. Those seven department groupings were Business/Economics (40\%), Computer Science, Math, Physics and Engineering (40.63\%), Fine Art (Theatre, Music and Film)/Art (44.44\%), Political Science/History/Geography (25\%), Psychology/Sociology/Social Work (40\%), Science (Biology, Chemistry, Agriculture) (30.77\%) and Other (46.15\%).

Minimal agreement was shown for Item 12 (use of smart or wireless devices to conduct lessons and disperse class materials) and Item 13 (use of guest speakers via technology-driven means). When data were disaggregated for these two items, agreement ratings for all 12 department groupings were less than $50 \%$. The highest agreement rating for Item 12 was $41.7 \%$ recorded for Communication Studies/Speech. Communication Studies/Speech also reported the highest agreement rating for Item 13 with $25 \%$ of 
respondents utilizing that technology-enabled instruction. This indicated that all respondents were not reporting these technology-enhanced instructional practices as ones being used often, but some use was starting to be adopted. The results for the univariate analysis of the data for Items $7-14$, examining utilization of technology-enhanced instruction, disaggregated by departments and divided into agreement versus disagreement frequencies and percentages are shown in Table 30, located in Appendix I.

Chi-Square analysis was also completed, checking for relationship of technologyenhanced instructional practices to departments within the institution. When Chi-square distribution tables were examined, (Field, 2005; Fraenkel \& Wallen, 2006) it was shown at a 0.05 level of significance (p) and 33 degrees of freedom (df) as specified for these items by SPSS, a Chi-square $\left(\mathrm{X}^{2}\right)$ value of 47.39 would show a relationship between the type of institution demographic and the survey item. When the data were analyzed, two items showed significance levels (p) less than 0.05 indicating a relationship may exist, Item 9 (using video-based instruction to support activities) and Item 14 (students use web-based tool to complete assignments). However, when the Chi-square values for these two items were more closely examined the values were well above 47.39 . This indicates no relationship between department and Items $7-14$. Therefore, the null hypothesis should be accepted for these data. Table 31 details the results of the Chi-square analysis for these items. 
Table 31

Chi-square Analysis Results for Department and Items 7 - 14 - (RQ5.3)

\begin{tabular}{lccc}
\hline \multicolumn{1}{c}{ Item } & X2 & df & p \\
\hline I7 - Technology-enabled classroom environment & 35.133 & 33 & .367 \\
I8 - Use technology-based tools to support instruction & 36.794 & 33 & .297 \\
I9 - Use video-based instruction to support activities & 57.487 & 33 & .005 \\
I10 - Use technology means to communicate w/ students & 34.952 & 33 & .375 \\
I11 - Encourage student communication using technology & 42.100 & 33 & .133 \\
I12 - Use smart or wireless devices to conduct lessons/materials & 37.159 & 33 & .283 \\
I13 - Use of guest speakers via technology-driven means & 34.143 & 33 & .413 \\
I14 - Students use web-based tools to complete assignments & 66.935 & 33 & .000 \\
\hline
\end{tabular}

The data for Items 15 - 24 were next examined as disaggregated by departments. The analysis revealed only one item received agreement ratings above $70 \%$ by all departments. Item 18, the perception that students learn basic skills in the context of mastering complex content, showed strong agreement with the lowest agreement rating (81.25\%) being shown by both the Criminal Justice, Social Science and Human Behavior Science and Computer Science, Math, Physics and Engineering departments. Item 16, pertaining to the most important part of the instruction is the content of the curriculum, showed agreement ratings above $70 \%$ by 11 departments, with the Business/Economics department grouping reporting a $66.67 \%$. This still indicated agreement, indicating a majority of respondents supported this concept.

Next examined were Items 23 and 24. Item 24, stating students should learn basic skills before mastering complex content, had agreement ratings above $70 \%$ by nine of the departments. Furthermore, the ratings by the remaining three departments, Computer Science, Math, Physics and Engineering (67.74\%) Education (60\%) and English, Foreign Language and Reading (65\%) were still above the 50\% threshold, indicating agreement. Item 23 also had ratings above 50\%, indicating levels of agreement. Business and 
Economics reported 60\%, Computer Science, Math, Physics and Engineering reported 65.63\%, Education showed 66.67\% while Psychology, Sociology and Social Work revealed $60 \%$.

Items 15 and 17 also indicated levels of agreement by all departments. Item 15, pertaining to instructors assuming the role of facilitator and guiding students to construct knowledge for themselves, reported agreement ratings below $70 \%$ for five departments, but when the data for the five departments was more closely examined, it was shown that all the agreement ratings were above $50 \%$. The lowest agreement rating, reported for the Fine Arts/Art department was 55.56\%, while the other four departments reported agreement ratings ranging from $62.5 \%$ to $65.63 \%$. Item $17^{\text {‘ }}$ s data showed six departments with agreement ratings below 70\%. However, Item 17 which pertained to having all sorts of activities going on in the classroom, received no agreement ratings below 50\%, which still indicated agreement by all departments.

Next examined was Item 21, pertaining to the most important instruction encouraging "sense-making" and thinking. Again, while nine departments showed agreement ratings below 70\%, none of the departments showed agreement ratings below $50 \%$, indicating levels of agreement by all 12 departments. The lowest ratings were shown by Business and Economics reporting 50\% and Fine Arts and Art also reporting $50 \%$. This particular item indicated a more contemporary viewpoint concerning instructor role and showed agreement by a majority of survey respondents.

Item 22, stating it is critical for students to become interested in doing academic work, showed levels of agreement below $70 \%$ for 11 of the departments. However, only two departments, Business and Economics and Political Science, History and Geography 
had data showing agreement ratings below 50\%, reporting $21.43 \%$ and $42.86 \%$

respectively, still indicating agreement by a majority of respondents. Similarly, Item 19, it is better to give the whole class the same assignment in small intervals, reported levels of agreement below $70 \%$ for 11 of the departments with only two of those departments reporting agreement below 50\%. The departments showing lower levels of agreement $(<50 \%)$ on this item were Computer Science, Math, Physics and Engineering (48.39\%) and Education (43.33\%).

The last item to be examined concerning perceptions of instructor role was Item 20, examining views on textbook core content being most important. All 12 departments reported agreement percentages below $70 \%$, but only three of these were below $50 \%$, indicating that overall, $75 \%$ of respondents agreed with the importance of the textbook. Departments reporting disagreement were Communication Studies and Speech (25\%), Education (31.03\%) and Fine Arts and Art (44.44\%), indicating these departments may support a more contemporary instructor role overall. The data analysis is reported more completely in Table 32.

Chi-Square analysis was also completed, checking for relationship perceptions of instructor role to departments within the institution. When Chi-square distribution tables were examined, (Field, 2005; Fraenkel \& Wallen, 2006) it was shown at a 0.05 level of significance (p) and 33 degrees of freedom (df) as specified for these items by SPSS, a Chi-square $\left(\mathrm{X}^{2}\right)$ value of 47.39 would show a relationship between the type of institution demographic and the survey item. When the data were analyzed, two items, Item 15 (role of facilitator, students construct knowledge for themselves) and Item 24 (students learn basic skills before mastering complex content) showed significance levels (p), less than 
0.05 , indicating a relationship may exist. However, when the Chi-square values for these two items were more closely examined, they were well above 47.39 . This indicates no relationship between department and Items $15-24$. Therefore, the null hypothesis should be accepted for these data. The results of the Chi-square analysis for these items are shown in complete detail in Table 32 found in Appendix I.

Table 33

Chi-square Analysis Results for Department and Items 15 - 24 - (RQ5.3)

\begin{tabular}{lccc}
\hline \multicolumn{1}{c}{ Item } & $\mathrm{X}^{2}$ & $\mathrm{df}$ & $\mathrm{p}$ \\
\hline I15 - Role of facilitator; students construct knowledge for selves & 61.119 & 33 & .002 \\
I16 - Most important part of instruction is the content/curriculum & 34.135 & 33.413 \\
I17 - All sorts of activities going on in the classroom & 44.746 & 33 & .083 \\
I18 - Students learn basic skills in context of mastering content & 32.652 & 33.484 \\
I19 - Better to give the whole class same assignment-small intervals & 27.578 & 33.734 \\
I20 - Textbook core content is more important-not student motivation & 35.327 & 33.359 \\
I21 - Most important instruction encourages "sense-making"/thinking & 43.123 & 33.112 \\
I22 - Critical for students to become interested in doing academic work & 33.764 & 33.430 \\
I23 - Material must be covered in a structured way; job to explain & 31.235 & 33.555 \\
I24 - Students learn basic skills before mastering complex content & 51.375 & 33.022 \\
\hline
\end{tabular}

Disaggregation of the data concerning preferred student learning styles compared to department was next examined. The data were examined concerning Items $25-40$ and agreement percentages were determined. Overall, it was determined that levels of agreement were present for all items being examined. Items $25,26,27,28,30,31,33,34$, 37,38 and 40 had agreement ratings percentages above $70 \%$, exhibiting strong agreement for these 11 items.

Further investigation of the data disaggregated by department showed Item 35 and 36 , both concerning students working in groups, each indicated only one agreement rating below 70\%. Both of these were reported by Criminal Justice, Social Science and 
Human Behavior Sciences with a rating of $62.5 \%$ being shown for Item 35 and $56.25 \%$ being reported for Item 36 . These items still reported levels of agreement by all departments as the rating were all above $50 \%$, indicating a strong majority of respondents' agreement with this concept. Similarly, Item 29 (students explore a new learning concept independently) and Item 32 (students expect immediate feedback on learning from instructors and peers) showed levels of agreement above $50 \%$ for all departments, although two departments did report agreement levels below 70\%. Details of the analysis are shown in Table 34 located in Appendix I.

Chi-Square analysis was also completed, checking for relationship of perceptions of preferred learning styles to the department within the institution. Chi-square distribution tables (Field, 2005; Fraenkel \& Wallen, 2006) indicate at a 0.05 level of significance (p) using 33 degrees of freedom (df) as specified for 13 of these items by SPSS, a Chi-square $\left(\mathrm{X}^{2}\right)$ value of 47.39 is needed to show a relationship between the department demographic and the survey item. Three items had 22 degrees of freedom. Chi-square distribution tables indicate at 22 degrees of freedom, when applying a 0.05 significance level, values should be below 33.92 .

Data showed all but three of the survey items reported significance levels (p), greater than 0.05 , indicating no relationship. Item 26 , integrating learning concepts into self-directed projects, showed a p-value of 0.017 . Item 31, connect current practice to individual experiences, had a p-value of 0.014 , while Item 36 , work together in groups to share knowledge, had a p-value of 0.020 . This indicated a relationship could exist. However, when the Chi-square values for these three items were examined more closely, 
it showed values above 47.39, again indicating no relationship existed between department and the individual survey items listed.

One item, Item 37, integrate learning of concepts with other activities in and out of the classroom, showed a p-value of 0.056 , very close to the required 0.050 . Therefore, the Chi-square value was more closely examined. This value was 33.426. At 22 degrees of freedom, this was below the threshold of 33.92. This was deemed to be the item closest to showing a relationship. However, using the strict guidelines, it was determined a relationship was not shown among these items and the department demographic and the null hypothesis could not be rejected. Table 35 details these results.

Table 35

Chi-square Analysis Results for Department and Items 25 - 40 - (RQ5.3)

\begin{tabular}{lccc}
\hline \multicolumn{1}{c}{ Item } & $\mathrm{X}^{2}$ & $\mathrm{df}$ & $\mathrm{p}$ \\
\hline I25 - Students establish understanding based on individual experiences & 39.458 & 33 & .203 \\
I26 - Students integrate learning concepts into self-directed projects & 52.537 & 33 & .017 \\
I27 - Students research new concepts/questions further individually & 39.311 & 33 & .208 \\
I28 - Student pursue learning concepts to create individual learning & 27.064 & 22 & .209 \\
I29 - Students explore a new learning concept independently & 37.578 & 33 & .267 \\
I30 - Students demonstrate methods to realistically solve problems & 33.273 & 33 & .454 \\
I31 - Students connect current practice to individual experiences & 53.304 & 33 & .014 \\
I32 - Students expect immediate feedback from teachers and peers & 38.227 & 33 & .244 \\
I33 - Students can apply knowledge independently in other contexts & 28.378 & 33 & .697 \\
I34 - Students explain a learning concept using individual perspectives & 28.957 & 22 & .146 \\
I35 - Students can work in groups to establish individual knowledge & 37.367 & 33 & .275 \\
I36 - Students work in groups to share knowledge; reach agreement & 51.764 & 33 & .020 \\
I37 - Students integrate learning of concepts with other activities & 33.426 & 22 & .056 \\
I38 - Students understand individual thinking ;seek independent help & 30.237 & 33 & .605 \\
I39 - Students show mastery of knowledge by various assessments & 45.420 & 33 & .073 \\
I40 - Students relate experiences when explaining learning concepts & 45.303 & 33 & .075 \\
\hline
\end{tabular}

Research Question 5.4 which stated "What are the significant differences in responses among Rank (Item 4) - (Adjunct, Instructor, Assistant Professor, Associate 
Professor, and Full Professor) as determined by frequency counts and percentages and Chi square analysis?" was next examined. The analyses for this question are shown in Tables 36, 38 and 40, all shown in Appendix I. Chi square analyses to examine relationships between rank and the various survey items for Research Question 5.4 are further illustrated in Tables 37, 39 and 41.

When the data were analyzed concerning usage versus non-usage among the survey items examining technology-enhanced instructional practices and rank among Missouri higher education faculty, usage was indicated from a majority of SHIEP respondents. When the percentages of agreement for each survey item were examined, Items 12, use smart of wireless devices to conduct lessons or disseminate course materials, showed no rank indicating agreement $(>50 \%)$ with the highest percentages being shown as $40 \%$. This indicated a majority of the survey respondents, when examined by rank, did not use this technology-enhanced instructional practice. Item 13, use of guest speakers via technology-driven means, showed even lower levels of agreement, with the highest percentage showing use was adjuncts at a mere $20 \%$. This again, indicated that a majority of the respondents, when disaggregated by rank, did not employee this technology-enhanced instructional practice.

Further examination of the other survey items (Items 7, 8, 9, 10,11 and 14), indicated a majority of the respondents reported employing these technology-enhanced instructional practices, with only 6 of the remaining 30 responses showing percentages of agreement less than $70 \%$. Closer scrutiny showed only two of those responses with values lower than 50\%, indicating disagreement. Both of those responses were shown for Item 11, encouraging student communication using a technology-driven means. The 
ranks showing disagreement were associate professor (48\%) and full professor (35.9\%). Overall, SHEIP responses indicated that a majority of the respondents were employed technology-enhanced instructional practices when the data are examined disaggregated by rank. Results are shown in Table 36, located in Appendix I.

Chi-Square analysis was also completed, checking for relationship of technologyenhanced instructional practices to the rank (adjunct, instructor, assistant professor, associate professor or full professor) of the SHEIP respondents. Table 37 delineates the results. When Chi-square distribution tables were examined, (Field, 2005; Fraenkel \& Wallen, 2006) it was shown at a 0.05 level of significance (p) and 12 degrees of freedom (df) as shown for these items by the SPSS analysis, a Chi-square $\left(\mathrm{X}^{2}\right)$ value of 21.03 is needed to show a relationship between the demographic of rank and individual survey items.

When the data were analyzed, relationships were not indicated for five of the eight items (Items 8, 10, 12, 13 and 14) as significance levels (p), were greater than 0.05 even though the Chi-square values were below 21.03. Closer examination of the three items (Items 7, 9 and 11) with p-values below 0.05 showed Chi-squared values higher than 21.03, there indicating no relationship as well. The data showed no relationship between rank and Items 7-14, therefore the null hypothesis cannot be rejected. 
Table 37

Chi-square Analysis Results for Rank and Items 7 - 14 - (RQ5.4)

\begin{tabular}{llcc}
\hline \multicolumn{1}{c}{ Item } & X2 & df & $\mathrm{p}$ \\
\hline I7 - Technology-enabled classroom environment & 27.149 & 12 & .007 \\
I8 - Use technology-based tools to support instruction & 11.005 & 12 & .528 \\
I9 - Use video-based instruction to support activities & 25.825 & 12 & .011 \\
I10 - Use technology means to communicate w/ students & 12.092 & 12 & .438 \\
I11 - Encourage student communication using technology & 33.014 & 12 & .001 \\
I12 - Use smart or wireless devices to conduct lessons/materials & 18.538 & 12 & .100 \\
I13 - Use of guest speakers via technology-driven means & 17.054 & 12 & .148 \\
I14 - Students use web-based tools to complete assignments & 10.418 & 12 & .579 \\
\hline
\end{tabular}

The data were next examined for agreement versus disagreement among the rank demographic (adjunct, instructor, assistant professor, associate professor or full professor) for survey items studying perceptions of instructor role. When the percentages for each rank and survey item were studied, agreement was shown by a majority of the respondents, as only 3 of the 30 percentages examined indicated a percentage less than 50\%. The three percentages below 50\% were found in the data for Item 19 and Item 20 . Item 19, better to give the whole class the same assignment, had one percentage level below $50 \%$ (49.2\%) shown when examining the data of full professor rank. Item 20 , textbook core content is more important, not student motivation, showed disagreement $(<50 \%)$ by both adjunct rank, reporting $29.2 \%$ and assistant professor rank, reporting 44.2\%. Overall, this indicated that perceptions of the SHEIP respondents agreed with the statements in the survey and a majority chose either Stongly Agree or Agree (Choice 1 or 2) on the survey's Likert scale. Detailed analysis is further shown in Table 38 located in Appendix I.

Chi-Square analysis was also completed, checking for relationship of perceptions of instructional role to rank (adjunct, instructor, assistant professor, associate professor or 
full professor) of the SHEIP respondents. When Chi-square distribution tables were examined, (Field, 2005; Fraenkel \& Wallen, 2006) it was shown at a 0.05 level of significance (p) using 12 degrees of freedom (df) as specified for these items by SPSS, a Chi-square $\left(\mathrm{X}^{2}\right)$ value of 21.03 is needed to show a relationship between the rank demographic and the survey item. When the data were analyzed, eight of the ten items has significance levels (p), greater than 0.05 , even though the Chi-square values were lower than 21.03. Relationships could not be shown.

Items 20 and 21 were discovered to have significance levels lower than 0.050 . Item 20, textbook core content is more important, not student motivation, had a significance level (p) below 0.05, showing 0.040, but when the Chi-square value was more closely examined it was slightly greater than 21.03 (21.759). Likewise, Item 21, most important instruction encourages "sense-making" or thinking, showed a p-value of 0.002. However, the Chi-square value was 31.159 , much greater than the 21.03 shown as acceptable by Chi-square distribution tables. Give the analysis, it was determined a relationship was not shown among these items and the type of institution demographic. Results are shown in Table 39. 
Table 39

Chi-square Analysis Results for Rank and Items 15 - 24 - (RQ5.4)

\begin{tabular}{lccc}
\hline \multicolumn{1}{c}{ Item } & $\mathrm{X}^{2}$ & $\mathrm{df}$ & $\mathrm{p}$ \\
\hline I15 - Role of facilitator; students construct knowledge for selves & 13.105 & 12 & .361 \\
I16 - Most important part of instruction is the content/curriculum & 11.948 & 12 & .450 \\
I17 - All sorts of activities going on in the classroom & 10.553 & 12 & .568 \\
I18 - Students learn basic skills in context of mastering content & 12.015 & 12 & .444 \\
I19 - Better to give the whole class same assignment-small intervals & 10.105 & 12 & .607 \\
I20 - Textbook core content is more important-not student motivation & 21.759 & 12 & .040 \\
I21 - Most important instruction encourages "sense-making"/thinking & 31.159 & 12 & .002 \\
I22 - Critical for students to become interested in doing academic work & 13.657 & 12 & .323 \\
I23 - Material must be covered in a structured way; job to explain & 11.348 & 12 & .499 \\
I24 - Students learn basic skills before mastering complex content & 10.974 & 12 & .531 \\
\hline
\end{tabular}

The data examining the frequency and percentage of responses for Items 25-40, perceptions of preferred millennial students' learning styles, were next examined disaggregated by rank (adjunct, instructor, assistant professor, associate professor or full professor). The percentages of agreement were studied for each of the 16 survey items. Strong agreement was shown as only 5 of the 80 percentage figures showing agreement levels were shown to be below 70\%. One of those was shown for the full professor rank for Item 32, students expect immediate feedback from teachers and peers. This item indicated a level of $68.3 \%$. The other four percentages were shown for Item 39, students show mastery of knowledge by self-choosing various assessments. These percentages were shown by instructor rank (67.4\%), assistant professor rank (63.5\%), associate professor rank (41.7\%) and full professor rank (58.7\%).

Further analysis of Item 39 showed only one of these responses was below the $50 \%$ level of agreement, which would indicate disagreement. That response was shown for the rank of associate professor at a $41.7 \%$ level of agreement, showing that a majority 
of the respondents at the associate professor rank disagree with the statement, students show mastery of knowledge by self-choosing various assessments. The overall analysis of these items showed agreement by a vast majority of the respondents when studied according to rank. Only one of the total agree responses (80) showed disagreement. Details of the frequency of responses concerning perceptions of millennial students' learning preferences when disaggregated by rank are shown in Table 40 located in Appendix I.

Chi-Square analysis was also completed, checking for relationship of perceptions of students' preferred learning styles to the rank reported by the respondents. Chi-square distribution tables (Field, 2005; Fraenkel \& Wallen, 2006) indicate at a 0.05 level of significance (p) using 12 degrees of freedom (df) as specified for 13 of these items by SPSS, a Chi-square $\left(\mathrm{X}^{2}\right)$ value of 21.03 is needed to show a relationship between the rank demographic and survey items. Three items had 8 degrees of freedom. Chi-square distribution tables indicate at 8 degrees of freedom, when applying a 0.05 significance level, values should be below 15.51 .

Data showed all but one survey item reported significance levels (p), greater than 0.05, indicating no relationship. Item 40, students relate individual experiences when explaining learning concepts, showed a p-value of 0.050 . This indicated a relationship could exist. It was noticed another item, Item 35, students can work in groups to establish individual knowledge, showed a significance level of 0.056 , very close to the applied 0.05 level. When the Chi-square values for these three items were examined more closely, values were shown of 21.014 for Item 40, indicating a relationship existed between department and Item 40. Item 35 was also further scrutinized. The Chi-square 
value for this item was 20.645 which was within the accepted range. It was reasoned Item 35 and rank could have a relationship. However, using strict guidelines, it was determined a relationship was not shown for this item as the significance level was over the 0.050 . However, Item 40 did show a relationship. Therefore, the null hypothesis was rejected and it was deemed there was a relationship between rank and Item 40. Table 41 details these results.

Table 41

Chi-square Analysis Results for Rank and Items 25 - 40 - (RQ5.4)

\begin{tabular}{lrcc}
\hline \multicolumn{1}{c}{ Item } & \multicolumn{1}{c}{$\mathrm{X}^{2}$} & $\mathrm{df}$ & $\mathrm{p}$ \\
\hline I25 - Students establish understanding based on individual experiences & 20.241 & 12 & .063 \\
I26 - Students integrate learning concepts into self-directed projects & 20.074 & 12 & .066 \\
I27 - Students research new concepts/questions further individually & 18.061 & 12 & .114 \\
I28 - Student pursue learning concepts to create individual learning & 6.685 & 8 & .571 \\
I29 - Students explore a new learning concept independently & 17.074 & 12 & .147 \\
I30 - Students demonstrate methods to realistically solve problems & 11.831 & 12 & .459 \\
I31 - Students connect current practice to individual experiences & 15.645 & 12 & .208 \\
I32 - Students expect immediate feedback from teachers and peers & 17.667 & 12 & .126 \\
I33 - Students can apply knowledge independently in other contexts & 12.663 & 12 & .394 \\
I34 - Students explain a learning concept using individual perspectives & 6.655 & 8 & .574 \\
I35 - Students can work in groups to establish individual knowledge & 20.645 & 12 & .056 \\
I36 - Students work in groups to share knowledge; reach agreement & 17.766 & 12 & .123 \\
I37 - Students integrate learning of concepts with other activities & 8.532 & 8 & .383 \\
I38 - Students understand individual thinking ;seek independent help & 14.730 & 12 & .257 \\
I39 - Students show mastery of knowledge by various assessments & 20.272 & 12 & .062 \\
I40 - Students relate experiences when explaining learning concepts & 21.014 & 12 & .050 \\
\hline
\end{tabular}

The next sub-question investigated was 5.5 which stated "What are the significant differences in responses between Gender (Item 5) - (Male and Female) as determined by frequency counts and percentages and Chi square analysis?" The univariate analysis for survey questions regarding technology-enhanced instruction disaggregated by gender is shown in Table 42. A closer examination of the data shows many similarities in 
responses between the different genders with differences indicated in responses to two questions.

Question 9, reporting the use of video-based instruction to support teaching activities, has a 56.4\% ( $\mathrm{N}=57)$ response rate among males, while a $71.6 \%(\mathrm{~N}=101)$ response rate was reported among female respondents. Also showing some disparity was Question 13, which highlighted faculty encouragement of student communication using technology means, reported $39 \%(\mathrm{~N}=39)$ use among male participants and $62.4 \%(\mathrm{~N}=88)$ use among female respondents. These showed females reported using these technologyenabled instructional practices more often than males.

Overall, examination of the data showed agreement by the majority of the respondents to all items except Item 12, use of smart or wireless devices to conduct lessons or disseminate materials, and Item 13, use of guest speakers via technologydriven means. The remaining six items showed a implementation of technology-enhanced instructional practices by a majority $(>50 \%)$ of the SHEIP respondents. This indicates that technology-enhanced instructional practices are being employed by most Missouri higher education faculty, meeting one of what research shows is desired by Millennials (Christensen, et al., 2008; Green, 2010; Prensky, 2001c, 2012; Tapscott, 1998, 2009). The frequency and percentages of responses disaggregated by gender and concerning utilization of technology-enhanced instructional practices are shown more fully in Table 42. 
Table 42

Frequency of Responses (Agree vs. Disagree) Disaggregated by Gender-Utilization of Technology-Enhanced Instructional Practices (RQ5.5)

\begin{tabular}{|c|c|c|c|c|c|c|c|c|c|}
\hline \multirow[b]{3}{*}{ Variable } & \multicolumn{4}{|c|}{ Male } & \multicolumn{4}{|c|}{ Female } & \multirow[b]{3}{*}{$\mathrm{N}$} \\
\hline & \multicolumn{2}{|c|}{ Agree } & \multicolumn{2}{|c|}{ Disagree } & \multicolumn{2}{|c|}{ Agree } & \multicolumn{2}{|c|}{ Disagree } & \\
\hline & $\mathrm{n}$ & $\%$ & $\mathrm{n}$ & $\%$ & $\mathrm{n}$ & $\%$ & $\mathrm{n}$ & $\%$ & \\
\hline I7 - Technology-enabled classroom environment & 94 & 93.1 & 7 & 6.9 & 131 & 92.9 & 10 & 7.1 & 242 \\
\hline I8 - Use technology-based tools to support instruction & 95 & 94.1 & 6 & 5.9 & 133 & 94.3 & 8 & 5.7 & 242 \\
\hline I9 - Use video-based instruction to support activities & 57 & 56.4 & 44 & 43.6 & 101 & 71.6 & 40 & 28.4 & 242 \\
\hline I10 - Use technology means to communicate w/ students & 95 & 95.0 & 5 & 5.0 & 138 & 97.9 & 3 & 2.1 & 241 \\
\hline I11 - Encourage student communication using technology & 39 & 39.0 & 61 & 61.0 & 88 & 62.4 & 53 & 37.6 & 241 \\
\hline I12 - Use smart or wireless devices to conduct lessons/materials & 24 & 23.8 & 77 & 76.2 & 35 & 24.8 & 106 & 75.2 & 242 \\
\hline I13 - Use of guest speakers via technology-driven means & 8 & 8.0 & 92 & 92.0 & 15 & 10.7 & 125 & 89.3 & 240 \\
\hline I14 - Students use web-based tools to complete assignments & 72 & 71.3 & 29 & 28.7 & 110 & 78.0 & 31 & 22.0 & 242 \\
\hline
\end{tabular}

Chi-Square analysis was also completed, checking for relationship of technologyenhanced instructional practices to gender of the respondents. When Chi-square distribution tables were examined, (Field, 2005; Fraenkel \& Wallen, 2006) it was shown at a 0.05 level of significance (p) and 3 degrees of freedom (df) as specified for these items by SPSS, a Chi-square (X2) value of 7.81 would show a relationship between the type of institution demographic and the survey item. When the data were analyzed, only one item showed significance levels (p) less than 0.05 indicating a relationship may exist.

Item 11, encouraging student communication using technology-based methods, showed a significance level (p) of 0.005 , much less than the threshold 0.05 significance level chosen for this study. However, when the Chi-square value for Item 11 was more closely examined the Chi-square values was greater than the value of 7.81 at 12.935 . As seven of the items had significance levels were greater than 0.05 and the remaining item (Item 11) had a Chi-square value greater than that shown as valid in the Chi-square distribution table, it was determined no relationships were present. As the analysis of the 
data indicates no relationships exist between gender and Items $7-14$, which examine the utilization of technology-enhanced instructional practices the null hypothesis could not be rejected for these data. Table 43 details the results of the Chi-square analysis for these items.

Table 43

Chi-square Analysis Results for Gender and Items 7 - 14 - (RQ5.5)

\begin{tabular}{lrrc}
\hline \multicolumn{1}{c}{ Item } & \multicolumn{1}{c}{ X2 } & \multicolumn{1}{c}{ df } & \multicolumn{1}{c}{$\mathrm{p}$} \\
\hline I7 - Technology-enabled classroom environment & 1.377 & 3 & .711 \\
I8 - Use technology-based tools to support instruction & 5.677 & 3 & .128 \\
I9 - Use video-based instruction to support activities & 6.255 & 3 & .100 \\
I10 - Use technology means to communicate w/ students & 3.602 & 3 & .308 \\
I11 - Encourage student communication using technology & 12.935 & 3 & .005 \\
I12 - Use smart or wireless devices to conduct lessons/materials & .365 & 3 & .947 \\
I13 - Use of guest speakers via technology-driven means & 2.807 & 3 & .422 \\
I14 - Students use web-based tools to complete assignments & 5.946 & 3 & .114 \\
\hline
\end{tabular}

Responses (agree versus disagree) for survey items 15-24 disaggregated by gender are delineated in Table 44. The frequency of male responses indicated that most male Missouri higher education faculty believe their role is more traditional. Items 16 , most important part of instruction is the content or curriculum, Item 19, better to give the whole class the same assignment, and Item 20, textbook core content is more important, not student motivation, all signify perceptions of traditional instructor role. Item 23, material must be covered in a structured way, and Item 24, students learn basic before mastering complex content also indicate traditional instructor role. When items 16, 23 and 24 were more closely examined, the male agreement percentages were $80.2 \%, 72.3 \%$ and $83.2 \%$ respectively. This indicates strong agreement by male respondents for these three items, indicating traditional instructor roles. The other two indicator items, Items 19 
and 20 also showed male agreement greater than 50\%, reporting 56.4\% (Item 19) and $54.5 \%($ Item 20).

Items 15, 17, 18, 21 and 22 all indicate perceptions of a contemporary instructor role. Item 15, role of facilitator, students construct knowledge for themselves, showed agreement by males $(68.3 \%)$ and females $(85.7 \%)$. Item 17, all sorts of activities going on in the classroom, also showed agreement by both genders, males $(80.2 \%)$ and females (87.4\%). Agreement levels for Item 18, students learn basic skills in context of mastering content, revealed agreement by both genders, male (84.2\%) and female (74.3\%). Further examination of the data for Item 21, most important instruction encourages "sensemaking" or thinking, also showed agreement for both genders with males displaying a $55.4 \%$ and females exhibiting $70.7 \%$. The last item indicating contemporary instructor role, Item 22, states it is critical for students to become interested in doing academic work. Agreement was again shown with males and females both agreeing at a level more than $50 \%$, at $51.5 \%$ (males) and $60.7 \%$ (females).

While female respondents showed agreement with the items indicating traditional instructor role, the percentages of females agreeing with the contemporary instructor role were higher overall. This indicated that a greater number of female than male higher education faculty perceive their use of more contemporary instructional methods, indicating that female faculty tend to use more instructional methods preferred by millennial students. 
Table 44

Frequency of Responses (Agree vs. Disagree) Disaggregated by Gender-Instructional

Role (RQ5.5)

\begin{tabular}{|c|c|c|c|c|c|c|c|c|c|}
\hline \multirow[b]{3}{*}{ Variable } & \multicolumn{4}{|c|}{ Male } & \multicolumn{4}{|c|}{ Female } & \multirow[b]{3}{*}{$\mathrm{N}$} \\
\hline & \multicolumn{2}{|c|}{ Agree } & \multicolumn{2}{|c|}{ Disagree } & \multicolumn{2}{|c|}{ Agree } & \multicolumn{2}{|c|}{ Disagree } & \\
\hline & $\mathrm{n}$ & $\%$ & $\mathrm{n}$ & $\%$ & $\mathrm{n}$ & $\%$ & $\mathrm{n}$ & $\%$ & \\
\hline I15 - Role of facilitator; students construct knowledge for selves & 69 & 68.3 & 32 & 31.7 & 120 & 85.7 & 20 & 14.3 & 241 \\
\hline I16 - Most important part of instruction is the content/curriculum & 81 & 80.2 & 20 & 19.8 & 122 & 87.1 & 18 & 12.9 & 241 \\
\hline I17 - All sorts of activities going on in the classroom & 63 & 62.4 & 38 & 37.6 & 104 & 74.3 & 35 & 25.0 & 240 \\
\hline I18 - Students learn basic skills in context of mastering content & 85 & 84.2 & 16 & 15.8 & 123 & 87.9 & 17 & 12.1 & 241 \\
\hline I19 - Better to give the whole class same assignment-small intervals & 57 & 56.4 & 43 & 42.6 & 80 & 57.1 & 59 & 42.1 & 239 \\
\hline I20 - Textbook core content is more important-not student motivation & 55 & 54.5 & 46 & 45.5 & 66 & 47.1 & 72 & 51.4 & 239 \\
\hline I21 - Most important instruction encourages "sense-making"/thinking & 56 & 55.4 & 43 & 42.6 & 99 & 70.7 & 39 & 27.9 & 237 \\
\hline I22 - Critical for students to become interested in doing academic work & 52 & 51.5 & 48 & 47.5 & 85 & 60.7 & 54 & 38.6 & 239 \\
\hline I23 - Material must be covered in a structured way; job to explain & 73 & 72.3 & 28 & 27.7 & 105 & 75.0 & 35 & 25.0 & 241 \\
\hline I24 - Students learn basic skills before mastering complex content & 84 & 83.2 & 17 & 16.8 & 107 & 76.4 & 33 & 23.6 & 241 \\
\hline
\end{tabular}

Chi-Square analysis was also completed, checking for relationship of perceptions of instructional role to the gender demographic. Chi-square distribution tables indicated at a 0.05 level of significance (p) using 3 degrees of freedom (df) as derived from SPSS data, a Chi-square $\left(\mathrm{X}^{2}\right)$ value of 7.81 is needed to show a relationship between gender of a survey participant and the survey item (Field, 2005; Fraenkel \& Wallen, 2006). When the data were analyzed, seven of the ten items has significance levels (p) greater than 0.05. Chi-square values were lower than 7.81 , but relationships were not shown as the significance levels for these seven items were above 0.05 . The three items with significance levels below 0.05 were more closely examined.

The analysis of Item 15, role of facilitator and students construct knowledge for themselves, had a significance level of 0.005 , but the Chi-square value was 12.843 . Item 18 , students learn basic skills in context of mastering content, showed a significance level of 0.034 , but had a Chi-square value of 8.652 . Item 23 , material must be covered in a 
structured way; job to explain, had a significance level 0.032, but had a Chi-square value of 8.803. When these Chi-square values was more closely evaluated, all Chi-square values were greater than the 7.81, deemed the highest value that would indicate a relationship. Consequently, it was determined relationships were not shown among these items and the gender demographic. Therefore, the null hypothesis could not be rejected.

Results are shown in Table 45.

Table 45

Chi-square Analysis Results for Gender and Items 15 - 24 - (RQ5.5)

\begin{tabular}{lrrr}
\hline \multicolumn{1}{c}{ Item } & \multicolumn{1}{c}{$\mathrm{X}^{2}$} & $\mathrm{df}$ & $\mathrm{p}$ \\
\hline I15 - Role of facilitator; students construct knowledge for selves & 12.843 & 3 & .005 \\
I16 - Most important part of instruction is the content/curriculum & 5.724 & 3 & .126 \\
I17 - All sorts of activities going on in the classroom & 5.393 & 3 & .145 \\
I18 - Students learn basic skills in context of mastering content & 8.652 & 3 & .034 \\
I19 - Better to give the whole class same assignment-small intervals & .041 & 3 & .998 \\
I20 - Textbook core content is more important-not student motivation & 3.258 & 3 & .354 \\
I21 - Most important instruction encourages "sense-making"/thinking & 7.424 & 3 & .060 \\
I22 - Critical for students to become interested in doing academic work & 2.167 & 3 & .539 \\
I23 - Material must be covered in a structured way; job to explain & 8.803 & 3 & .032 \\
I24 - Students learn basic skills before mastering complex content & 1.878 & 3 & .598 \\
\hline
\end{tabular}

Frequency of responses, showing agreement versus disagreement for survey items 25 - 40 which featured items exploring Missouri higher education faculty perceptions of millennial student learning are shown in Table 46. To determine these responses, the data for the SHEIP responses were examined for Items $7-14$. The data were then disaggregated by age range (under 30, 31-50 and over 50) and further evaluated for frequencies and percentages of agreement versus disagreement among all.

When the details of the data were examined, a high level of agreement was shown among all respondents. When agreement and disagreement responses were compared, the 
data showed that of 32 percentages measuring agreement, only one item was below $50 \%$.

Item 39, students show mastery of knowledge by various means of assessments, was

shown at $49.5 \%$ by male respondents. Further analysis showed only two of the 32

responses was shown to be below $70 \%$ and only seven showed agreement percentages

below $80 \%$. This indicated strong agreement for both genders concerning perceptions of

millennial students' learning preferences.

Table 46

Frequency of Responses (Agree vs. Disagree) Disaggregated by Gender-Millennial

Students' Preferred Learning Styles (RQ5.5)

\begin{tabular}{|c|c|c|c|c|c|c|c|c|c|}
\hline \multirow[b]{3}{*}{ Variable } & \multicolumn{4}{|c|}{ Male } & \multicolumn{4}{|c|}{ Female } & \multirow[b]{3}{*}{$\mathrm{N}$} \\
\hline & \multicolumn{2}{|c|}{ Agree } & \multicolumn{2}{|c|}{ Disagree } & \multicolumn{2}{|c|}{ Agree } & \multicolumn{2}{|c|}{ Disagree } & \\
\hline & $\mathrm{n}$ & $\%$ & $\mathrm{n}$ & $\%$ & $\mathrm{n}$ & $\%$ & $\mathrm{n}$ & $\%$ & \\
\hline I25 - Students establish understanding based on individual experiences & 89 & 88.1 & 12 & 11.9 & 128 & 91.4 & 12 & 8.6 & 241 \\
\hline I26 - Students integrate learning concepts into self-directed projects & 84 & 83.2 & 17 & 16.8 & 130 & 92.9 & 10 & 7.1 & 241 \\
\hline I27 - Students research new concepts/questions further individually & 83 & 82.2 & 18 & 17.8 & 127 & 91.4 & 12 & 8.6 & 240 \\
\hline I28 - Student pursue learning concepts to create individual learning & 89 & 89.0 & 11 & 11.0 & 128 & 92.1 & 11 & 7.9 & 239 \\
\hline I29 - Students explore a new learning concept independently & 79 & 78.2 & 22 & 21.8 & 124 & 88.6 & 16 & 11.4 & 241 \\
\hline I30 - Students demonstrate methods to realistically solve problems & 95 & 94.1 & 6 & 5.9 & 129 & 92.8 & 10 & 7.2 & 240 \\
\hline I31 - Students connect current practice to individual experiences & 92 & 91.1 & 9 & 8.9 & 136 & 97.8 & 3 & 2.2 & 240 \\
\hline I32 - Students expect immediate feedback from teachers and peers & 76 & 75.2 & 25 & 24.8 & 107 & 77.0 & 32 & 23.0 & 240 \\
\hline I33 - Students can apply knowledge independently in other contexts & 93 & 92.1 & 8 & 7.9 & 132 & 94.3 & 8 & 5.7 & 241 \\
\hline I34 - Students explain a learning concept using individual perspectives & 91 & 90.1 & 10 & 9.9 & 132 & 95.0 & 7 & 5.0 & 240 \\
\hline I35 - Students can work in groups to establish individual knowledge & 76 & 75.2 & 25 & 24.8 & 124 & 88.6 & 16 & 11.4 & 241 \\
\hline I36 - Students work in groups to share knowledge; reach agreement & 77 & 76.2 & 24 & 23.8 & 128 & 91.4 & 12 & 8.6 & 241 \\
\hline I37 - Students integrate learning of concepts with other activities & 91 & 90.1 & 10 & 9.9 & 131 & 94.2 & 8 & 5.8 & 240 \\
\hline I38 - Students understand individual thinking ;seek independent help & 88 & 88.0 & 12 & 12.0 & 136 & 97.1 & 4 & 2.9 & 240 \\
\hline I39 - Students show mastery of knowledge by various assessments & 49 & 49.5 & 50 & 50.5 & 94 & 67.1 & 46 & 32.9 & 239 \\
\hline I40 - Students relate experiences when explaining learning concepts & 88 & 88.0 & 12 & 12.0 & 134 & 96.4 & 5 & 3.6 & 239 \\
\hline
\end{tabular}

Chi-Square analysis was also completed, checking for relationship of perceptions

of students' preferred learning styles to the gender (male, female) of the respondent. Chisquare distribution tables (Field, 2005; Fraenkel \& Wallen, 2006) indicate at a 0.05 level 
of significance (p) using 3 degrees of freedom (df) as specified for 13 of these items by SPSS, a Chi-square (X2) value of 7.81 is needed to show a relationship between the gender demographic and the individual survey item. SPSS indicated three items have 2 degrees of freedom. Chi-square distribution tables indicate at 2 degrees of freedom, when applying a 0.05 significance level, the value should be below 5.99. First, data were examined for significance levels.

Data showed six of the items had significance levels (p), greater than 0.05 . This indicated there was no relationship for Items 25, students establish understanding based on individual experiences, Item 32, students expect immediate feedback from teachers and peers and Item 33, students can apply knowledge independently in other contexts, were deemed to show no relationships to gender. Item 37, students integrate learning of concepts with other activities and Item 40, students relate experiences when explaining learning concepts, also did not show a relationship with gender due to significance levels above 0.05 . Item 35 , students can work in groups to establish individual knowledge, had a significance level of 0.051 , close to the 0.05 . The Chi-square value for Item 35 was shown to be 7.792. If a higher significance level had been chosen, this item and gender would have been deemed to show a relationship.

The remaining 10 items reported significance levels less than 0.05 . To establish if a relationship existed, the Chi-square values were next examined. When these values were scrutinized, Chi-square values for all items with significance levels below 0.05 were determined to have Chi-square values above the accepted values of 7.81 for those showing three degrees of freedom and 5.99 for those items with two degrees of freedom. Therefore, it was determined a relationship was not shown among these items and the 
gender demographic and the null hypothesis could not be rejected. Table 47 details these

results.

Table 47

Chi-square Analysis Results for Gender and Items 25 - 40 - (RQ5.5)

\begin{tabular}{lrrc}
\hline \multicolumn{1}{c}{ Item } & \multicolumn{1}{c}{$\mathrm{X}^{2}$} & $\mathrm{df}$ & $\mathrm{p}$ \\
\hline I25 - Students establish understanding based on individual experiences & 2.097 & 3 & .552 \\
I26 - Students integrate learning concepts into self-directed projects & 14.077 & 3 & .003 \\
I27 - Students research new concepts/questions further individually & 19.393 & 3 & .000 \\
I28 - Student pursue learning concepts to create individual learning & 12.114 & 2 & .002 \\
I29 - Students explore a new learning concept independently & 9.878 & 3 & .020 \\
I30 - Students demonstrate methods to realistically solve problems & 7.854 & 3 & .049 \\
I31 - Students connect current practice to individual experiences & 17.563 & 3 & .001 \\
I32 - Students expect immediate feedback from teachers and peers & 5.575 & 3 & .134 \\
I33 - Students can apply knowledge independently in other contexts & 3.175 & 3 & .365 \\
I34 - Students explain a learning concept using individual perspectives & 6.603 & 2 & .037 \\
I35 - Students can work in groups to establish individual knowledge & 7.792 & 3 & .051 \\
I36 - Students work in groups to share knowledge; reach agreement & 11.502 & 3 & .009 \\
I37 - Students integrate learning of concepts with other activities & 3.859 & 2 & .145 \\
I38 - Students understand individual thinking ;seek independent help & 8.524 & 3 & .036 \\
I39 - Students show mastery of knowledge by various assessments & 9.963 & 3 & .019 \\
I40 - Students relate experiences when explaining learning concepts & 7.084 & 3 & .069 \\
\hline
\end{tabular}

The final research question, Question 5.6 stating, "What are the significant differences in responses among Age Range (Item 6) - (Under 30, 31-50, and Over 50) as determined by frequency counts and percentages and Chi square analysis applying a .05 significance level?" To determine these responses, the data for the SHEIP responses were examined for Items 7 - 14, Items 15-24 and Items 25-40. The data were then disaggregated by age range (under 30,31-50 and over 50) and further evaluated for frequencies and percentages of agreement versus disagreement among all. Investigation of data by group of items was then completed. 
Very strong usage percentages were shown for Item 7, teach in a technologyenabled classroom environment, Item 8 , use technology-based tools to support instruction and Item 10, use technology means to communicate with students. These three items showed usage or agreement levels of above $90 \%$ for all three age ranges. Item 9, use video-based instruction to support activities and Item 14 also showed a majority of respondents agreeing with all responses above $50 \%$. This indicated a majority of Missouri higher education faculty do use the technology-enhanced instructional practices indicated in these items.

Item 12, use smart or wireless devices to conduct lessons and disseminate materials, and Item 13, use of guest speakers via technology-driven means, show low levels of agreement by all ranges. Item 12 show agreement levels of $27.3 \%$ for those under $30,22.5 \%$ for those $31-50$ and $25.6 \%$ for those over 50 . Item 13 showed even lower rates of agreement. Those under 30 reported agreement rates of $0 \%$, those $31-50$ indicated $11.8 \%$ agreement and those over 50 showed an $8.7 \%$ agreement rating.

Only one other item showed agreement levels lower than 50\%, indicating disagreement. Item 11, encourage student communication using technology-driven means, showed a $48.4 \%$ agreement rating by those over 50 . Items examining technologyenhanced instructional practices showed agreement levels by a majority of the respondents. This indicated that these instructional practices were being used in higher education by all age ranges. Data are further delineated in Table 48 . 
Table 48

Frequency of Responses (Agree vs. Disagree) - Utilization of Technology-Enhanced

Instructional Methods (RQ5.6) - Disaggregated by Age Range

\begin{tabular}{|c|c|c|c|c|c|c|c|c|c|c|c|c|c|}
\hline \multirow[b]{3}{*}{ Variable } & \multicolumn{4}{|c|}{ Under 30} & \multicolumn{4}{|c|}{$31-50$} & \multicolumn{4}{|c|}{ Over 50} & \multirow[b]{3}{*}{$\mathrm{N}$} \\
\hline & \multicolumn{2}{|c|}{ Agree } & \multicolumn{2}{|c|}{ Disagree } & \multicolumn{2}{|c|}{ Agree } & \multicolumn{3}{|c|}{ Disagree } & Agree & \multicolumn{2}{|c|}{ Disagree } & \\
\hline & $\mathrm{n}$ & $\%$ & $\mathrm{n}$ & $\%$ & $\mathrm{n}$ & $\%$ & $\mathrm{n}$ & $\%$ & $\mathrm{n}$ & $\%$ & $\mathrm{n}$ & $\%$ & \\
\hline $\begin{array}{l}\text { I7 - Technology-enabled classroom } \\
\text { environment }\end{array}$ & 11 & 100.0 & 0 & 0.0 & 98 & 96.1 & 4 & 3.9 & 117 & 790.7 & 12 & 9.3 & 242 \\
\hline $\begin{array}{l}\text { I8 - Use technology-based tools to } \\
\text { support instruction }\end{array}$ & 11 & 100.0 & 0 & 0.0 & 94 & 92.2 & 8 & 7.8 & 122 & 294.6 & 7 & 5.4 & 242 \\
\hline $\begin{array}{l}\text { I9 - Use video-based instruction to } \\
\text { support activities }\end{array}$ & 11 & 100.0 & 0 & 0.0 & 69 & 67.6 & 33 & 32.4 & 78 & 60.5 & 51 & 39.5 & 242 \\
\hline $\begin{array}{l}\text { I10 - Use technology means to } \\
\text { communicate w/ students }\end{array}$ & 11 & 100.0 & 0 & 0.0 & 100 & 98.0 & 2 & 2.0 & 122 & 295.3 & 6 & 4.7 & 241 \\
\hline $\begin{array}{l}\text { I11 - Encourage student } \\
\text { communication using technology }\end{array}$ & 7 & 63.6 & 4 & 36.4 & 58 & 56.9 & 44 & 43.1 & 62 & 48.4 & 66 & 51.6 & 241 \\
\hline $\begin{array}{l}\text { I12 - Use smart or wireless devices to } \\
\text { conduct lessons/materials }\end{array}$ & 3 & 27.3 & 8 & 72.7 & 23 & 22.5 & 79 & 77.5 & 33 & 25. & 96 & 74.4 & 242 \\
\hline $\begin{array}{l}\text { I13 - Use of guest speakers via } \\
\text { technology-driven means }\end{array}$ & 0 & 0.0 & 11 & 100.0 & 12 & 11.8 & 90 & 88.2 & 11 & 8.7 & $\begin{array}{c}11 \\
6\end{array}$ & 91.3 & 240 \\
\hline $\begin{array}{l}\text { I14 - Students use web-based tools to } \\
\text { complete assignments }\end{array}$ & 9 & 81.8 & 2 & 18.2 & 83 & 81.4 & 19 & 18.6 & 89 & 69.0 & 40 & 31.0 & 242 \\
\hline
\end{tabular}

$* \mathrm{n}=244$

Chi-Square analysis was also completed, checking for relationship between

perceptions of instructor role to age range (under 30, 31-50, over 50) of respondents.

According to Chi-square distribution tables, at a 0.05 level of significance (p) and 6

degrees of freedom (df) as specified for these items by SPSS, a Chi-square $\left(\mathrm{X}^{2}\right)$ value of

12.59 would show a relationship between the age range demographic and survey items

(Field, 2005; Fraenkel \& Wallen, 2006).

When data were analyzed, only one item, Item 9, use video-based instruction to support activities, yielded a significance level below 0.05. The p-value indicated for this item was 0.40 , showing a relationship may exist. However, when the Chi-square value for Item 9 was more closely examined, it was above 12.59 at 13.221 . This indicates no relationship between age range and Item 9. As the remaining items all exhibited 
significance levels above the .05 chosen for this study, it was determined that no items showed evidence of a relationship between age range and Items 7-14. Therefore, the null hypothesis should be accepted for these data. Chi-square analysis results for Items 7-14 are detailed in Table 49.

Table 49

Chi-square Analysis Results for Age Range and Items 7 - 14 - (RQ5.6)

\begin{tabular}{lrlc}
\hline \multicolumn{1}{c}{ Item } & \multicolumn{1}{c}{$\mathrm{X}^{2}$} & \multicolumn{1}{c}{ df } & \multicolumn{1}{c}{$\mathrm{p}$} \\
\hline I7 - Technology-enabled classroom environment & 4.059 & 6 & .669 \\
I8 - Use technology-based tools to support instruction & 2.681 & 6 & .848 \\
I9 - Use video-based instruction to support activities & 13.221 & 6 & .040 \\
I10 - Use technology means to communicate w/ students & 4.312 & 6 & .635 \\
I11 - Encourage student communication using technology & 5.596 & 6 & .470 \\
I12 - Use smart or wireless devices to conduct lessons/materials & 6.357 & 6 & .384 \\
I13 - Used of guest speakers via technology-driven means & 9.692 & 6 & .138 \\
I14 - Students use web-based tools to complete assignments & 9.876 & 6 & .130 \\
\hline
\end{tabular}

When data were examined by age range, it was shown that 18 of the 30 levels of agreement were above $70 \%$, indicating high levels of agreement among the respondents disaggregated by age range (under $30,31-50$, under 50 ). This indicated that a majority of the respondents agreed with the statements in Items 15-24. A close examination of the data showed 10 of those agreement percentages were from respondents in the 31-50 and over 50 age range, five from each age range. Those percentages below $70 \%$ for those two age ranges were for the same items as well. Item 17, all sorts of activities going on in the classroom, showed agreement percentages of $68.0 \%$ for $31-50$ year olds and $69.77 \%$ for those over 50 .

Item 21, most important instruction encourages "sense-making" or thinking, showed rates of $68.69 \%$ and $61.42 \%$ for those $31-50$ and those over 50 respectively. Item 22, critical for students to become interested in doing academic work, showed agreement 
percentages of $59.41 \%$ (31-50) and $53.54 \%$ (over 50). Item 19, better to give the whole class the same assignment, presented agreement percentages under $70 \%$ for all three age ranges. Respondents under 30 reported $54.55 \%$, those $31-50$ showed $65.35 \%$ and those over $50,50.39 \%$. Item 20 , textbook core content is more important, not student motivation, also showed agreement percentages below $70 \%$ by all three age ranges. Percentages of $27.27 \%$ (under 30), 53.47\% (31-50) and $49.61 \%$ were reported. Agreement by a majority of participants was still indicated as only one item had two agreement percentage levels below 50\%. Item 20 indicated rates of agreement below $50 \%$ (27.27\% and $49.61 \%$ ) showing disagreement for only this item by both the under 30 and over 50 age ranges. The data details were presented in Table 50 .

Table 50

Frequency of Responses (Agree vs. Disagree) - Perceptions of Instructional Role (RQ5.6) - Disaggregated by Age Range

\begin{tabular}{|c|c|c|c|c|c|c|c|c|c|c|c|c|c|}
\hline \multirow[b]{3}{*}{ Variable } & \multicolumn{4}{|c|}{ Under 30} & \multicolumn{4}{|c|}{$31-50$} & \multicolumn{4}{|c|}{ Over 50} & \multirow[b]{3}{*}{$\mathrm{N}$} \\
\hline & \multicolumn{2}{|c|}{ Agree } & \multicolumn{2}{|c|}{ Disagree } & \multicolumn{4}{|c|}{ Agree Disagree } & \multicolumn{2}{|c|}{ Agree } & \multicolumn{2}{|c|}{ Disagree } & \\
\hline & $\mathrm{n}$ & $\%$ & $\mathrm{n}$ & $\%$ & $\mathrm{n}$ & $\%$ & $\mathrm{n}$ & $\%$ & $\mathrm{n}$ & $\%$ & $\mathrm{n}$ & $\%$ & \\
\hline $\begin{array}{l}\text { I15 - Role of facilitator; students } \\
\text { construct knowledge for selves }\end{array}$ & 10 & 90.91 & 1 & 9.09 & 81 & 80.20 & 20 & 19.80 & 98 & 75.97 & 31 & 24.03 & 241 \\
\hline $\begin{array}{l}\text { I16 - Most important part of } \\
\text { instruction is content/curriculum }\end{array}$ & 10 & 90.91 & 1 & 9.09 & 82 & 81.19 & 19 & 18.81 & 110 & 85.27 & 19 & 14.73 & 241 \\
\hline $\begin{array}{l}\text { I17 - All sorts of activities going on } \\
\text { in the classroom }\end{array}$ & 8 & 72.73 & 3 & 27.27 & 68 & 68.00 & 32 & 32.00 & 90 & 69.77 & 39 & 30.23 & 240 \\
\hline $\begin{array}{l}\text { I18 - Students learn basic skills in } \\
\text { context of mastering content }\end{array}$ & 9 & 81.82 & 2 & 18.18 & 84 & 83.17 & 17 & 16.83 & 115 & 89.15 & 14 & 10.85 & 241 \\
\hline $\begin{array}{l}\text { I19 - Better to give the whole class } \\
\text { same assignment-small intervals }\end{array}$ & 6 & 54.55 & 5 & 45.45 & 66 & 65.35 & 35 & 34.65 & 64 & 50.39 & 63 & 49.61 & 239 \\
\hline $\begin{array}{l}\text { I20 - Textbook core content is more } \\
\text { important-not student motivation }\end{array}$ & 3 & 27.27 & 8 & 72.73 & 54 & 53.47 & 47 & 46.53 & 63 & 49.61 & 64 & 50.39 & 239 \\
\hline $\begin{array}{l}\text { I21 - Most important instruction } \\
\text { encourages "sense-making"/thinking }\end{array}$ & 10 & 90.91 & 1 & 9.09 & 68 & 68.69 & 31 & 31.31 & 78 & 61.42 & 49 & 38.58 & 237 \\
\hline $\begin{array}{l}\text { I22 - Critical for students to become } \\
\text { interested in doing academic work }\end{array}$ & 10 & 90.91 & 1 & 9.09 & 60 & 59.41 & 41 & 40.59 & 68 & 53.54 & 59 & 46.46 & 239 \\
\hline $\begin{array}{l}\text { I23 - Material must be covered in a } \\
\text { structured way; job to explain }\end{array}$ & 8 & 72.73 & 3 & 27.27 & 77 & 76.24 & 24 & 23.76 & 92 & 71.32 & 37 & 28.68 & 241 \\
\hline $\begin{array}{l}\text { I24 - Students learn basic skills } \\
\text { while mastering complex content }\end{array}$ & 10 & 90.91 & 1 & 9.09 & 80 & 80.00 & 20 & 20.00 & 100 & 77.52 & 29 & 22.48 & 240 \\
\hline
\end{tabular}


Chi-Square analyses were also completed, checking for relationship perceptions of instructor role to age range (under 30, 31-50, over 50) of the respondents. According to Chi-square distribution tables, at a 0.05 level of significance (p) and 6 degrees of freedom (df) as specified for these items by SPSS, a Chi-square $\left(\mathrm{X}^{2}\right)$ value of 12.59 would show a relationship between the age range demographic and the survey item (Field, 2005; Fraenkel \& Wallen, 2006).

When data were analyzed, only one item, Item 9, use video-based instruction to support activities, yielded a significance level below 0.05 . The p-value indicated for this item was 0.40 , showing a relationship may exist. However, when the Chi-square value for Item 9 was more closely examined, it was above 12.59 at 13.221 . This indicates no relationship between age range and Item 9. As remaining items all exhibited significance levels above the .05 chosen for this study, it was determined that no items showed evidence of relationship between age range and Items 15-24. Therefore, the null hypothesis should be accepted for these data. The results of the Chi-square analysis for these items are shown in in Table 51.

Table 51

Chi-square Analysis Results for Age Range and Items 15 - 24 - (RQ5.6)

\begin{tabular}{lccc}
\hline \multicolumn{1}{c}{ Item } & $\mathrm{X}^{2}$ & $\mathrm{df}$ & $\mathrm{p}$ \\
\hline I15 - Role of facilitator; students construct knowledge for selves & 4.300 & 6 & .636 \\
I16 - Most important part of instruction is the content/curriculum & 2.641 & 6 & .852 \\
I17 - All sorts of activities going on in the classroom & .904 & 6 & .989 \\
I18 - Students learn basic skills in context of mastering content & 3.816 & 6 & .702 \\
I19 - Better to give the whole class same assignment-small intervals & 9.402 & 6 & .152 \\
I20 - Textbook core content is more important-not student motivation & 5.497 & 6 & .482 \\
I21 - Most important instruction encourages "sense-making"/thinking & 5.884 & 6 & .436 \\
I22 - Critical for students to become interested in doing academic work & 9.821 & 6 & .132 \\
I23 - Material must be covered in a structured way; job to explain & 4.330 & 6 & .632 \\
I24 - Students learn basic skills before mastering complex content & 8.089 & 6 & .232 \\
\hline
\end{tabular}


Data looking at perceptions of millennial learning styles were examined as divided by age range (under $30,31-50$, under 50 ). The data were examined by the frequencies and percentages of agreement versus disagreement for each age range. When analyzing the data, it was shown that there were large majority agreed with the statements describing millennial students' preferred learning styles. Of the 48 possible agreement percentages, 42 of those showed agreement by over $80 \%$ of the respondents. Further examination of the data showed only two of these agreement percentages were less than $70 \%$ with none below the 50\% agreement percentage level. Closer examination indicated the under 30 age range showed no responses of less than $80 \%$ agreement. Those in the $31-50$ age range represented four of the agreement ratings less than $80 \%$ and those over 50 showed two of the agreement percentage levels lower than $80 \%$.

Those items exhibiting percentages below $70 \%$ were Item 32 and Item 39. Item 32, students expect immediate feedback from teachers and peers, showed percentage levels of $72.23 \%$ by the age range $31-50$, and $78.29 \%$ by those over 50 . Item 39 , students show mastery of knowledge by various assessment, revealed the lowest agreement percentages. The $31-50$ age range gave a $61 \%$ agreement rating and the lowest percentage was given by the over 50 age ranges at $56.69 \%$.This data indicated that a large majority of Missouri higher education faculty agree with the statements made in Items 25-40, concerning millennial students' preferred learning styles. Data are further delineated in Table 52. 
Table 52

Frequency of Responses (Agree vs. Disagree) - Perceptions of Millennial Learning Styles

(RQ5.6) - Disaggregated by Age Range

\begin{tabular}{|c|c|c|c|c|c|c|c|c|c|c|c|c|c|}
\hline \multirow[b]{3}{*}{ Variable } & \multicolumn{4}{|c|}{ Under 30} & \multicolumn{4}{|c|}{$31-50$} & \multicolumn{4}{|c|}{ Over 50} & \multirow[b]{3}{*}{$\mathrm{N}$} \\
\hline & \multicolumn{2}{|c|}{ Agree } & \multicolumn{2}{|c|}{ Disagree } & \multicolumn{2}{|c|}{ Agree } & \multicolumn{2}{|c|}{ Disagree } & \multicolumn{2}{|c|}{ Agree } & \multicolumn{2}{|c|}{ Disagree } & \\
\hline & $\mathrm{n}$ & $\%$ & $\mathrm{n}$ & $\%$ & $\mathrm{n}$ & $\%$ & $\mathrm{n}$ & $\%$ & $\mathrm{n}$ & $\%$ & $\mathrm{n}$ & $\%$ & \\
\hline $\begin{array}{l}\text { I25 - Students establish understanding } \\
\text { based on individual experiences }\end{array}$ & 11 & 100.00 & $\begin{array}{ll}0 & 0\end{array}$ & 0.00 & 94 & 94.00 & 6 & 6.00 & 111 & 86.05 & 18 & 13.95 & 5240 \\
\hline $\begin{array}{l}\text { I26 - Students integrate learning } \\
\text { concepts into self-directed projects }\end{array}$ & 9 & 81.82 & 2 & 18.18 & 94 & 94.00 & 6 & 6.00 & 110 & 85.27 & 19 & 14.73 & 3240 \\
\hline $\begin{array}{l}\text { I27 - Students research new } \\
\text { concepts/questions further individually }\end{array}$ & 9 & 81.82 & 2 & 18.18 & 87 & 87.88 & 312 & 12.12 & 113 & 87.60 & 16 & 12.40 & 0239 \\
\hline $\begin{array}{l}\text { I } 28 \text { - Student pursue learning concepts } \\
\text { to create individual learning }\end{array}$ & 10 & 90.91 & 1 & 9.09 & 88 & 88.00 & 9 & 9.00 & 118 & 92.91 & 9 & 7.09 & 235 \\
\hline $\begin{array}{l}\text { I29 - Students explore a new learning } \\
\text { concept independently }\end{array}$ & 9 & 81.82 & 2 & 18.18 & 84 & 84.00 & 16 & 16.00 & 109 & 84.50 & 20 & 15.50 & 0240 \\
\hline $\begin{array}{l}\text { I30 - Students demonstrate methods to } \\
\text { realistically solve problems }\end{array}$ & 9 & 90.00 & 1 & 10.00 & 97 & 97.00 & 3 & 3.00 & 117 & 90.70 & 12 & 9.30 & 239 \\
\hline $\begin{array}{l}\text { I31 - Students connect current practice } \\
\text { to individual experiences }\end{array}$ & 11 & 100.00 & 0 & 0.00 & 97 & 97.00 & 3 & 3.00 & 119 & 92.97 & 9 & 7.03 & 239 \\
\hline $\begin{array}{l}\text { I32 - Students expect immediate } \\
\text { feedback from teachers and peers }\end{array}$ & 9 & 81.82 & 2 & 18.18 & 72 & 72.73 & 327 & 27.27 & 101 & 78.29 & 28 & 21.71 & 1239 \\
\hline $\begin{array}{l}\text { I33 - Students can apply knowledge } \\
\text { independently in other contexts }\end{array}$ & 11 & 100.00 & 0 & 0.00 & 95 & 95.00 & 5 & 5.00 & 118 & 91.47 & 11 & 8.53 & 240 \\
\hline $\begin{array}{l}\text { I34 - Students explain a learning } \\
\text { concept using individual perspectives }\end{array}$ & 11 & 100.00 & 0 & 0.00 & 95 & 94.06 & 56 & 5.94 & 117 & 91.41 & 11 & 8.59 & 240 \\
\hline $\begin{array}{l}\text { I35 - Students can work in groups to } \\
\text { establish individual knowledge }\end{array}$ & 11 & 100.00 & 0 & 0.00 & 79 & 79.00 & 21 & 21.00 & 109 & 84.50 & 20 & 15.50 & 0240 \\
\hline $\begin{array}{l}\text { I36 - Students work in groups to share } \\
\text { knowledge; reach agreement }\end{array}$ & 11 & 100.00 & 0 & 0.00 & 80 & 79.21 & 21 & 20.79 & 114 & 88.37 & 15 & 11.63 & 3241 \\
\hline $\begin{array}{l}\text { I37 - Students integrate learning of } \\
\text { concepts with other activities }\end{array}$ & 11 & 100.00 & 0 & 0.00 & 94 & 94.00 & 6 & 6.00 & 117 & 90.70 & 12 & 9.30 & 240 \\
\hline $\begin{array}{l}\text { I38 - Students understand individual } \\
\text { thinking ;seek independent help }\end{array}$ & 11 & 100.00 & 0 & 0.00 & 93 & 93.00 & 7 & 7.00 & 119 & 92.97 & 9 & 7.03 & 239 \\
\hline $\begin{array}{l}\text { I39 - Students show mastery of } \\
\text { knowledge by various assessments }\end{array}$ & 9 & 81.82 & 2 & 18.18 & 61 & 61.00 & 39 & 39.00 & 72 & 56.69 & 55 & 43.31 & 1238 \\
\hline $\begin{array}{l}\text { I } 40 \text { - Students relate experiences when } \\
\text { explaining learning concepts }\end{array}$ & 11 & 100.00 & 0 & 0.00 & 94 & 94.00 & 6 & 6.00 & 117 & 91.41 & 11 & 8.59 & 239 \\
\hline
\end{tabular}

$$
* \mathrm{n}=244
$$

Chi-Square analyses were also completed, checking for relationship of

perceptions of students' preferred learning styles to the age range reported by the

respondents. Six degrees of freedom was shown by SPSS for 13 of the items. According

to Chi-square distribution tables at a 0.05 level of significance (p) using six degrees of

freedom (df), a Chi-square $\left(\mathrm{X}^{2}\right)$ value of 10.65 is needed to show a relationship between 
the rank demographic and survey items (Field, 2005; Fraenkel \& Wallen, 2006). Three items reported four degrees of freedom. Chi-square distribution tables indicate at four degrees of freedom, when applying a 0.05 significance level, values should not be above 9.49 .

Data showed all survey items reported significance levels (p), greater than 0.05 , indicating no relationship. When the Chi-square values for the items were examined more closely, they were below the required 10.65 and 9.49 Chi-square values. However, as the significance levels were all greater than the 0.05 level chosen, it was deemed there was no relationship and the null hypothesis for Research Question 5.6 was accepted. Table 53 details data results.

Table 53

Chi-square Analysis Results for Age Range and Items 25 - 40 - (RQ5.6)

\begin{tabular}{lrrr}
\hline Item & $\mathrm{X}^{2}$ & $\mathrm{df}$ & $\mathrm{p}$ \\
\hline I25 - Students establish understanding based on individual experiences & 9.602 & 6 & .142 \\
I26 - Students integrate learning concepts into self-directed projects & 5.929 & 6 & .431 \\
I27 - Students research new concepts/questions further individually & 4.319 & 6 & .634 \\
I28 - Student pursue learning concepts to create individual learning & 2.708 & 4 & .608 \\
I29 - Students explore a new learning concept independently & 4.922 & 6 & .554 \\
I30 - Students demonstrate methods to realistically solve problems & 7.160 & 6 & .306 \\
I31 - Students connect current practice to individual experiences & 4.104 & 6 & .663 \\
I32 - Students expect immediate feedback from teachers and peers & 4.872 & 6 & .560 \\
I33 - Students can apply knowledge independently in other contexts & 2.866 & 6 & .825 \\
I34 - Students explain a learning concept using individual perspectives & 5.172 & 4 & .270 \\
I35 - Students can work in groups to establish individual knowledge & 7.122 & 6 & .310 \\
I36 - Students work in groups to share knowledge; reach agreement & 10.778 & 6 & .095 \\
I37 - Students integrate learning of concepts with other activities & 3.305 & 4 & .508 \\
I38 - Students understand individual thinking ;seek independent help & 4.963 & 6 & .549 \\
I39 - Students show mastery of knowledge by various assessments & 5.401 & 6 & .493 \\
I40 - Students relate experiences when explaining learning concepts & 5.745 & 6 & .452 \\
\hline
\end{tabular}




\section{Summary}

Chapter 4 provided an analysis of the data acquired to answer the research questions developed to guide this study. Statistical analyses were conducted to determine validity and reliability of the Survey of Higher Education Instructional Practices (SHEIP) and examine the utilization of technology-enhanced instructional practices by Missouri HE faculty. Missouri HE faculty perceptions of their instructional role and millennial students' preferred learning styles were also examined. The data indicated that a majority of Missouri higher education faculty survey participants reported employed technologyenhanced instructional practices in their classroom. The division of survey participants reporting using traditional instructor role, such as lecturer, and those using more contemporary instructor role, such as interactive projects and group work, were closely equal. Data also indicated that a majority of Missouri higher education faculty identified millennial students' preferred learning styles.

Chapter 5 investigated the implications of these findings. An introduction to the chapter was given, as well as a review of the research design, including the population chosen for the study. The findings from the data evaluation were next analyzed and discussed, including the conclusions drawn. Recommendations and thoughts for future studies were given. Finally a summary of the study and of Chapter 5 was offered. 


\section{CHAPTER FIVE}

\section{FINDINGS, CONCLUSIONS AND RECOMMENDATIONS}

This study created and tested a researcher-developed survey instrument, the Survey of Higher Education Instructional Practices (SHEIP). This survey was based on the Maine Learning Technology Initiative (MLTI) Teacher Survey Form B - Fall 2003 (Gritter, 2005), as summarized by Hawley (2004), and the Survey of Current Teaching Instructional Practice and Application of Internet Technology for University Faculty: Faculty Form (Li, 2008). Utilization of technology-enhanced instructional practices was investigated. Missouri higher education faculty perceptions concerning instructional role in the classroom and perceptions concerning millennial students' preferred learning styles were also explored.

Chapter 5 was presented in six sections. An overview, including statement of the problem, purpose of the study as well as the research questions and null hypotheses was first presented. Next summarized the study research design. This second section included a description of the population of the study group and statistical analysis methods employed for this research study. The third section provided a discussion of the findings. Findings were organized per research question, following a similar format to Chapter 4. Each research question was addressed and findings for the specific research question delineated. The fourth section of Chapter 5 furnished conclusions obtained from analyses of the data. Section five provided discussion of the findings and proposed recommendations for further studies. Lastly, the sixth section presented a summary of the study. 


\section{Overview}

As stated in Chapter 1 of this study, today's higher education institutions are experiencing a different type of student population than foregoing eras. Traditional students are known as "gadget fanatics, social networkers, Internet enthusiasts, optimists, multitaskers, and inductive learners" (Garcia, 2007, p. 12). Their viewpoints and aptitudes concerning technology differ from those rarely using it (Frand, 2000; Newton, 2000; Oblinger, 2003; Prensky, 2001a, 2008, 2012). Moreover, research indicates that this generation has been "connected" to technology almost since birth, (Bok, 2006; Carlson, 2005; Healy, 1998, 1999; Israel, 2006; Knapper, 2007; Nicoletti \& Merriman, 2007; Oblinger, 2005, Prensky, 2005; Skiba \& Barton, 2005). This “perpetual connection" has led to issues that must be addressed by universities (Carlson, 2005; Healy, 1998, 1999; Israel, 2006; Knapper, 2007; Nicoletti \& Merriman, 2007; Oblinger, 2005, Prensky, 2005; Skiba \& Barton, 2005).

For Millennials, using technology is as "fundamental as reading was for their parents and grandparents" (Prensky, 2012, p. 1). The extensive degree to which the current generation has been affected by technology is of critical importance to academia and presents challenges to higher education institutions (Christensen \& Eyring, 2011; Gorman, Nelson, \& Glassman, 2004; Tapscott, 1998, 2009). These issues have led higher education faculty and administrators to re-examine views of students and professors with regard to effective delivery systems (Bok, 2006; Carlson, 2005; McGlynn, 2005; Nevgi, Virtanen, \& Niemi, 2006; Nicoletti \& Merriman, 2007; Schneider, 2001). Facilities, faculty, and curriculum may not be prepared to address the demand of students' differing 
learning preferences and expectations (Christensen, et al. 2008; Christensen \& Eyring, 2011, Prensky, 2008).

\section{Statement of the Problem}

Current literature reveals millennial students prefer technology-enhanced instructional practices (Fine, 2008; Green, 2010; Oblinger, 2010; Oblinger \& Oblinger, 2005; Prensky, 2001a, 2001c, 2012; Tapscott, 1998, 2009). Furthermore, research indicated Millennials learn differently, preferring non-traditional instructor roles and different learning styles (Nicoletti \& Merriman, 2007; Oblinger, 2010; Oblinger \& Oblinger, 2005; Prensky, 2001a, 2012; Tapscott, 1998, 2009). However, little research determining utilization of technology-enhanced instruction by Missouri higher education faculty or faculty perceptions concerning their instructional role in college classrooms and millennial students' preferred learning styles was discovered. Additionally, the researcher's investigation yielded no known inventory or survey instrument assessing all three concepts examined in this study: (a) utilization of technology-enhanced instructional practices, (b) perceptions of Missouri higher education faculty concerning self-reported instructor role, and (c) perceptions of millennial students' preferred learning styles. The Survey of Higher Education Instructional Practices (SHEIP) would provide such an instrument to allow higher education to determine the utilization of technologyenhanced instruction and perceptions of instructor roles and learning styles shown by research to be preferred by current higher-education students.

\section{Purpose of the Study}

The primary purpose of this study was to design a valid and reliable survey instrument gauging three concepts: (a) utilization of technology-enhanced instructional 
practices, (b) perceptions of Missouri higher education faculty concerning self-reported instructor role, and (c) perceptions of millennial students' preferred learning styles. The secondary purpose of this study was to identify differences and similarities among various subsets of the data, examined by investigated concepts, as well as disaggregated by each demographic for individual survey items.

Current research indicated millennial students' learning preferences have evolved and the desire for technology-enhanced instructional practices have increased (Christensen, et al, 2008; Christensen \& Eyring, 2011; Green, 2010; Oblinger \& Oblinger, 2005; Prensky, 2001c, 2012; Tapscott, 1998, 2009), but little current research was discovered determining the utilization of technology-enhanced instructional practices by Missouri higher education faculty or perceptions concerning instructional role or students' preferred learning styles.

Higher education institutions nationwide are experiencing a disengagement of millennial students in the classroom (Levin \& Arafeh, 2002; Prensky, 2005, 2012; Tapscott, 1998, 2009; Woempner, 2007). Instructional practices previously deemed effective now seem to be unproductive at all levels of education (Prensky, 2001a, 2005; Tapscott, 1998, 2009). Traditionally used higher education teaching methodologies seem to be ineffective for the millennial student (McGlynn, 2008; Nicoletti \& Merriman, 2007). Nicoletti and Merriman (2007) asserted, "Millennial students are different with different learning styles requiring different teaching methods" (p. 28). McGlynn (2008) states, "these students learn ... and interact differently than former students" (p. 13). While research shows instructional practices currently employed by higher education faculty may not be meeting learning preferences of millennial students, little is 
shown to have been done to bring about change. Little information was discovered concerning the use of technology-enhanced instructional practices, shown by research to be preferred by millennial students (Christensen, et al, 2008; Green, 2010; Prensky, 2001c, 2012; Tapscott, 1998, 2009). A gap in the knowledge concerning higher education faculty perceptions of millennial students and their preferred learning styles as well as perceptions of instructor role was also perceived (Prensky, 2001a, 2001b, 2005; Tapscott, 1998, 2009).

Research Questions and Null Hypotheses

Five research questions were developed to guide this study. The questions, subquestions and null hypotheses follow.

\section{Research Question 1}

Is the Survey of Current Instructional Practices and Perceptions reliable and valid?

Sub research question 1.1. Is the survey instrument valid?

Sub research question 1.2. Is the survey instrument reliable?

$\mathrm{H}_{0} 1$ : The Survey of Current Instructional Practices and Perceptions is neither reliable nor valid.

\section{Research Question 2}

To what degree do Missouri HE faculty significantly utilize technology-enhanced instructional practices (Items 7-14)?

$\mathrm{H}_{\mathrm{o}}$ 2: Missouri HE faculty do not significantly utilize technology-enhanced instructional practices when applying a .05 significance level. 


\section{Research Question 3}

To what degree do Missouri HE faculty perceptions of their instructional role in the classroom significantly match those identified in current research as preferred by millennial students (Items 15-24)?

$\mathrm{H}_{\mathrm{o}} 3$ : Missouri HE faculty perceptions of their instructional role in the classroom do not significantly match those identified in current research as preferred by millennial students.

\section{Research Question 4}

To what degree do Missouri HE faculty perceptions of millennial students' learning characteristics significantly match learning characteristics identified in current research (Items 25-40)?

Ho4: Missouri HE faculty perceptions of millennial students' learning characteristics do not significantly match learning characteristics identified in current research.

\section{Research Question 5}

What are the overall summary statistics broken down by demographic(Items 1-6)?

Sub research question 5.1. What are the significant differences of responses among the different types of Missouri HE institutions (Item 1) - (2-year, 4-year public and 4-year private) as determined by frequency counts and percentages and Chi square analysis applying a .05 significance level?

Sub research question 5.2. What are significant differences of responses among the various size institutions based on Carnegie Size Classifications (Item 2) - (Very small 2year (<500 FTE student enrollment), small 2-year (500-1,999 FTE student enrollment), 
medium 2-year (2,000-4,999 FTE student enrollment), large 2-year (5,000-9,999 FTE student enrollment), very large 2-year (10,000 or more FTE student enrollment), very small 4-year (< 1,000 FTE student enrollment), small 4-year (1,000-2,999 FTE student enrollment), Medium 4-year (3,000-9,999 FTE student enrollment), and Large-4 year (10,000 or more FTE student enrollment) as determined by frequency counts and percentages and Chi square analysis applying a .05 significance level?

Sub research question 5.3. What are the significant differences of responses among Departments (Item 3) as determined by frequency counts and percentages and Chi square analysis at a .05 significance level?

Sub research question 5.4. What are the significant differences in responses among Rank (Item 4) - (Adjunct, Instructor, Assistant Professor, Associate Professor, and Full Professor) as determined by frequency counts and percentages and Chi square analysis applying a .05 significance level?

Sub research question 5.5. What are the significant differences in responses between Gender (Item 5) - (Male and Female) as determined by frequency counts and percentages and Chi square analysis applying a .05 significance level?

Sub research question 5.6. What are the significant differences in responses among Age Range (Item 6) - (Under 30, 31-50, and Over 50) as determined by frequency counts and percentages and Chi square analysis applying a .05 significance level?

$\mathrm{H}_{\mathrm{o}} 5$ : There are no significant differences among respondents according to demographics when applying a .05 significance level.

Table 54 details each research question, the purpose, the statistical methodologies applied to the data and the outcomes. 
Table 54

Summation of Research Questions and Applied Statistical Techniques

\begin{tabular}{|c|c|c|c|}
\hline Research Question & Purpose & Methodology & Anticipated Outcome \\
\hline $\begin{array}{l}\text { RQ1 - Is the Survey of } \\
\text { Higher Education } \\
\text { Instructional Practices } \\
\text { valid and reliable? }\end{array}$ & $\begin{array}{l}\text { To determine validity } \\
\text { and reliability of survey } \\
\text { items }\end{array}$ & $\begin{array}{l}\text { Expert Panel Pilot Survey (RQ1.1) } \\
\text { Cronbach's alpha (RQ1.2) }\end{array}$ & $\begin{array}{l}\text { The validity and reliability } \\
\text { of the Survey of Higher } \\
\text { Education Instructional } \\
\text { Practices (SHEIP) will be } \\
\text { established }\end{array}$ \\
\hline $\begin{array}{l}\text { RQ2- To what degree are } \\
\text { Missouri HE faculty } \\
\text { utilizing technology- } \\
\text { enhanced instructional } \\
\text { practices (Items 7-14)? }\end{array}$ & $\begin{array}{l}\text { To determine utilization } \\
\text { of technology-enhanced } \\
\text { instructional practices } \\
\text { by Missouri HE faculty }\end{array}$ & $\begin{array}{l}\text { Univariate analysis including: } \\
\text { Cross tabulations and graphs } \\
\text { showing frequency counts and } \\
\text { percentages } \\
\text { Measures of central tendency and } \\
\text { dispersion; mean, median, mode } \\
\text { and standard deviation }\end{array}$ & $\begin{array}{l}\text { The degree of technology- } \\
\text { enhanced instruction } \\
\text { utilization by MO HE } \\
\text { faculty will be established }\end{array}$ \\
\hline $\begin{array}{l}\text { RQ3- To what degree do } \\
\text { Missouri HE faculty } \\
\text { perceptions of their } \\
\text { instructional role in the } \\
\text { classroom match those } \\
\text { identified in current } \\
\text { research as preferred by } \\
\text { millennial students (Items } \\
\text { 15-24)? }\end{array}$ & $\begin{array}{l}\text { To determine } \\
\text { perceptions of Missouri } \\
\text { HE faculty concerning } \\
\text { classroom instructional } \\
\text { roles and the "match" to } \\
\text { millennial students' } \\
\text { learning preferences }\end{array}$ & $\begin{array}{l}\text { Univariate analysis including: } \\
\text { Cross tabulations and graphs } \\
\text { showing frequency counts and } \\
\text { percentages } \\
\text { Measures of central tendency and } \\
\text { dispersion; mean, median, mode } \\
\text { and standard deviation }\end{array}$ & $\begin{array}{l}\text { The perceptions of MO HE } \\
\text { faculty concerning their } \\
\text { instructional role will be } \\
\text { reported and the degree to } \\
\text { which these correspond to } \\
\text { identified Millennial } \\
\text { learning styles will be } \\
\text { established. }\end{array}$ \\
\hline $\begin{array}{l}\text { RQ4- To what degree do } \\
\text { Missouri HE faculty } \\
\text { perceptions of millennial } \\
\text { students' learning } \\
\text { characteristics match } \\
\text { learning characteristics } \\
\text { identified in current } \\
\text { research (Items 25-40)? }\end{array}$ & $\begin{array}{l}\text { To determine Missouri } \\
\text { HE faculty perceptions } \\
\text { of millennial students' } \\
\text { learning characteristics } \\
\text { as identified by research }\end{array}$ & $\begin{array}{l}\text { Univariate analysis including: } \\
\text { Cross tabulations and graphs } \\
\text { showing frequency counts and } \\
\text { percentages } \\
\text { Measures of central tendency and } \\
\text { dispersion; mean, median, mode } \\
\text { and standard deviation }\end{array}$ & $\begin{array}{l}\text { The perceptions of MO HE } \\
\text { faculty concerning } \\
\text { millennial students' } \\
\text { learning characteristics and } \\
\text { the degree to which these } \\
\text { match those identified by } \\
\text { research will be } \\
\text { established. }\end{array}$ \\
\hline $\begin{array}{l}\text { RQ5- What are the overall } \\
\text { summary statistics broken } \\
\text { down by demographic } \\
\text { (Items 1-6)? }\end{array}$ & $\begin{array}{l}\text { To compare summary } \\
\text { results disaggregated by } \\
\text { the various } \\
\text { demographic items }\end{array}$ & $\begin{array}{l}\text { Chi Square } \\
\text { Cross tabulations showing } \\
\text { frequency numbers and percentages } \\
\text { of each survey item disaggregated } \\
\text { for each of the six demographic } \\
\text { items }\end{array}$ & $\begin{array}{l}\text { The number and percent for } \\
\text { each scale response will be } \\
\text { reported by demographic } \\
\text { Similarities and differences } \\
\text { among the various } \\
\text { demographic groups will } \\
\text { be identified }\end{array}$ \\
\hline
\end{tabular}




\section{Research Study Design}

This research employed a quantitative, non-experimental, descriptive research design. Quantitative research is defined as research involving the collection of data in numerical form and analyzed numerically (Field, 2005; Springer, 2010). Furthermore, according to experts, a non-experimental, descriptive design includes utilization of a survey instrument (Springer, 2010). Springer (2010) and Trochim (2006) both postulate stratified random sampling is the process of dividing the population into subgroups, then randomly choosing a specific number of participants from each subgroup.

As the population for this study included faculty at Missouri higher education institutions and subgroups were formed from this population (2-year public, 4-year public and 4-year private institutions), followed by the random selection of 5 institutions from each of these subgroups, this study employed stratified random sampling (Springer, 2010; Trochim, 2006). Furthermore, this is a cross-sectional study as it takes place at a single point in time (Springer, 2010; Trochim, 2006). Accordingly, this study utilized a quantitative, non-experimental, descriptive research design employing stratified random sampling to investigate five research questions identified earlier in this dissertation (Field, 2005; Springer, 2010; Trochim, 2006).

\section{Statistical Methods}

Statistical techniques used in this study to determine validity and reliability include an expert panel pilot of the survey instrument and Cronbach's alpha (Field, 2005). Univariate analysis techniques, including cross tabulations showing frequency counts and frequency percentages, as well as the measures of central tendencies including mean, median, mode and standard deviation were also utilized. Contingency tables are 
used to depict the relationship between categorical variables and report descriptive statistics (Field, 2005; Fraenkel \& Wallen, 2006; Springer, 2006). Thus, cross tabulations or contingency tables were used to show frequency numbers and percentages for data in this study. Chi square analyses were applied for each demographic item and individual survey items. This nonparametric test can provide information concerning the strength of association or relationship between variables (Field, 2005; Fraenkel \& Wallen, 2006; Springer, 2006).

An expert panel pilot of the Survey of Higher Education Instructional Practices (SHEIP) was completed to determine the content validity of survey items. Cronbach's alpha was also utilized to determine reliability of the survey items as it was shown to be a statistical technique to measure internal consistency or reliability (Field, 2005; Fraenkel \& Wallen, 2006; Springer, 2006). The dependent variables within the last three sections of the survey which examined utilization of technology-enhanced instructional practices, perceptions of instructional role and perceptions of students' preferred learning styles were investigated using univariate analyses. This investigation included cross tabulations or contingency tables, showing frequency counts and percentages as well as measures of central tendency including mean, median, mode, standard deviation and variance.

To investigate the dependent variables disaggregated by each demographic, cross tabulations or contingency tables, illustrating frequency numbers and percentages were implemented (Field, 2005; Fraenkel \& Wallen; 2006, Springer, 2006). To determine significance or relationship between survey items and demographics the statistical Chisquare test was employed (Field, 2005; Fraenkel \& Wallen; 2006; Springer, 2006). Table 55 further illustrates the statistical techniques and information for each research question. 
Table 55

Summary of Data Sources, Types and Analysis Applied by Research Question

\begin{tabular}{|c|c|c|c|c|c|c|}
\hline $\begin{array}{l}\text { Research } \\
\text { Question } \\
\#\end{array}$ & $\begin{array}{c}\text { Data } \\
\text { Source }\end{array}$ & $\begin{array}{l}\text { Number } \\
\text { of Items }\end{array}$ & $\mathrm{N}$ & $\begin{array}{l}\text { Response } \\
\text { Type }\end{array}$ & $\begin{array}{l}\text { Data } \\
\text { Type }\end{array}$ & $\begin{array}{c}\text { Analysis } \\
\text { Applied }\end{array}$ \\
\hline 1.1 & $\begin{array}{l}\text { Survey } \\
\text { Responses }\end{array}$ & 40 & 9 & Likert Scale & Nominal & $\begin{array}{l}\text { Expert Panel Pilot } \\
\text { Survey }\end{array}$ \\
\hline 1.2 & $\begin{array}{l}\text { Survey } \\
\text { Items }\end{array}$ & 40 & 40 & Likert Scale & Nominal & Cronbach's alpha \\
\hline 2 & $\begin{array}{l}\text { Survey } \\
\text { Responses }\end{array}$ & 8 & 244 & Likert Scale & Nominal & $\begin{array}{l}\text { Univariate } \\
\text { Analysis }\end{array}$ \\
\hline 3 & $\begin{array}{l}\text { Survey } \\
\text { Responses }\end{array}$ & 10 & 243 & Likert Scale & Nominal & $\begin{array}{l}\text { Univariate } \\
\text { Analysis }\end{array}$ \\
\hline 4 & $\begin{array}{l}\text { Survey } \\
\text { Responses }\end{array}$ & 16 & 244 & Likert Scale & Nominal & $\begin{array}{l}\text { Univariate } \\
\text { Analysis }\end{array}$ \\
\hline 5.1 & $\begin{array}{l}\text { Survey } \\
\text { Responses }\end{array}$ & 35 & 244 & Likert Scale & Nominal & $\begin{array}{l}\text { Chi Square \& } \\
\text { Cross } \\
\text { Tabulations }\end{array}$ \\
\hline 5.2 & $\begin{array}{l}\text { Survey } \\
\text { Responses }\end{array}$ & 35 & 243 & Likert Scale & Nominal & $\begin{array}{l}\text { Chi Square \& } \\
\text { Cross } \\
\text { Tabulations }\end{array}$ \\
\hline 5.3 & $\begin{array}{l}\text { Survey } \\
\text { Responses }\end{array}$ & 35 & 228 & Likert Scale & Nominal & $\begin{array}{l}\text { Chi Square \& } \\
\text { Cross } \\
\text { Tabulations }\end{array}$ \\
\hline 5.4 & $\begin{array}{l}\text { Survey } \\
\text { Responses }\end{array}$ & 35 & 237 & Likert Scale & Nominal & $\begin{array}{l}\text { Chi Square \& } \\
\text { Cross } \\
\text { Tabulations }\end{array}$ \\
\hline 5.5 & $\begin{array}{l}\text { Survey } \\
\text { Responses }\end{array}$ & 35 & 242 & Likert Scale & Nominal & $\begin{array}{l}\text { Chi Square \& } \\
\text { Cross } \\
\text { Tabulations }\end{array}$ \\
\hline 5.6 & $\begin{array}{l}\text { Survey } \\
\text { Responses }\end{array}$ & 35 & 244 & Likert Scale & Nominal & $\begin{array}{l}\text { Chi Square \& } \\
\text { Cross } \\
\text { Tabulations }\end{array}$ \\
\hline
\end{tabular}




\section{Findings and Conclusions}

This section contains five sub-sections, delineated by the study's research questions and summarizes the findings of data analyses. These findings were obtained from the data analyses delineated earlier, principally in Chapter 4 of this research study. Research Question 1 - Validity and Reliability Measures

According to research, the "quality of the instruments used in research is very important" (Fraenkel \& Wallen, 2006) and in order for credence to be given to the findings of the study, validity and reliability need to be proven (Springer, 2006).

Research Question 1 stated "Is the Survey of Higher Education Instructional Practices (SHEIP) valid and reliable?" More specifically, Research Question 1.1 asked "Is the survey instrument valid?" and Research Question 1.2 asked "Is the survey instrument reliable?" Expert panel members completed a pilot survey and answered six questions designed to gather feedback and show content validity of the SHEIP. Based on the expert panel's survey completion and feedback, the SHEIP possessed content valid.

In order to determine reliability, Cronbach's alpha coefficient was determined and results examined. According to Field (2005), Cronbach's alpha values above 0.7 are deemed acceptable indicators of reliability. Values above 0.7 were determined, thus proving reliability of the survey instrument. Cronbach's alpha of 0.735 was shown when all 40 survey items from the SHEIP were evaluated, indicating reliability among these questions.

Field (2005) also stated "if several factors exist, then the formula should be applied separately to items relating to different factors" (p.668). Although the 40 survey items were shown to be reliable, it was decided more in depth analysis could be 
completed. A Cronbach's alpha analysis would be completed for each subset or section of the Survey of Higher Education Instructional Practices (SHEIP) as three distinct concepts were part of this survey. The first section was considered to be Survey Items 7-14, examining technology-enhanced instructional practices. The second section consisted of Items 15-24, examining perceptions of instructor role, while the third distinct section consisted of Items 25-40, pertaining to perceptions of millennial students' preferred learning styles.

When items from each subsection of the SHEIP were further evaluated, reliability was still shown. The survey items examining technology enhanced instruction (Items 714) returned a Cronbach's alpha value of 0.714 , again deemed acceptable (Field, 2005). Items 15-24, pertaining to instructor role, yielded a Cronbach's alpha of 0.457. As a reliability measure, this was deemed weak (Field, 2005). This section of the survey contained 10 items which were focusing on two different concepts, traditional versus contemporary instructor roles. The researcher used SPSS to find the Cronbach's alpha for each of the concepts.

Cronbach's alpha for the group of items examining traditional instructor role returned a value of 0.553 . The statements focused on contemporary teaching roles yielded a Cronbach's alpha of 0.624 . While neither met the 0.70 benchmark for acceptable, the Cronbach's alpha scores were higher when the questions were separated. As statistical experts stated, depending on the diversity of the data being measured, Cronbach's alpha values below 0.70 can realistically be considered valid (Field, 2005). Another consideration was the fact that the survey items in the section examining instructor role were worded differently than the items in the other survey sections. The participants were 
asked to indicate their agreement with a statement, rather than choose how often they use an instructional practice or what they believe their students should do. According to Field (2005), "in reliability analysis, these reverse-scored items do make a difference" (p. 669). As these survey sections were "different" or diverse, the researcher deemed all survey items were reliable, even with lower Cronbach's alpha score.

The Cronbach's alpha for the final section of SHEIP, Items 24-40, examining Missouri higher education faculty perceptions of millennial students' preferred learning styles, was 0.892 . This result was well above the 0.70 result needed to be deemed acceptable, showing evidence these survey items were highly reliable or had "good reliability" (Field, 2005, p. 667). Furthermore, as the data from the expert panel pilot survey indicated content validity and the Cronbach's alpha value for all survey items was deemed acceptable at 0.0735 , indicated reliability, the null hypothesis $\mathrm{H}_{\mathrm{o}} 1$ was rejected, indicating the Survey of Higher Education Instructional Practices (SHEIP) was both valid and reliable. The valid and reliable survey could help higher education institutions identify facultys' use of technology-enhanced instruction, instructor role in the classroom and how millennial students are perceived. Identifying these factors could assist higher education institutions to determine innovations which need to be implemented to facilitate the learning students demand and assure higher education institutions remain completive in the rapidly changing world of higher education.

\section{Research Question 2 - Utilization of Technology-Enhanced Instruction}

Research Question 2 examined faculty utilization of technology-enhanced instructional practices as determined by univariate analysis, including cross tabulations or contingency tables of frequency counts and percentages. Analysis of the data indicated 
that a majority of study participants utilized the technology-enhanced instructional tools addressed in survey items 7-14. The only two items which indicated percentages less than 50\% were Item 12 and Item 13. Item 12 stated "I use smart or wireless devices (iPhone, Android, iPods, tablets, etc.) to conduct course lessons or disperse course materials." Item 13 stated "I make use of guest speakers via technology-driven means (i.e. Skype, WebMeeting, etc.)". Both items both referred to newer technology tools which it seems have not yet been adopted by higher education faculty.

As technology-enhanced instructional practices were revealed in the literature as preferred by millennial students (Carlson, 2005; Howe \& Strauss, 2007; Tapscott, 1998, 2009), adoption of these classroom tools in higher education is significant for higher education in meeting the learning needs of their students. Additionally, high level of agreement by survey respondents indicated that a majority ( $>50 \%)$ of Missouri higher education faculty do significantly utilize technology-enhanced instructional practices. This signified null hypothesis $\mathrm{H}_{\mathrm{o}} 2$ for Research Question 2 should be rejected, implying that Missouri higher education faculty do show significant utilization of technologyenhanced instructional practices. Higher education adoption of technology-enhanced instruction provides one manner to better assist millennial students' learning and provide innovations needed to remain successful and competitive (Christensen \& Eyring, 2011). Research Question 3 - Perceptions of Missouri HE Faculty Concerning Instructional Role

Research Question 3 assessed Missouri higher education faculty perceptions concerning their instructional role in the classroom and the match to those identified as preferred by millennial students. Research indicated millennial students prefer a more 
contemporary or interactive instructor role (Carlson, 2005; Howe \& Strauss, 2007, Prensky, 2001; Tapscott, 1998, 2009) referred to a "guide on the side" instructor by King (1993). Millennials think and learn in a different manner and traditional methods of instruction taking place on most campuses may no longer meet students' learning needs (Carlson, 2005; Howe \& Strauss, 2007; Prensky, 2001; Tapscott, 1998, 2009). As stated by Prensky (2001c), “today's students are no longer the people our educational system was designed to teach" (p.1).

Data collected from SHEIP items 15-24 were used to assess these perceptions of instructor role. The 10 survey items were further divided and examined to determine traditional instructor role or "sage on the stage" role (King, 1993; Howe \& Strauss, 2007; Oblinger \& Oblinger, 2005; Prensky, 2005; Skiba \& Barton, 2006; Tapscott, 1998) perceptions as indicated by SHEIP Items 16, 19, 20, 23 and 24) versus a more "guide on the side" role (King, 1993; Howe \& Strauss, 2007; Oblinger \& Oblinger, 2005; Prensky, 2005; Skiba \& Barton, 2006; Tapscott, 1998) or contemporary instructor role, as shown by SHEIP Items 15, 17, 18, 21 and 22.

Univariate analysis was completed and frequency counts and percentages examined. Data indicated that traditional instructional role displayed a $66.98 \%$ agreement rating with 834 responses while contemporary instructional role yielded a $71.37 \%$ agreement with 860 responses. This indicated a majority of Missouri higher education faculty perceive they adopt a more contemporary or "guide on the side" (King, 1993) instructor role. This majority agreement led the researcher to reject the null hypothesis for Research Question 3 and conclude that Missouri higher education faculty perceptions of instructor role do match that preferred by millennial students. This indicates to address 
educational needs of millennial students, higher education institutions may be transitioning for the "old generation of learning" to the "new generation of learning" and changes conceivably are being implemented to better meet the learning preferences of current students (Christensen, et al., 2008; Christensen \& Eyring, 2011; Milliron, 2000).

Data gathered in this research study showed a majority $(>50 \%)$ of the respondents reported agreement with contemporary instructor role, matching millennial students' preferred learning styles (King, 1993; Howe \& Strauss, 2007; Oblinger \& Oblinger, 2005; Prensky, 2005; Skiba \& Barton, 2006; Tapscott, 1998). This signified null hypotheses $\mathrm{H}_{\mathrm{o}} 3$ should be rejected, indicating that Missouri higher education faculty perceptions of their instructor role do significantly match those identified in current research as preferred by millennial students. However, with only 26 fewer faculty supporting traditional instructor, higher education needs to continue to innovate and implement more contemporary instructor roles, including more interactive learning, technology-enhanced instruction and "student-centered" practices.

\section{Research Question 4 - Perceptions of Missouri HE Faculty Concerning Millennial}

\section{Students' Preferred Learning Styles}

Research Question 4 assessed Missouri higher education faculty perceptions concerning millennial students' learning characteristics and the match to learning characteristics identified as preferred in current research. Research indicates millennial students prefer learning differently than students of previous eras (Oblinger, 2003; Tapscott, 1998, 2009; Strauss \& Howe, 2000). This research question assessed data collected from survey items $25-40$. Frequency counts and percentages for these items were analyzed, with the data indicating there were strong levels of agreement among 
respondents, with 15 of the 16 items demonstrating agreement levels above $70 \%$. Item 39 was identified as the only survey item with percentage ratings below $70 \%$, but it still indicated agreement showing an agreement level of 59.6\%.

Millennials are dissimilar from any generation of students before them and these disparities are present not only in traits and characteristics, but also in learning styles (Howe \& Strauss, 2000; Jonas-Dwyer \& Pospisil, 2004; McGlynn, 2005; Skiba \& Barton, 2006). Understanding of the learning styles preferred by students will allow faculty to better meet their learning needs (Prensky, 2005, Tapscott, 2009). The strong level of agreement shown by the data indicated Missouri higher education faculty do perceive millennial students' preferred learning styles as identified in current research. This indication led the researcher to reject null hypothesis, $\mathrm{H}_{0} 4$, and conclude Missouri higher education faculty perceptions of millennial students' learning characteristics match millennial characteristics as identified in current research. For higher education to continue innovating learning on their campuses and changing instruction to meet the different learning needs of their current students, it is imperative that both higher education faculty and administration understand the learning preferences. Research Question 5 - Overall Summary Statistics by Demographic

Research Question 5 examined the summary statistics broken down by each demographic. When the frequencies and percentages were examined for each demographic, data showed fairly equal distribution for all respondents among three of the demographics. Three demographics variables were skewed when responses were broken by demographic. Type of institution showed 4-Year public responsible for 157 of the 244 responses or $64.34 \%$. Size of institution as categorized by Carnegie Size Classification 
showed 108 or $44.44 \%$ of responses for Medium 4-Year in a demographic containing eight categories and 244 responses. Age range showed $64.3 \%$ or 157 of responses came from one of the three divisions, 31-50.

Sub Research Question 5.1 examined the significant differences of responses among the different types of Missouri HE institutions (Item 1) - (2-Year, 4-Year public and 4-Year private). Examination of the data revealed a majority of all types of the institutions studied utilized technology-enhanced instructional practices. The 2-Year institutions showed the highest level of usage on five of the eight items, while 4-Year private institutions showed the highest level of utilization on two of the eight items. None of the highest levels of utilization was reported by 4-Year public institutions, but when the lowest utilization levels were analyzed, it was shown that 4-Year public institutions reported the lowest rate on four of the eight items. While Items 12 and 13 showed the lowest overall utilization rate overall, 2-Year institutions demonstrated the highest utilization rates $(33.33 \%$ and $11.11 \%$, respectively). Traditionally, instructional practices employed by education have not used technology as anything more than a presentation mode (Fine, 2008; Howe \& Strauss, 2007; McGlynn, 2008; Prensky, 2001a). All types of institutions need to use technology-enhanced instructional practices to "spawn engagement" and "allow students to follow spontaneous ideas and interests" (Jukes, et al., 2011, p. 17) and fit into identified Millennial preferred learning modes (Oblinger \& Oblinger, 2005; Prensky, 2005; Tapscott, 1998, 2009). The data indicates this circumstance.

When responses for items 15-24, pertaining to instructor role, were examined, it was shown there were few differences among the types of institutions regarding all ten 
items. When the items were disaggregated and examined as to traditional versus contemporary instructor roles, the percentages were close. It was apparent that 2-Year institutions did show the highest levels of agreement with all five of the items indicating traditional instructor role. Contemporary role was $1.9 \%$ higher overall when agreement ratings were more closely examined, perhaps indicating while higher education as a whole may employ traditional instructor role, perhaps the trend is changing. However, since the values assessing contemporary versus traditional instructor roles were closely equivalent, higher education needs to continue to adopt more contemporary instructor roles and continue to innovate the learning occurring in higher education classrooms to assure the learning needs of millennial students are met.

When examining responses for the items referring to preferred student learning styles (Items 25-40), strong agreement (>50\%) was shown by all the types of institutions (2-year, 4-year public, 4-year private). The data indicated that a majority of the respondents for all of the institutions divided by type, understood how their students preferred to learn. To assure changing student learning demands are met, higher education faculty must be encouraged to "meet students where they are" (Blackboard, 2007). Higher education institutions need to continue to provide faculty needed information to assure millennial students' learning preferences are understood.

Sub Research Question 5.2 examined the survey data by size of institution, based on the Carnegie Size Classification. When responses were examined for Items 7-14, it showed that a majority of the institutions indicated utilization of technology-enhanced instruction. While schools have typically resisted integrating technology into everyday instructional practices, Millennials have embraced and implemented technology, both in 
their personal and academic lives, and bring this expectation to the higher education classroom (Tapscott, 1998, 2009). Faculty included in this study seem to be making this transition. Use of newer technologies, indicated in Item 12, pertaining to using smart or wireless devices and Item 13, pertaining to use of guest speakers via technology-driven means showed low utilization rates by all sizes of the participating institutions. Item 11 , encouraging students to communicate using technology, showed lower levels of agreement by large 4-year institutions, perhaps indicative of its size and the number of students. All higher education institutions need to continue to encourage faculty adoption of new technologies, especially those shown to be readily adopted by millennial students.

Examination of Items 15-24, pertaining to perceptions of instructor role, showed the data to be dispersed fairly equally among the various size categories of institutions. Closer scrutiny showed responses to be slightly higher for the 4-year institutions overall when examined by traditional versus contemporary instructor role. The other sizes of institutions show higher levels of agreement with the items showing agreement with the contemporary instructor role. Higher education faculty are discerning students do not respond to the same degree when employing traditional teaching methods (Carlson, 2005; Howe \& Strauss, 2007; Tapscott, 1998). Missouri higher education faculty are shown by the data to be employing these desired instructor roles and all faculty need to continue to adopt more contemporary instructional roles to teach course content.

Examination of Items 25-40, related to students' preferred learning styles, showed agreement by almost all size categories with only one of the 144 agreement percentages being below $50 \%$. Understanding how students prefer to learn enables faculty to better 
meet their learning needs (Christensen, et al., 2008; Tapscott, 1998) and needs to be encouraged by all higher education institutions.

Sub Research Question 5.3 examined the survey data disaggregated by department. When responses were examined for Items 7-14, it showed that a majority of the departments did indicate utilization of technology-enhanced instruction, with the exception of smart and wireless device use in the classroom and use of guest speakers via technology-driven means. None of the departments reported a majority usage for those two items. Nine other responses showed less than $50 \%$ agreement ratings as well. Research shows that millennial students prefer learning through the use of technology (Prensky, 2001a, Tapscott, 1998, 2005). In order to most effectively meet students' learning needs, departments need to continue to increase technology usage to show agreement for all items as shown on the survey.

Examination of Items 15-24, pertaining to perceptions of instructor role, showed the data to be dispersed fairly equally among the various departments. Closer scrutiny showed 10 of the 120 responses were less than $50 \%$. Those 10 responses were shown to be on three items which all pertained to items indicating traditional instructor role. With a shifting student body, it is imperative that education understand the learning needs of students (Bok, 2006; Carlson, 2005; Oblinger \& Oblinger, 2005). As higher education faculty are discerning students do not respond to the same degree when employing traditional teaching methods (Carlson, 2005; Howe \& Strauss, 2007; Tapscott, 1998) respondents within all departments need to continue to shift to more contemporary instructor roles to continue to meet the learning needs of their students. 
Examination of Items 25-40, related to students' preferred learning styles, showed agreement by almost departments with only one item, students show mastery of knowledge by various assessments, indicating percentages of agreement below $50 \%$ by four of the twelve departments. A disconnect exists between Millennials' learning styles and higher education (Jukes, et al., 2010; Prensky, 2001a, 2001c; Tapscott, 1998, 2009). Departments seem to comprehend students' preferred learning styles, but need to continue to change according to how students prefer to better meet their learning needs (Christensen, et al., 2008; Tapscott, 1998).

Sub Research Question 5.4 looked at responses to survey items disaggregated by rank. Responses for Items 7-14, it showed that a majority of the departments did indicate utilization of technology-enhanced instruction, with the exception of smart and wireless device use in the classroom and use of guest speakers via technology-driven means which showed agreement levels $>50 \%$ by none of the ranks. Two other responses showed less than 50\% agreement concerning encouraging student communication using technology (Item 11). It is shown by research that today's students are dissimilar and these disparities are present in preferred learning styles (Howe \& Strauss, 2000; McGlynn, 2005; Skiba \& Barton, 2006). All ranks at higher education institutions need to continue to adopt technology, exploring even the newer available technology tools. All ranks need to continue to increase technology usage to confirm majority usage for all technologyenhanced instructional practices included on the survey.

Examination of Items 15-24, pertaining to perceptions of instructor role, showed agreement of over $50 \%$ for 47 of the 50 rank responses. Closer scrutiny showed three of those responses, two (adjunct and assistant professor) for textbook core content is more 
important, not student motivation and one (full professor) for better to give the whole class the same assignment. This indicated all three items showing disagreement referred to a traditional instructor role. As Millennials prefer a "learner-centered model", a shift from a traditional teaching paradigm to a more contemporary learning paradigm needs to take place (Prensky, 2005; Skiba \& Barton, 2006). Faculty are recognizing differences in the way students respond to traditional instructor role (Carlson, 2005; Howe \& Strauss, 2007; Tapscott, 1998) and respondents within all ranks need to continue to shift to more contemporary instructor roles to continue reach their students most effectively.

Examination of Items 25-40, responding to students' preferred learning styles, showed agreement by all ranks. Only one item, students show mastery of knowledge by various assessments, indicated percentages of agreement below $50 \%$ by only one of the ranks (associate professor). Respondents disaggregated by rank also seem to comprehend students' preferred learning styles, but need to continue to build and change classroom instruction according to how students prefer to meet their learning needs (Christensen, et al., 2008; Tapscott, 1998).

Sub Research Question 5.5 examined responses between the genders of survey respondents. Examination of the data revealed a majority of responses from both genders (male, female) studied indicated utilization of technology-enhanced instructional practices. Female respondents exhibited the highest level of usage on seven of the eight items. Males reported the highest percentage $(93.1 \%)$ on only one item, Item 7, teaching in a technology-enable classroom environment. While Items 12 and 13, use of smart or wireless devices and use of guest speakers via technology-driven means, exhibited the lowest overall utilization rate overall, females still showed the highest utilization rates 
(24.8\% and $10.7 \% \%)$. Males reported 23.8\% (Item 12) and 8\% (Item 13). Today's students are referred to as "gadget fanatics, social networkers, Internet enthusiasts, .. . and multitaskers" (Garcia, 2007, p. 12). Their viewpoints and aptitudes concerning technology differ from previous generations (Frand, 2000; Newton, 2000; Oblinger, 2003; Prensky, 2012). The data indicates overall, a majority of respondents disaggregated by gender are employing technology and should continue to adopt even the most up-todate technology-enhanced instructional practices to continue to meet the learning needs of the changing student population.

Responses for items 15-24, pertaining to instructor role, were examined and indicated only one of the ten items with percentage levels $<50 \%$ by only one gender (female). When the items were disaggregated and examined as traditional versus contemporary instructor roles, the percentages were close. Female respondents did show the highest levels of agreement with all five of the items indicating contemporary instructor role. Higher education administrators and faculty need to understand the needed changes in instructor role to meet the demands of students with different preferred learning styles (Oblinger \& Oblinger, 2005; Prensky, 2005, Skiba \& Barton, 2005). Contemporary role agreement was also higher overall indicating higher education as a whole may still employ traditional instructor role, SHEIP respondents indicate perhaps instructor role is transforming. Higher education institutions need to encourage and provide the support needed by faculty to continue to implement more innovative or contemporary instructor role.

When examining responses for the items referring to preferred student learning styles (Items $25-40)$, strong agreement (>50\%) was shown by both genders (male, 
female) on all but one item. Item 39 , students show mastery of knowledge by selfchoosing various assessments showed agreement of $49.5 \%$ for males. The data indicated that a majority of the respondents (19 of 20 responses), when examined by gender, understood how their students preferred to learn. To assure changing student learning demands are met, higher education faculty must be encouraged to "meet students where they are" (Blackboard, 2007), including the use of technology.

The last question, Research Question 5.6 examined the survey data disaggregated by age range (under $30,31-50$, over 50 ). When responses by age range were examined for Items 7-14, it showed that a majority of the respondents indicated utilization of technology-enhanced instruction as indicated by usage percentages $>50 \%$. While schools have typically resisted integrating technology into everyday instructional practices, Millennials have adopted and implemented technology, both in their personal and academic lives and now bring this expectation to the higher education classroom (Prensky, 2013; Tapscott, 1998, 2009). Faculty included in this study seem to be making this transition. However, use of newer technologies, indicated in Item 12, pertaining to using smart or wireless devices and Item 13, pertaining to use of guest speakers via technology-driven means showed low utilization rates by all age ranges. Item 11, encouraging students to communicate using technology such as blogs and wikis, showed lower levels of agreement respondents over 50, perhaps due to the fact the technologies mentioned were digital native tools rather than tools favored by digital immigrants, which would include those faculty over 50 (Prensky, 2001b).

Examination of Items 15-24, pertaining to perceptions of instructor role, showed the data to be dispersed fairly equally among the various size categories of institutions. 
Closer scrutiny showed responses to be slightly higher overall supporting more contemporary instructor roles. Respondents under 30 reported higher percentages of agreement when compared to the other two age ranges on items supporting contemporary instructor role. While higher education faculty are discerning students do not respond to the same degree to traditional teaching methods (Carlson, 2005; Howe \& Strauss, 2007; Tapscott, 1998), Missouri higher education faculty of all age ranges are shown by the data to be, at least in part, to be transitioning these desired instructor roles.

Examination of Items $25-40$, related to students' preferred learning styles, showed agreement by almost all size categories with none of the 48 agreement percentages being below $50 \%$. Understanding how students prefer to learn enables faculty to better meet their learning needs (Christensen, et al., 2008; Tapscott, 1998). With only six responses showing percentages below $80 \%$, it appears the faculty involved in this study agree or indicate good understanding of students' preferred learning styles and should transition this understanding to use in the classroom.

Chi-square analysis for individual survey Items 7-40 as compared to individual demographic, did not indicated significance levels (p) and Chi-square $\left(\mathrm{X}^{2}\right)$ values allowing the researcher to reject the null hypothesis, $\mathrm{H}_{0} 5$. However, according to $\mathrm{M}$. McBride (personal interview, October 24, 2013), Chi-square analysis of large amounts of data can lend itself to errors that cause the Chi-square values to not be true indicators of significance. Relationships can still exist, even if Chi-square significance levels and values do not fall below the values shown in the Chi-square distribution tables required to show relationships (M. McBride, personal interview, October 24, 2013). Given this information, frequency counts and percentages as shown in the cross tabulations or 
contingency tables were examined. Based on the data shown by this examination, overall agreement $(>50 \%)$ existed for all demographics in support of all sub-research questions listed in Research Question 5. Therefore, null hypothesis $\mathrm{H}_{\mathrm{o}} 5$ was accepted. It was determined that there were no significant differences among respondents according to demographics when applying a .05 significance level.

\section{Conclusions}

Data concerning validity and reliability of a researcher-designed survey instrument and utilization of technology-enhanced instructional practices were collected and studied. Data indicating perceptions of instructor role and millennial students' preferred learning styles were also examined. New knowledge was gained from the data and the findings of this study. From the knowledge gained from this study, the following conclusions are proposed, based on individual research questions.

\section{Conclusion - Research Question 1}

The primary purpose of this study was to design a valid and reliable survey instrument gauging three concepts: (a) utilization of technology-enhanced instructional practices, (b) perceptions of Missouri higher education faculty concerning self-reported instructor role, and (c) perceptions of millennial students' preferred learning styles. The secondary purpose of this study was to identify differences and similarities among various subsets of the data, examined by investigated concepts, as well as disaggregated by each demographic for individual survey items.

Through the research completed for this study, the content validity and reliability of the researcher-developed Survey of Higher Education Instructional Practices (SHEIP) was shown. While researching concepts for this study, no tools were located to help 
identify the utilization of technology-enhanced instruction in higher education or perceptions of instructor role or students' preferred learning styles and the match to those identified in current research as desired by Millennials. With a shifting student body, it is imperative that academia understands the learning needs of current students and recognizes challenges to be faced and needed changes (Bok, 2006; Carlson, 2005;

Christensen \& Eyring, 2011; Knapper, 2007; Oblinger, 2003; Prensky, 2005; Skiba \& Barton, 2005). A valid and reliable tool to identify these concepts would allow educational institutions to survey the current status of these three concepts among their faculty and discern how faculty could best be provided tools to provide the learning today's students are demanding. This study revealed the Survey of Higher Education Instructional Practices to possess both validity and reliability. It can be used in future studies to allow higher education institutions or other researchers to gather data concerning current faculty practices and discerning tools needed to implement the innovations needed for institutions in the rapidly changing world of academia.

\section{Conclusion - Research Question 2}

The use of technology-enhanced instructional practices was examined as determined by survey responses to survey Items 7-14. A majority of Missouri higher education faculty indicated use of a majority (six of eight) of the technology-enhanced instructional practices featured in the SHEIP. Research indicates that Millennials have been "connected to technology since birth" and this perpetual connection has led to issues that must be addressed by universities (Bok, 2006; Carlson, 2005; Israel, 2006; Knapper, 2007; Nicoletti \& Merriam, 2007; Prensky, 2005, Skiba \& Barton, 2005). Indications of a majority of faculty implementing technology-enhanced instructional practices reveals 
universities surveyed may be taking the first step to solving these issues. Higher

education institutions need to continue to provide the tools to allow faculty to continue to implement technology-enhanced instruction and innovate their curriculum to meet the learning needs of their current students, the Millennials.

Conclusion - Research Question 3

Missouri higher education faculty perceptions of their instructor role was studied employing responses to survey Items 15-24. A majority (>50\%) of respondents indicated use of contemporary instructor role, identified by current research to be preferred by millennial students (Carlson, 2005; Howe \& Strauss, 2007; Prensky, 2001; Tapscott, 1998, 2009). Woempner (2007) states "a lack of understanding and appreciation for generational characteristics ... can bring about conflict and impasse” (p. 5).

To address educational needs of current students, higher education institutions must implement desired change or "innovative disruptions" and must transition for the "old generation of learning" to the "new generation of learning" (Christensen, et al., 2008; Christensen \& Eyring, 2011; Milliron, 2000). Faculty at Missouri higher education should keep "disrupting" traditional or "sage on the stage" instructor roles and continue to implement more contemporary or "guide on the side" roles (Christensen, et al., 2008; Christensen \& Eyring, 2011; King, 1993; Howe \& Strauss, 2007; Oblinger \& Oblinger, 2005; Prensky, 2005; Tapscott, 1998). To flourish in the ever-changing and competitive world of academia, institutions of higher learning must assure their faculty continually strive to understand the ever-changing views and wants of their students, assuring the "consumers" or students get the education they demand. 


\section{Conclusion-Research Question 4}

Perceptions of millennial students' preferred learning styles as explained by frequency and percentages of responses from SHEIP participants indicated agreement (>50\%) or identification by Missouri HE faculty. The theory of disruptive innovation can help higher education face many of the challenges due to the changing environment and shift composition of the current student body (Christensen, et al., 2008; Christensen \& Eyring, 2011). In order to effectively implement this change, faculty need to understand the need for currency and be able to identify students' learning characteristics to meet their demands (Bok, 2006; Carlson, 2005; Oblinger \& Obilinger, 2005; Prensky, 2001a, 2005; Skiba \& Barton, 2005). Data explored and analyzed for survey Items 24-40 indicated the Missouri HE faculty responding to this study were able to identify millennials students' preferred learning styles. With that knowledge, faculty should be able to adjust classroom role to ensure to "meet students where they are" and "disrupt" traditional instruction (Christensen, et al., 2008; Blackboard, 2007).

\section{Conclusion - Research Question 5}

When survey data were disaggregated by demographic variables of this study, relationships were shown to be weak between independent demographic variables and the 34 dependent variables included in this study. Millennial students' characteristics also do not seem to be influenced by demographics as much as their proclivity for "digital literacy, experiential learning, interactivity and immediacy" (Skiba \& Barton, 2006, p. 6). Higher education faculty "must make a fundamental shift in their paradigm for teaching and learning. . . the current education system has been set up to prepare students perfectly for a world that no longer exists" (Jukes, et al. 2010, p. 21). As implied by the theory of 
disruptive innovation, higher education must adapt and face this challenge to provide millennial students with the education they desire (Christensen, et al., 2011; Oblinger \& Oblinger, Prensky, 2001b; Tapscott, 2009). All faculty, no matter what demographic, must strive to make themselves familiar with the proclivities and learning preferences of their students and adapt their instructor role accordingly. Student consider themselves consumers of their education and demand different instruction than the generations before them. Academia must innovate and provide what is demanded.

\section{Discussion and Recommendations for Future Research}

This section encapsulated analysis of the data collected from the SHEIP for this research study. Brief summaries of the analysis were given. Based on this analysis, recommendations and ideas for future studies were delineated.

\section{Discussion}

The Survey of Higher Education Instructional Practices (SHEIP) was determined to be a valid and reliable survey instrument which could be used in other research studies to examine three concepts: (a) the use of technology-enhanced instruction, (b) examine educators' perceptions of their instructional role and (c) perceptions of the preferred learning styles of current students. The availability of a valid and reliable tool to identify these three concepts, will allow higher education institutions to better identify student learning preferences being met and changes which need to be implemented to better meet the learning preferences of current students. Identifying the status and perceptions of faculty concerning the three concepts examined in the SHEIP, will enable higher education institutions to determine resources needed by their faculty and establish how to best use their limited resources to meet the demands of millennial students. 
In order to remain competitive in the ever-changing world of academia, the status quo must be disrupted and innovations put into place (Christensen, et al,. 2008; Christensen \& Eyring, 2010). Research indicates technology-enhanced instruction provides one tool preferred by Millennials which could be used in this manner (Christensen, et al., 2008; Christensen \& Eyring, 2010; Prensky, 2005; Tapscott, 2008). Data gathered and analyzed through this study indicated a majority of the Missouri higher education faculty surveyed utilized technology-enhanced instructional practices. The researcher found this somewhat surprising, based on past experience in higher education classrooms.

However, data gathered via the SHEIP was unable to determine the depth and quality of technology use. Questions were left unanswered as to the specific academic uses of technology-enhanced instruction and how instructors are adapting this tool to help further curriculum and content in higher education classrooms. Since the data was selfreported, it would be pertinent to conduct future studies focusing on more specific uses by individual instructors in varying content areas in higher education classrooms. Qualitative studies would also be able to provide more in depth information concerning the types of uses of technology-enhanced instruction in the classroom.

This study also indicated a slight majority of faculty perceive they employee instructor roles which meet the expectations of millennial students. However, the percentages of faculty agreeing and disagreeing with statements referring to traditional and contemporary instructional roles were nearly equal. Data showed only $1.9 \%$ more faculty respondents agreed with statements referencing contemporary instructor roles compared to those agreeing with statements referring to more traditional instructor roles. 
The researcher believes higher education faculty need to reconsider their role in the classroom and assure their instructor role help their students learn in the best possible manner. In the existing higher education environment, it would be pertinent to innovate and adopt more contemporary or "guide on side" (King, 1993) strategies shown by research to better meet the needs of millennial students.

Data obtained by the SHEIP indicated that a majority of Missouri higher education faculty agreed with or seemed to understand learning preferences of their millennial students. In order to best assure faculty are meeting learners' needs, it is imperative students' learning preferences are understood. Research indicated a disconnect exists between Millennials' learning styles and instructional practices traditionally supported in higher education (Jukes, et al., 2010; Prensky, 2001a, 2001c; Tapscott, 1998, 2009). Furthermore, it was indicated if learners' needs are not met or learners are disengaged, deep learning may not take place (Prensky, 2001a, 2001b, 2005; Tapscott, 1998, 2009). While data indicated understanding by Missouri higher education faculty of Millennnials' preferred learning, higher education institutions and faculty should continue to strive to understand how their students learning and adapt instruction as necessary to assure needed learning takes place.

Disaggregation of the data by independent or demographic variables showed some of the respondents did not choose to report a few of the demographic variables on the SHEIP. Specifically, department was reported by only 228 of the 244 respondents and rank was reported by only 237 of the 244 respondents. Without further research, the specific reason for non-response by some of the participants, although the researcher reasoned it might have been due to respondents wanting to assure anonymity. 


\section{Recommendations for Future Research}

The researcher discovered interesting information concerning the utilization of technology-enhanced instruction and the perceptions of Missouri higher education faculty concerning instructor role and millennial students' preferred learning styles. However, there were some areas in which further research could provide useful information.

Although found to be valid and reliable, The Study of Higher Education Instructional Practices (SHEIP) should be further tested and changed as needed. This would provide higher education institutions an even better instrument with ability to be widely used by all educational institutions to examine changes needed in this changing world of education.

Further research concerning concepts involved in this study would provide more useful information to educators at all sizes of higher education institutions. This study determined that technology-enhanced instructional practices were reported as being used by Missouri higher education faculty. However, the depth and specific types of use was not able to be discerned. Another study, focusing on the depth and quality of use of technology-enhanced instructional practices in higher education would be pertinent. A qualitative study would enable more in-depth information to be gathered concerning specific technology-enhanced instructional practices by individual faculty. This would provide implementation examples which could be used to guide technology-enhanced instruction at other higher education institutions. A follow-up qualitative study could provide pertinent and important information concerning the technology-enhanced instructional practices being implemented as well as the technology that is actually making a difference in academia. 
Further study to determine which faculty are not employing technology-enhanced instructional practices and researching why technology is not being used in those classrooms would also be useful. Research showed education is changing and technology is more important than ever to students (Oblinger \& Oblinger, Prensky, 2001b; Tapscott, 2009). Pinpointing barriers to technology use in the higher education classroom and faculty instruction and discovering ways to overcome those barriers would be beneficial to all of those involved in higher education. A qualitative study to examine more in-depth those higher education faculty not employing technology-enhanced instruction in their classrooms and discovering the reasons for this non-use would provide useful information for higher education institutions, faculty and educational researchers.

Instructor role, contemporary versus traditional, needs to be studied more thoroughly. This study showed higher levels of agreement to contemporary instructor role overall, but levels of agreement for more traditional instructor role were very close (1.9\% difference). This phenomenon should be examined more closely to determine specific instructor roles used and their more exact uses in the classrooms. Differences should also be pinpointed. A more in-depth quantitative study, employing a larger population would provide more information from varying higher education institutions. Once this information was collected and analyzed, a follow-up qualitative study would then provide even more specific data. These studies could indicate traditional or contemporary instructor roles being implemented in higher education and more specifically how and why as well as barriers.

Faculty need to better understand expectations of millennial students (Prensky, 2001a; Tapscott, 2008). It would also be useful to study which contemporary instructor 
roles are being implemented and more specifically, exactly how they are being used in instruction. This would provide information to higher education institutions, such as reasons faculty are implementing contemporary instructor roles and solutions or resources, such as professional development, that might prove useful to institutions as they provide tools for faculty to encourage implementation of more contemporary instructor roles.

\section{Summary of the Study}

Today's higher education institutions are experiencing a different type of student population than foregoing eras (Frand, 2000; Newton, 2000; Oblinger, 2003; Prensky, 2001a, 2008, 2012). Facilities, faculty, and curriculum may not be prepared to address the demand of these students' differing learning preferences and expectations (Christensen, et al., 2008; Christensen \& Eyring, 2011). The educational landscape is shifting due to advances in technology (Hawley, 2005). "Colleges and universities are responding in different ways to new benefits and pressures as these advances evolve" (Hawley, 2005). This study utilized the Study of Higher Education Instructional Practices (SHEIP) to examine the utilization of technology-enhanced instructional practices by Missouri higher education faculty.

Chapter 5 was divided into six sections. First, an overview of the study was presented. The problem statement for this study and the purpose statement were then given. Research questions were next delineated, including all sub-questions and null hypotheses. Section 2 discussed the research design. A detailed explanation of the population was given. Statistical analysis methods were delineated. The third section detailed the finding of this research study. Conclusions were next specified and tied to the 
research. Discussion of the research study, the findings and conclusions was then given. Recommendations and suggestions for future studies were then demarcated. Lastly a summary of Chapter 5 and of the study was outlined.

Overall, study data indicated a valid and reliable survey instrument could be developed to examine three concepts: (a) the use of technology-enhanced instruction, (b) examine educators' perceptions of their instructional role and (c) perceptions of the preferred learning styles of current students. Additionally, data showed a majority of Missouri higher education faculty are employing technology-enhanced instruction. Data further indicated a majority of Missouri higher education faculty perceive more contemporary or interactive instructor roles are being used in their classrooms. Perceptions of Missouri higher education faculty concerning millennial students’ preferred learning styles also indicated an understanding of students currently in classrooms. These factors were all positive indicators for higher education.

Research indicates that millennial students prefer differing learning methodologies, specifically technology-enhanced instruction and more interactive learning (Christensen, et al., 2008; Christensen \& Eyring, 2010;Oblinger \& Oblinger, 2005; Prensky, 2005; Tapscott, 2008). Data analyses for this study indicated Missouri higher education understand and are innovating the learning happening in their classrooms. As this was a pilot survey and results were self-reported, more in-depth analysis, employing both qualitative and quantitative research techniques, would be pertinent to further examine the information gathered for this study. 


\section{References}

Blackboard. (2007). A view from the top: Building the 21st century campus. White Paper 01.15.07. http://www.blackboard.com/CMSPages/GetFile.aspx ?guid=cd63f2d77339-4c9c-a097-bfce93ff5781. (accessed December 12, 2011).

Borges, N. J., Manuel, R., Elam, C. L., \& Jones, B. J. (2010). Differences in motives between millennial and generation x medical students. Medical Education, 44(6), $570-576$.

Brandt, Ronald S. (Eds.) (2000). Education in a new era. Alexandria, VA : Association for Supervision and Curriculum Development (ASCD).

Bransford, J., National Research Council (U.S.) \& National Research Council (U.S.). (2000). How people learn: Brain, mind, experience, and school. Washington, D.C: National Academy Press.

Carlson, S., (2005). The Net Generation goes to college. The Chronicle of Higher Education, October 7. http://chronicle.com/free/v52/i07/07a03401.htm (accessed February 7, 2012).

Chandler, B. J., Powell, D. and Hazard, W. R. (1971). Education and the new teacher. New York: Dodd, Mead.

Christensen, C. M., Baumann, H., Ruggles, R., \& Sadtler, T. M. (2006). Disruptive innovation for social change. Harvard Business Review, 84(12), 94-101.

Christensen, C. M., Horn, M. B., \& Johnson, C. W. (2008). Disrupting class: How disruptive innovation will change the way the world learns. New York: McGrawHill. 
Christensen, C. M., \& Eyring, H. J. (2011). The innovative university: Changing the DNA of higher education from the inside out. San Francisco: Jossey-Bass.

Coomes, M. D., \& DeBard, R. (2004). A generational approach to understanding students. In M. D. Coomes. \& R. DeBard (Eds.), Serving the Millennial Generation. San Francisco: Jossey-Bass.

Creative Research Systems. (2012). Sample size calculator. Retrieved from http://www.surveysystem.com/sscalc.htm

Denham, T. J., \& Adbow, N. (2002). Literature Review: Factors Affecting the Development of Generation X and Millennials. Societal Factors Affecting Education. Retrieved from EBSCOhost.

Emeagwali, N. (2011). Millennials: Leading the charge for change. Techniques: Connecting Education and Careers, 86(5), 22-26. Retrieved from EBSCOhost.

Feiertag, J., and Berge, Z. L. (2008). Training generation N: How educators should approach the net generation. Education + Training, 50(6), 457-464.

Field, A. P. (2005). Discovering statistics using SPSS: (and sex, drugs and rock ' $n$ ' roll). London: Sage Publications.

Fine, A., (2008). The Millennials Are Coming!. Retrieved from http://www.allisonfine.com/2008/08/19/the-millennials-are-coming/ February 6, 2013.

Finn, C. and Rebarber, T.(eds), (1992). Education Reform in the 90's. New York: Macmillan Pub. Co.

Frand, J. L. (2000). The information-age mindset: Changing students and implications for higher education. EDUCAUSE Review, 35, 15-24. 
Fraenkel, J., and Wallen, N. (2006). How to design and evaluate research in education. New York: McGraw-Hill.

Garcia, L. L. (2007). Millennial students' and faculty's perceptions of a new generation of learning classrooms. (Doctoral Dissertation) Retrieved from ProQuest Dissertations and Theses database, (Accession Order No. 3310788).

Gorman, P., Nelson, T., \& Glassman, A. (2004). The millennial generation: A strategic opportunity. Organizational Analysis, 12(3). 255-270.

Green, B. (2010). Knowledge, the future, and education(al) research: A new-millennial challenge. Australian Educational Researcher. Australian Association for Research in Education, 37(4), 43-62.

Gritter, A. (2005). Belief drives action: How teaching philosophy affects technology use in the classroom. Annual Meeting of the New England Educational Research Organization. Northampton, MA.

Hawley, D. (2005). The influence of developing a web-based course on university professor classroom instructional techniques as measures by the MTQ. Doctoral Dissertation.

Howe, N., \& Strauss, W. (2000). Millennials rising: the next great generation. New York: Vintage Books.

Howe, N., Strauss, W., \& LifeCourse Associates. (2007). Millennials go to college: Strategies for a new generation on campus : recruiting and admissions, campus life, and the classroom. Great Falls, Va: LifeCourse Associates.

Israel, B. (2006, November 5). The overconnecteds. The New York Times, pp. 4A; 20. 
Jackson, S, \& Crawford. D.,(2008). Digital Learners: How Are They Expanding the Horizon of Learning? Retrieved from http://cnx.org/content/m17218/1.2 on November 11, 2012.

Jones, C., Ramanau, R., Cross, S., and Healing, G., (2010). Net generation or digital natives: Is there a distinct new generation entering the university?, Computers \& Education, 54(3), 722-732.

Jones, S. and Madden, M. (2002). The internet goes to college: How students are living in the future with today's technology. 〈http://www.pewinternet.org/Reports/2002/The-Internet-Goes-to-College.aspx > Retrieved February 6, 2013.

Jukes, I., McCain, T., \& Crockett, L. (2010). Education and the Role of the Educator in the Future. Phi Delta Kappan, 92(4). 15-21.

Kent, T. W., \& McNergney, R. F. (1999). Will technology really change education?: From blackboard to Web. Thousand Oaks, Calif: Corwin Press.

King, A. (1993). From sage on the stage to guide on the side. College Teaching. 41(1). 30-35.

Knapper, C. (2007). Engaging students through active learning. Teaching and Learning in Higher Education. 45. 1-4.

Kuh, G. D, Kinzie, J., Schuh, J., Whitt, E. J., \& Associates (2005). Student success in college: creating conditions that matter. San Francisco: Jossey-Bass.

Lancaster, L. C., \& Stillman, D. (2010). The M-factor: How the millennial generation is rocking the workplace. New York: HarperBusiness. 
Laseter, T. (2012). The University's Dilemma: In the face of disruptive change, higher education needs a new, more innovative business model. Strategy and Business, 69, 24-28.

Levine, A., \& Cureton, J. S. (1998). When hope and fear collide: A portrait of today's college student. San Francisco: Jossey-Bass.

Li, J. (2009). Determining reliability and validity of a faculty survey to identify current teaching strategies and application of internet technologies in a taiwanese university. (Doctoral Dissertation).

Martin, L. (2007). Defining the scholarship of teaching versus scholarly teaching. Teaching and learning in higher education. 46, 1-3.

McAlister, A. (2009). Teaching the millennial generation. American Music Teacher, 59(1), 13-15. Retrieved from EBSCOhost

McDermott, L. (1993). How we teach and how students learn - A mismatch? American Journal of Physics. 61(4). 295-298.

McGlynn, A. (2008). Millennials in college: How do we motivate them?. Education Digest, 73(6), 19-22. Retrieved from EBSCOhost.

McHugh, J. (2005). Synching up with the iKid: Educators must work to understand and motivate a new kind of digital learner. Edutopia, 1(7), 33-35.

McNamara, B. R. (2009). The Skill Gap: Will the Future Workplace Become an Abyss. Techniques: Connecting Education and Careers, 84(5), 24-27.

Milton, Ohmer. (1972). Alternatives to the Traditional. San Francisco: Jossey-Bass. Print. 
National Education Commission on Time and Learning. (1994). Prisoners of time.

Washington D.C.: U.S. Government Printing Office. Retrieved on February 7, 2013, from http://www2.ed.gov/pubs/PrisonersOfTime/index.html.

Nevgi, A., Virtanen, P., \& Niemi, H. (2006). Supporting students to develop collaborative learning skills in technology-based environments. British Journal of Educational Technology, 37(6). 937-947.

Nicoletti, A., \& Merriman, W. (2007). Teaching millennial generation students, Momentum, 38(2). 28-31.

Nikirk, M. (2009). Today's Millennial Generation: A Look Ahead to the Future They Create. Techniques: Connecting Education and Careers, 84(5). 20-23. Retrieved from EBSCOhost.

O'Banion, T., Wilson, C., \& League for Innovation in the Community College. (2011). Focus on learning: A learning college reader. Phoenix, AZ: League for Innovation in the Community College.

Oblinger, D. G. (2010). A Commitment to Learning: Attention, Engagement, and the Next Generation. Educause Review. 45(5). 4-6.

Oblinger, D. G., \& Oblinger, J. (Eds.). (2005). Educating the net generation. Washington, D.C.: Educause.

Plous, S. (2001). Tips on Creating and Maintaining an Educational World Wide Web Site. Teaching of Psychology. 27 (1). 63-70.

Prensky, M. (2001a). Digital game-based learning. New York: McGraw-Hill. Prensky, M. (2001b). Digital natives, digital immigrants Part 1. On the Horizon - the Strategic Planning Resource for Education Professionals. 9(5), 1-6. 
Prensky, M. (2001c). Digital natives, digital immigrants Part 2. On the Horizon - the Strategic Planning Resource for Education Professionals. 9(5), 1-9.

Prensky, M. (2008, September). New college courses for the 21st century. The Greentree Gazette. 48.

Prensky, M. (2005). "Engage Me or Enrage Me": What Today's Learners Demand. Educause Review, 40 (5), 60-65.

Prensky, M. (2013). Time travel as punishment: What our kids really hate. Educational Technology. Jan/Feb 1-2

Richardson, J. (2010). Disrupting How and Where We Learn. Phi Delta Kappan, 92(4), $32-38$.

Sandeen, C. (2008). Boomers, xers, and millennials: Who are they and what do they really want from continuing higher education?. Continuing Higher Education Review, 72, 11-31. Retrieved from EBSCOhost.

Skiba, D., Barton, A., (2006). "Adapting Your Teaching to Accommodate the Net Generation of Learners". OJIN: The Online Journal of Issues in Nursing. 11 (2).

Spady, W. G. 1988. Organizing for Results: the Basis of Authentic Restructuring and Reform. Educational Leadership. 46 (2): 4-8

Springer, K. (2010). Educational research: A contextual approach. Hoboken, N.J: Wiley. Stewart, K. (2009). Lessons from teaching millennials. College Teaching, 57(2), 111118.

Strauss, H. (2003). My Dog Knows HTML - Should Your Faculty? Syllabus. Retrieved on October 7, 2012, from http://campustechnology.com/articles/2003/05/my-dogknows-htmlshould-your-faculty.aspx?sc_lang=en 
Sweeney, R. (2007). How the new generation of well-wired multitaskers is changing campus culture. The Chronical of Higher Education, 53(18), B10.

Tapscott, D. (1998). Growing up digital: The rise of the net generation. New York: McGraw-Hill.

Tapscott, D. (2009). Grown up digital: How the net generation is changing your world. New York: McGraw-Hill.

Tapscott, D., \& Williams, A. D. (2006). Wikinomics: How mass collaboration changes everything. New York: Portfolio.

The Carnegie Classification of Institutions of Higher Education". Carnegie Foundation for the Advancement of Teaching. no date. Retrieved March, 2012.

Trochim, W. M. K. (2006). Research methods knowledge base. S.1.: Web Center for Social Research Methods. www.socialresearchmethods.net

Vail, K. (2005). The world of e-learning: How the national education technology plan can help you teach today's 'technology natives'. American School Board Journal, 192(9), 30-31.

Wilson, S. P., \& Harris, A. (2002). Evaluation of the psychology place: A web-based instructional tool for psychology courses. Teaching of Psychology, 29(2). 165.

Woempner, Carolyn (2007). "Teaching the next generation.” The Future of Education: A Structured Response to Uncertainty, Trend of the Month. Mid-continent Research for Education and Learning (McREL) 
Appendix A

Survey of Missouri Higher Education Instructional Practices

Directions: Please respond by checking or filling in the answers to questions 1 through 6 with the

most accurate response:

Employed at what type of Higher Education Institution:
(C) 2 Year Public
C. 4 Year Public
C 4 Year Private

Full Time Enrollment:
$C<500$
C. $500-1000$
(C) 1001-2000
C 2001-3000
C $3001-5000$
C 5001-10000
C. $>10000$

Department:

Rank:
C Adjunct
Instructor
C. Assistant Professor
C Associate Professor
Full Professor 
Gender:

C Male

Female

Age Range:

(c) Under 30

C $31-50$

Over 50

Directions: Thinking about a currently taught class, respond to the following questions. Reflect on your instructional practices in that class only. Use the provided 4 point scale (Always to Never) to respond.

I teach in a technology enabled classroom environment (technology enabled teacher station, LCD projector and/or other tools)
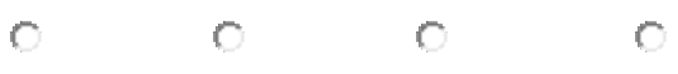

I use technology based tools (i.e. Internet, PowerPoint,etc.) to support my teaching activities.
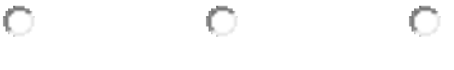

C.

I use video-based instuction (YouTube, Tegrity, streaming video, etc.) to support my teaching activities.

I use e-mail or other technology means (instant messaging, Skype, etc.) to communicate with students.

I encourage student communication using some type of technology based tool (blog, wiki, threaded discussion)

I use smart or wireless devices (iPhone, Android, iPods, tablets, etc.) to conduct course lessons or disperse course materials.

I make use of guest speakers via technology driven means (i.e. Skype, WebMeeting, etc.).

Students are required to use web-based technology tools in completion of classroom assignments. 
Directions: Using the provided 4 point scale (Strongly Agree to Strongly Disagree), respond to the following statements by choosing the response that most accurately expresses your level of agreement with each statement.

\section{Strongly \\ Agree}

Strongly

Disagree

"I see my role as mainly class facilitator and I need to provide opportunities and resources for my students to discover or construct knowledge for themselves."

"The most important part of instruction is the content of the curriculum or what students need to know and be able to do."

"Although hard to organize, it is a good idea to have all sorts of activities going on in the classroom."

"Students can learn basic skills in the context of mastering complex content."
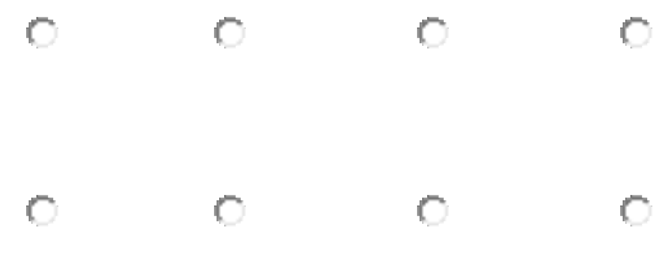

"It's better to give the whole class the same assignment, one that can be done in short intervals that match student's attention spans and the daily class schedule."

"While student motivation is important, it should not drive what students study as the core content in textbooks is most important."

5

"The most important part of instruction is that it encourages 'sense-making' or thinking among students; content is 'secondary'."

"It is critical for students to become interested in doing academic work - interest and efforts are more important than the particular subject matter they are working on."

"In order for the students to learn, the material must be covered in a structured way and it's my job to explain, show the students how to do the work, and assign specific projects." "Students must learn basic skills before they can master complex content."
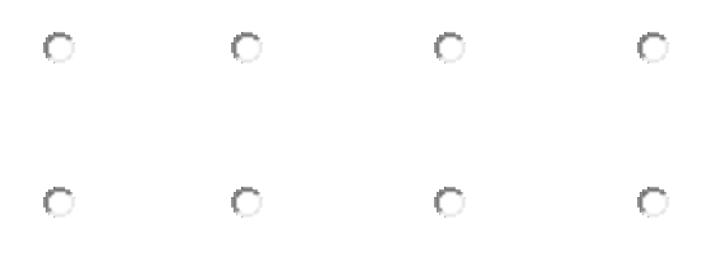

Directions: Using the provided 4-point scale (Strongly Agree to Strongly Disagree), respond to the following questions by choosing the response that most accurately 
expresses your perceptions concerning your current students' learning based on the following prompt:

According to my educational perceptions, I believe my students should be able to individually:

\section{Strongly}

Agree

Establish understanding based on individual experiences.

Integrate learning concepts into self-directed projects.

Research further individually concerning questions related to new concepts.

Pursue a learning concept to create individual learning.

Explore a new learning concept

independently.

Practice and independently demonstrate methods used to realistically solve problems.

Connect current practice to individual experiences.

Expect immediate feedback on learning from the instructor and peers.

Apply knowledge independently in other contexts.

Explain a learning concept using individual perspectives and ideas.

Work in groups to establish individual knowledge concerning new learning concepts.

Work together in groups to share knowledge and reach an agreement on learning concepts.

Integrate learning of concepts with other activities in and out of the classroom.

Understand individual thinking and how to seek help independently if needed.

Show mastery of knowledge by self-choosing various means of assessment (quizzes, projects, presentations, videos, etc.).

Relate individual experiences when comprehending and explaining learning concepts.
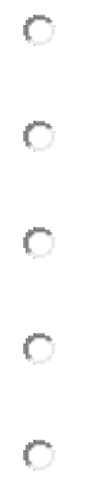

Strongly

Disagree
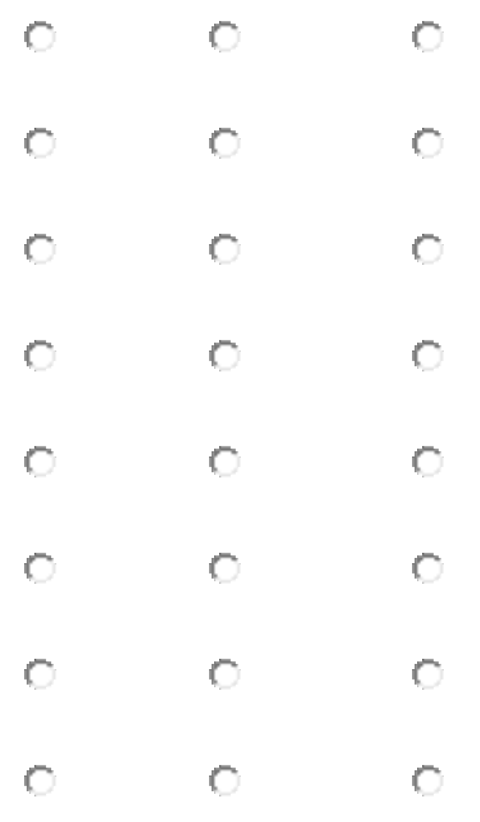

$c$
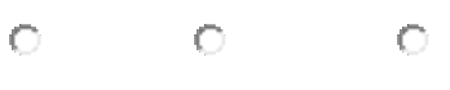

C
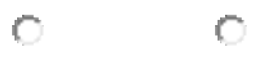

$C$
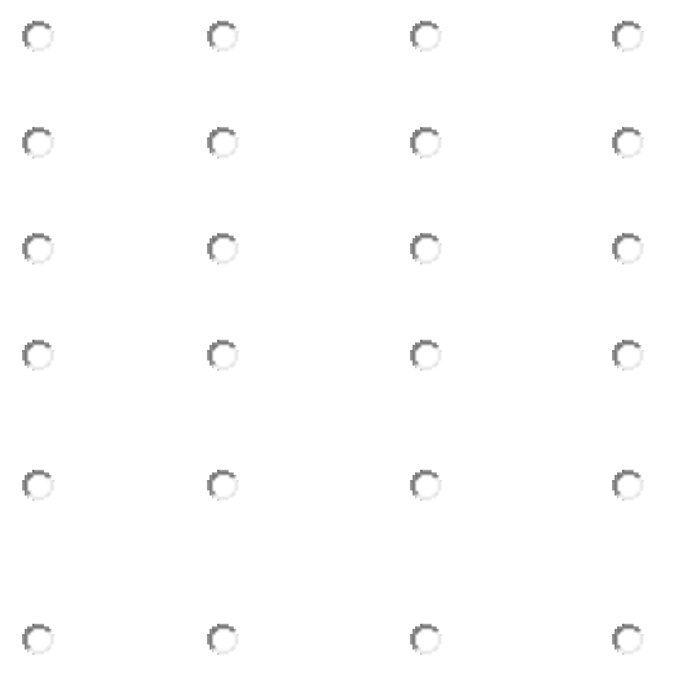
Appendix B

\section{Survey of Current Instructional Practices and Perceptions}

Directions: Please respond by checking or filling in the answers to questions 1-6 with the most accurate response:

1. Employed at what type of Higher Education Institution:

2 Year Public ___ 4 Year Public___ 4 Year Private

2. Full Time Enrollment: __ $<500 \_500-1000 \_1001-2000 \_$_ _ _ _ _

$3001-5000 \_5001-10000 \_>10000$

3. Department:

4. Rank:

__Adjunct _ Instructor___Assistant Professor_ _ Associate Professor__ Full Professor

5. Gender: __ M

6. Age range: ___ Under $30 \_31-50 \_$Over 50

Directions: Thinking about one currently taught class, respond to the following questions. Reflect on your instructional practices in that class only. Use the provided 5-point scale (Always to Never) to respond.

1. I teach in a technology enabled classroom environment (technology enabled teacher station, LCD projector and other tools).

$\begin{array}{ccccc}\text { Always } & & \text { Sometimes } & & \text { Never } \\ 5 & 4 & 3 & 2 & 1\end{array}$

2. I use technology based tools (i.e. Internet, PowerPoint, etc.) to support my teaching activities.

$\begin{array}{ccccc}\text { Always } & & \text { Sometimes } & \text { Never } \\ 5 & 4 & 3 & 2 & 1\end{array}$

3. I use video-based instruction (Youtube, Tegrity, streaming video, etc.) to support teaching activities. 


$\begin{array}{ccccc}\text { Always } & & \text { Sometimes } & & \text { Never } \\ 5 & 4 & 3 & 2 & 1\end{array}$

4. I use e-mail or other technology means (instant message, Skype, etc.) to communicate with students.

$\begin{array}{ccccc}\text { Always } & & \text { Sometimes } & \text { Never } \\ 5 & 4 & 3 & 2 & 1\end{array}$

5. I encourage student communication using some type of technology based tool (blog, wiki, threaded discussion).

$\begin{array}{ccccc}\text { Always } & & \text { Sometimes } & \text { Never } \\ 5 & 4 & 3 & 2 & 1\end{array}$

6. I use smart or wireless devices (iPhone, Android, iPods, tablets, etc.) to conduct course lessons or disperse course materials.

$\begin{array}{llccc}\text { Always } & & \text { Sometimes } & \text { Never } \\ 5 & 4 & 3 & 2 & 1\end{array}$

7. I make use of guest speakers via technology driven means (i.e. Skype, WebMeeting, etc.)

$\begin{array}{ccccc}\text { Always } & & \text { Sometimes } & & \text { Never } \\ 5 & 4 & 3 & 2 & 1\end{array}$

8. Students are required to use web technology tools in completion of classroom assignments.

$\begin{array}{ccccc}\text { Always } & & \text { Sometimes } & \text { Never } \\ 5 & 4 & 3 & 2 & 1\end{array}$

Directions: Using the provided 5-point scale (Strongly Agree to Strongly Disagree), respond to the following statements by choosing the response that most accurately expresses your level of agreement with the statement.

9. "I see my role as mainly class facilitator and I need to provide opportunities and resources for my students to discover or construct concepts for themselves."

\begin{tabular}{|c|c|c|}
\hline Strongly Agree & Agree & Strongly Disagree \\
\hline 4 & 3 & 2 \\
\hline
\end{tabular}

10. "The most important part of instruction is the content of the curriculum or what children need to know and be able to do."

\begin{tabular}{|c|c|c|}
\hline Strongly Agree & Agree & Strongly Disagree \\
\hline 5 & 3 & 2 \\
\hline
\end{tabular}


11. "Although hard to organize, it is a good idea to have all sorts of activities going on in the classroom as the successes are so much more important than the failures."

\begin{tabular}{|c|c|}
\hline ree & Agree \\
\hline 4 & 3 \\
\hline
\end{tabular}

12. "Students can learn basic skills in the context of mastering complex content."

\begin{tabular}{ccccc} 
Strongly Agree & Agree & \multicolumn{2}{c}{ Strongly Disagree } \\
5 & 4 & 3 & 2 & 1
\end{tabular}

13. "It's better to give the whole class the same assignment, one that has clear directions, and one that can be done in short intervals that match student's attention spans and the daily class schedule."

\begin{tabular}{|c|c|}
\hline Stro & Agree \\
\hline 5 & 3 \\
\hline
\end{tabular}

14. "While student motivation is certainly useful, it should not drive what students study as the core content in textbooks is most important."

$\underset{5}{\text { Strongly Agree }} \quad \begin{gathered}\text { Agree } \\ 4\end{gathered} \quad 3 \quad 2^{\text {Strongly Disagree }}$

15. "The most important part of instruction is that it encourages 'sense-making' or thinking among students and content is 'secondary'."

\begin{tabular}{|c|c|c|}
\hline ongly Agree & Agre & Strongly Disagree \\
\hline 5 & 3 & 1 \\
\hline
\end{tabular}

16. "It is critical for students to become interested in doing academic work - interest and efforts are more important than the particular subject matter they are working on."

\begin{tabular}{|c|c|}
\hline Strongly Agree & Agree \\
\hline 4 & 3 \\
\hline
\end{tabular}

17. "In order for the students to learn, the material must be covered in a structured way and it's my job to explain, show the students how to do the work, and assign specific projects."

\begin{tabular}{|c|c|}
\hline y Agree & Agree \\
\hline 4 & 3 \\
\hline
\end{tabular}

18. "Students must learn basic skills before they can master complex content."

\begin{tabular}{|c|c|c|}
\hline Strongly Agree & Agree & Strongly Disagree \\
\hline 4 & 3 & 1 \\
\hline
\end{tabular}


Directions: Using the provided 5-point scale (Strongly Agree to Strongly Disagree), respond to the questions by choosing the response that most accurately expresses your perceptions concerning your current students' learning based on the following prompt:

According to my educational perceptions, I believe my students should be able to individually:

19. Establish understanding based on individual experiences.

\begin{tabular}{ccccc} 
Strongly Agree & Agree & \multicolumn{2}{c}{ Strongly Disagree } \\
5 & 4 & 3 & 2 & 1
\end{tabular}

20. Integrate learning concepts into self directed projects.

\begin{tabular}{|c|c|}
\hline Strongly Agree & Agree \\
\hline 5 & 3 \\
\hline
\end{tabular}

21. Research further concerning questions related to new concepts.

\begin{tabular}{|c|c|}
\hline Strongly Agree & Agree \\
\hline 5 & 3 \\
\hline
\end{tabular}

22. Pursue a learning concept to create individual learning.

\begin{tabular}{ccccc} 
Strongly Agree & Agree & \multicolumn{2}{c}{ Strongly Disagree } \\
5 & 4 & 3 & 2 & 1
\end{tabular}

23. Explore a new learning concept independently.

\begin{tabular}{ccccc} 
Strongly Agree & Agree & \multicolumn{2}{c}{ Strongly Disagree } \\
5 & 4 & 3 & 2 & 1
\end{tabular}

24. Practice and independently demonstrate methods used to realistically solve problems.

\begin{tabular}{|c|}
\hline Strongly Agree \\
\hline 5 \\
\hline
\end{tabular}

25. Connect current practice to individual experiences.

\begin{tabular}{ccccc} 
Strongly Agree & Agree & \multicolumn{2}{c}{ Strongly Disagree } \\
5 & 4 & 3 & 2 & 1
\end{tabular}

26. Expect immediate feedback on learning from the instructor and peers.

\begin{tabular}{|c|c|}
\hline Strongly Agree & Agree \\
\hline 5 & 3 \\
\hline
\end{tabular}


27. Apply knowledge independently in other contexts.

\begin{tabular}{ccccc} 
Strongly & Agree & Agree & \multicolumn{2}{c}{ Strongly Disagree } \\
5 & 4 & 3 & 2 & 1
\end{tabular}

28. Explain a learning concept using individual perspectives and ideas.

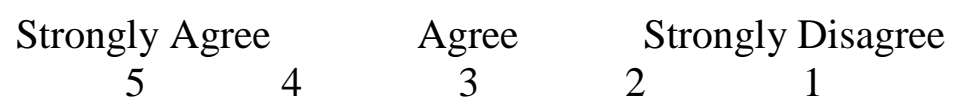

29. Work in groups to establish individual knowledge concerning new learning concepts.

\begin{tabular}{|c|c|}
\hline Strongly Agree & Agree \\
\hline 5 & 3 \\
\hline
\end{tabular}

30. Work together in groups to share knowledge and reach an agreement on learning concepts.

\begin{tabular}{|c|c|}
\hline Strongly Agree & Agree \\
\hline 5 & 3 \\
\hline
\end{tabular}

31. Integrate learning of concepts with other activities in and out of the classroom.

\begin{tabular}{|c|}
\hline Strongly Agree \\
\hline 5 \\
\hline
\end{tabular}

32. Understand individual thinking and how to seek help independently if needed.

\begin{tabular}{ccccc} 
Strongly Agree & Agree & \multicolumn{2}{c}{ Strongly Disagree } \\
5 & 4 & 3 & 2 & 1
\end{tabular}

33. Show mastery of knowledge by self-choosing various means of assessment (quizzes, projects, presentations, videos, etc.).

\begin{tabular}{|c|c|}
\hline Strongly Agree & Agree \\
\hline 5 & 3 \\
\hline
\end{tabular}

34. Relate individual experiences when understanding and explaining learning concepts.

\begin{tabular}{|c|c|c|}
\hline Strongly Agree & Agree & Strongly Disagree \\
\hline 4 & 3 & 2 \\
\hline
\end{tabular}




\section{Appendix C - Initial Email Correspondence to Expert Panel}

\section{Colleague:}

I am in the process of completing my dissertation proposal and need some assistance from an expert panel in testing my survey instrument.

I am hopeful you will aid my effort by serving as a professional on my pilot expert panel. The link and password required to complete this survey are found at the bottom of this email. There will be 34 questions and it should involve approximately 10-15 minutes of your time.

I would also ask for your assistance by providing feedback based on the following questions:

1. Are the directions for taking the survey clear and concise?

2. Is the language in each item clear and understandable?

3. Are there any items which should be eliminated or added?

4. Which items are unclear or confusing?

5. Are there items which may not be answered?

6. Is the survey too time consuming or appropriate in length?

7. How long did it take for you to complete the survey?

8. Do you have any comments concerning the survey?

I appreciate your time and assistance in this important step in my dissertation process. Your feedback and suggestions will prove to be valuable in this endeavor.

Please let me know if you are unable to respond to the survey and the feedback questions to allow me to choose another expert if needed.

Thank you,

Cindy

Survey location: [SERVER]

The password: [PSWD]

Note: This email has been created automatically. The password indicated in this E-MAIL cannot be traced to you. Your vote is anonymous. 
Appendix D - Reminder email to expert panel

\section{Colleague:}

Just a friendly reminder that your feedback is needed.

I am in the process of completing my dissertation proposal and need some assistance from an expert panel in testing my survey instrument.

I am hopeful you will aid my effort by serving as a professional on my pilot expert panel. The link and password required to complete this survey are found at the bottom of this email. There will be 34 questions and it should involve less than 10 minutes of your time.

I would also ask for your assistance by providing feedback based on the following questions:

1. Are the directions for taking the survey clear and concise?

2. Is the language in each item clear and understandable?

3. Are there any items which should be eliminated or added?

4. Which items are unclear or confusing?

5. Are there items which may not be answered?

6 . Is the survey too time consuming or appropriate in length?

7. How long did it take for you to complete the survey?

8. Do you have any comments concerning the survey?

I appreciate your time and assistance in this important step in my dissertation process. Your feedback and suggestions will prove to be valuable in this endeavor.

Please let me know if you are unable to respond to the survey and the feedback questions to allow me to choose another expert if needed.

Thank you, Cindy

Survey location: [SERVER]

The password: [PSWD]

Note: This email has been created automatically. The password indicated in this E-MAIL cannot be traced to you. Your vote is anonymous. 


\section{Appendix E \\ Statement of Informed Consent/Recruitment Invitation}

I would like to invite you to participate in a research study, part of the process to complete a doctoral dissertation entitled "Establishing the Validity and Reliability of the Survey of Higher Education Instructional Practices in the Millennial Age" which may be published in the future. This survey is being used to establish validity and reliability of an instrument to explore utilization of technology-enhanced instructional practices and perceptions concerning instructor role and preferred student learning styles reported by Missouri higher education faculty. Data will also be examined as to the relationships and differences in the technology-enhanced instructional practices as well as perceptions of instructional role and student learning styles when data are grouped by the type of higher education institution ( 2 year or 4 year, public or private), institution size based on Carnegie Classifications, departments, years as faculty, rank (adjunct, instructor, assistant professor, associate professor or full professor), gender, and age range. The questionnaire will be completed and submitted via a secure Internet connection, contains 40 items and should take less than 15 minutes to complete.

- Participation in this study is completely voluntary: You may withdraw from participation at any time you wish, including in the middle of the survey or after it is completed. You may choose not to answer any single question or group of questions if you prefer. You will not be personally compensated in any way for participating in this research. However, your contribution regarding technology-enhanced instructional practices and perceptions of instructor role and students' learning preferences, will assist me in completion of this dissertation.

- Your identity and the identity of your organization will be protected in the reporting of my findings: Responses will be kept confidential and no institution or individual will be named in this study. Within the gathering of data or report of the findings, no actual individual names or names of institutions will be collected or used in any manner.

To address any questions and/or concerns you may contact the parties below:

- The researcher: Cynthia Wells, Doctoral Candidate, University of Missouri-Columbia; by email at cindywells@grm.net or ciwfy6@mail.missouri.edu or by phone at 816-387-7481.

- The researcher's faculty advisors:

Dr. Phillip E. Messsner; by email at pemday@nwmissouri.edu or by phone at 660-5621478.

Dr. Carole Edmonds; by email at cake@nwmissouri.edu or by phone at 660-562-1258.

- For additional information regarding human participation in research: The University of Missouri Campus IRB Office at 573-882-9585.

If at this point you are still interested and agree to complete the survey, please read the statement below, click on the hyperlink and enter the designated password to complete the questionnaire. You may print this web form for future reference. Thank you for your time and consideration.

Sincerely,

Cindy Wells

By clicking the hyperlink below, I agree to participate in the study of survey development for the University of Missouri; I understand that data collected by the researcher will be used in a doctoral dissertation and may be published. My participation is completely voluntary, I may 
withdraw my participation in the survey at any time, and my identity will not be used in reporting of the findings.

Link: https://www.esurveycreator.com/s/81389d2

Campus IRB Approved 4/18/2013

IRB \#1207599

Password: survey13 
Appendix F - Initial Participant Email

Please read the Statement of Informed Consent/Recruitment Invitation below. Then to continue to the survey, please click the arrow at the bottom of this page. Thank you in advance for your participation.

I would like to invite you to participate in a research study, part of the process to complete a doctoral dissertation entitled "Establishing the Validity and Reliability of the Survey of Higher Education Instructional Practices in the Millennial Age" which may be published in the future. This survey is being used to establish validity and reliability of an instrument to explore utilization of technology-enhanced instructional practices and perceptions concerning instructor role and preferred student learning styles reported by Missouri higher education faculty. Data will also be examined as to the relationships and differences in the technology-enhanced instructional practices as well as perceptions of instructional role and student learning styles when data are grouped by the type of higher education institution (2 year or 4 year, public or private), institution size based on Carnegie Classifications, departments, years as faculty, rank (adjunct, instructor, assistant professor, associate professor or full professor), gender, and age range. The questionnaire will be completed and submitted via a secure Internet connection, contains 40 items and should take less than 15 minutes to complete.

- Participation in this study is completely voluntary: You may withdraw from participation at any time you wish, including in the middle of the survey or after it is completed. You may choose not to answer any single question or group of questions if you prefer. You will not be personally compensated in any way for participating in this research. However, your contribution regarding technology-enhanced instructional practices and perceptions of instructor role and students' learning preferences, will assist me in completion of this dissertation.

- Your identity and the identity of your organization will be protected in the reporting of my findings: Responses will be kept confidential and no institution or individual will be named in this study. Within the gathering of data or report of the findings, no actual individual names or names of institutions will be collected or used in any manner.

To address any questions and/or concerns you may contact the parties below:

- The researcher:

Cynthia Wells, Doctoral Candidate, University of Missouri-Columbia; by email at cindywells@grm.net or ciwfy6@mail.missouri.edu or by phone at 816-387-7481.

- The researcher's faculty advisors:

Dr. Phillip E. Messsner; by email at pemday@nwmissouri.edu or by phone at 660-5621478.

Dr. Carole Edmonds; by email at cake@ nwmissouri.edu or by phone at 660-562-1258.

- For additional information regarding human participation in research:

The University of Missouri Campus IRB Office at 573-882-9585.

If at this point you are still interested and agree to complete the survey, please click the arrow below and continue to the questionnaire. You may print this web form for future reference. Thank you for your time and consideration.

Sincerely,

Cindy Wells

University of Missouri Doctoral Candidate 
Appendix G - Reminder Email to Participants

\section{Reminder: Statement of Informed Consent/Recruitment Invitation}

This is a simple reminder. The original invitation for participation in this study, seen below, was sent approximately 1 week ago. If you have already completed this questionnaire, please accept my thanks for your responses and disregard this reminder. If you have not yet responded, please take a few minutes to now complete the questionnaire. It will be greatly appreciated.

I would like to invite you to participate in a research study, part of the process to complete a doctoral dissertation entitled "Establishing the Validity and Reliability of the Survey of Higher Education Instructional Practices in the Millennial Age" which may be published in the future. This survey is being used to establish validity and reliability of an instrument to explore utilization of technology-enhanced instructional practices and perceptions concerning instructor role and preferred student learning styles reported by Missouri higher education faculty. Data will also be examined as to the relationships and differences in the technology-enhanced instructional practices as well as perceptions of instructional role and student learning styles when data are grouped by the type of higher education institution (2 year or 4 year, public or private), institution size based on Carnegie Classifications, departments, years as faculty, rank (adjunct, instructor, assistant professor, associate professor, full professor), gender, and age range. The questionnaire will be completed and submitted via a secure Internet connection, contains 40 items and should take less than 15 minutes to complete.

- Participation in this study is completely voluntary: You may withdraw from participation at any time you wish, including in the middle of the survey or after it is completed. You may choose not to answer any single question or group of questions if you prefer. You will not be personally compensated in any way for participating in this research. However, your contribution regarding technology-enhanced instructional practices and perceptions of instructor role and students' learning preferences, will assist me in completion of this dissertation.

- Your identity and the identity of your organization will be protected in the reporting of my findings: Responses will be kept confidential and no institution or individual will be named in this study. Within the gathering of data or report of the findings, no actual individual names or names of institutions will be collected or used in any manner.

To address any questions and/or concerns you may contact the parties below:

- The researcher: Cynthia Wells, Doctoral Candidate, University of Missouri-Columbia; by email at cindywells@grm.net or ciwfy6@mail.missouri.edu or by phone at 816-387-7481.

- The researcher's faculty advisors:

Dr. Phillip E. Messsner; by email at pemday@nwmissouri.edu or by phone at 660-562-1478. Dr. Carole Edmonds; by email at cake@ @wmissouri.edu or by phone at 660-562-1258.

- For additional information regarding human participation in research:

The University of Missouri Campus IRB Office at 573-882-9585. 
If at this point you are still interested and agree to complete the survey, please read the statement below, click on the hyperlink and enter the designated password to complete the questionnaire. You may print this web form for future reference. Thank you for your time and consideration.

Sincerely,

\section{Cindy Wells}

By clicking the hyperlink below, I agree to participate in the study of survey development for the University of Missouri; I understand that data collected by the researcher will be used in a doctoral dissertation and may be published. My participation is completely voluntary, I may withdraw my participation in the survey at any time, and my identity will not be used in reporting of the findings.

Link: https://www.esurveycreator.com/s/81389d2 $\quad$ Password: survey13 
Appendix $\mathrm{H}$

List of Higher Education institutions from MDHE

Institution

Faculty

\# Random \#

PUBLIC BACCALAUREATE AND HIGHER DEGREE-GRANTING INSTITUTIONS

4-Year Public

Harris-Stowe State University

2 Lincoln University

48

Missouri Southern State University

166

4 Missouri State University 701

5 Missouri University of Science and Technology 377

6 Missouri Western State University 188

7 Northwest Missouri State University 261

8 Southeast Missouri State University 409

9 Truman State University 318

10 University of Central Missouri 446

11 University of Missouri-Columbia 3130

12 University of Missouri-Kansas City 1290

13 University of Missouri-St Louis 533

$\begin{array}{ll}\text { Subtotal } & 8,073\end{array}$

PUBLIC CERTIFICATE AND ASSOCIATE DEGREE-GRANTING INSTITUTIONS

2-Year Public

$2,4,13,14,19$

1 Crowder College $\quad 99$

2 East Central College $\quad 70$

3 Jefferson College 90

4 Linn State Technical College 84

5 Metropolitan Community College-Blue River 38

6 Metropolitan Community College-Business \& Technology 16

7 Metropolitan Community College-Kansas City 3

8 Metropolitan Community College-Longview 82

9 Metropolitan Community College-Maple Woods 53

10 Metropolitan Community College-Penn Valley 96

11 Mineral Area College $\quad 68$

12 Missouri State University-West Plains 32

13 Moberly Area Community College 72

14 North Central Missouri College 39

15 Ozarks Technical Community College 188 
16 St Charles Community College 98

17 St Louis Community College 444

18 State Fair Community College 69

19 Three Rivers Community College 62

Subtotal 1703

PRIVATE NOT-FOR-PROFIT (INDEPENDENT) BACCALAUREATE AND HIGHER DEGREE-GRANTING INSTITUTIONS

4-Year Private

1 Avila University 63

$36,8,20,22$

2 Central Methodist University-College of Liberal Arts 61

3 College of the Ozarks $\quad 89$

4 Columbia College $\quad 69$

5 Culver-Stockton College 48

6 Drury University 143

7 Evangel University $\quad 86$

8 Fontbonne University 81

9 Hannibal-Lagrange College $\quad 59$

10 Lindenwood University 244

11 Maryville University of Saint Louis 114

12 Missouri Baptist University 75

13 Missouri Valley College $\quad 83$

14 Park University 127

15 Rockhurst University 125

16 Saint Louis University-Main Campus 1,356

17 Southwest Baptist University 128

18 Stephens College $\quad 55$

19 Washington University in St Louis $\quad 3,184$

20 Webster University 192

21 Westminster College $\quad 62$

22 William Jewell College $\quad 67$

23 William Woods University $\quad 56$

$\begin{array}{ll}\text { Subtotal } & 6,567\end{array}$

Total HE Faculty in Missouri $\quad 16,343$ 
Appendix I

Tables 
Table 24

Frequency of Responses (Agree vs. Disagree) - Utilization of Technology-Enhanced Instructional Practices (RQ5.2) -

Disaggregated by Carnegie Size Classification

\begin{tabular}{|c|c|c|c|c|c|c|c|c|c|c|c|c|c|c|c|c|c|c|c|c|}
\hline \multirow[b]{3}{*}{ Variable } & \multicolumn{4}{|c|}{ Very Small 2 - Year } & \multicolumn{4}{|c|}{ Small 2 - Year } & \multicolumn{4}{|c|}{ Medium 2 - Year } & \multicolumn{4}{|c|}{ Large 2 - Year } & \multicolumn{4}{|c|}{ Very Large 2 - Year } \\
\hline & \multicolumn{2}{|c|}{ Agree } & \multicolumn{2}{|c|}{ Disagree } & \multicolumn{2}{|c|}{ Agree } & \multicolumn{2}{|c|}{ Disagree } & \multicolumn{2}{|c|}{ Agree } & \multicolumn{2}{|c|}{ Disagree } & \multicolumn{2}{|c|}{ Agree } & \multicolumn{2}{|c|}{ Disagree } & \multicolumn{2}{|c|}{ Agree } & \multicolumn{2}{|c|}{ Disagree } \\
\hline & $\mathrm{n}$ & $\%$ & $\mathrm{n}$ & $\%$ & $\mathrm{n}$ & $\%$ & $\mathrm{n}$ & $\%$ & $\mathrm{n}$ & $\%$ & $\mathrm{n}$ & $\%$ & $\mathrm{n}$ & $\%$ & $\mathrm{n}$ & $\%$ & $\mathrm{n}$ & $\%$ & $\mathrm{n}$ & $\%$ \\
\hline $\begin{array}{l}\text { I7 - Technology-enabled classroom } \\
\text { environment }\end{array}$ & 4 & 100.0 & 0 & 0.0 & 12 & 92.31 & 1 & 7.69 & 22 & 95.65 & 1 & 4.35 & 5 & 100.0 & 0 & 0.0 & 0 & 0.0 & 0 & 0.0 \\
\hline $\begin{array}{l}\text { I8 - Use technology-based tools to } \\
\text { support instruction }\end{array}$ & 4 & 100.0 & 0 & 0.0 & 12 & 92.31 & 1 & 7.69 & 23 & 100.0 & 0 & 0 & 5 & 100.0 & 0 & 0.0 & 0 & 0.0 & 0 & 0.0 \\
\hline $\begin{array}{l}\text { I9 - Use video-based instruction to } \\
\text { support activities }\end{array}$ & 4 & 100.0 & 0 & 0.0 & 9 & 69.23 & 4 & 30.8 & 16 & 69.57 & 7 & 30.43 & 2 & 40.0 & 3 & 60.0 & 0 & 0.0 & 0 & 0.0 \\
\hline $\begin{array}{l}\text { I10 - Use technology means to } \\
\text { communicate w/ students }\end{array}$ & 4 & 100.0 & 0 & 0.0 & 11 & 84.62 & 2 & 15.4 & 22 & 95.65 & 1 & 4.35 & 5 & 100.0 & 0 & 0.0 & 0 & 0.0 & 0 & 0.0 \\
\hline $\begin{array}{l}\text { I11 - Encourage student } \\
\text { communication using technology }\end{array}$ & 3 & 75.0 & 1 & 25.0 & 7 & 53.85 & 6 & 46.2 & 15 & 65.22 & 8 & 34.78 & 3 & 60.0 & 2 & 40.0 & 0 & 0.0 & 0 & 0.0 \\
\hline $\begin{array}{l}\text { I12 - Use smart or wireless devices to } \\
\text { conduct lessons/materials }\end{array}$ & 2 & 50.0 & 2 & 50.0 & 5 & 38.46 & 8 & 61.5 & 7 & 30.43 & 16 & 69.57 & 1 & 20.0 & 4 & 80.0 & 0 & 0.0 & 0 & 0.0 \\
\hline $\begin{array}{l}\text { I13 - Use of guest speakers via } \\
\text { technology-driven means }\end{array}$ & 1 & 25.0 & 3 & 75.0 & 2 & 15.38 & 11 & 84.6 & 2 & 8.70 & 21 & 91.30 & 0 & 0.0 & 5 & 100.0 & 0 & 0.0 & 0 & 0.0 \\
\hline $\begin{array}{l}\text { I14 - Students use web-based tools to } \\
\text { complete assignments }\end{array}$ & 4 & 100.0 & 0 & 0.0 & 9 & 69.23 & 4 & 30.8 & 20 & 86.96 & 3 & 13.04 & 5 & 100.0 & 0 & 0.0 & 0 & 0.0 & 0 & 0.0 \\
\hline
\end{tabular}

(Table 24 continues) 


\section{(Table 24 continued)}

\begin{tabular}{|c|c|c|c|c|c|c|c|c|c|c|c|c|c|c|c|c|c|}
\hline \multirow[b]{3}{*}{ Variable } & \multicolumn{4}{|c|}{ Very Small 4 - Year } & \multicolumn{4}{|c|}{ Small 4 - Year } & \multicolumn{4}{|c|}{ Medium 4 - Year } & \multicolumn{4}{|c|}{ Large $4-$ Year } & \multirow[b]{3}{*}{$\mathrm{N}$} \\
\hline & \multicolumn{2}{|c|}{ Agree } & \multicolumn{2}{|c|}{ Disagree } & \multicolumn{2}{|c|}{ Agree } & \multicolumn{2}{|c|}{ Disagree } & \multicolumn{2}{|c|}{ Agree } & \multicolumn{2}{|c|}{ Disagree } & \multicolumn{2}{|c|}{ Agree } & \multicolumn{2}{|c|}{ Disagree } & \\
\hline & $\mathrm{n}$ & $\%$ & $\mathrm{n}$ & $\%$ & $\mathrm{n}$ & $\%$ & $\mathrm{n}$ & $\%$ & $\mathrm{n}$ & $\%$ & $\mathrm{n}$ & $\%$ & $\mathrm{n}$ & $\%$ & $\mathrm{n}$ & $\%$ & \\
\hline $\begin{array}{l}\text { - Technology-enabled classroom } \\
\text { hvironment }\end{array}$ & 3 & 1000 & 0 & 0.0 & 27 & 90.00 & 3 & 1000 & 00 & 259 & 8 & 7.41 & 53 & 2.98 & 4 & .02 & 243 \\
\hline $\begin{array}{l}\text { I8 - Use technology-based tools to } \\
\text { support instruction }\end{array}$ & 3 & 100.0 & 0 & 0.0 & 25 & 3 & 5 & 5.67 & 103 & 7 & 5 & 3 & 3 & 98 & 4 & .02 & 243 \\
\hline $\begin{array}{l}\text { I9 - Use video-based instruction to } \\
\text { support activities }\end{array}$ & 3 & 100.0 & 0 & & 18 & 60.00 & 12 & 0.00 & 67 & 4 & 41 & 37.96 & 38 & 66.67 & 19 & 33.33 & 243 \\
\hline $\begin{array}{l}\text { I10 - Use technology means to } \\
\text { communicate w/ students }\end{array}$ & 3 & 100.0 & 0 & 00 & 29 & 96.67 & 1 & 3.33 & 104 & 97.20 & 3 & 2.80 & 55 & 96.49 & 2 & 3.51 & 242 \\
\hline $\begin{array}{l}\text { I1 } 1 \text { - Encourage student } \\
\text { communication using technology }\end{array}$ & 2 & 66.7 & 1 & 33.3 & 15 & 50.00 & 15 & 50.00 & 55 & 51.40 & 52 & 48.60 & 7 & 47.37 & 30 & 52.63 & 242 \\
\hline I12 - Use smart or wireless devices to & 3 & 100.0 & 0 & 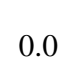 & 5 & 16.67 & 25 & 33 & 23 & 21.30 & 85 & 78.70 & 13 & 22.81 & 44 & 77.19 & 243 \\
\hline $\begin{array}{l}\text { I13 - Use of guest speakers via } \\
\text { technology-driven means }\end{array}$ & 1 & 33.3 & 2 & 66.7 & 2 & 6.67 & 28 & & 9 & 8.49 & 97 & 1 & 6 & 10.53 & 51 & 9.47 & 241 \\
\hline $\begin{array}{l}\text { I14 - Students use web-based tools to } \\
\text { complete assignments }\end{array}$ & 3 & 100.0 & 0 & 0.0 & 22 & 73.33 & 8 & 26.67 & 79 & 73.15 & 29 & 26.85 & 39 & 68.42 & 18 & 31.58 & 243 \\
\hline
\end{tabular}


Table 26

Frequency of Responses (Agree vs. Disagree) - Perception of Instructor Role (RQ5.2) - Disaggregated by Carnegie Size

\section{Classification}

\begin{tabular}{|c|c|c|c|c|c|c|c|c|c|c|c|c|c|c|c|c|c|c|c|c|}
\hline \multirow[b]{3}{*}{ Variable } & \multicolumn{4}{|c|}{ Very Small 2 - Year } & \multicolumn{4}{|c|}{ Small 2 - Year } & \multicolumn{4}{|c|}{ Medium 2 - Year } & \multicolumn{4}{|c|}{ Large 2 - Year } & \multicolumn{4}{|c|}{ Very Large 2 - Year } \\
\hline & \multicolumn{2}{|c|}{ Agree } & \multicolumn{2}{|c|}{ Disagree } & \multicolumn{2}{|c|}{ Agree } & \multicolumn{2}{|c|}{ Disagree } & \multicolumn{2}{|c|}{ Agree } & \multicolumn{2}{|c|}{ Disagree } & \multicolumn{2}{|c|}{ Agree } & \multicolumn{2}{|c|}{ Disagree } & \multicolumn{2}{|c|}{ Agree } & \multicolumn{2}{|c|}{ Disagree } \\
\hline & $\mathrm{n}$ & $\%$ & $\mathrm{n}$ & $\%$ & $\mathrm{n}$ & $\%$ & $\mathrm{n}$ & $\%$ & $\mathrm{n}$ & $\%$ & $\mathrm{n}$ & $\%$ & $\mathrm{n}$ & $\%$ & $\mathrm{n}$ & $\%$ & $\mathrm{n}$ & $\%$ & $n$ & $\%$ \\
\hline $\begin{array}{l}\text { I15 - Role of facilitator; students } \\
\text { construct knowledge for selves }\end{array}$ & 3 & 75.0 & 1 & 25.0 & 9 & 69.23 & 4 & 30.77 & 16 & 69.57 & 7 & 30.43 & 5 & 100.0 & 0 & 0.0 & 0 & 0.0 & 0 & 0.0 \\
\hline $\begin{array}{l}\text { I16 - Most important part of instruction } \\
\text { is the content/curriculum }\end{array}$ & 4 & 100.0 & 0 & 0.0 & 13 & 100.0 & 0 & 0.00 & 17 & 73.91 & 6 & 26.09 & 5 & 100.0 & 0 & 0.0 & 0 & 0.0 & 0 & 0.0 \\
\hline $\begin{array}{l}\text { I17 - All sorts of activities going on in } \\
\text { the classroom }\end{array}$ & 2 & 50.0 & 2 & 50.0 & 9 & 69.23 & 4 & 30.77 & 16 & 69.57 & 7 & 30.43 & 4 & 80.0 & 1 & 20.0 & 0 & 0.0 & 0 & 0.0 \\
\hline $\begin{array}{l}\text { I18 - Students learn basic skills in } \\
\text { context of mastering content }\end{array}$ & 3 & 75.0 & 1 & 25.0 & 8 & 61.54 & 5 & 38.46 & 20 & 86.96 & 3 & 13.04 & 4 & 80.0 & 1 & 20.0 & 0 & 0.0 & 0 & 0.0 \\
\hline $\begin{array}{l}\text { I19 - Better to give the whole class } \\
\text { same assignment-small intervals }\end{array}$ & 1 & 25.0 & 3 & 75.0 & 9 & 69.23 & 4 & 30.77 & 16 & 69.57 & 7 & 30.43 & 3 & 60.0 & 2 & 40.0 & 0 & 0.0 & 0 & 0.0 \\
\hline $\begin{array}{l}\text { I20 - Textbook core content is more } \\
\text { important-not student motivation }\end{array}$ & 4 & 100.0 & 0 & 0.0 & 6 & 46.15 & 7 & 53.85 & 15 & 65.22 & 8 & 34.78 & 4 & 80.0 & 1 & 20.0 & 0 & 0.0 & 0 & 0.0 \\
\hline $\begin{array}{l}\text { I21 - Most important instruction } \\
\text { encourages "sense-making"/thinking }\end{array}$ & 3 & 75.0 & 1 & 25.0 & 8 & 61.54 & 5 & 38.46 & 16 & 69.57 & 7 & 30.43 & 4 & 80.0 & 1 & 20.0 & 0 & 0.0 & 0 & 0.0 \\
\hline $\begin{array}{l}\text { I22 - Critical for students to become } \\
\text { interested in doing academic work }\end{array}$ & 2 & 50.0 & 2 & 50.0 & 6 & 46.15 & 7 & 53.85 & 12 & 52.17 & 11 & 47.83 & 3 & 60.0 & 2 & 40.0 & 0 & 0.0 & 0 & 0.0 \\
\hline $\begin{array}{l}\text { I23 - Material must be covered in a } \\
\text { structured way; job to explain }\end{array}$ & 3 & 75.0 & 1 & 25.0 & 11 & 84.62 & 2 & 15.38 & 17 & 73.91 & 6 & 26.09 & 4 & 80.0 & 1 & 20.0 & 0 & 0.0 & 0 & 0.0 \\
\hline $\begin{array}{l}\text { I } 24 \text { - Students learn basic skills before } \\
\text { mastering complex content }\end{array}$ & 4 & 100.0 & 0 & 0.0 & 13 & 100.0 & 0 & 0.00 & 17 & 73.91 & 6 & 26.09 & 5 & 100.0 & 0 & 0.0 & 0 & 0.0 & 0 & 0.0 \\
\hline
\end{tabular}

(Table 26 continues) 
(Table 26 continued)

\begin{tabular}{|c|c|c|c|c|c|c|c|c|c|c|c|c|c|c|c|c|c|}
\hline \multirow[b]{3}{*}{ Variable } & \multicolumn{4}{|c|}{ Very Small 4 - Year } & \multicolumn{4}{|c|}{ Small 4 - Year } & \multicolumn{4}{|c|}{ Medium 4 - Year } & \multicolumn{4}{|c|}{ Large $4-$ Year } & \multirow[b]{3}{*}{$\mathrm{N}$} \\
\hline & \multirow{2}{*}{\multicolumn{2}{|c|}{ Agree }} & \multirow{2}{*}{\multicolumn{2}{|c|}{$\frac{\text { Disagree }}{\mathrm{n}}$}} & \multirow{2}{*}{\multicolumn{2}{|c|}{ Agree }} & \multicolumn{2}{|c|}{ Disagree } & \multicolumn{2}{|c|}{ Agree } & \multicolumn{2}{|c|}{ Disagree } & \multicolumn{2}{|c|}{ Agree } & \multicolumn{2}{|c|}{ Disagree } & \\
\hline & & & & & & & $\mathrm{n}$ & $\%$ & $\mathrm{n}$ & $\%$ & $\mathrm{n}$ & $\%$ & $\mathrm{n}$ & $\%$ & $\mathrm{n}$ & $\%$ & \\
\hline $\begin{array}{l}\text { I15 - Role of facilitator; students } \\
\text { construct knowledge for selves }\end{array}$ & 3 & 100.0 & 0 & 0.0 & 24 & 80.00 & 6 & 20.00 & 85 & 79.44 & 22 & 20.56 & 44 & 77.19 & 13 & 22.81 & 242 \\
\hline $\begin{array}{l}\text { I16 - Most important part of instruction } \\
\text { is the content/curriculum }\end{array}$ & 3 & 100.0 & 0 & 0.0 & 22 & 73.33 & 8 & 26.67 & 88 & 82.24 & 19 & 17.76 & 51 & 89.47 & 6 & 10.53 & 242 \\
\hline $\begin{array}{l}\text { I17 - All sorts of activities going on in } \\
\text { the classroom }\end{array}$ & 3 & 100.0 & 0 & 0.0 & 17 & 56.67 & 13 & 43.33 & 75 & 70.75 & 31 & 29.25 & 40 & 70.18 & 17 & 29.82 & 241 \\
\hline $\begin{array}{l}\text { I1 } 8 \text { - Students learn basic skills in } \\
\text { context of mastering content }\end{array}$ & 3 & 100.0 & 0 & 0.0 & 23 & 76.67 & 7 & 23.33 & 94 & 87.85 & 13 & 12.15 & 53 & 94.64 & 3 & 5.36 & 241 \\
\hline $\begin{array}{l}\text { I19 - Better to give the whole class } \\
\text { same assignment-small intervals }\end{array}$ & 1 & 33.3 & 2 & 66.7 & 13 & 43.33 & 17 & 56.67 & 61 & 57.55 & 45 & 42.45 & 32 & 58.18 & 23 & 41.82 & 239 \\
\hline $\begin{array}{l}\text { I } 20 \text { - Textbook core content is more } \\
\text { important-not student motivation }\end{array}$ & 1 & 33.3 & 2 & 66.7 & 12 & 41.38 & 17 & 58.62 & 53 & 50.00 & 53 & 50.00 & 26 & 45.61 & 31 & 54.39 & 240 \\
\hline $\begin{array}{l}\text { I21 - Most important instruction } \\
\text { encourages "sense-making"/thinking }\end{array}$ & 2 & 66.7 & 1 & 33.3 & 15 & 55.56 & 12 & 44.44 & 71 & 66.98 & 35 & 33.02 & 36 & 64.29 & 20 & 35.71 & 237 \\
\hline $\begin{array}{l}\text { I22 - Critical for students to become } \\
\text { interested in doing academic work }\end{array}$ & 1 & 33.3 & 1 & 33.3 & 18 & 62.07 & 11 & 37.93 & 66 & 61.68 & 41 & 38.32 & 29 & 51.79 & 27 & 48.21 & 239 \\
\hline $\begin{array}{l}\text { I } 23 \text { - Material must be covered in a } \\
\text { structured way; job to explain }\end{array}$ & 2 & 66.7 & 1 & 33.3 & 20 & 66.67 & 10 & 33.33 & 82 & 76.64 & 25 & 23.36 & 39 & 68.42 & 18 & 31.58 & 242 \\
\hline $\begin{array}{l}\text { I } 24 \text { - Students learn basic skills before } \\
\text { mastering complex content }\end{array}$ & 1 & 33.3 & 2 & 66.7 & 19 & 65.52 & 10 & 34.48 & 88 & 82.24 & 19 & 17.76 & 44 & 77.19 & 13 & 22.81 & 241 \\
\hline
\end{tabular}


Table 28

Frequency of Responses (Agree vs. Disagree) - Perception of Millennial Students' Preferred Learning Styles (RQ5.2) -

\section{Disaggregated by Carnegie Size Classification}

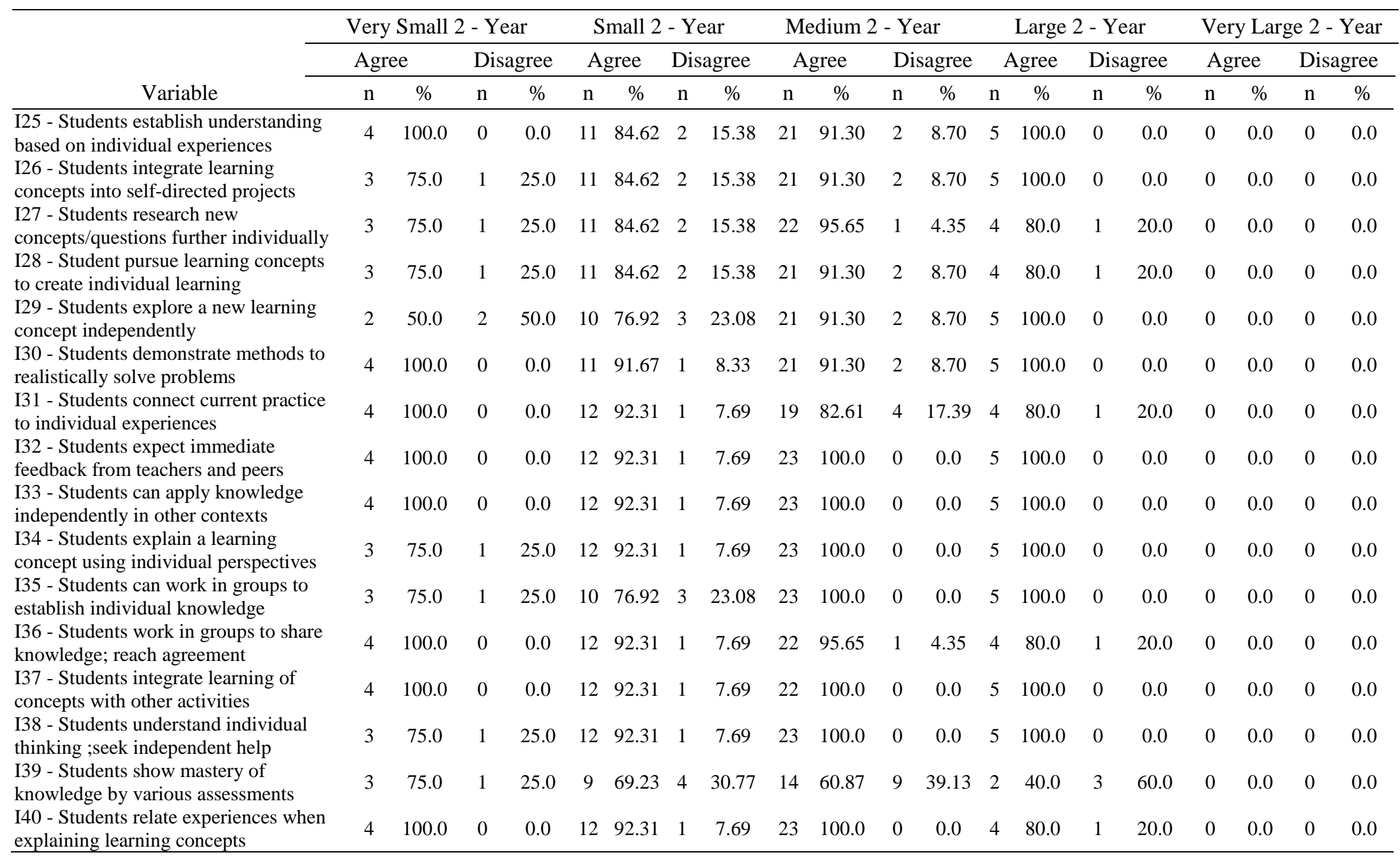

(Table 28 continues) 


\begin{tabular}{|c|c|c|c|c|c|c|c|c|c|c|c|c|c|c|c|c|c|}
\hline \multirow[b]{3}{*}{ Variable } & \multicolumn{4}{|c|}{ Very Small 4 - Year } & \multicolumn{4}{|c|}{ Small 4 - Year } & \multicolumn{4}{|c|}{ Medium 4 - Year } & \multicolumn{4}{|c|}{ Large $4-$ Year } & \multirow[b]{3}{*}{$\mathrm{N}$} \\
\hline & \multicolumn{2}{|c|}{ Agree } & \multicolumn{2}{|c|}{ Disagree } & \multicolumn{2}{|c|}{ Agree } & \multicolumn{2}{|c|}{ Disagree } & \multicolumn{2}{|c|}{ Agree } & \multicolumn{2}{|c|}{ Disagree } & \multicolumn{2}{|c|}{ Agree } & \multicolumn{2}{|c|}{ Disagree } & \\
\hline & $\mathrm{n}$ & $\%$ & $\mathrm{n}$ & $\%$ & $\mathrm{n}$ & $\%$ & $\mathrm{n}$ & $\%$ & $\mathrm{n}$ & $\%$ & $\mathrm{n}$ & $\%$ & $\mathrm{n}$ & $\%$ & $\mathrm{n}$ & $\%$ & \\
\hline $\begin{array}{l}\text { I25 - Students establish understanding } \\
\text { based on individual experiences }\end{array}$ & 3 & 100.0 & 0 & 0.0 & 25 & 86.21 & 4 & 13.79 & 98 & 91.59 & 9 & 8.41 & 49 & 87.50 & 7 & 12.50 & 240 \\
\hline $\begin{array}{l}\text { I26 - Students integrate learning } \\
\text { concepts into self-directed projects }\end{array}$ & 3 & 100.0 & 0 & 0.0 & 25 & 86.21 & 4 & 13.79 & 94 & 87.85 & 13 & 12.15 & 51 & 91.07 & 5 & 8.93 & 240 \\
\hline $\begin{array}{l}\text { I27 - Students research new } \\
\text { concepts/questions further individually }\end{array}$ & 3 & 100.0 & 0 & 0.0 & 25 & 86.21 & 4 & 13.79 & 93 & 86.92 & 14 & 13.08 & 49 & 87.50 & 7 & 12.50 & 240 \\
\hline $\begin{array}{l}\text { I } 28 \text { - Student pursue learning concepts } \\
\text { to create individual learning }\end{array}$ & 3 & 100.0 & 0 & 0.0 & 26 & 89.66 & 3 & 10.34 & 96 & 90.57 & 10 & 9.43 & 52 & 94.55 & 3 & 5.45 & 238 \\
\hline $\begin{array}{l}\text { I } 29 \text { - Students explore a new learning } \\
\text { concept independently }\end{array}$ & 3 & 100.0 & 0 & 0.0 & 23 & 79.31 & 6 & 20.69 & 88 & 82.24 & 19 & 17.76 & 50 & 89.29 & 6 & 10.71 & 240 \\
\hline $\begin{array}{l}\text { I30 - Students demonstrate methods to } \\
\text { realistically solve problems }\end{array}$ & 3 & 100.0 & 0 & 0.0 & 26 & 89.66 & 3 & 10.34 & 100 & 93.46 & 7 & 6.54 & 53 & 94.64 & 3 & 5.36 & 239 \\
\hline $\begin{array}{l}\text { I31 - Students connect current practice } \\
\text { to individual experiences }\end{array}$ & 3 & 100.0 & 0 & 0.0 & 22 & 75.86 & 7 & 24.14 & 75 & 70.75 & 31 & 29.25 & 43 & 76.79 & 13 & 23.21 & 239 \\
\hline $\begin{array}{l}\text { I32 - Students expect immediate } \\
\text { feedback from teachers and peers }\end{array}$ & 3 & 100.0 & 0 & 0.0 & 28 & 96.55 & 1 & 3.45 & 97 & 90.65 & 10 & 9.35 & 53 & 92.98 & 4 & 7.02 & 241 \\
\hline $\begin{array}{l}\text { I33 - Students can apply knowledge } \\
\text { independently in other contexts }\end{array}$ & 3 & 100.0 & 0 & 0.0 & 28 & 96.55 & 1 & 3.45 & 97 & 90.65 & 10 & 9.35 & 53 & 92.98 & 4 & 7.02 & 241 \\
\hline $\begin{array}{l}\text { I34 - Students explain a learning } \\
\text { concept using individual perspectives }\end{array}$ & 3 & 100.0 & 0 & 0.0 & 26 & 89.66 & 3 & 10.34 & 100 & 93.46 & 7 & 6.54 & 51 & 89.47 & 6 & 10.53 & 241 \\
\hline $\begin{array}{l}\text { I35 - Students can work in groups to } \\
\text { establish individual knowledge }\end{array}$ & 3 & 100.0 & 0 & 0.0 & 21 & 72.41 & 8 & 27.59 & 84 & 78.50 & 23 & 21.50 & 51 & 89.47 & 6 & 10.53 & 241 \\
\hline $\begin{array}{l}\text { I36 - Students work in groups to share } \\
\text { knowledge; reach agreement }\end{array}$ & 3 & 100.0 & 0 & 0.0 & 22 & 73.33 & 8 & 26.67 & 88 & 82.24 & 19 & 17.76 & 51 & 89.47 & 6 & 10.53 & 242 \\
\hline $\begin{array}{l}\text { I37 - Students integrate learning of } \\
\text { concepts with other activities }\end{array}$ & 3 & 100.0 & 0 & 0.0 & 26 & 89.66 & 3 & 10.34 & 96 & 89.72 & 11 & 10.28 & 53 & 94.64 & 3 & 5.36 & 239 \\
\hline $\begin{array}{l}\text { I38 - Students understand individual } \\
\text { thinking ;seek independent help }\end{array}$ & 3 & 100.0 & 0 & 0.0 & 27 & 93.10 & 2 & 6.90 & 99 & 92.52 & 8 & 7.48 & 52 & 92.86 & 4 & 7.14 & 240 \\
\hline $\begin{array}{l}\text { I39 - Students show mastery of } \\
\text { knowledge by various assessments }\end{array}$ & 2 & 66.7 & 1 & 33.3 & 15 & 51.72 & 14 & 48.28 & 64 & 60.38 & 42 & 39.62 & 33 & 58.93 & 23 & 41.07 & 239 \\
\hline $\begin{array}{l}\text { I } 40 \text { - Students relate experiences when } \\
\text { explaining learning concepts }\end{array}$ & 3 & 100.0 & 0 & 0.0 & 25 & 89.29 & 3 & 10.71 & 99 & 92.52 & 8 & 7.48 & 52 & 92.86 & 4 & 7.14 & 239 \\
\hline
\end{tabular}

$$
\mathrm{n}=244
$$


Table 30

Frequency of Responses (Agree vs. Disagree) - Utilization of Technology-Enhanced Instruction (RQ5.3) - Disaggregated by

\section{Department}

\begin{tabular}{|c|c|c|c|c|c|c|c|c|c|c|c|c|c|c|c|c|c|c|c|c|c|c|c|c|}
\hline \multirow[b]{3}{*}{ Variable } & \multicolumn{4}{|c|}{ Business/Economics } & \multicolumn{5}{|c|}{ Com. Stud./Speech } & \multicolumn{4}{|c|}{ CJ, SoSc/Hum Beh Sc } & \multicolumn{4}{|c|}{ CS, Math, Phy, Engin } & \multicolumn{3}{|c|}{ Education } & \multicolumn{4}{|c|}{ English/ForLang/Rdg } \\
\hline & \multicolumn{2}{|c|}{ Agree } & \multicolumn{2}{|c|}{ Disagre } & \multicolumn{2}{|c|}{ Agree } & \multicolumn{3}{|c|}{ Disagree } & \multicolumn{2}{|c|}{ Agree } & \multicolumn{2}{|c|}{ Disagree } & \multicolumn{2}{|c|}{ Agree } & \multicolumn{2}{|c|}{ Disagree } & Agree & \multicolumn{2}{|c|}{ Disagree } & \multicolumn{2}{|c|}{ Agree } & \multicolumn{2}{|c|}{ Disagree } \\
\hline & $\mathrm{n}$ & $\%$ & $\mathrm{n}$ & $\%$ & $\mathrm{n}$ & $\%$ & 1 & $\%$ & $\mathrm{n}$ & $\%$ & $\mathrm{n}$ & $\%$ & $\mathrm{n}$ & $\%$ & $\mathrm{n}$ & $\%$ & $\mathrm{n}$ & $\%$ & $\mathrm{n}$ & $\%$ & $n$ & $\%$ & $\mathrm{n}$ & $\%$ \\
\hline $\begin{array}{l}\text { I7 - Technology-enabled } \\
\text { classroom environment }\end{array}$ & 13 & 86.67 & 2 & 13.33 & 12 & 100.0 & 0 & 0.0 & 15 & 93.75 & 1 & 6.25 & 32 & 100.0 & 0 & 0.0 & 27 & 87.10 & 4 & 12.90 & 19 & 95.00 & 1 & .00 \\
\hline $\begin{array}{l}\text { I8 - Use technology-based tools to } \\
\text { support instruction }\end{array}$ & 14 & 93.33 & 1 & 6.67 & 12 & 100.0 & 0 & 0.0 & 15 & 93.75 & 1 & .25 & 30 & 93.75 & 2 & .25 & 29 & 93.55 & 2 & 6.45 & 19 & 5.00 & 1 & 5.00 \\
\hline $\begin{array}{l}\text { I9 - Use video-based instruction to } \\
\text { support activities }\end{array}$ & 4 & 26.67 & 11 & 73.33 & 11 & 91.67 & 1 & 8.33 & 9 & 56.25 & 7 & 43.75 & 16 & 50.00 & 16 & 50.00 & 25 & 80.65 & 6 & 19.35 & 11 & 55.00 & 9 & 45.00 \\
\hline $\begin{array}{l}\text { I10 - Use technology means to } \\
\text { communicate w/ students }\end{array}$ & 14 & 93.33 & 1 & 6.7 & 11 & 91.67 & 1 & 8.33 & 16 & 100.0 & 0 & 0.0 & 29 & 90.63 & 3 & 9.38 & 30 & 96.77 & 1 & 3.23 & 20 & 100.0 & 0 & 0.0 \\
\hline $\begin{array}{l}\text { I11 - Encourage student } \\
\text { communication using technology }\end{array}$ & 6 & 40.00 & 9 & 60.00 & 7 & 58.33 & 5 & 41.67 & 10 & 62.50 & 6 & 37.50 & 13 & 40.63 & 19 & .38 & 22 & 0.97 & 9 & .03 & 15 & 8.95 & 4 & 21.05 \\
\hline $\begin{array}{l}\text { I12 - Use smart or wireless devices } \\
\text { to conduct lessons/materials }\end{array}$ & 2 & 13.33 & 13 & 86.67 & 5 & 41.7 & 7 & 58.3 & 3 & 18.75 & 13 & 81.25 & 7 & 21.88 & 25 & 78.13 & 11 & 35.48 & 20 & 64.52 & 4 & 20.00 & 16 & 80.0 \\
\hline $\begin{array}{l}\text { I13 - Use of guest speakers via } \\
\text { technology-driven means }\end{array}$ & 0 & 0.00 & 15 & 100.0 & 3 & 25.0 & 9 & 75.0 & 2 & 12.50 & 14 & 87.50 & 3 & 9.38 & 29 & 90.63 & 2 & 6.45 & 29 & 93.55 & 2 & 10.00 & 18 & 90.00 \\
\hline $\begin{array}{l}\text { I14 - Students use web-based tools } \\
\text { to complete assignments }\end{array}$ & 8 & 53.33 & 7 & 46.67 & 8 & 66.67 & 4 & 33.33 & 12 & 75.00 & 4 & 25.00 & 28 & 87.50 & 4 & 12.50 & 27 & 7.10 & 4 & 12.90 & 19 & 95.00 & 1 & 5.00 \\
\hline
\end{tabular}

(Table 30 continues) 
(Table 30 continued)

\begin{tabular}{|c|c|c|c|c|c|c|c|c|c|c|c|c|c|c|c|c|c|c|c|c|c|c|c|c|c|}
\hline \multirow[b]{3}{*}{ Variable } & \multicolumn{4}{|c|}{ Fine Art(Th, Mus,Film)/Art } & \multicolumn{4}{|c|}{ Nursing/Health } & \multicolumn{4}{|c|}{ Pol. Sc/Hist/Geo } & \multicolumn{5}{|c|}{ Psychology/Soc/SocWork } & \multicolumn{4}{|c|}{ Science (Bio,Chem, Ag) } & \multicolumn{4}{|c|}{ Other } \\
\hline & \multicolumn{2}{|c|}{ Agree } & \multicolumn{2}{|c|}{ Disagree } & \multicolumn{2}{|c|}{ Agree } & \multicolumn{2}{|c|}{ Disagree } & \multicolumn{2}{|c|}{ Agree } & \multicolumn{2}{|c|}{ Disagree } & \multicolumn{2}{|c|}{ Agree } & \multicolumn{3}{|c|}{ Disagree } & \multicolumn{2}{|c|}{ Agree } & \multicolumn{2}{|c|}{ Disagree } & \multicolumn{2}{|c|}{ Agree } & \multicolumn{2}{|c|}{ Disagree } \\
\hline & $\mathrm{n}$ & $\%$ & $\mathrm{n}$ & $\%$ & $\mathrm{n}$ & $\%$ & $\mathrm{n}$ & $\%$ & $\mathrm{r}$ & $\%$ & $\mathrm{n}$ & $\%$ & $\mathrm{n}$ & $\%$ & $\mathrm{n}$ & $\%$ & $\mathrm{n}$ & $\%$ & $\mathrm{n}$ & $\%$ & & $\%$ & & $\%$ & $\mathrm{~N}$ \\
\hline $\begin{array}{l}\text { I7 - Technology-enabled classroom } \\
\text { environment }\end{array}$ & 14 & 77.78 & 4 & $22.22 \quad 2$ & 26 & 96.30 & 1 & 3.70 & 7 & 87.50 & 1 & $12.50 \quad 1$ & 10 & 100.0 & 0 & 0.0 & 24 & 92.31 & 2 & $\begin{array}{ll}7.69 & 13\end{array}$ & 31 & 100.0 & 0 & 0.0 & 228 \\
\hline $\begin{array}{l}\text { I8 - Use technology-based tools to } \\
\text { support instruction }\end{array}$ & 16 & 88.89 & 2 & 11.11 & 27 & 100.0 & 0 & 0.0 & 7 & 87.50 & 1 & 12.50 & 10 & 100.0 & 0 & 0.0 & 23 & 88.46 & 3 & 11.54 & 13 & 100.0 & 0 & 0.0 & 228 \\
\hline $\begin{array}{l}\text { I9 - Use video-based instruction to } \\
\text { support activities }\end{array}$ & 14 & 77.78 & 4 & 22.22 & 24 & 88.89 & 3 & 11.11 & 6 & 75.00 & 2 & 25.00 & 9 & 90.00 & 1 & 10.00 & 10 & 38.46 & 16 & 561.54 & 9 & 69.23 & 4 & 30.77 & 228 \\
\hline $\begin{array}{l}\text { I10 - Use technology means to } \\
\text { communicate w/ students }\end{array}$ & 17 & 94.44 & 1 & 5.56 & 27 & 100.0 & 0 & 0.0 & 7 & 87.50 & 1 & 12.50 & 10 & 100.0 & 0 & 0.0 & 25 & 96.15 & 1 & 3.85 & 13 & 100.0 & 0 & 0.0 & 228 \\
\hline $\begin{array}{l}\text { I1 } 1 \text { - Encourage student } \\
\text { communication using technology }\end{array}$ & 8 & 44.44 & 10 & 55.56 & 17 & 62.96 & 10 & 37.04 & 2 & 25.00 & 6 & 75.00 & 4 & 40.00 & 6 & 60.00 & 8 & 30.77 & 18 & $\begin{array}{l}3 \\
69.23\end{array}$ & 6 & 46.15 & 7 & 53.85 & 227 \\
\hline $\begin{array}{l}\text { I12 - Use smart or wireless devices } \\
\text { to conduct lessons/materials }\end{array}$ & 3 & 16.67 & 15 & 83.33 & 9 & 33.33 & 18 & 66.67 & 2 & 25.00 & 6 & 75.00 & 1 & 10.00 & 9 & 90.00 & 4 & 15.38 & 22 & 84.62 & 4 & 30.77 & 9 & 69.23 & 228 \\
\hline $\begin{array}{l}\text { I13 - Use of guest speakers via } \\
\text { technology-driven means }\end{array}$ & 2 & 11.11 & 16 & 88.89 & 3 & 11.54 & 23 & 88.46 & 0 & 0.00 & 8 & 100.0 & 1 & 10.00 & 9 & 90.00 & 0 & 0.00 & 25 & 5100.0 & 3 & 23.08 & 10 & 76.92 & 226 \\
\hline $\begin{array}{l}\text { I14 - Students use web-based tools } \\
\text { to complete assignments }\end{array}$ & 13 & 72.22 & 5 & 27.78 & 23 & 85.19 & 4 & 14.81 & 3 & 37.50 & 5 & 62.50 & 8 & 80.00 & 2 & 20.00 & 15 & 57.69 & 11 & 42.31 & 6 & 46.15 & 7 & 53.85 & 228 \\
\hline
\end{tabular}

$$
*^{n}=244
$$


Table 32

Frequency of Responses (Agree vs. Disagree) - Perception of Instructional Role (RQ5.3) - Disaggregated by Department

\begin{tabular}{|c|c|c|c|c|c|c|c|c|c|c|c|c|c|c|c|c|c|c|c|c|c|c|c|c|}
\hline \multirow[b]{3}{*}{ Variable } & \multicolumn{4}{|c|}{ Business/Economics } & \multicolumn{4}{|c|}{ Com. Stud./Speech } & \multicolumn{5}{|c|}{ CJ, SoSc/Hum Beh Sc } & \multicolumn{3}{|c|}{ CS, Math, Phy, Engin } & \multicolumn{4}{|c|}{ Education } & \multicolumn{4}{|c|}{ English/ForLang/Rdg } \\
\hline & \multicolumn{2}{|c|}{ Agree } & \multicolumn{2}{|c|}{ Disagree } & \multicolumn{2}{|c|}{ Agree } & \multicolumn{2}{|c|}{ Disagree } & \multicolumn{2}{|c|}{ Agree } & \multicolumn{2}{|c|}{ Disagree } & \multicolumn{2}{|r|}{ Agree } & \multicolumn{2}{|c|}{ Disagree } & \multicolumn{2}{|c|}{ Agree } & \multicolumn{2}{|c|}{ Disagree } & \multicolumn{3}{|c|}{ Agree } & Disagre \\
\hline & $\mathrm{n}$ & $\%$ & $\mathrm{n}$ & $\%$ & $\mathrm{n}$ & $\%$ & $\mathrm{n}$ & $\%$ & $\mathrm{n}$ & $\%$ & $\mathrm{n}$ & $\%$ & $\mathrm{n}$ & $\%$ & $\mathrm{n}$ & $\%$ & $\mathrm{n}$ & $\%$ & $\mathrm{n}$ & $\%$ & $\mathrm{n}$ & $\%$ & & $\mathrm{n}$ \\
\hline $\begin{array}{l}\text { I15 - Role of facilitator; students } \\
\text { construct knowledge for selves }\end{array}$ & 12 & 80.00 & 3 & 20.00 & 12 & 100.0 & 0 & 0.0 & 10 & 62.50 & 6 & 37.50 & 21 & 65.63 & 11 & 34.38 & 27 & 90.00 & 3 & 10.00 & 18 & 90.00 & 2 & 10.00 \\
\hline $\begin{array}{l}\text { I16 - Most important part of instruction } \\
\text { is the content/curriculum }\end{array}$ & 10 & 66.67 & 5 & 33.33 & 12 & 100.0 & 0 & 0.0 & 13 & 81.25 & 3 & 18.75 & 27 & 84.38 & 5 & 15.63 & 25 & 83.33 & 5 & 16.67 & 17 & 85.00 & 3 & 15.00 \\
\hline $\begin{array}{l}\text { I17 - All sorts of activities going on in } \\
\text { Othe classroom }\end{array}$ & 9 & 60.00 & 6 & 40.00 & 7 & 58.3 & 5 & 41.7 & 11 & 73.33 & 4 & 26.67 & 19 & 59.38 & 13 & 40.63 & 25 & 83.33 & 5 & 16.67 & 16 & 80.00 & 4 & 20.00 \\
\hline $\begin{array}{l}\text { I18 - Students learn basic skills in } \\
\text { context of mastering content }\end{array}$ & 13 & 86.7 & 2 & 13.3 & 11 & 91.67 & 1 & 8.33 & 13 & 81.25 & 3 & 18.75 & 26 & 81.25 & 6 & 18.75 & 28 & 93.33 & 2 & 6.67 & 18 & 90.00 & 2 & 10.00 \\
\hline $\begin{array}{l}\text { I19 - Better to give the whole class } \\
\text { same assignment-small intervals }\end{array}$ & 8 & 53.33 & 7 & 46.67 & 8 & 66.67 & 4 & 33.33 & 9 & 56.25 & 7 & 43.75 & 15 & 48.39 & 16 & 51.61 & 13 & 43.33 & 17 & 56.67 & 10 & 52.63 & 9 & 47.37 \\
\hline $\begin{array}{l}\text { I20 - Textbook core content is more } \\
\text { important-not student motivation }\end{array}$ & 8 & 53.33 & 7 & 46.67 & 3 & 25.0 & 9 & 75.0 & 10 & 62.50 & 6 & 37.50 & 21 & 65.63 & 11 & 34.38 & 9 & 31.03 & 20 & 68.97 & 12 & 60.00 & 8 & 40.00 \\
\hline $\begin{array}{l}\text { I21 - Most important instruction } \\
\text { encourages "sense-making"/thinking }\end{array}$ & 7 & 50.00 & 7 & 50.00 & 11 & 91.7 & 1 & 8.3 & 11 & 68.75 & 5 & 31.25 & 22 & 68.75 & 10 & 31.25 & 20 & 66.7 & 10 & 33.3 & 11 & 57.89 & 8 & 42.11 \\
\hline $\begin{array}{l}\text { I22 - Critical for students to become } \\
\text { interested in doing academic work }\end{array}$ & 3 & 21.43 & 11 & 78.57 & 8 & 66.67 & 4 & 33.33 & 9 & 56.25 & 7 & 43.75 & 17 & 53.13 & 15 & 46.88 & 20 & 68.97 & 9 & 31.03 & 12 & 60.00 & 8 & 40.00 \\
\hline $\begin{array}{l}\text { I } 23 \text { - Material must be covered in a } \\
\text { structured way; job to explain }\end{array}$ & 9 & 60.00 & 6 & 40.00 & 10 & 83.33 & 2 & 16.67 & 14 & 87.50 & 2 & 12.50 & 21 & 65.63 & 11 & 34.38 & 20 & 66.67 & 10 & 33.33 & 16 & 80.00 & 4 & 20.00 \\
\hline $\begin{array}{l}\text { I24 - Students learn basic skills before } \\
\text { mastering complex content }\end{array}$ & 14 & 93.33 & 1 & 6.67 & 11 & 91.67 & 1 & 8.33 & 12 & 75.00 & 4 & 25.00 & 21 & 67.74 & 10 & 32.26 & 18 & 60.00 & 12 & 40.00 & 13 & 65.00 & 7 & 35.00 \\
\hline
\end{tabular}

(Table 32 continues) 


\section{(Table 32 continued)}

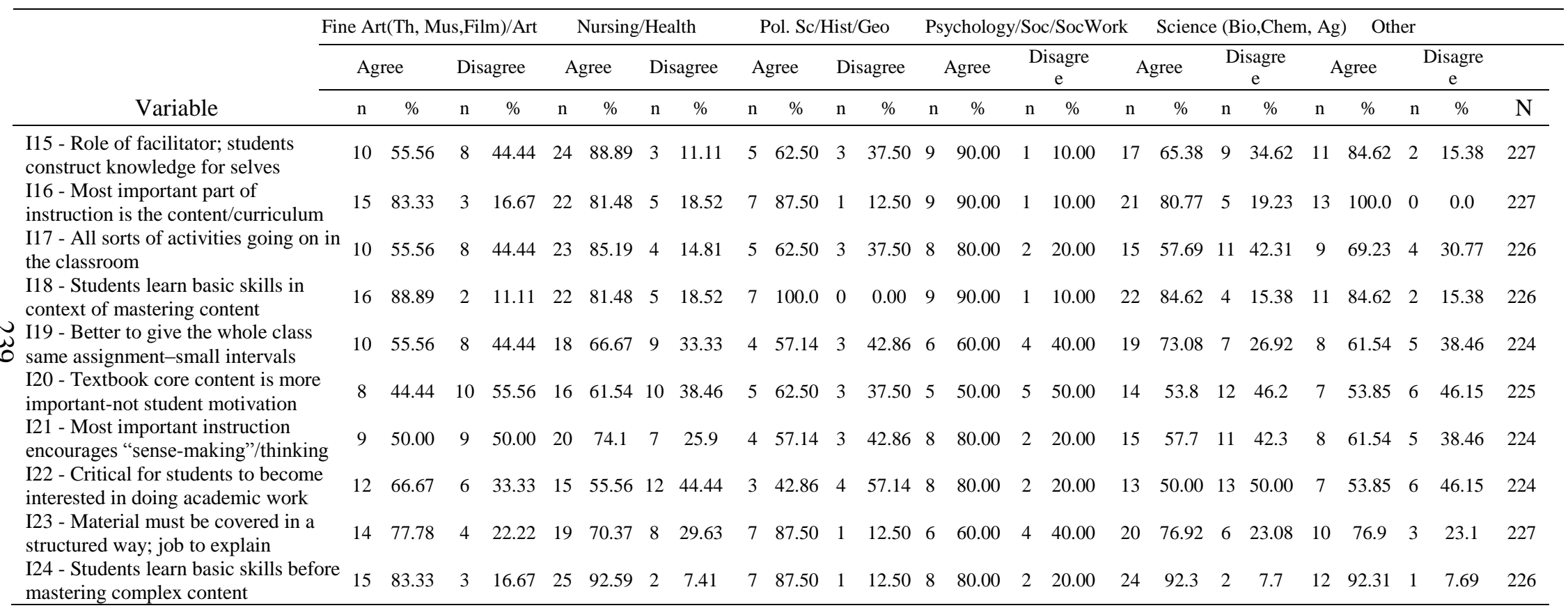

$$
* \mathrm{n}=244
$$


Table 34

Frequency of Responses (Agree vs. Disagree) - Millennial Students' Preferred Learning Styles (RQ5.3) - Disaggregated by

\section{Department}

\begin{tabular}{|c|c|c|c|c|c|c|c|c|c|c|c|c|c|c|c|c|c|c|c|c|c|c|c|c|}
\hline \multirow[b]{3}{*}{ Variable } & \multicolumn{4}{|c|}{ Business/Economics } & \multicolumn{4}{|c|}{ Com. Stud./Speech } & \multicolumn{4}{|c|}{ CJ, SoSc/Hum Beh Sc } & \multicolumn{4}{|c|}{ CS, Math, Phy, Engin } & \multicolumn{4}{|c|}{ Education } & \multicolumn{4}{|c|}{ English/ForLang/Rdg } \\
\hline & \multicolumn{2}{|c|}{ Agree } & \multicolumn{2}{|c|}{ Disagree } & \multicolumn{2}{|c|}{ Agree } & \multicolumn{2}{|c|}{ Disagree } & \multicolumn{2}{|c|}{ Agree } & \multicolumn{2}{|c|}{ Disagree } & \multicolumn{2}{|c|}{ Agree } & \multicolumn{2}{|c|}{ Disagree } & \multicolumn{2}{|c|}{ Agree } & \multicolumn{2}{|c|}{ Disagree } & \multicolumn{2}{|c|}{ Agree } & \multicolumn{2}{|c|}{ Disagree } \\
\hline & $\mathrm{n}$ & $\%$ & $\mathrm{n}$ & $\%$ & $\mathrm{n}$ & $\%$ & $\mathrm{n}$ & $\%$ & $\mathrm{n}$ & $\%$ & $\mathrm{n}$ & $\%$ & $\mathrm{n}$ & $\%$ & $\mathrm{n}$ & $\%$ & $\mathrm{n}$ & $\%$ & $\mathrm{n}$ & $\%$ & $\mathrm{n}$ & $\%$ & $\mathrm{n}$ & $\%$ \\
\hline $\begin{array}{l}\text { I25 - Students establish understanding } \\
\text { based on individual experiences }\end{array}$ & 12 & 80.00 & 3 & 20.00 & 11 & 91.67 & 1 & 8.33 & 12 & 75.00 & 4 & 25.00 & 27 & 87.10 & 4 & 12.90 & 29 & 96.67 & 1 & 3.33 & 18 & 90.00 & 2 & 10.00 \\
\hline $\begin{array}{l}\text { I26 - Students integrate learning concepts } \\
\text { into self-directed projects }\end{array}$ & 11 & 73.33 & 4 & 26.67 & 12 & 100.0 & 0 & 0.0 & 12 & 75.00 & 4 & 25.00 & 26 & 83.87 & 5 & 16.13 & 28 & 93.33 & 2 & 6.67 & 19 & 95.00 & 1 & 5.00 \\
\hline $\begin{array}{l}\text { I27 - Students research new } \\
\text { concepts/questions further individually }\end{array}$ & 13 & 86.67 & 2 & 13.33 & 12 & 100.0 & 0 & 0.0 & 12 & 75.00 & 4 & 25.00 & 26 & 83.87 & 5 & 16.13 & 28 & 93.33 & 2 & 6.67 & 19 & 95.00 & 1 & 5.00 \\
\hline $\begin{array}{l}\text { I28 - Student pursue learning concepts to } \\
\text { create individual learning }\end{array}$ & 15 & 100.0 & 0 & 0.00 & 11 & 91.67 & 1 & 8.33 & 12 & 75.00 & 4 & 25.00 & 26 & 86.67 & 4 & 13.33 & 29 & 96.67 & 1 & 3.33 & 17 & 85.00 & 2 & 10.00 \\
\hline $\begin{array}{l}\text { I29 - Students explore a new learning } \\
\text { concept independently }\end{array}$ & 9 & 60.00 & 6 & 40.00 & 11 & 91.67 & 1 & 8.33 & 10 & 62.50 & 6 & 37.50 & 27 & 87.10 & 4 & 12.90 & 29 & 96.67 & 1 & 3.33 & 16 & 80.00 & 4 & 20.00 \\
\hline $\begin{array}{l}\text { I30 - Students demonstrate methods to } \\
\text { realistically solve problems }\end{array}$ & 13 & 86.67 & 2 & 13.33 & 12 & 100.0 & 0 & 0.0 & 14 & 87.50 & 2 & 12.50 & 31 & 100.0 & 0 & 0.00 & 28 & 93.33 & 2 & 6.67 & 17 & 85.00 & 3 & 15.00 \\
\hline $\begin{array}{l}\text { I31 - Students connect current practice to } \\
\text { individual experiences }\end{array}$ & 13 & 86.67 & 2 & 13.33 & 12 & 100.0 & 0 & 0.0 & 13 & 81.25 & 3 & 18.75 & 30 & 96.77 & 1 & 3.23 & 30 & 100.0 & 0 & 0.0 & 17 & 85.00 & 2 & 10.00 \\
\hline $\begin{array}{l}\text { I32 - Students expect immediate } \\
\text { feedback from teachers and peers }\end{array}$ & 12 & 80.00 & 3 & 20.00 & 8 & 66.67 & 4 & 33.33 & 10 & 62.50 & 6 & 37.50 & 24 & 77.42 & 7 & 22.58 & 27 & 90.00 & 3 & 10.00 & 14 & 70.00 & 6 & 30.00 \\
\hline $\begin{array}{l}\text { I33 - Students can apply knowledge } \\
\text { independently in other contexts }\end{array}$ & 12 & 80.00 & 3 & 20.00 & 11 & 91.67 & 1 & 832 & 13 & 8 & 3 & 75 & 30 & 90 & 1 & 3 & 28 & 3 & 2 & 67 & 19 & 95.00 & 1 & 5.00 \\
\hline $\begin{array}{l}\text { I34 - Students explain a learning concept } \\
\text { using individual perspectives }\end{array}$ & 14 & 93.33 & 1 & 6.67 & 11 & 91.67 & 1 & 8.33 & 15 & 93.75 & 1 & 25 & 30 & 93.75 & 2 & 6.25 & 28 & 93.33 & 2 & 67 & 16 & 80.00 & 3 & 15.00 \\
\hline $\begin{array}{l}\text { I35 - Students can work in groups to } \\
\text { establish individual knowledge }\end{array}$ & 13 & 86.67 & 2 & 13.33 & 11 & 91.67 & 1 & 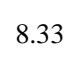 & 10 & 50 & 6 & 37.50 & 26 & 83.87 & 5 & 10.10 & 25 & 83.33 & 5 & 16.67 & 20 & 100.0 & 0 & 0.0 \\
\hline $\begin{array}{l}\text { I36 - Students work in groups to share } \\
\text { knowledge; reach agreement }\end{array}$ & 14 & 93.33 & 1 & 6.67 & 10 & 83.33 & 2 & 16.67 & 9 & 56.25 & 7 & 43.75 & 29 & 90.63 & 3 & 9.38 & 25 & 83.33 & 5 & 16.67 & 20 & 100.0 & 0 & 0.0 \\
\hline $\begin{array}{l}\text { I37 - Students integrate learning of } \\
\text { concepts with other activities }\end{array}$ & 14 & 93.33 & 1 & 6.67 & 11 & 91.67 & 1 & 8.33 & 12 & 75.00 & 4 & 25.00 & 29 & 93.55 & 2 & 6.45 & 28 & 93.33 & 2 & 6.67 & 17 & 85.00 & 3 & 15.00 \\
\hline $\begin{array}{l}\text { I38 - Students understand individual } \\
\text { thinking; seek independent help }\end{array}$ & 14 & 93.33 & 1 & 6.67 & 12 & 100.0 & 0 & 0.0 & 15 & 93.75 & 1 & 25 & 28 & 93.33 & 2 & 6.67 & 29 & 96.67 & 1 & 33 & 18 & 0.00 & 2 & 0.00 \\
\hline $\begin{array}{l}\text { I39 - Students show mastery of } \\
\text { knowledge by various assessments }\end{array}$ & 7 & 46.67 & 8 & 53.33 & 7 & 58.33 & 5 & 41.67 & 11 & 68.75 & 5 & 31.25 & 19 & 61.29 & 12 & 38.71 & 23 & 76.67 & 7 & 23.33 & 10 & 50.00 & 10 & 50.00 \\
\hline $\begin{array}{l}\text { I } 40 \text { - Students relate experiences when } \\
\text { explaining learning concepts }\end{array}$ & 13 & 86.67 & 2 & 13.33 & 12 & 100.0 & 0 & 0.0 & 15 & 93.75 & 1 & 6.25 & 31 & 96.88 & 1 & 3.13 & 29 & 96.67 & 1 & 3.33 & 17 & 85.00 & 3 & 15.00 \\
\hline
\end{tabular}

(Table 34 continues) 


\section{(Table 34 continued)}

\begin{tabular}{|c|c|c|c|c|c|c|c|c|c|c|c|c|c|c|c|c|c|c|c|c|c|c|c|c|c|}
\hline \multirow[b]{3}{*}{ Variable } & \multicolumn{5}{|c|}{ Fine Art(Th, Mus,Film)/Art } & \multicolumn{3}{|c|}{ Nursing/Health } & \multicolumn{4}{|c|}{ Pol. Sc/Hist/Geo } & \multicolumn{4}{|c|}{ Psychology/Soc/SocWork } & \multicolumn{5}{|c|}{ Science (Bio,Chem,Ag) } & \multicolumn{3}{|l|}{ Other } & \multirow[b]{3}{*}{$\mathrm{N}$} \\
\hline & \multicolumn{2}{|c|}{ Agree } & \multicolumn{2}{|c|}{ Disagree } & \multicolumn{2}{|c|}{ Agree } & \multicolumn{2}{|c|}{ Disagree } & \multicolumn{2}{|c|}{ Agree } & \multicolumn{2}{|c|}{ Disagree } & \multicolumn{2}{|c|}{ Agree } & \multicolumn{2}{|c|}{ Disagree } & \multicolumn{2}{|c|}{ Agree } & \multicolumn{2}{|c|}{ Disagree } & \multicolumn{2}{|c|}{ Agree } & \multicolumn{2}{|c|}{ Disagree } & \\
\hline & $\mathrm{n}$ & $\%$ & $\mathrm{n}$ & $\%$ & $\mathrm{n}$ & $\%$ & $\mathrm{n}$ & $\%$ & $\mathrm{n}$ & $\%$ & $\mathrm{n}$ & $\%$ & $\mathrm{n}$ & $\%$ & $\mathrm{n}$ & $\%$ & $\mathrm{n}$ & $\%$ & $\mathrm{n}$ & $\%$ & $\mathrm{n}$ & $\%$ & $\mathrm{n}$ & $\%$ & \\
\hline $\begin{array}{l}\text { I25 - Students establish understanding } \\
\text { based on individual experiences }\end{array}$ & 16 & 88.89 & 2 & 11.11 & 25 & 92.59 & 2 & 7.41 & 7 & 100.0 & 0 & 0.0 & 10 & 100.0 & 0 & 0.0 & 25 & 96.15 & 1 & 3.85 & 11 & 84.62 & 22 & 15.38 & 225 \\
\hline $\begin{array}{l}\text { I26 - Students integrate learning } \\
\text { concepts into self-directed projects }\end{array}$ & 17 & 94.44 & 1 & 5.56 & 26 & 96.30 & 1 & 3.70 & 7 & 100.0 & 0 & 0.0 & 9 & 90.00 & 1 & 10.00 & 21 & 80.77 & 5 & 19.23 & 11 & 84.62 & 22 & 15.38 & 225 \\
\hline $\begin{array}{l}\text { I27 - Students research new } \\
\text { concepts/questions further individually }\end{array}$ & 15 & 83.33 & 3 & 16.67 & 25 & 96.15 & 1 & 3.85 & 7 & 100.0 & 0 & 0.0 & 8 & 80.00 & 2 & 20.00 & 22 & 84.62 & 4 & 15.38 & 10 & 76.92 & 23 & 23.08 & 224 \\
\hline $\begin{array}{l}\text { I28 - Student pursue learning concepts } \\
\text { to create individual learning }\end{array}$ & 17 & 94.44 & 1 & 5.56 & 26 & 96.30 & 1 & 3.70 & 6 & 85.71 & 1 & 14.29 & 10 & 100.0 & 0 & 0.0 & 23 & 88.46 & 3 & 11.54 & 12 & 92.31 & 1 & 7.69 & 223 \\
\hline $\begin{array}{l}\text { I29 - Students explore a new learning } \\
\text { concept independently }\end{array}$ & 16 & 88.89 & 2 & 11.11 & 24 & 88.89 & 3 & 11.11 & 6 & 85.71 & 1 & 14.29 & 9 & 90.00 & 1 & 10.00 & 24 & 92.31 & 2 & 7.69 & 12 & 92.31 & 1 & 7.69 & 225 \\
\hline $\begin{array}{l}\text { I30 - Students demonstrate methods to } \\
\text { realistically solve problems }\end{array}$ & 15 & 83.33 & 3 & 16.67 & 26 & 96.30 & 1 & 3.70 & 7 & 100.0 & 0 & 0.0 & 9 & 90.00 & 1 & 10.00 & 26 & 100.0 & 0 & 0.0 & 12 & 100.0 & 0 & 0.0 & 224 \\
\hline $\begin{array}{l}\text { I31 - Students connect current practice } \\
\text { to individual experiences }\end{array}$ & 17 & 94.44 & 1 & 5.56 & 27 & 100.0 & 0 & 0.0 & 6 & 85.71 & 1 & 14.29 & 10 & 100.0 & 0 & 0.0 & 26 & 100.0 & 0 & 0.0 & 11 & 84.62 & 2 & 15.38 & 224 \\
\hline $\begin{array}{l}\text { I32 - Students expect immediate } \\
\text { feedback from teachers and peers }\end{array}$ & 14 & 77.78 & 4 & 22.22 & 22 & 81.48 & 5 & 18.52 & 4 & 57.14 & 3 & 42.86 & 8 & 88.89 & 1 & 11.11 & 19 & 73.08 & 7 & 26.92 & 9 & 69.23 & 4 & 30.77 & 224 \\
\hline $\begin{array}{l}\text { I33 - Students can apply knowledge } \\
\text { independently in other contexts }\end{array}$ & 17 & 94.44 & 1 & 5.56 & 27 & 100.0 & 0 & 0.00 & 8 & 100.0 & 0 & 0.0 & 9 & 90.00 & 1 & 10.00 & 25 & 96.15 & 1 & 3.85 & 13 & 100.0 & 0 & 0.0 & 226 \\
\hline $\begin{array}{l}\text { I34 - Students explain a learning } \\
\text { concept using individual perspectives }\end{array}$ & 15 & 83.33 & 3 & 16.67 & 27 & 100.0 & 0 & 0.00 & 6 & 75.00 & 2 & 25.00 & 9 & 90.00 & 1 & 10.00 & 26 & 100.0 & 0 & 0.0 & 12 & 92.31 & 1 & 7.69 & 226 \\
\hline $\begin{array}{l}\text { I35 - Students can work in groups to } \\
\text { establish individual knowledge }\end{array}$ & 14 & 77.78 & 4 & 22.22 & 24 & 88.89 & 3 & 11.11 & 6 & 75.00 & 2 & 25.00 & 8 & 80.00 & 2 & 20.00 & 20 & 76.92 & 6 & 23.08 & 11 & 84.62 & 2 & 15.38 & 226 \\
\hline $\begin{array}{l}\text { I36 - Students work in groups to share } \\
\text { knowledge; reach agreement }\end{array}$ & 14 & 77.78 & 4 & 22.22 & 27 & 100.0 & 0 & 0.0 & 6 & 75.00 & 2 & 25.00 & 7 & 70.00 & 3 & 30.00 & 20 & 76.92 & 6 & 23.08 & 12 & 92.31 & 1 & 7.69 & 227 \\
\hline $\begin{array}{l}\text { I37 - Students integrate learning of } \\
\text { concepts with other activities }\end{array}$ & 16 & 88.89 & 2 & 11.11 & 26 & 100.0 & 0 & 0.0 & 7 & 100.0 & 0 & 0.0 & 9 & 90.00 & 1 & 10.00 & 26 & 100.0 & 0 & 0.0 & 13 & 100.0 & 0 & 0.0 & 224 \\
\hline $\begin{array}{l}\text { I38 - Students understand individual } \\
\text { thinking; ;seek independent help }\end{array}$ & 17 & 94.44 & 1 & 5.56 & 27 & 100.0 & 0 & 0.0 & 8 & 100.0 & 0 & 0.0 & 9 & 90.00 & 1 & 10.00 & 22 & 84.62 & 4 & 15.38 & 12 & 92.31 & 1 & 7.69 & 225 \\
\hline $\begin{array}{l}\text { I39 - Students show mastery of } \\
\text { knowledge by various assessments }\end{array}$ & 10 & 55.56 & 8 & 44.44 & 22 & 84.62 & 4 & 15.38 & 3 & 37.50 & 5 & 62.50 & 4 & 40.00 & 6 & 60.00 & 11 & 44.00 & 14 & 56.00 & 9 & 69.23 & 4 & 30.77 & 224 \\
\hline $\begin{array}{l}\text { I } 40 \text { - Students relate experiences when } \\
\text { explaining learning concepts }\end{array}$ & 16 & 88.89 & 2 & 11.11 & 26 & 100.0 & 0 & 0.0 & 6 & 85.71 & 1 & 14.29 & 7 & 77.78 & 2 & 22.22 & 25 & 96.15 & 1 & 3.85 & 11 & 84.62 & 2 & 15.38 & 224 \\
\hline
\end{tabular}

$$
* n=244
$$


Table 36

Frequency of Responses (Agree vs. Disagree) - Utilization of Technology-Enhanced Instructional Practices (RQ5.4) -

\section{Disaggregated by Rank}

\begin{tabular}{|c|c|c|c|c|c|c|c|c|c|c|c|c|c|c|c|c|c|c|c|c|c|}
\hline \multirow[b]{3}{*}{ Variable } & \multicolumn{4}{|c|}{ Adjunct } & \multicolumn{4}{|c|}{ Instructor } & \multicolumn{4}{|c|}{ Assistant Professor } & \multicolumn{4}{|c|}{ Associate Professor } & \multicolumn{4}{|c|}{ Full Professor } & \multirow[b]{3}{*}{$\mathrm{N}$} \\
\hline & \multicolumn{2}{|c|}{ Agree } & \multicolumn{2}{|c|}{ Disagree } & \multicolumn{2}{|c|}{ Agree } & \multicolumn{2}{|c|}{ Disagree } & \multicolumn{2}{|c|}{ Agree } & \multicolumn{2}{|c|}{ Disagree } & \multicolumn{2}{|c|}{ Agree } & \multicolumn{2}{|c|}{ Disagree } & \multicolumn{2}{|c|}{ Agree } & \multicolumn{2}{|c|}{ Disagree } & \\
\hline & $\mathrm{n}$ & $\%$ & $\mathrm{n}$ & $\%$ & $\mathrm{n}$ & $\%$ & $\mathrm{n}$ & $\%$ & $\mathrm{n}$ & $\%$ & $\mathrm{n}$ & $\%$ & $\mathrm{n}$ & $\%$ & $\mathrm{n}$ & $\%$ & $\mathrm{n}$ & $\%$ & $\mathrm{n}$ & $\%$ & \\
\hline $\begin{array}{l}\text { I7 - Technology-enabled classroom } \\
\text { environment }\end{array}$ & 19 & 76.0 & 6 & 24.0 & 43 & 93.5 & 3 & 6.5 & 51 & 98.1 & 1 & 1.9 & 48 & 96.0 & 2 & 4.0 & 59 & 92.2 & 5 & 7.8 & 237 \\
\hline $\begin{array}{l}\text { I8 - Use technology-based tools to } \\
\text { support instruction }\end{array}$ & 23 & 92.0 & 2 & 8.0 & 45 & 97.8 & 1 & 2.2 & 50 & 96.2 & 2 & 3.8 & 46 & 92.0 & 4 & 8.0 & 58 & 90.6 & 6 & 9.4 & 237 \\
\hline $\begin{array}{l}\text { I9 - Use video-based instruction to } \\
\text { support activities }\end{array}$ & 22 & 88.0 & 3 & 12.0 & 32 & 69.6 & 14 & 30.4 & 38 & 73.1 & 14 & 26.9 & 28 & 56.0 & 22 & 44.0 & 33 & 51.6 & 31 & 48.4 & 237 \\
\hline $\begin{array}{l}\text { I10 - Use technology means to } \\
\text { communicate w/ students }\end{array}$ & 24 & 96.0 & 1 & 4.0 & 43 & 93.5 & 3 & 6.5 & 51 & 98.1 & 1 & 1.9 & 49 & 98.0 & 1 & 2.0 & 60 & 95.2 & 3 & 4.8 & 236 \\
\hline $\begin{array}{l}\text { I1 } 1 \text { - Encourage student } \\
\text { communication using technology }\end{array}$ & 18 & 75.0 & 6 & 25.0 & 31 & 67.4 & 15 & 32.6 & 28 & 53.8 & 24 & 46.2 & 24 & 48.0 & 26 & 52.0 & 23 & 35.9 & 41 & 64.1 & 236 \\
\hline $\begin{array}{l}\text { I1 } 2 \text { - Use smart or wireless devices to } \\
\text { conduct lessons/materials }\end{array}$ & 10 & 40.0 & 15 & 60.0 & 17 & 37.0 & 29 & 63.0 & 10 & 19.2 & 42 & 80.8 & 7 & 14.0 & 43 & 86.0 & 14 & 21.9 & 50 & 78.1 & 237 \\
\hline $\begin{array}{l}\text { I13 - Use of guest speakers via } \\
\text { technology-driven means }\end{array}$ & 5 & 20.0 & 20 & 80.0 & 7 & 15.6 & 39 & 86.7 & 4 & 7.7 & 48 & 92.3 & 3 & 6.1 & 46 & 93.9 & 2 & 3.2 & 61 & 96.8 & 235 \\
\hline $\begin{array}{l}\text { I14 - Students use web-based tools to } \\
\text { complete assignments }\end{array}$ & 19 & 76.0 & 6 & 24.0 & 34 & 73.9 & 12 & 26.1 & 40 & 76.9 & 12 & 23.1 & 39 & 78.0 & 11 & 22.0 & 44 & 68.8 & 20 & 31.3 & 237 \\
\hline
\end{tabular}

$$
*_{n}=244
$$


Table 38

Frequency of Responses (Agree vs. Disagree) - Perceptions of Instructional Role (RQ5.4) - Disaggregated by Rank

\begin{tabular}{|c|c|c|c|c|c|c|c|c|c|c|c|c|c|c|c|c|c|c|c|c|c|}
\hline \multirow[b]{3}{*}{ Variable } & \multicolumn{4}{|c|}{ Adjunct } & \multicolumn{4}{|c|}{ Instructor } & \multicolumn{4}{|c|}{ Assistant Professor } & \multicolumn{4}{|c|}{ Associate Professor } & \multicolumn{5}{|c|}{ Full Professor } \\
\hline & \multicolumn{2}{|c|}{ Agree } & \multicolumn{2}{|c|}{ Disagree } & \multicolumn{2}{|c|}{ Agree } & \multicolumn{2}{|c|}{ Disagree } & \multicolumn{2}{|c|}{ Agree } & \multicolumn{2}{|c|}{ Disagree } & \multicolumn{2}{|c|}{ Agree } & \multicolumn{2}{|c|}{ Disagree } & \multicolumn{2}{|c|}{ Agree } & \multicolumn{3}{|c|}{ Disagree } \\
\hline & $\mathrm{n}$ & $\%$ & $\mathrm{n}$ & $\%$ & $\mathrm{n}$ & $\%$ & $\mathrm{n}$ & $\%$ & $\mathrm{n}$ & $\%$ & $\mathrm{n}$ & $\%$ & $\mathrm{n}$ & $\%$ & $\mathrm{n}$ & $\%$ & $\mathrm{n}$ & $\%$ & $\mathrm{n}$ & $\%$ & $\mathrm{~N}$ \\
\hline $\begin{array}{l}\text { I15 - Role of facilitator; students construct } \\
\text { knowledge for selves }\end{array}$ & 18 & 75.0 & 6 & 25.0 & 36 & 78.3 & 10 & 21.7 & 44 & 84.6 & 8 & 15.4 & 41 & 82.0 & 9 & 18.0 & 44 & 68.8 & 20 & 31.3 & 236 \\
\hline $\begin{array}{l}\text { I16 - Most important part of instruction is } \\
\text { the content/curriculum }\end{array}$ & 22 & 91.7 & 2 & 8.3 & 38 & 82.6 & 8 & 17.4 & 45 & 86.5 & 7 & 13.5 & 37 & 74.0 & 13 & 26.0 & 57 & 89.1 & 7 & 10.9 & 236 \\
\hline $\begin{array}{l}\text { I17 - All sorts of activities going on in the } \\
\text { classroom }\end{array}$ & 17 & 70.8 & 7 & 29.2 & 31 & 67.4 & 15 & 32.6 & 37 & 71.2 & 15 & 28.8 & 33 & 66.0 & 17 & 34.0 & 44 & 69.8 & 19 & 30.2 & 235 \\
\hline $\begin{array}{l}\text { I18 - Students learn basic skills in context } \\
\text { of mastering content }\end{array}$ & 20 & 83.3 & 4 & 16.7 & 38 & 82.6 & 8 & 17.4 & 41 & 80.4 & 10 & 19.6 & 46 & 92.0 & 4 & 8.0 & 57 & 89.1 & 7 & 10.9 & 235 \\
\hline $\begin{array}{l}\text { I19 - Better to give the whole class same } \\
\text { assignment-small intervals }\end{array}$ & 15 & 62.5 & 9 & 37.5 & 28 & 60.9 & 18 & 39.1 & 31 & 62.0 & 19 & 38.0 & 29 & 58.0 & 21 & 42.0 & 31 & 49.2 & 32 & 50.8 & 233 \\
\hline $\begin{array}{l}\text { I20 - Textbook core content is more } \\
\text { important-not student motivation }\end{array}$ & 7 & 29.2 & 17 & 70.8 & 30 & 65.2 & 16 & 34.8 & 23 & 44.2 & 29 & 55.8 & 26 & 52.0 & 24 & 48.0 & 33 & 53.2 & 29 & 46.8 & 234 \\
\hline $\begin{array}{l}\text { I21 - Most important instruction } \\
\text { encourages "sense-making"/thinking }\end{array}$ & 18 & 78.3 & 5 & 21.7 & 35 & 77.8 & 10 & 22.2 & 38 & 74.5 & 13 & 25.5 & 26 & 53.1 & 23 & 46.9 & 34 & 54.0 & 29 & 46.0 & 231 \\
\hline $\begin{array}{l}\text { I22 - Critical for students to become } \\
\text { interested in doing academic work }\end{array}$ & 15 & 62.5 & 9 & 37.5 & 26 & 56.5 & 20 & 43.5 & 31 & 60.8 & 20 & 39.2 & 30 & 60.0 & 20 & 40.0 & 34 & 54.8 & 28 & 45.2 & 233 \\
\hline $\begin{array}{l}\text { I23 - Material must be covered in a } \\
\text { structured way; job to explain }\end{array}$ & 19 & 79.2 & 5 & 20.8 & 33 & 71.7 & 13 & 28.3 & 40 & 76.9 & 12 & 23.1 & 31 & 62.0 & 19 & 38.0 & 51 & 79.7 & 13 & 20.3 & 236 \\
\hline $\begin{array}{l}\text { I24 - Students learn basic skills before } \\
\text { mastering complex content }\end{array}$ & 20 & 83.3 & 4 & 16.7 & 40 & 87.0 & 6 & 13.0 & 42 & 80.8 & 10 & 19.2 & 38 & 77.6 & 11 & 22.4 & 47 & 73.4 & 17 & 26.6 & 235 \\
\hline
\end{tabular}

$$
*_{n}=244
$$


Table 40

Frequency of Responses (Agree vs. Disagree) - Perceptions of Millennial Students' Preferred Learning Styles (RQ5.4) -

\section{Disaggregated by Rank}

\begin{tabular}{|c|c|c|c|c|c|c|c|c|c|c|c|c|c|c|c|c|c|c|c|c|c|}
\hline \multirow[b]{3}{*}{ Variable } & \multicolumn{4}{|c|}{ Adjunct } & \multicolumn{4}{|c|}{ Instructor } & \multicolumn{4}{|c|}{ Assistant Professor } & \multicolumn{4}{|c|}{ Associate Professor } & \multicolumn{5}{|c|}{ Full Professor } \\
\hline & \multicolumn{2}{|c|}{ Agree } & \multicolumn{2}{|c|}{ Disagree } & \multicolumn{2}{|c|}{ Agree } & \multicolumn{2}{|c|}{ Disagree } & \multicolumn{2}{|c|}{ Agree } & \multicolumn{2}{|c|}{ Disagree } & \multicolumn{2}{|c|}{ Agree } & \multicolumn{2}{|c|}{ Disagree } & \multicolumn{2}{|c|}{ Agree } & \multicolumn{2}{|c|}{ Disagree } & \multirow[b]{2}{*}{$\mathrm{N}$} \\
\hline & $\mathrm{n}$ & $\%$ & $\mathrm{n}$ & $\%$ & $\mathrm{n}$ & $\%$ & $\mathrm{n}$ & $\%$ & $\mathrm{n}$ & $\%$ & $\mathrm{n}$ & $\%$ & $\mathrm{n}$ & $\%$ & $\mathrm{n}$ & $\%$ & $\mathrm{n}$ & $\%$ & $\mathrm{n}$ & $\%$ & \\
\hline $\begin{array}{l}\text { I25 - Students establish understanding } \\
\text { based on individual experiences }\end{array}$ & 24 & 100.0 & 0 & 0.0 & 42 & 91.3 & 4 & 8.7 & 47 & 92.2 & 4 & 7.8 & 43 & 87.8 & 6 & 12.2 & 55 & 85.9 & 9 & 14.1 & 234 \\
\hline $\begin{array}{l}\text { I26 - Students integrate learning } \\
\text { concepts into self-directed projects }\end{array}$ & 24 & 100.0 & 0 & 0.0 & 40 & 87.0 & 6 & 13.0 & 48 & 94.1 & 3 & 5.9 & 43 & 87.8 & 6 & 12.2 & 52 & 81.3 & 12 & 18.8 & 234 \\
\hline $\begin{array}{l}\text { I27 - Students research new } \\
\text { concepts/questions further individually }\end{array}$ & 24 & 100.0 & 0 & 0.0 & 41 & 89.1 & 5 & 10.9 & 44 & 88.0 & 6 & 12.0 & 41 & 83.7 & 8 & 16.3 & 53 & 82.8 & 11 & 17.2 & 233 \\
\hline $\begin{array}{l}\text { I } 28 \text { - Student pursue learning concepts } \\
\text { to create individual learning }\end{array}$ & 23 & 95.8 & 1 & 4.2 & 41 & 89.1 & 5 & 10.9 & 45 & 90.0 & 5 & 10.0 & 43 & 87.8 & 6 & 12.2 & 58 & 92.1 & 5 & 7.9 & 232 \\
\hline $\begin{array}{l}\text { I29 - Students explore a new learning } \\
\text { concept independently }\end{array}$ & 21 & 87.5 & 3 & 12.5 & 38 & 82.6 & 8 & 17.4 & 44 & 86.3 & 7 & 13.7 & 40 & 81.6 & 9 & 18.4 & 53 & 82.8 & 11 & 17.2 & 234 \\
\hline $\begin{array}{l}\text { I30 - Students demonstrate methods to } \\
\text { realistically solve problems }\end{array}$ & 23 & 95.8 & 1 & 4.2 & 44 & 95.7 & 2 & 4.3 & 48 & 96.0 & 2 & 4.0 & 44 & 89.8 & 5 & 10.2 & 60 & 93.8 & 4 & 6.3 & 233 \\
\hline $\begin{array}{l}\text { I31 - Students connect current practice } \\
\text { to individual experiences }\end{array}$ & 24 & 100.0 & 0 & 0.0 & 44 & 95.7 & 2 & 4.3 & 51 & 100.0 & 0 & 0.0 & 46 & 93.9 & 3 & 6.1 & 58 & 92.1 & 5 & 7.9 & 233 \\
\hline $\begin{array}{l}\text { I32 - Students expect immediate } \\
\text { feedback from teachers and peers }\end{array}$ & 23 & 95.8 & 1 & 4.2 & 39 & 84.8 & 7 & 15.2 & 36 & 70.6 & 15 & 29.4 & 38 & 77.6 & 11 & 22.4 & 43 & 68.3 & 20 & 31.7 & 233 \\
\hline $\begin{array}{l}\text { I33 - Students can apply knowledge } \\
\text { independently in other contexts }\end{array}$ & 24 & 100.0 & 0 & 0.0 & 45 & 97.8 & 1 & 2.2 & 49 & 94.2 & 3 & 5.8 & 43 & 87.8 & 6 & 12.2 & 58 & 90.6 & 6 & 9.4 & 235 \\
\hline $\begin{array}{l}\text { I34 - Students explain a learning } \\
\text { concept using individual perspectives }\end{array}$ & 22 & 95.7 & 1 & 4.3 & 44 & 95.7 & 2 & 4.3 & 50 & 96.2 & 2 & 3.8 & 44 & 88.0 & 6 & 12.0 & 58 & 90.6 & 6 & 9.4 & 235 \\
\hline $\begin{array}{l}\text { I35 - Students can work in groups to } \\
\text { establish individual knowledge }\end{array}$ & 18 & 75.0 & 6 & 25.0 & 43 & 93.5 & 3 & 6.5 & 47 & 90.4 & 5 & 9.6 & 37 & 75.5 & 12 & 24.5 & 49 & 76.6 & 15 & 23.4 & 235 \\
\hline $\begin{array}{l}\text { I36 - Students work in groups to share } \\
\text { knowledge; reach agreement }\end{array}$ & 20 & 83.3 & 4 & 16.7 & 43 & 93.5 & 3 & 6.5 & 47 & 90.4 & 5 & 9.6 & 41 & 82.0 & 9 & 18.0 & 49 & 76.6 & 15 & 23.4 & 236 \\
\hline $\begin{array}{l}\text { I37 - Students integrate learning of } \\
\text { concepts with other activities }\end{array}$ & 21 & 87.5 & 3 & 12.5 & 44 & 95.7 & 2 & 4.3 & 51 & 100.0 & 0 & 0.0 & 42 & 87.5 & 6 & 12.5 & 57 & 89.1 & 7 & 10.9 & 233 \\
\hline $\begin{array}{l}\text { I38 - Students understand individual } \\
\text { thinking ;seek independent help }\end{array}$ & 22 & 91.7 & 2 & 8.3 & 42 & 91.3 & 4 & 8.7 & 52 & 100.0 & 0 & 0.0 & 44 & 89.8 & 5 & 10.2 & 58 & 92.1 & 5 & 7.9 & 234 \\
\hline $\begin{array}{l}\text { I39 - Students show mastery of } \\
\text { knowledge by various assessments }\end{array}$ & 19 & 79.2 & 5 & 20.8 & 31 & 67.4 & 15 & 32.6 & 33 & 63.5 & 19 & 36.5 & 20 & 41.7 & 28 & 58.3 & 37 & 58.7 & 26 & 41.3 & 233 \\
\hline $\begin{array}{l}\text { I40 - Students relate experiences when } \\
\text { explaining learning concepts }\end{array}$ & 23 & 95.8 & 1 & 4.2 & 46 & 100.0 & 0 & 0.0 & 47 & 92.2 & 4 & 7.8 & 45 & 91.8 & 4 & 8.2 & 56 & 88.9 & 7 & 11.1 & 233 \\
\hline
\end{tabular}

$$
* \mathrm{n}=244
$$


VITA

Cynthia (Cindy) Irene Ott Wells was born September 28, 1960 and grew up in rural Northwest Missouri, living in the Helena, Barnard and Union Star, MO communities. Cindy graduated from Union Star R-II high school as valedictorian. She continued her education, receiving 2 undergraduate degrees from Missouri Western, one in Business Administration with an Accounting major and management minor and another in Education with a secondary business major. A graduate degree in education with an instructional technology emphasis was received from Northwest Missouri State University. In 2013, she received her Ed. D. in Educational Leadership and Policy Analysis from the University of Missouri - Columbia.

Cindy's passion is education and her professional career has allowed her to "teach" students from kindergarten to 70+-year olds. She has taught in both the K-12 and higher education realms and acted as mentor to many students. Cindy is also an experienced professional development trainer and consultant, serving the state of Missouri, especially the Northwest region, for five years. She has also managed distance education and faculty training programs, as well as acted as academic dean.

Cindy and her husband, Michael, reside on a farm outside of Guilford, MO along with their miniature pinchers, horses, various cats and cattle. They have been married for 36 years and have 3 sons, Dustin, Doren and Daman. Mike and Cindy also have two grandchildren, Brilynn and Brody, the lights of their life. Cindy enjoys cooking, playing with her grandchildren, including rides in the John Deere Gator, reading and crafting. She also enjoys spending time with friends and family, eating at a good restaurant, being outside in God's beauty and finding new adventures. 